Thiago Fernandes Martins

Estudo do complexo Amblyomma cajennense no Brasil

São Paulo

2014 
Thiago Fernandes Martins

\section{Estudo do complexo Amblyomma cajennense no Brasil}

Tese apresentada ao Programa de Pós-Graduação em Epidemiologia Experimental Aplicada às Zoonoses da Faculdade de Medicina Veterinária e Zootecnia da Universidade de São Paulo para obtenção do título de Doutor em Ciências

\section{Departamento:}

Medicina Veterinária Preventiva e Saúde Animal

Área de Concentração:

Epidemiologia Experimental Aplicada às Zoonoses

Orientador:

Prof. Dr. Marcelo Bahia Labruna

São Paulo 
Autorizo a reprodução parcial ou total desta obra, para fins acadêmicos, desde que citada a fonte.

DADOS INTERNACIONAIS DE CATALOGAÇÃO-NA-PUBLICAÇÃO

(Biblioteca Virginie Buff D’Ápice da Faculdade de Medicina Veterinária e Zootecnia da Universidade de São Paulo)

Martins, Thiago Fernandes

Estudo do complexo Amblyomma cajennense no Brasil / Thiago Fernandes Martins. -- 2014. 113 f. : il.

Tese (Doutorado) - Universidade de São Paulo. Faculdade de Medicina Veterinária e Zootecnia. Departamento de Medicina Veterinária Preventiva e Saúde Animal, São Paulo, 2014.

Programa de Pós-Graduação: Epidemiologia Experimental Aplicada às Zoonoses.

Área de concentração: Epidemiologia Experimental Aplicada às Zoonoses.

Orientador: Prof. Dr. Marcelo Bahia Labruna.

1. Carrapatos. 2. Complexo. 3. Amblyomma cajennense. 4. Amblyomma sculptum. 5. Brasil. I. Título. 


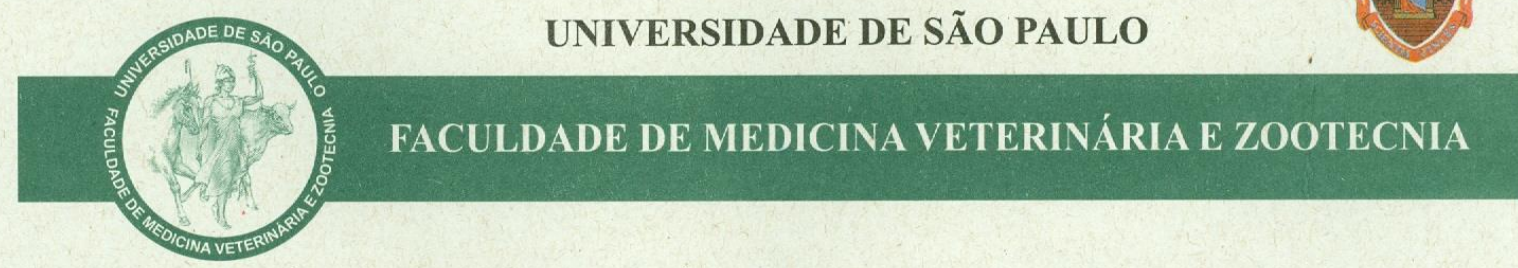

Comissão de Ética no uso de animais

\section{CERTIFICADO}

Certificamos que o Projeto intitulado "Estudo do complexo Amblyomma cajennense no Brasil", protocolado sob o $\mathrm{n}^{\circ}$ 2660/2012, utilizando 200 (duzentos) cavalos, sob a responsabilidade do Prof. Dr. Marcelo Bahia Labruna, está de acordo com os princípios éticos de experimentação animal da "Comissão de Ética no uso de animais" da Faculdade de Medicina Veterinária e Zootecnia da Universidade de São Paulo e foi aprovado em reunião de $20 / 6 / 2012$.

We certify that the Research "Study of the complex Amblyomma cajennense in Brazil", protocol number 2660/2012, utilizing 200 (two hundred) horses, under the responsibility Prof. Dr. Marcelo Bahia Labruna, agree with Ethical Principles in Animal Research adopted by "Ethic Committee in the use of animals" of the School of Veterinary Medicine and Animal Science of University of São Paulo and was approved in the meeting of day 6/20/2012.

São Paulo, 18 de março de 2013.

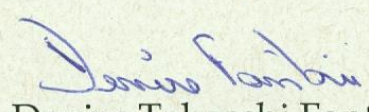

Denise Tabacchi Fantoni

Presidente 


\section{FOLHA DE AVALIAÇÃO}

Nome: MARTINS, Thiago Fernandes

Título: Estudo do complexo Amblyomma cajennense no Brasil

Tese apresentada ao Programa de Pós-Graduação em Epidemiologia Experimental Aplicada às Zoonoses da Faculdade de Medicina Veterinária e Zootecnia da Universidade de São Paulo para obtenção do título de Doutor em Ciências

Data:

\section{Banca Examinadora}

Prof. Dr.

Instituição: Julgamento:

Prof. Dr.

Instituição: Julgamento:

Prof. Dr.

Instituição: Julgamento:

Prof. Dr.

Instituição: Julgamento:

Prof. Dr.

Instituição: Julgamento: 


\section{DEDICATÓRIA}

Ao meu pai Luis Fernandes Martins (in memoriam) a minha mãe Maria Fátima Fernandes Martins, ao meu irmão Felipe Fernandes Martins, e ao meu sobrinho Sérgio Luis Theodoro Martins pelo apoio e incentivo em todos os momentos. 


\section{AGRADECIMENTOS}

Ao meu orientador Prof. Dr. Marcelo Bahia Labruna da Faculdade de Medicina Veterinária e Zootecnia (FMVZ) da Universidade de São Paulo (USP), pela oportunidade, confiança, amizade, paciência e aprendizado dentro e fora das salas de aula, que foram de fundamental importância para o meu aprimoramento técnico-científico.

Ao Prof. Dr. Ricardo Augusto Dias do Departamento de Medicina Veterinária Preventiva e Saúde Animal (VPS) da FMVZ-USP, pela grande ajuda prestada e suporte técnico na construção dos mapas.

Aos amigos do Laboratório de Doenças Parasitárias (LDP) do VPS da FMVZ-USP, Francisco Borges Costa, Amália Regina Mar Barbieri e Arlei Marcili, pela ajuda na coleta do material a campo especialmente no estado do Maranhão, pela ajuda nas análises moleculares e pela ajuda nas análises filogenéticas, respectivamente.

À todos os docentes, funcionários, pós-graduandos e alunos do VPS da FMVZ-USP, em especial Solange Maria Gennari, Rodrigo Martins Soares, José Henrique Hildebrand Grisi Filho, Hilda de Fátima de Jesus Pena, Sheila Oliveira de Souza Silva, Pedro César Ferreira da Silva, Renato Caravieri, Marcos Monteiro da Silva, Washington Carlos Agostinho, Antônio dos Santos Rodrigues, Danival Lopes Moreira, Matias Pablo Juan Szabó, Maria Halina Ogrzewalska, Carlos Roberto Prudencio, Mariana Granziera Spolidorio, Fernanda Aparecida Nieri-Bastos, Jonas Moraes-Filho, Iara Silveira, Herbert Sousa Soares, Tatiana Evelyn Hayama Ueno, João Fábio Soares, Felipe da Silva Krawczak, Monize Gerardi, Ricardo Corassa Arrais, Danilo Gonçalves Saraiva, Aline Pontes Almeida, Igor da Cunha Lima Acosta, Juliana Isabel Giuli da Silva, Aline Diniz Cabral, Estela Gallucci Lopes, Antônio Humberto Hamad Minervino, Julia Teresa Ribeiro de Lima, Sérgio Netto Vitaliano, Marcos Gomes Lopes, Andréa Pereira da Costa, Gislene Fátima da Silva Rocha Fournier, Eveline Zuniga, André Saidenberg, Nairléia dos Santos Silva, Aline Gil Alves Guilloux, Guilherme Basseto Braga, Isabella Fontana, Bruno Miotto e Alexandre Guerra pela ajuda e amizade.

À todos os funcionários da Biblioteca Virginie Buff D’Ápice da FMVZ-USP, pela atenção e esclarecimentos bibliográficos. 
Ao pesquisador Dr. Adriano Pinter dos Santos da Superintendência de Controle de Endemias (SUCEN), pelas valiosas sugestões e correções na qualificação do presente estudo.

À Dra. Darci Moraes Barros-Battesti do Laboratório Especial de Coleções Zoológicas (LECZ) do Instituto Butantan (IB), pela disposição em ajudar sempre e pelos importantes conselhos acadêmicos.

A todos os pesquisadores, funcionários e pós-graduandos do LECZ-IB, em especial Diego Garcia Ramirez, Aline Girotto, Fernando De Castro Jacinavicius, Renata Kazuko Sakai, Jânio dos Santos Sampaio e Gabrielle Ribeiro de Andrade, pela ajuda mútua.

Ao pesquisador Me. Cássio Roberto Leonel Peterka e ao motorista Mowglas Lima Fernandes da Fundação de Medicina Tropical do Tocantins (FUNTROP), pela ajuda na coleta do material a campo especialmente no estado do Tocantins.

Ao Prof. Dr. Luís Marcelo Aranha Camargo do Instituto de Ciências Biomédicas da Universidade de São Paulo (ICB5) da USP e ao Prof. Me. Flávio Aparecido Terassini da Faculdade São Lucas, pela ajuda na coleta do material a campo especialmente no estado de Rondônia.

Ao Prof. Dr. Richard de Campos Pacheco e ao motorista Carlos Roberto Benedito Conceição da Silva da Universidade Federal de Mato Grosso (UFMT) Cuiabá, pela ajuda na coleta do material a campo especialmente no estado de Mato Grosso.

Agradeço profundamente aos seguintes amigos, que nos enviaram machos e fêmeas de carrapatos da espécie Amblyomma cajennense sensu lato utilizados no presente estudo: Me. José Brites-Neto do Programa de Vigilância e Controle de Carrapatos (PVCC) da Secretaria Municipal de Saúde de Americana, São Paulo; Prof. Dr. Maurício Cláudio Horta da Universidade Federal do Vale do São Francisco (UNIVASF) Petrolina, Pernambuco; Profa. Dra. Alessandra Scofield da Universidade Federal do Pará (UFPA) Castanhal; Prof. Dr. Artur Kanadani Campos da Universidade Federal de Mato Grosso (UFMT) Sinop; Me. Rodrigo Hidalgo Friciello Teixeira do Parque Zoológico Municipal Quinzinho de Barros (PZMQB) Sorocaba, São Paulo; e Me. Fabiano Benitez Vendrame da Agência de Defesa Sanitária Agrosilvopastoril do estado de Rondônia (IDARON) Porto Velho. 
Aos Médicos Veterinários Allan Cristian Mesacasa, Flávio Gomes Barcelos e Dieneson Bourscheid do Instituto de Defesa Agropecuária do estado de Mato Grosso (INDEA) dos municípios de Jangada, Rosário Oeste e Lucas do Rio Verde, respectivamente, pelos contatos e ajuda na coleta do material a campo no estado de Mato Grosso.

Por fim, agradeço à todos os pesquisadores e projetos de pesquisa que de forma direta ou indireta contribuíram com as coletas a campo dos carrapatos depositados na Coleção Nacional de Carrapatos (CNC) da FMVZ-USP e na Coleção Acarológica do Instituto Butantan de São Paulo (IBSP).

Aos pesquisadores Dr. Alberto Guglielmone, Dr. Santiago Nava e Dr. Atilio Mangold do Instituto Nacional de Tecnologia Agropecuária (INTA) Argentina, por disponibilizar dados de seus arquivos de publicações sobre carrapatos da Região Neotropical, pela receptividade e atenção no estágio em taxonomia e biologia de carrapatos, que foi uma experiência profissional e pessoal única na minha vida.

À Dra. Andreza Conti Patara, por ter cuidado tão bem do meu dogo argentino Netuno (in memoriam) durante a minha ausência devido às coletas do material a campo no presente estudo.

Ao meu primo Gustavo Fernandes Fernochi, pelas sugestões e pela grande experiência compartilhada na utilização dos softwares nos trabalhos paralelos realizados no Laboratório.

À todos os animais e aos proprietários dos mesmos, em especial Francisco Gil Cruz Alencar do Criadouro Conservacionista Ararajuba do Ipê, pelo apoio ao projeto.

Ao Instituto Chico Mendes de Conservação da Biodiversidade (ICMBio), pelo suporte logístico.

Ao Conselho Nacional de Desenvolvimento Científico e Tecnológico (CNPq) processo 141945/2010-9, pelo apoio financeiro.

Aos amigos, Ricardo Conte Fazzio, Franco Panzolini Gonçales, Alan Mazzonetto Fonseca e Alex Mazzonetto Fonseca, pela amizade sincera. 

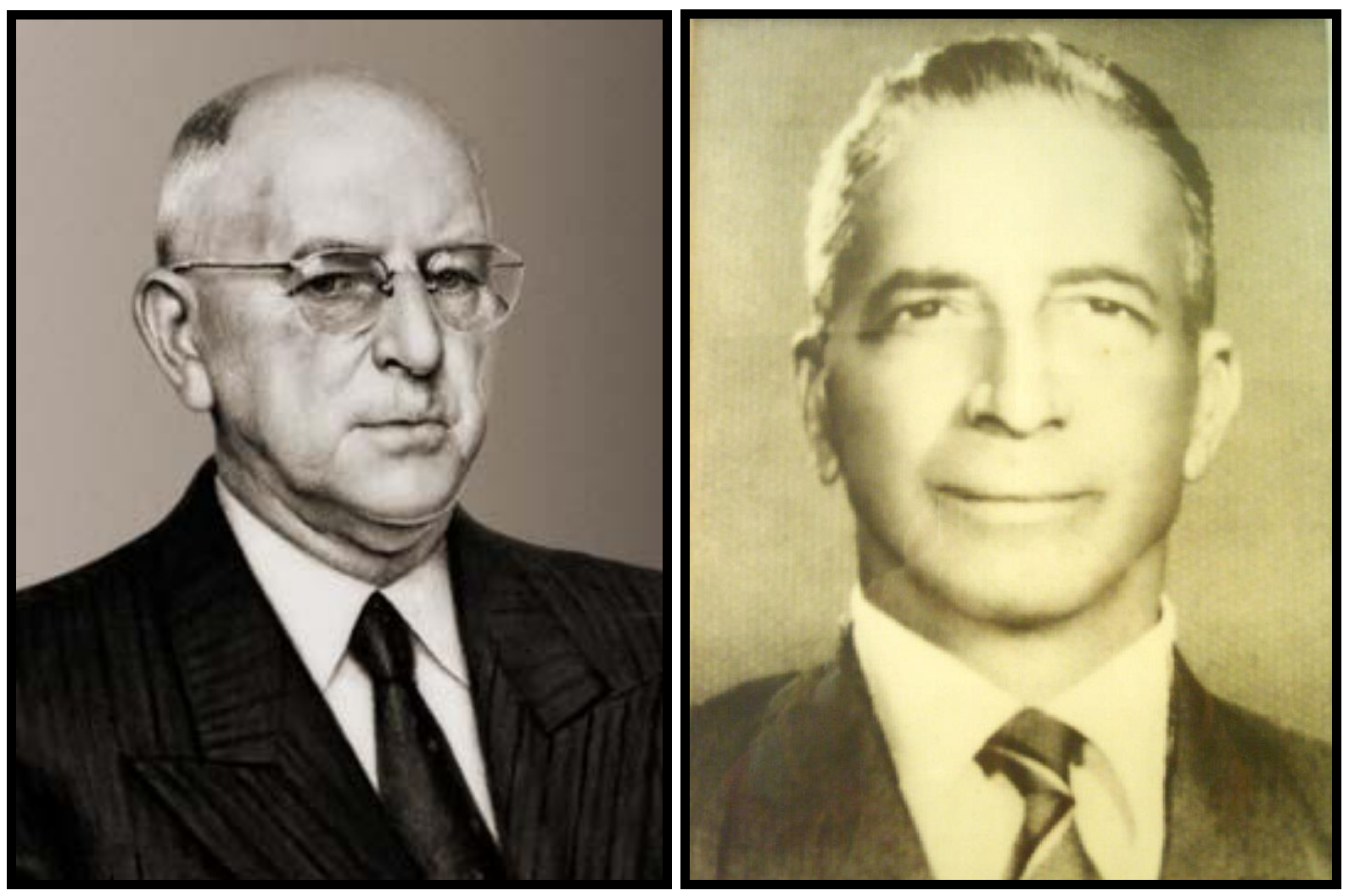

“O homem e os animais silvestres são muito perseguidos pelo Amblyomma cajennense em qualquer das fases de sua evolução larvária, ninfal ou adulta, muito especialmente nas duas primeiras que, por se tornarem abundantíssimas na estação sêca e mais fria do ano, constituem uma praga justamente temida nas zonas rurais." 


\section{RESUMO}

MARTINS, T. F. Estudo do complexo Amblyomma cajennense no Brasil. [Study of the complex Amblyomma cajennense in Brazil]. 2014. 113 f. Tese (Doutorado em Ciências) Faculdade de Medicina Veterinária e Zootecnia, Universidade de São Paulo, São Paulo, 2014.

Trabalhos recentes de genética, morfologia e biologia conduzidos nas Américas, demostraram que Amblyomma cajennense é um complexo de pelo menos seis espécies distintas, cada espécie associada a uma área biogeográfica. Neste contexto, o presente estudo conduzido no Brasil realizou análises morfológicas e moleculares de carrapatos adultos, previamente identificados como A. cajennense e depositados nas coleções de carrapatos "Coleção Nacional de Carrapatos", da Faculdade de Medicina Veterinária e Zootecnia da Universidade de São Paulo, e na "Coleção Acarológica do Instituto Butantan" do Instituto Butantan de São Paulo. Amostras adicionais de carrapatos foram obtidos através de trabalhos de campo. Os carrapatos foram coletados em vida livre, animais domésticos (equinos, suínos) e silvestres atropelados (anta, tamanduá), durante três expedições de coleta, sendo uma no nordeste do país entre os municípios de Bequimão/MA e Estrela do Norte/GO; uma no noroeste do país entre os municípios de Presidente Médici/RO e Vila Bela da Santíssima Trindade/MT; e uma terceira no centro-norte do país entre os municípios de Sinop/MT e Cuiabá/MT. Os resultados morfológicos e moleculares obtidos demonstraram a ocorrência de pelo menos duas espécies distintas de carrapatos (A. cajennense sensu stricto e Amblyomma sculptum) do complexo A. cajennense ocorrendo no território nacional. De modo geral, a distribuição da espécie $A$. cajennense s. s. está confirmada no Brasil em três estados da região Norte (Pará, Rondônia e Tocantins), em um estado da região Nordeste (Maranhão) e do Centro-Oeste (Mato Grosso). Salienta-se um único encontro de uma fêmea de $A$. cajennense s. s. em uma propriedade rural do município de Porangatu, no extremo norte do estado de Goiás, na divisa com o estado de Tocantins. A ocorrência de A. sculptum está confirmada nos seguintes estados brasileiros da região Norte: Pará, Rondônia e Tocantins; Nordeste: Bahia, Maranhão, Pernambuco e Piauí; Centro-Oeste: Distrito Federal, Goiás, Mato Grosso e Mato Grosso do Sul; Sudeste: Espírito Santo, Minas Gerais, Rio de Janeiro e São Paulo; e Sul: Paraná. Estes dados indicam que o papel de cada uma destas espécies na transmissão de patógenos deve ser reavaliado de acordo com seu novo status taxonômico. 
Palavras-chave: Carrapatos. Complexo. Amblyomma cajennense. Amblyomma sculptum. Brasil. 


\begin{abstract}
MARTINS, T. F. Study of the complex Amblyomma cajennense in Brazil. [Estudo do complexo Amblyomma cajennense no Brasil]. 2014. 113 f. Tese (Doutorado em Ciências) Faculdade de Medicina Veterinária e Zootecnia, Universidade de São Paulo, São Paulo, 2014.
\end{abstract}

Recent genetic, biological and morphological studies have demonstrated that Amblyomma cajennense is a complex of at least six distinct species, each species linked to a biogeographic area in the American continent. In this context, the present study aimed to perform morphological and molecular analyzes of adult ticks, previously identified as A. cajennense, deposited in the collections of ticks "Coleção Nacional de Carrapatos", the Faculty of Veterinary Medicine and Zootechny of the University of São Paulo and in the "Coleção Acarológica do Instituto Butantan" the Butantan Institute of São Paulo. Adicional tick specimens were obtained through fieldwork. Ticks were collected in the vegetation, domestic animals (horses, pigs) and road-killed wild animals (tapir, anteater) during three field expeditions, one in the northeast of the country between the municipalities of Bequimão/MA and Estrela do Norte/GO; one in the northwest of the country between the municipalities of Presidente Médici/RO and Vila Bela da Santíssima Trindade/MT; and a third one in the center-north of the country between the municipalities of Sinop/MT and Cuiabá/MT. The morphological and molecular results demonstrated the occurrence of at least two distinct species of ticks (A. cajennense sensu stricto and Amblyomma sculptum) of the A. cajennense species complex occurring in the Brazilian land. In general, the distribution of the species $A$. cajennense s. s. is confirmed in Brazil in three northernern states (Pará, Rondônia and Tocantins) one Northeast state (Maranhão) and one Midwest state (Mato Grosso). It is note worthy the findings of a single female of $A$. cajennense s. s. on a farm in the municipality of Porangatu, in the far north of the state of Goiás at the northern end of the state of Goiás, at the border with the state of Tocantins. The occurrence of A. sculptum is confirmed in the following Brazilian states Northern region: Pará, Rondônia and Tocantins; Northeastern region: Bahia, Maranhão, Piauí and Pernambuco; Midwester region: Distrito Federal, Goiás, Mato Grosso and Mato Grosso do Sul; Southeastern region: Espírito Santo, Minas Gerais, Rio de Janeiro and São Paulo; and Southern region: Paraná. These data indicate that the role of each of these species in pathogen transmission should be re-assessed according to its new taxonomic status. 
Keywords: Ticks. Complex. Amblyomma cajennense. Amblyomma sculptum. Brazil. 


\section{LISTA DE FIGURAS}

Figura 1 - Coleta de carrapatos em equinos (Equus caballus) durante a expedição no noroeste do país

Figura 2 - Coleta de carrapatos em suínos (Sus scrofa) durante a expedição no nordeste do país

Figura 3 - Macho de Amblyomma cajennense sensu lato coletado eventualmente em humano (Homo sapiens) durante a expedição no nordeste do país.

Figura 4 - Coleta de carrapatos em anta (Tapirus terrestris) atropelada durante a expedição no centro-norte do país....

Figura 5 - Coleta de carrapatos em tamanduá-bandeira (Myrmecophaga tridactyla) atropelado durante a expedição no nordeste do país.

Figura 6 - Técnica de arrasto com flanela branca utilizada dentro de um recinto de anta (Tapirus terrestris) durante a expedição no nordeste do país. .41

Figura 7 - Macho de Amblyomma cajennense sensu lato coletado em vida livre através da técnica visual durante a expedição no noroeste do país.

Figura 8 - Tentativa de coleta de carrapatos em zebra (Equus grevyi) durante a expedição no nordeste do país.

Figura 9 - Animal e proprietários que apoiaram o projeto durante a expedição no nordeste do país

Figura 10 - Triagem de carrapatos do complexo Amblyomma cajennense no campo durante a expedição no nordeste do país.

Figura 11 - Abertura genital em forma de "V" com duas projeções largas nos bordos laterais da fêmea de Amblyomma cajennense sensu stricto.

Figura 12 - Abertura genital em forma de "U" com duas projeções estreitas nos bordos laterais da fêmea de Amblyomma sculptum....

Figura 13 - Árvore filogenética construída por máxima parcimônia, baseada em seqüências de ITS2 rDNA mitocondrial (1034 caracteres, 114 sítios informativos) de carrapatos de 30 diferentes localidades. Amblyomma americanum foi utilizado como grupo externo. Legenda: Os números nos ramos correspondem aos valores de suporte de bootstrap em 100 replicatas. As sequências geradas no presente estudo estão em negrito, representadas pelo nome do município, seguido pelo estado brasileiro entre parênteses. Números entre colchetes representam números de acesso do Genbank. 


\section{LISTA DE FIGURAS}

Figura 14 - Árvore filogenética construída por máxima parcimônia, baseada em sequiências de ITS2 rDNA mitocondrial (871 caracteres, 71 sítios informativos) de carrapatos de 30 diferentes localidades. Amblyomma americanum foi utilizado como grupo externo, além de sequências de Amblyomma mixtum, Amblyomma interandinum, Amblyomma patinoi e Amblyomma tonelliae obtidas no GenBanK. Legenda: Os números correspondem aos valores de suporte de bootstrap em 100 replicatas. As sequências geradas no presente estudo estão em negrito, representadas pelo nome do município, seguido pelo estado brasileiro entre parênteses. Números entre colchetes representam números de acesso do

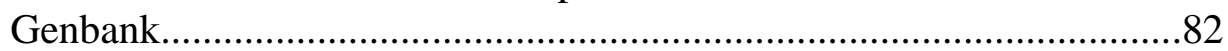

Figura 15 - Localidades (regiões geopolíticas) onde amostras de carrapatos do complexo Amblyomma cajennense foram coletados no Brasil para as análises moleculares e filogenéticas no presente estudo. Legenda: Os pontos $(\square \bullet)$ correspondem às localidades descritas no Quadro $1 \ldots \ldots . . .83$

Figura 16 - Localidades (estados da federação) onde amostras de carrapatos do complexo Amblyomma cajennense foram coletados no Brasil para as análises moleculares e filogenéticas no presente estudo. Legenda: Os pontos $(\square \bullet)$ correspondem às localidades descritas no Quadro 1

Figura 17 - Mapa do Brasil com os estados da federação, demonstrando a distribuição geográfica do complexo Amblyomma cajennense no país. 86

Figura 18 - Mapa do Brasil com os biomas, demonstrando a distribuição geográfica do complexo Amblyomma cajennense no país.

Figura 19 - Mapa do Brasil com a vegetação remanescente, demonstrando a distribuição geográfica do complexo Amblyomma cajennense no país...88

Figura 20 - Mapa do Brasil com os climas, demonstrando a distribuição geográfica do complexo Amblyomma cajennense no país 


\section{LISTA DE QUADRO}

Quadro 1 - Origem dos carrapatos do complexo Amblyomma cajennense que foram utilizados para as análises moleculares e filogenéticas no presente estudo. 
LISTA DE ABREVIATURAS E SIGLAS

A.

$\mathrm{AC}$

$\mathrm{AL}$

Am

$\mathrm{AM}$

AP

$\mathrm{B}$

BA

$\mathrm{Ca}$

$\mathrm{Ce}$

CE

Co

$\mathrm{CNC}$

$\mathrm{CNPq}$

$\mathrm{DF}$

DNA

E.

$\mathrm{E}$

$\mathrm{Eq}$

ES

ex

FMVZ

FUNTROP

GenBank

GO

GPS

GT

IB

IBGE

IBSP
Amblyomma

Acre

Alagoas

Amazônia

Amazonas

Amapá

análise bayeseana

Bahia

Caatinga

Cerrado

Ceará

Centro-Oeste

Coleção Nacional de Carrapatos

Conselho Nacional de Desenvolvimento Científico e Tecnológico

Distrito Federal

ácido desoxirribonucleico

Equus

Leste

Equatorial

Espírito Santo

exemplo

Faculdade de Medicina Veterinária e Zootecnia

Fundação de Medicina Tropical do Tocantins

banco de dados de sequências genéticas

Goiás

sistema de posicionamento global

técnica de isotiocianato de guanidina

Instituto Butantan

Instituto Brasileiro de Geografia e Estatística

Coleção Acarológica do Instituto Butantan de São Paulo 


\section{LISTA DE ABREVIATURAS E SIGLAS}

ICB5 Instituto de Ciências Biomédicas

ICMBio Instituto Chico Mendes de Conservação da Biodiversidade

IDARON Agência de Defesa Sanitária Agrosilvopastoril do estado de Rondônia

INDEA Instituto de Defesa Agropecuária do estado de Mato Grosso

INTA Instituto Nacional de Tecnologia Agropecuária

ITS2 segundo espaço transcrito interno

LDP Laboratório de Doenças Parasitárias

LECZ Laboratório Especial de Coleções Zoológicas

Ma Mata Atlântica

MA Maranhão

MG Minas Gerais

MMA Ministério do Meio Ambiente

MP máxima parcimônia

MS Mato Grosso do Sul

MT Mato Grosso

$\mathrm{n}$ número

$\mathrm{N} \quad$ Norte

$\mathrm{Nd} \quad$ Nordeste

n. sp. nova espécie

PA Pará

$\mathrm{pb} \quad$ par de bases

PB Paraíba

PCR reação em cadeia pela polimerase

PE Pernambuco

PI Piauí

Pp Pampa

PR Paraná

Pt Pantanal

PVCC Programa de Vigilância e Controle de Carrapatos

PZMQB Parque Zoológico Municipal Quinzinho de Barros 


\section{LISTA DE ABREVIATURAS E SIGLAS}

\begin{tabular}{ll}
$R$. & Rickettsia \\
rDNA & ácido desoxirribonucléico ribossomal \\
RJ & Rio de Janeiro \\
RN & Rio Grande do Norte \\
RO & Rondônia \\
RR & Roraima \\
RS & Rio Grande do Sul \\
S & Sul \\
SAD69 & South American Datum 1969 \\
Sb & Subtropical \\
SBH & Sociedade Brasileira de Herpetologia \\
SC & Santa Catarina \\
Sd & Sudeste \\
SE & Sergipe \\
s. l. & sensu lato \\
Sm & Semiárido \\
SP & São Paulo \\
s. s. & sensu stricto \\
SUCEN & Superintendência de Controle de Endemias \\
T & Tropical \\
TO & Tocantins \\
U & u \\
UFMT & Universidade Federal do Mato Grosso \\
UFPA & Universidade Federal do Pará \\
UNIVASF & Universidade Federal do Vale do São Francisco \\
USP & Universidade de São Paulo \\
UV & ultravioleta \\
V & v \\
VPS & Departamento de Medicina Veterinária Preventiva e Saúde Animal \\
W & Oeste \\
& \\
\hline &
\end{tabular}




\section{LISTA DE SÍMBOLOS}

\begin{tabular}{|c|c|}
\hline $\mathrm{i}$ & primeira \\
\hline ii & segunda \\
\hline iii & terceira \\
\hline $\mathrm{Km}$ & quilômetros \\
\hline , & linha \\
\hline$\mu l$ & microlitro \\
\hline $\mathrm{x}$ & vezes \\
\hline ( & marca registrada \\
\hline $\mathrm{H}_{2} \mathrm{O}$ & água \\
\hline${ }^{\circ} \mathrm{C}$ & graus Celsius \\
\hline$\%$ & por cento \\
\hline $\mathrm{pH}$ & potencial de hidrogenico \\
\hline $\mathrm{v}$ & volts \\
\hline $\mathrm{mA}$ & miliampère \\
\hline $\mathrm{ml}$ & mililitro \\
\hline ng & nanograma \\
\hline pmoles & picomol \\
\hline$*$ & coletados como ninfas \\
\hline$=$ & igual \\
\hline$\circ$ & graus \\
\hline ' & minutos \\
\hline$\hat{0}$ & macho \\
\hline 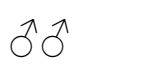 & machos \\
\hline q & fêmea \\
\hline 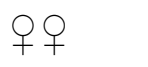 & fêmeas \\
\hline+ & mais \\
\hline
\end{tabular}




\section{SUMÁRIO}

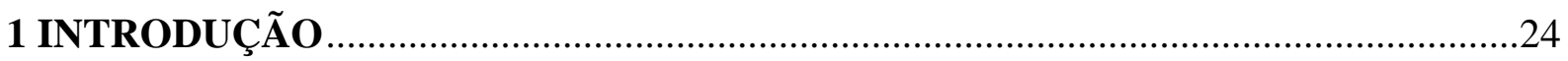

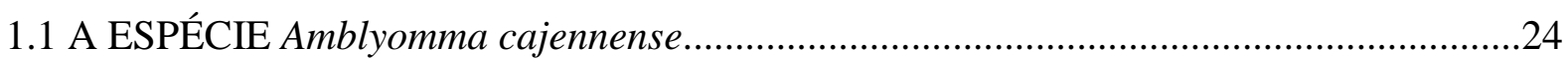

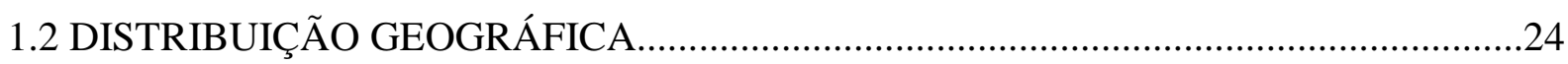

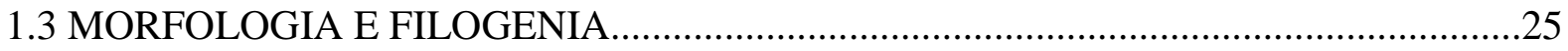

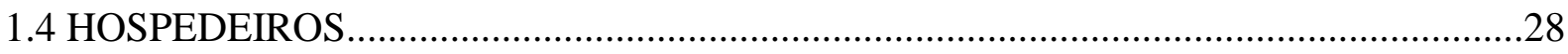

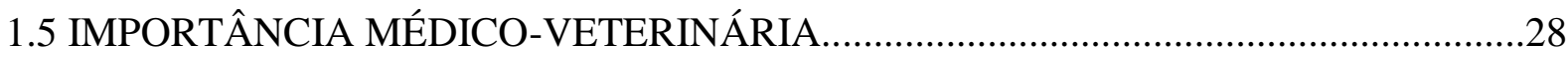

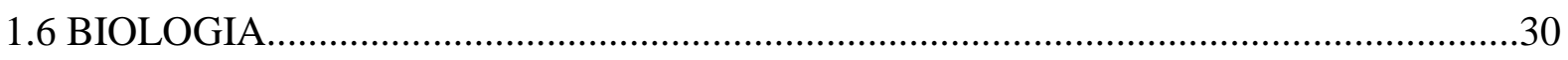

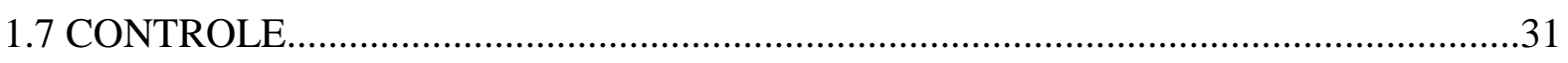

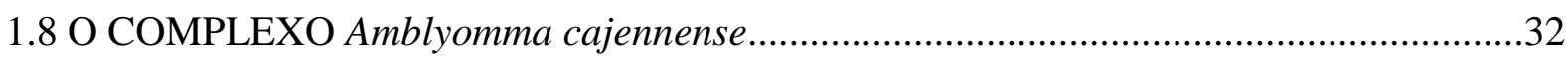

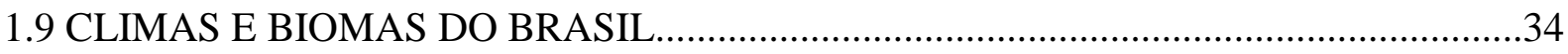

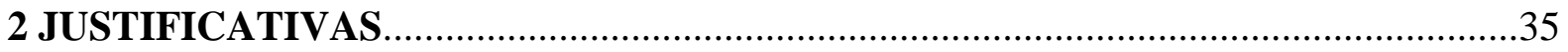

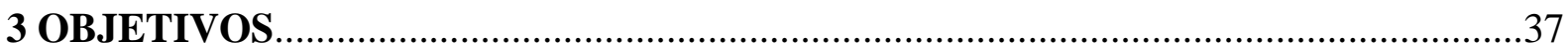

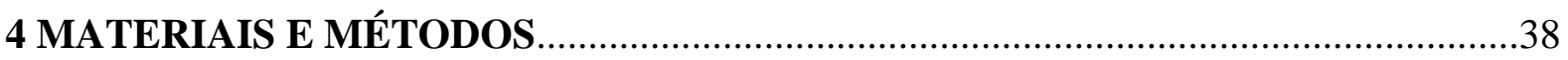

4.1 OBTENÇÃO DE CARRAPATOS DO COMPLEXO Amblyomma cajennense ..................38

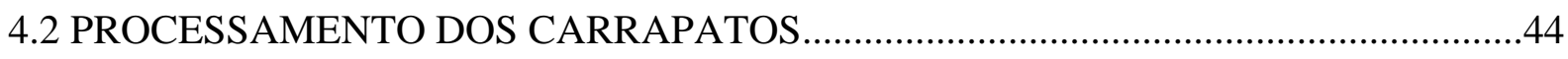

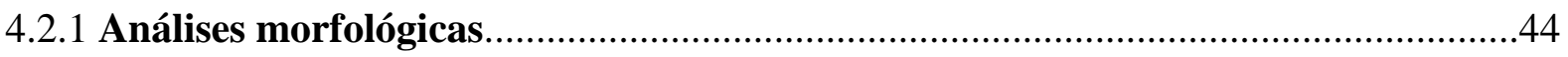

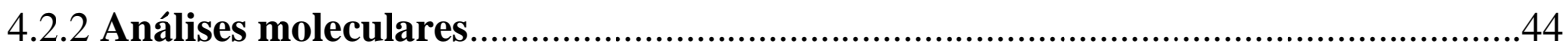

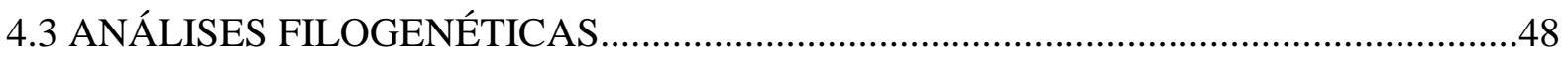

4.4 OBSERVAÇÃO DA DISTRIBUIÇÃO GEOGRÁFICA DO COMPLEXO

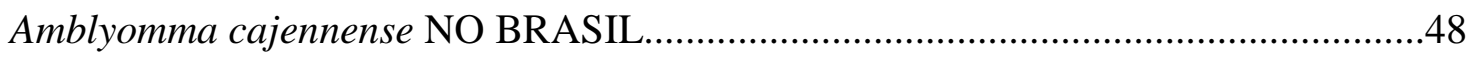

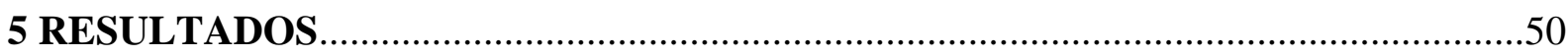

5.1 LOCALIDADES DO MATERIAL DEPOSITADO NA COLEÇÃO CNC ......................50

5.2 LOCALIDADES DO MATERIAL DEPOSITADO NA COLEÇÃO IBSP......................64

5.3 LOCALIDADES ADQUIRIDAS CASUALMENTE PELO LDP NO ANDAMENTO DO

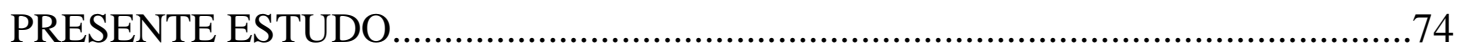

5.4 LOCALIDADES DA EXPEDIÇÃO BEQUIMÃO/MA À ESTRELA DO

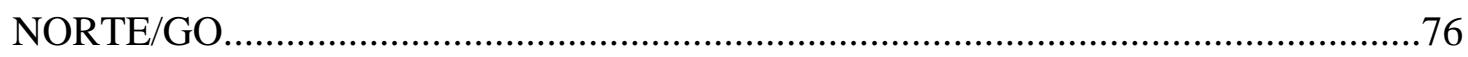

5.5 LOCALIDADES DA EXPEDIÇÃO PRESIDENTE MÉDICI/RO À VILA BELA DA

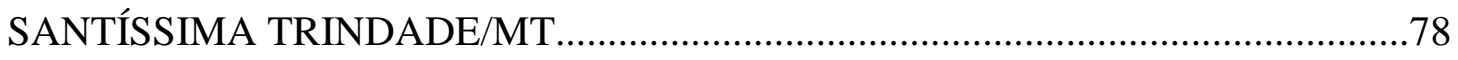

5.6 LOCALIDADES DA EXPEDIÇÃO SINOP/MT À CUIABÁ/MT...................................79

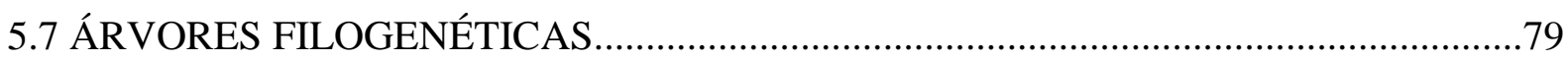


5.8 MAPAS DE DISTRIBUIÇÃO GEOGRÁFICA DE CARRAPATOS DO COMPLEXO Amblyomma cajennense NO BRASIL....................................................................85

6 DISCUSSÃO

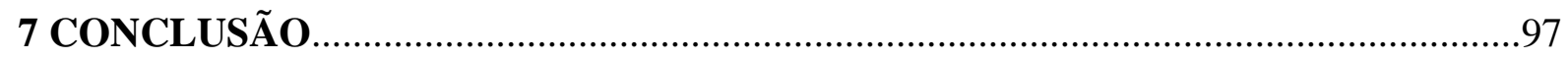

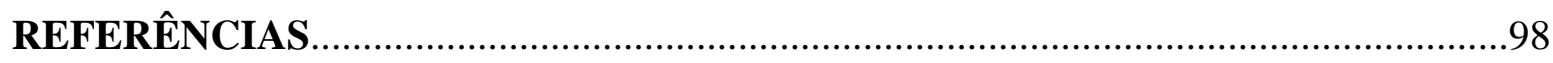

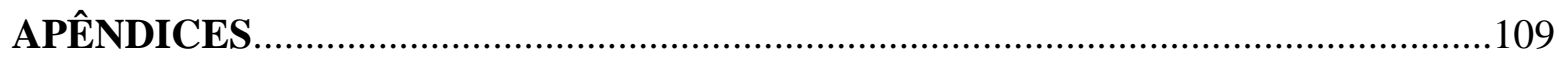




\section{INTRODUÇÃO}

\subsection{A ESPÉCIE Amblyomma cajennense}

A espécie Amblyomma cajennense (Fabricius, 1787) é originária da região Neotropical, tendo sido primeiramente descrita a partir de espécimes coletados na cidade de Cayena (Guiana Francesa), de onde deriva seu nome específico (GUGLIELMONE et al., 2006b). No Brasil, o estágio adulto de A. cajennense recebe diferentes designações populalares, tais como "carrapato-estrela", "rodolero" e "redolero" (GUIMARÃES; TUCCI; BARROS-BATTESTI, 2001; GUGLIELMONE et al., 2006b).

\subsection{DISTRIBUIÇÃO GEOGRÁFICA}

Distribui-se por todo o continente americano, desde o Sul dos Estados Unidos (Texas e Florida), América Central (incluindo as Antilhas), até o Norte da Argentina, com exceção do Chile, Uruguai e o extremo Sul do Brasil. (GUGLIELMONE et al., 2003; ESTRADA-PEÑA; GUGLIELMONE; MANGOLD, 2004; GUGLIELMONE et al., 2006b; ONOFRIO et al., 2006).

No Brasil, é encontrado com abundância em todos os estados das regiões Sudeste e Centro-Oeste, porém com distribuição limitada nas demais regiões (LABRUNA et al., 2001; VIEIRA et al., 2004). A distribuição geográfica do A. cajennense segundo unidades federativas do Brasil é ampla, ocorrendo nos estados do Amapá/AP, Amazonas/AM, Pará/PA, Rondônia/RO, Roraima/RR, Tocantins/TO, Bahia/BA, Ceará/CE, Maranhão/MA, Paraíba/PB, Pernambuco/PE, Piauí/PI, Rio Grande do Norte/RN, Sergipe/SE, Distrito Federal/DF, Goiás/GO, Mato Grosso/MT, Mato Grosso do Sul/MS, Espírito Santo/ES, Minas Gerais/MG, Rio de Janeiro/RJ, São Paulo/SP, Paraná/PR, Santa Catarina/SC e Rio Grande do Sul/RS (ARAGÃO, 1936; GUIMARÃES; TUCCI; BARROS-BATTESTI, 2001; VIEIRA et al., 2004; ONOFRIO 2007). 
Espécies com distribuição mais ampla tendem a apresentar variações de forma e função mais acentuadas, resultantes de adaptações às condições abióticas e bióticas encontradas ao longo de suas áreas de ocorrência. Nesse cenário, erros na identificação podem ocorrer em duas direções: espécies diferentes podem ser consideradas como sendo uma única espécie ou vise e versa. No caso de duas ou mais espécies crípticas, independente de serem filogeneticamente próximas ou não, recomenda-se a utilização de técnicas de biologia molecular que contribuirão para a determinação do táxon (FACCINI; BARROS-BATTESTI, 2006).

\subsection{MORFOLOGIA E FILOGENIA}

Embora caracteres morfológicos sejam mais do que suficientes para a separação das famílias, gêneros e a maioria das espécies de carrapatos, há existência de complexos de espécies, variações de tamanhos e formas intermediárias entre espécies próximas. Podem algumas vezes, tornarem-se de difícil identificação morfológica. O microscópio eletrônico de varredura pode ser útil no estudo das áreas genitais de fêmeas e tem ajudado nos estudos morfológicos de espécies crípticas (GUIMARÃES; TUCCI; BARROS-BATTESTI, 2001). Outros métodos usados na taxonomia de carrapatos são isoenzimas, análise dos hidrocarbonetos cuticulares e análises genéticas, especialmente por métodos moleculares (HUNT, 1986; KLOMPEN et al., 1996; POUCHER et al., 1999).

Um dos desafios enfrentados pelos estudiosos é, sem dúvida, compreender a imensa diversidade de formas e funções existentes nos seres vivos. Para tanto, é fundamental estabelecer as relações entre esses seres e seus ancestrais. O estudo desse segmento da biologia denomina-se sistemática filogenética. As relações entre os seres vivos são expressas através das árvores filogenéticas. Nos estudos de filogenia de carrapatos, além de técnicas convencionais, como comparação de determinados caracteres morfológicos, também são utilizadas técnicas biomoleculares, como a variabilidade do segundo espaço transcrito interno (ITS2), fragmentos de sequências gênicas do DNA ribossomal e mitocondrial ou ainda, a combinação de todas (FACCINI; BARROS-BATTESTI, 2006). O ITS2 demonstrou ser um marcador informativo no nível intragenérico em espécies Neotropicais de Amblyomma (MARRELLI et al., 2007; BEATI et al., 2013). 
O conceito de espécie tem sido amplamente discutido, e diferentes definições (biológicas, ecológicas, evolutivas e filogenéticas, entre outros) foram propostas (WHEELER; MEIER, 2000; STOCKMAN; BOND, 2007). Nestes conceitos, a delimitação das espécies é baseada em um único critério. Mas uma definição contemporânea de espécies é o "conceito de espécie unificadas". De acordo com este conceito, propriedades contingentes variadas como distinguibilidade fenética, monofilia recíproca, isolamento pré e pós-zigótico, estados de diferenças de carater fixo, são importantes linhas de evidências para a separação das linhagens de meta populações (DE QUEIROZ, 2005).

No passado, alguns autores consideraram diferenças fenotípicas para identificar espécies diferentes dentro do táxon A. cajennense (KOCH, 1844; TONELLI-RONDELLI, 1939). Entretanto, outros autores atribuíram diferenças morfológicas de A. cajennense ao simples polimorfismo intraespecífico (NEUMANN, 1899; KOHLS, 1958). Desta forma, vários táxons descritos como diferentes espécies foram sinonimizados com A. cajennense, sob o argumento de que eles meramente apresentavam variações morfológicas intraespecíficas, possivelmente ligadas a populações geograficamente distintas (ARAGÃO; FONSECA, 1953; KOHLS, 1958).

Todos os estágios pós-embrionários (larva, ninfa, macho e fêmea) do carrapato $A$. cajennense já foram descritos (GUGLIELMONE et al., 2003; ONOFRIO et al., 2006; GUGLIELMONE et al., 2014). Dois casos de ginandromorfismo de A. cajennense já foram relatados no Brasil (FONSECA, 1935; LABRUNA et al., 2002b).

Morfologicamente, A. cajennense se mostra próximo a Amblyomma imitator Kohls, 1958, Amblyomma tapirellum Dun, 1933 e Amblyomma oblongoguttatum, Koch, 1844. Difere das duas últimas, pela ornamentação típica de seu escudo e pela presença dos tubérculos quitinosos nos festões da fêmea. A fêmea de A. imitator difere de A. cajennense não só pela ausência dos tubérculos quitinosos, mas também, por apresentar projeções largas nos bordos laterais da abertura genital. Em A. cajennense, essas projeções são suaves. Já os machos de ambas as espécies são quase indistinguíveis (GUGLIELMONE et al., 2004; GUGLIELMONE et al., 2006b). Devido à proximidade morfológica entre A. cajennense e A. imitador demonstrada por Kohls (1958), Hilburn, Gunn e Castillo (1989) estudaram populações simpátricas de A. cajennense e A. imitador, encontrando enzimas de alto valor diagnóstico e nenhum sinal de hibridação entre estas espécies.

Diferenças no ciclo de vida de espécimes de A. cajennense de colônias de laboratório de distintas origens geográficas sugerem que este é um complexo de espécies crípticas (GUGLIELMONE; MANGOLD; OYOLA, 1992). No entanto, análises de hidrocarbonetos 
cuticulares de doze populações da América Central e do Sul não suportaram esta teoria (ESTRADA-PENÃ et al., 1993).

Neste contexto, dois estudos avaliaram a compatibilidade reprodutiva de cruzamentos entre populações geograficamente diferentes de carrapatos que foram identificados sob o táxon A. cajennense, demosntrando baixa fertilidade, sugerindo que o táxon A. cajennense pode ser representado por um complexo de espécies diferentes, como especulado anteriormente por outros autores (LABRUNA et al., 2011a; MASTROPAOLO et al., 2011).

Cruzamentos de duas populações geograficamente distantes para muitos outros grupos de animais e plantas já foram previamente relatados (VEITIA; VAIMAN, 2011). Incompatibilidade reprodutiva é uma condição possivelmente relacionada com a dissimilaridade genética, tem contribuído para a integridade das espécies. Em adição, outros fatores como preferências específicas para certas zonas bioclimáticas também podem ter contribuído para a integridade das espécies.

Mais estudos de genética de populações, juntamente com extensas análises morfológicas, são necessários para esclarecer e determinar um complexo possível de espécies válidas que podem ter sido classificadas no táxon A. cajennense (LABRUNA et al., 2011a). Portanto, é desejável realizar um amplo estudo sobre a variação morfológica, biológica e genética de A. cajennense ao longo de sua área de distribuição para resolver este problema (MASTROPAOLO et al., 2011).

Recentemente Beati et al. (2013) realizaram análises filogenéticas de espécimes de $A$. cajennense de diferentes países Americanos, demontrando segregação genética em diferentes clados. Desta forma, os autores conlcuíram que A. cajennense é um complexo de espécies, cada uma associada a uma região biogeográfica particular.

No mesmo ano Nava et al. $\left(2014^{1}\right)$, realizaram análises morfológicas demonstrando que A. cajennense é um complexo caracterizado por especiação parapátrica, onde cada uma das espécies do complexo está associado a ecorregiões particulares com zona de hibridização estreita, relatando que será essencial adquirir e analisar um novo material das áreas entre as faixas de distribuição reconhecidas, a fim de estabelecer se há ou não sobreposição geográfica.

\footnotetext{
${ }^{1}$ NAVA, S.; BEATI, L.; LABRUNA, M. B.; CÁCERES, A. G.; MANGOLD, A. J.; GUGLIELMONE, A. A. Reassessment of the taxonomic status of Amblyomma cajennense (Fabricius, 1787) with the description of three new species, Amblyomma tonelliae n. sp., Amblyomma interandinum n. sp. and Amblyomma patinoi n. sp., and resurrection of Amblyomma mixtum Koch, 1844 and Amblyomma sculptum Berlese, 1888 (Ixodida: Ixodidae). Ticks and Tick-borne Diseases, No prelo, 2014
} 


\subsection{HOSPEDEIROS}

$\mathrm{O}$ carrapato A. cajennense parasita um grande número de espécies entre mamíferos e aves, incluindo o homem (ARAGÃO, 1936; VIEIRA et al., 2004; ONOFRIO et al., 2006; GUGLIELMONE et al., 2014). Se caracteriza por parasitar humanos em maior intensidade que qualquer outra espécie de carrapato no Neotrópico (ARAGÃO, 1936; GUGLIELMONE et al., 2003; GUGLIELMONE et al., 2006a).

Os adultos têm preferência em parasitar grandes mamíferos como equinos, bovinos, antas e capivaras. Outros animais domésticos como búfalo, cão, porco, ovelha, cabra, coelho, assim como mamíferos silvestres de tamanho médio a grande, são também infestados por esta espécie. Existem registros de infestação de aves domésticas como perus e galinhas, além de aves silvestres e alguns répteis, porém o parasitismo nestes hospedeiros não é comum (GUGLIELMONE et al., 2004; GUGLIELMONE et al., 2006b; GUGLIELMONE et al., 2014). Esta espécie comumente ataca o homem em qualquer fase de seu desenvolvimento (GUIMARÃES; TUCCI; BARROS-BATTESTI, 2001).

Dada a menor especificidade parasitária das larvas e ninfas, estes são os principais estágios que parasitam os seres humanos. Geralmente, o estágio adulto é mais específico de grandes mamíferos. Quando as populações deste carrapato se apresentam muito numerosas, o estágio adulto é encontrado com mais frequência em outros mamíferos, inclusive humanos. Nas áreas rurais da região Sudeste do Brasil, os equinos são os principais hospedeiros domésticos para todos os estágios do A. cajennense, recentemente, as capivaras têm desempenhado o papel de principal hospedeiro silvestre para este carrapato em ambientes antropizados (LABRUNA et al., 2004a; VIEIRA et al., 2004; LABRUNA et al., 2013).

\subsection{IMPORTÂNCIA MÉDICO-VETERINÁRIA}

Infestações por esta espécie em muitos países da América Latina e Caribe têm causado grandes perdas econômicas, não só pela depreciação do couro dos animais infestados, mas também pela diminuição da produção animal, em decorrência da disseminação de agentes patogênicos através do parasitismo, elevando os custos associados ao seu controle (GUGLIELMONE et al., 2004; GUGLIELMONE et al., 2006b). 
Este carrapato é o principal vetor da bactéria Rickettsia rickettsii, o agente causal da Febre Maculosa Brasileira (LABRUNA, 2009; LABRUNA et al., 2011b). O A. cajennense é um dos responsáveis pela manutenção da $R$. rickettsii na natureza, pois ocorre transmissão transovariana e perpetuação transestadial (SOARES et al., 2011). Esta característica biológica permite ao carrapato permanecer infectado durante toda a sua vida e também por gerações consecutivas após uma infecção primária. Portanto, além de vetores, os carrapatos são verdadeiros reservatórios da riquétsia na natureza, uma vez que todas as fases evolutivas, no ambiente, são capazes de permanecer infectadas meses ou anos à espera do hospedeiro, garantindo um foco endêmico prolongado. É a principal espécie de carrapato que parasita seres humanos no centro-sul brasileiro, sendo considerado o principal vetor da Febre Maculosa Brasileira (LABRUNA et al., 2001; VIEIRA et al., 2004).

Seu parasitismo em humanos, muitas vezes em massa, é respondido com reações de hipersensibilidade imediata ou tardia a antígenos específicos presentes na saliva do carrapato, podendo causar intenso prurido, que persiste por vários dias no local de fixação. Infecções bacterianas secundárias podem ocorrer em função da deposição de bactérias nas feridas, durante ao ato de coçar intensamente (ARAGÃO; FONSECA, 1961). No homem, as picadas produzem intenso prurido e uma lesão granulomatosa, especialmente ao redor da cintura e pernas, que pode levar vários meses para cicatrizar (GUIMARÃES; TUCCI; BARROSBATTESTI, 2001).

Recentemente no Brasil, a bactéria Rickettsia amblyommii foi isolada do carrapato A. cajennense do estado de Rondônia (LABRUNA et al., 2004b). Até o momento, esta espécie de Rickettsia não foi associada com doenças em humanos ou animais. No entanto, a história da riquetsiologia mostra que nenhuma espécie deve ser considerada não patogênica, até que se mostre o contrário (LABRUNA; MACHADO, 2006).

Um Flavivirus (Flaviridae) foi isolado de espécimes de A. cajennense coletados de uma capivara doente no Sudeste do Brasil (FIGUEIREDO et al., 1999). O isolamento de outros vírus (arbovírus) de A. cajennense foi relatado na Jamaica (BELLE et al., 1980). Também é um reservatório e vetor eficiente para o vírus da encefalite equina venezuelana (CASALS, 1970; BELLE et al., 1980). Experimentos demonstraram que o vírus da encefalite equina venezuelana pode infectar A. cajennense em laboratório e que o carrapato é capaz de manter e transmitir o vírus, podendo estar potencialmente envolvido com o ciclo epizoótico dessa doença (LINTHICUM et al., 1991).

Em menor escala é um vetor experimental de Ehrlichia (Cowdria) ruminantium (UILENBERG, 1983; BARRÉ et al., 1987). O papel de A. cajennense como vetor de 
Theileria equi é controverso. No Brasil, todos os estudos experimentais foram negativos (RIBEIRO; SILVEIRA; BASTOS, 2011). Embora haja evidências epidemiológicas para um possível papel deste carrapato como vetor de T. equi nos estados de São Paulo e Rio de Janeiro (KERBER et al., 2009; PECKLE et al., 2013). Nos Estados Unidos, foi relatado um surto de piroplamose equina, aonde a espécie A. cajennense foi o carrapato predominante e experimentalmente transmitiu $T$. equi a um cavalo não infectado, sugerindo a transmissão deste agente por esta espécie de carrapato neste surto (SCOLES et al., 2011).

Um microsporídio Encephalitozoon-like foi encontrado em A. cajennense (RIBEIRO; GUIMARÃES, 1998). Embora seja incerto se este protozoário pode infectar os seres humanos através de picadas por carrapatos, tais achados são motivo de preocupação porque as infecções por microsporídio são relatadas em pacientes com o vírus da imunodeficiência humana/Síndrome da imunodeficiência adquirida (SCHWARTZ et al., 1996).

Existe um antecedente indicativo de que esta espécie de carrapato possa produzir paralisia em animais domésticos (GUGLIELMONE et al., 2004; GUGLIELMONE et al., 2006b). No Brasil, a paralisia por A. cajennense foi registrada em caprinos e ovinos (SERRAFREIRE, 1983). Além disso, pode ainda estar envolvida na transmissão de um agente causal desconhecido, que provoca uma sínrome similar à Doença de Lyme (Doença de Lyme- Símile brasileira/Síndrome Baggio-Yoshinari) em humanos no Brasil (YOSHINARI et al., 1997; FONSECA et al., 2005; MANTOVANI et al., 2007; SHINJO et al., 2009). Observações epidemiológicas sugerem que o agente seja transmitido por A. cajennense (LABRUNA; MACHADO, 2006).

\subsection{BIOLOGIA}

Dada sua importância na transmissão de doenças, ressaltam-se a seguir as características biológicas do A. cajennense. É um carrapato de três hospedeiros (trioxeno) (GUIMARÃES; TUCCI; BARROS-BATTESTI, 2001; GUGLIELMONE et al., 2006b).

Realiza apenas uma geração por ano sob condições naturais nas áreas do Norte da Argentina e Sudeste do Brasil (GUGLIELMONE et al., 1990; LABRUNA et al., 2002a). Este padrão se caracteriza pelo predomínio do estágio larval de abril a julho, do estágio ninfal de julho a outubro, e do estágio adulto nos meses mais quentes e chuvosos, de outubro a março, 
demostrando os três estágios parasitários marcadamente distribuídos ao longo do ano (SOUZA; SERRA-FREIRE, 1992; OLIVEIRA et al., 2000; LABRUNA et al., 2002a; OLIVEIRA et al., 2003; GUGLIELMONE et al., 2006b).

Em condições naturais da região Sudeste do Brasil, as larvas de A. cajennense eclodidas nos meses de novembro a março (época de maior atividade do estágio adulto) permanecem no solo sob a vegetação, até o próximo mês de abril, quando então sobem nas folhas do capim pela primeira vez, formando aglomerados com centenas de indivíduos cada. Este comportamento foi caracterizado como diapausa comportamental, sendo o principal fator regulador do ciclo biológico de A. cajennense em condições naturais (LABRUNA et al., 2003; CABRERA; LABRUNA, 2011).

Embora o A. cajennense tenha uma baixa especificidade parasitária, para que uma população esteja estabelecida em uma determinada área, há dois pontos críticos a serem considerados: presença de hospedeiros primários (ex. equinos, antas e capivaras) e condições ambientais favoráveis às fases de vida livre (não parasitária) do carrapato. Em termos práticos, um hospedeiro primário é o vertebrado, sem o qual, uma determinada população de carrapato não é capaz de se estabelecer em uma área. Em algumas áreas, mesmo na abundância de hospedeiros primários para o A. cajennense, este pode não se estabelecer em função de condições ambientais, que não propiciem um microclima adequado para as fases de vida livre do carrapato. Estas condições são dependentes principalmente da latitude (baixas temperaturas ao Sul do estado do Paraná limitam o estabelecimento deste carrapato) e do tipo de cobertura vegetal, que vai influir diretamente no microclima do solo. Tanto a presença como abundância de populações de A. cajennense estão fortemente associadas à presença de áreas com média a densa cobertura vegetal, tais como pastos "sujos", capoeiras e matas (LABRUNA et al., 2001; VIEIRA et al., 2004).

\subsection{CONTROLE}

Duas abordagens principais devem ser levadas em consideração quando se trata de controlar A. cajennense: uma relativa aos efeitos das infestações que levam ao risco da transmissão de riquetsioses (saúde púlica) e outra, relativa ao parasitismo de animais de produção (MARTINS; FURLONG; LEITE, 2006). 
Sendo assim, o controle das populações de A. cajennense pode ser executado em duas formas: intervindo na população parasitária de carrapatos, especialmente sobre os hospedeiros primários, e outra, intervindo na população de vida livre de carrapatos, presente principalmente nos locais do solo em que a cobertura vegetal e/ou as condições das instalações oferecem microclima favorável a seu desenvolvimento e sobrevivência (LABRUNA et al., 2001; VIEIRA et al., 2004).

Os adultos de $A$. cajennense são naturalmente mais tolerantes aos acaricidas que os estágios imaturos (BITTENCOURT; MASSARD; GRISI, 1989). Portanto, para um controle integrado, recomenda-se aspersão semanal dos hospedeiros durante o período de infestação de larvas e ninfas (estágios mais suscetíveis aos acaricidas). Durante a primavera e verão seguintes, a remoção manual das fêmeas desta espécie de carrapato dos hospedeiros, tais como os cavalos, é igualmente recomendada. Em algumas ocasiões, pode-se controlar a infestação de $A$. cajennense sem a utilização de acaricidas, mantendo os pastos limpos de carrapatos por meio do corte dos mesmos durante a estação chuvosa, período em que o crescimento da vegetação é mais favorável (LABRUNA et al., 2004a).

\subsection{O COMPLEXO Amblyomma cajennense}

O táxon A. cajennense vinha sendo considerado uma única espécie de carrapato distribuída desde o Sul dos Estados Unidos até o Norte da Argentina. Trabalhos recentes, baseados numa avaliação morfológica e genética de diferentes populações de A. cajennense no continente americano, indicaram que $A$. cajennense é de fato um complexo de pelo menos seis espécies: 1) A. cajennense sensu stricto, 2) Amblyomma mixtum Koch, 1844, revalidado, anteriormente conhecido como sinonímia de A. cajennense, 3) Amblyomma sculptum Berlese, 1888, revalidado, anteriormente conhecido como sinonímia de A. cajennense, 4) Amblyomma interandinum n. sp., 5) Amblyomma patinoi n. sp. e 6) Amblyomma tonelliae n. sp. (NAVA et al., 2014²).

\footnotetext{
${ }^{2}$ NAVA, S.; BEATI, L.; LABRUNA, M. B.; CÁCERES, A. G.; MANGOLD, A. J.; GUGLIELMONE, A. A. Reassessment of the taxonomic status of Amblyomma cajennense (Fabricius, 1787) with the description of three new species, Amblyomma tonelliae n. sp., Amblyomma interandinum n. sp. and Amblyomma patinoi n. sp., and resurrection of Amblyomma mixtum Koch, 1844 and Amblyomma sculptum Berlese, 1888 (Ixodida: Ixodidae). Ticks and Tick-borne Diseases, No prelo, 2014
} 
Análises de três sequências de DNA mitocondrial e um gene nuclear concordaram em classificar mutuamente os exemplares em seis clados monofiléticos exclusivos. Suas diferenças são compatíveis com a ocorrência de seis espécies tão ou mais diferentes umas das outras do que outras espécies também identificadas (BEATI et al., 2013).

A espécie A. cajennense s. s., correspondente aos tipos descritos na Guiana Francesa, está distribuída na zona Norte ocidental da bacia amazônica. A. interandinum é estabelecida na região inter-andina do Peru. A. mixtum é encontrada do Sul dos Estados Unidos ao NorteOeste da Colômbia, Equador e Venezuela. A distribuição de A. sculptum compreende os estados brasileiros do Sudeste (Espírito Santo, Minas Gerais, Rio de Janeiro e São Paulo), Centro-Oeste (Goiás, Mato Grosso e Mato Grosso do Sul), Nordeste (Pernambuco e Piauí) e o Sul do estado do Paraná, e áreas úmidas do Noroeste da Argentina (principalmente a região biogeográfica de Yungas). A. tonelliae é estabelecida na região do Chaco da Argentina e Paraguai. A. patinoi está presente no Oeste da Venezuela e Cordilheira Central na Colômbia (NAVA et al., 2014 ${ }^{3}$ ). A partir desses trabalhos recentes, as seis espécies citadas acima formam o complexo A. cajennense ou A. cajennense sensu lato, denominação que será usada daqui adiante, sempre que forem abordados aspectos gerais deste complexo, sem que uma determianda espécie seja especificada.

\footnotetext{
${ }^{3}$ NAVA, S.; BEATI, L.; LABRUNA, M. B.; CÁCERES, A. G.; MANGOLD, A. J.; GUGLIELMONE, A. A. Reassessment of the taxonomic status of Amblyomma cajennense (Fabricius, 1787) with the description of three new species, Amblyomma tonelliae n. sp., Amblyomma interandinum n. sp. and Amblyomma patinoi n. sp., and resurrection of Amblyomma mixtum Koch, 1844 and Amblyomma sculptum Berlese, 1888 (Ixodida: Ixodidae). Ticks and Tick-borne Diseases, No prelo, 2014
} 


\subsection{CLIMAS E BIOMAS DO BRASIL}

O Brasil possui enorme extensão territorial e apresenta climas e solos muito variados. Em função dessas características, há uma evidente diversidade de biomas, definidos sobretudo pelo tipo de cobertura vegetal. O país é predominantemente tropical, mais de $90 \%$ de seu território fica acima do trópico de Capricórnio. Mas o clima tropical se subdivide em outros quatro tipos principais, com base em critérios variados, sobretudo a partir da quantidade de chuva e das temperaturas médias anuais. Os climas no território brasileiro são (Equatorial, Tropical, Semiárido e Subtropical) (MENDONÇA; DANNI-OLIVEIRA, 2007; CAVALCANTI et al., 2009).

O Brasil, em razão de sua grande extensão territorial, apresenta o seu território nacional ocupado por seis grandes biomas que caracterizam-se, no geral, por uma grande biodiversidade de animais e vegetais. Os biomas brasileiros são (Amazônia, Cerrado, Pantanal, Mata Atlântica, Caatinga e Pampa) (FONSECA et al., 1996; PAGLIA et al., 2012). 


\section{JUSTIFICATIVAS}

A sistemática de carrapatos é frequentemente revista por morfologia ou biologia molecular, mas raramente por ambos. Desta forma é lamentável, porque a combinação de diferentes habilidades pode proporcionar uma melhor compreensão das mais refinadas questões taxonômicas. A. cajennense s. 1. compreende um grupo de carrapatos dentre os mais estudados nas Américas, por causa da sua importância médico-veterinária e do seu impacto econômico. O carrapato transmite doenças aos seres humanos e animais domésticos, sendo reconhecido como praga em toda a sua área de distribuição (ESTRADA-PEÑA; GUGLIELMONE; MANGOLD, 2004).

Antes considerado uma única espécie, A. cajennense s. 1. pode ocorrer em ecossistemas muito diferentes e pode se alimentar preferencialmente em diferentes hospedeiros vertebrados, dependendo da geografia (GUGLIELMONE et al., 2014). A área de distribuição ocupada por A. cajennense s. l. é subdividida por grandes barreiras geográficas, o que já sugeria uma possível diferenciação genética alopátrica. Trabalho recente de evolução e estruturação genética conduzido por Beati et al. (2013), analisaram todos os ecótipos ocupados por A. cajennense s. 1., comparando três genes mitocondriais e um gene nuclear. $\mathrm{O}$ trabalho molecular identificou seis unidades genéticas distintas dentro de A. cajennense s. 1., caracterizadas por haplótipos mutuamente exclusivos, indicando uma possível especiação críptica. A quantidade da diferença genética nem sempre dependeu da distância geográfica. A similaridade genética pareceu estar associada com características ecológicas. A filogeografia e demografia histórica de A. cajennense s. 1. demonstrou seguir padrões já encontrados em outros animais e plantas diversas na região Neotropical, com áreas de distribuição semelhantes na transamazônica.

Após o táxon ser subdividido em diferentes padrões genéticos, espécimes correspondentes a cada grupo genético foram analisados morfologicamente por Nava et al. $\left(2014^{4}\right)$, aonde caracteres diagnósticos fixos, que eram antes negligenciados, foram

\footnotetext{
${ }^{4}$ NAVA, S.; BEATI, L.; LABRUNA, M. B.; CÁCERES, A. G.; MANGOLD, A. J.; GUGLIELMONE, A. A. Reassessment of the taxonomic status of Amblyomma cajennense (Fabricius, 1787) with the description of three new species, Amblyomma tonelliae n. sp., Amblyomma interandinum n. sp. and Amblyomma patinoi n. sp., and resurrection of Amblyomma mixtum Koch, 1844 and Amblyomma sculptum Berlese, 1888 (Ixodida: Ixodidae). Ticks and Tick-borne Diseases, No prelo, 2014
} 
encontrados para cada um deles. Especiação não-críptica foi confirmada, dentro do que hoje pode-se chamar de complexo A. cajennense ou A. cajennense s. $1 .$.

Diante dos fatores expostos acima, especialmente no tocante à importância médicoveterinária de A. cajennense s. 1. no Brasil, e de poucos estudos sobre este complexo no território nacional, o presente estudo foi planejado com o objetivo de promover uma análise integrada das características morfológicas e moleculares da biosistemática de A. cajennense s. 1. no país, de forma a conhecer melhor a ocorrência e distribuição geográfica das espécies de carrapatos do complexo A. cajennense no território brasileiro. 


\section{OBJETIVOS}

- Determinar o número de espécies do complexo A. cajennense que ocorrem no Brasil.

- Determinar a distribuição geográfica das espécies do complexo A. cajennense que ocorrem no território brasileiro. 


\section{MATERIAIS E MÉTODOS}

\subsection{OBTENÇÃO DE CARRAPATOS DO COMPLEXO Amblyomma cajennense}

Vários espécimes de carrapatos adultos (machos e fêmeas), identificados de acordo com as chaves taxonômicas de Robinson (1926); Aragão e Fonseca (1961); Guimarães, Tucci e Barros-Battesti (2001) e Onofrio et al. (2006) já se encontravam disponíveis para o presente estudo, uma vez que encontravam-se depositados e conservados em álcool nas coleções de carrapatos "Coleção Nacional de Carrapatos" (CNC) da Faculdade de Medicina Veterinária e Zootecnia (FMVZ) da Universidade de São Paulo (USP) e na "Coleção Acarológica do Instituto Butantan” do Instituto Butantan de São Paulo (IBSP). As coordenadas geográficas foram obtidas através do site do Instituto Brasileiro de Geografia e Estatística (IBGE) de acordo com as localidades citadas nas fichas dos lotes examinados. A atualização da nomenclatura dos mamíferos, aves e répteis seguiu aquelas propostas por Reis et al. (2011); Sick (1997) e o site da Sociedade Brasileira de Herpetologia (SBH) (SBH, 2005), respectivamente. Alguns carrapatos recebidos pelo Laboratório de Doenças Parasitárias (LDP) durante o presente estudo não foram depositados nas coleções devido às análises moleculares deste estudo.

Para complementar este estudo, foram realizadas três expedições para coleta de carrapatos a campo em áreas supostamente de transição para A. cajennense s. s. e A. sculptum, baseando-se nos trabalhos de Beati et al. (2013) e Nava et al. (2014 ${ }^{5}$ ). Esses autores relataram a ocorrência de A. cajennense s. s. apenas no bioma Amazônia, ao passo que A. sculptum é relatado no bioma Cerrado que circunda a região Amazônica pelo sul e leste (além de outras áreas mais distantes da Amazônia). Desta forma, as expedições foram realizadas nos seguintes itinerários: (i) uma no nordeste do país (Figuras 8 e 9) entre os municípios de Bequimão/MA e Estrela do Norte/GO, realizada em janeiro de 2012; (ii) uma no noroeste do país entre os municípios de Presidente Médici/RO e Vila Bela da Santíssima Trindade/MT, realizada em

\footnotetext{
${ }^{5}$ NAVA, S.; BEATI, L.; LABRUNA, M. B.; CÁCERES, A. G.; MANGOLD, A. J.; GUGLIELMONE, A. A. Reassessment of the taxonomic status of Amblyomma cajennense (Fabricius, 1787) with the description of three new species, Amblyomma tonelliae n. sp., Amblyomma interandinum n. sp. and Amblyomma patinoi n. sp., and resurrection of Amblyomma mixtum Koch, 1844 and Amblyomma sculptum Berlese, 1888 (Ixodida: Ixodidae). Ticks and Tick-borne Diseases, No prelo, 2014
} 
janeiro de 2012; (iii) e uma terceira no centro-norte do país entre os municípios de Sinop/MT e Cuiabá/MT, realizada em fevereiro de 2013. As expedições foram realizadas nestas dadas, pois considera-se que janeiro e fevereiro sejam os picos de atividade do estágio adulto de $A$. cajennense s. s. e A. sculptum (LABRUNA et al., 2002a; LABRUNA; TERRASSINI; CAMARGO, 2009). Nestas expedições, conduzidas em veículo automotivo (Figura 10) pelas rodovias locais, a cada $50 \mathrm{Km}$ aproximadamente os ixodídeos foram coletados. Os carrapatos foram coletados em fase parasitária fixados aos animais domésticos (equinos, suínos) (Figuras 1 e 2), silvestres atropelados (anta, tamanduá) (Figuras 4 e 5) e eventualmente em humanos (Figura 3), ou ativamente em fase de vida livre (no meio ambiente), através da técnica de arrasto com flanela branca (VIEIRA et al., 2004; ARZUA; BRESCOVIT, 2006) e visual (TERASSINI et al., 2010) (Figuras 6 e 7). Os adultos coletados no campo foram acondicionados em criotubos devidamente identificados com a data, hospedeiro (quando foi o caso), nome do município e a coordenada geográfica da coleta utilizando aparelho de GPS modelo (SAD69). Os carrapatos foram trazidos preservados em álcool isopropílico absoluto para o LDP da FMVZ-USP, onde foram processados por análises morfológicas e moleculares, conforme descrito abaixo. O mesmo procedimento de identificação foi adotado para os carrapatos adquiridos casualmente pelo LDP no andamento do presente estudo e os que já se encontravam depositados nas coleções de carrapatos CNC e IBSP. 
Figura 1 - Coleta de carrapatos em equinos (Equus caballus) durante a expedição no noroeste do país

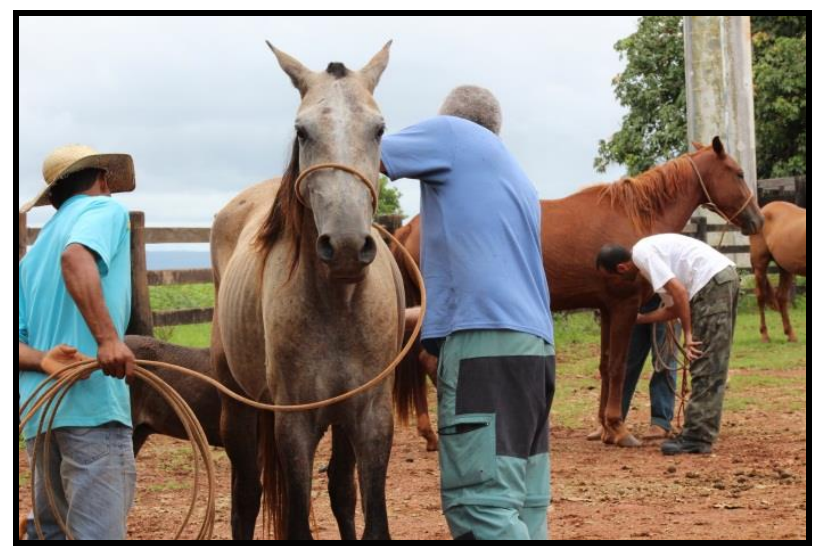

Fonte: (MARTINS, T. F., 2014)

Figura 2 - Coleta de carrapatos em suínos (Sus scrofa) durante a expedição no nordeste do país

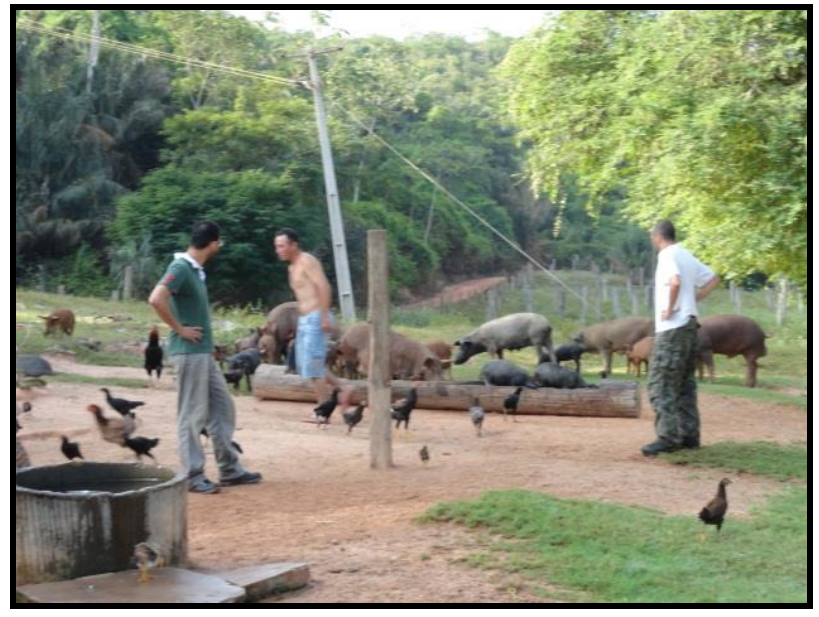

Fonte: (MARTINS, T. F., 2014)

Figura 3 - Macho de Amblyomma cajennense sensu lato coletado eventualmente em humano (Homo sapiens) durante a expedição no nordeste do país

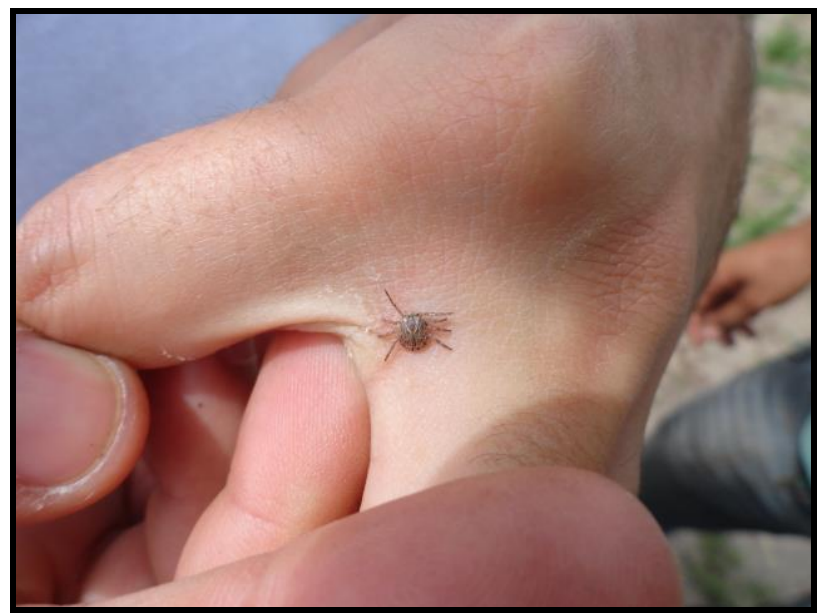

Fonte: (MARTINS, T. F., 2014) 
Figura 4 - Coleta de carrapatos em anta (Tapirus terrestris) atropelada durante a expedição no centro-norte do país

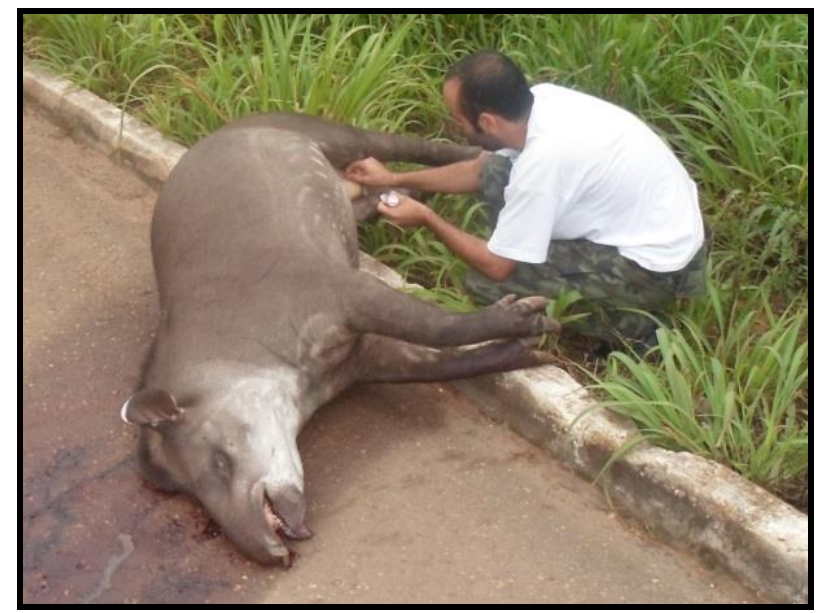

Fonte: (MARTINS, T. F., 2014)

Figura 5 - Coleta de carrapatos em tamanduá-bandeira (Myrmecophaga tridactyla) atropelado durante a expedição no nordeste do país

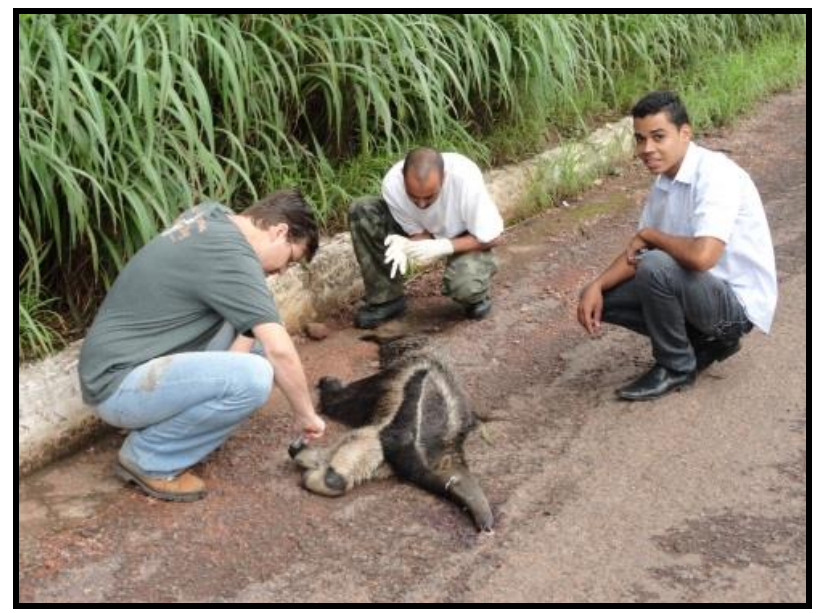

Fonte: (MARTINS, T. F., 2014)

Figura 6 - Técnica de arrasto com flanela branca utilizada dentro de um recinto de anta (Tapirus terrestris) durante a expedição no nordeste do país

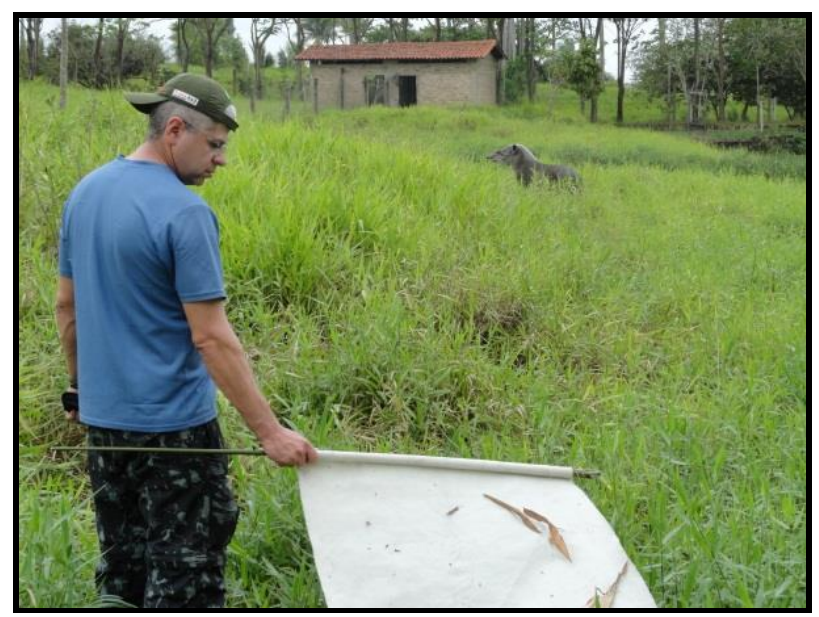

Fonte: (MARTINS, T. F., 2014) 
Figura 7 - Macho de Amblyomma cajennense sensu lato coletado em vida livre através da técnica visual durante a expedição no noroeste do país

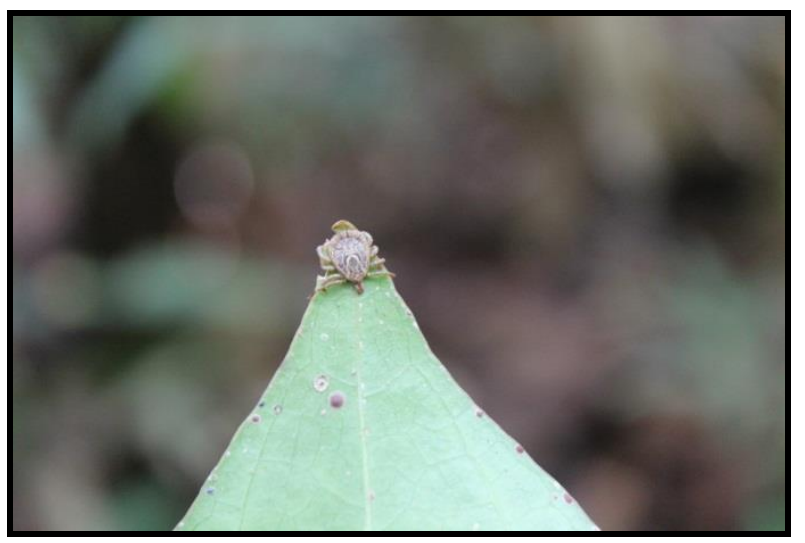

Fonte: (MARTINS, T. F., 2014)

Figura 8 - Tentativa de coleta de carrapatos em zebra (Equus grevyi) durante a expedição no nordeste do país

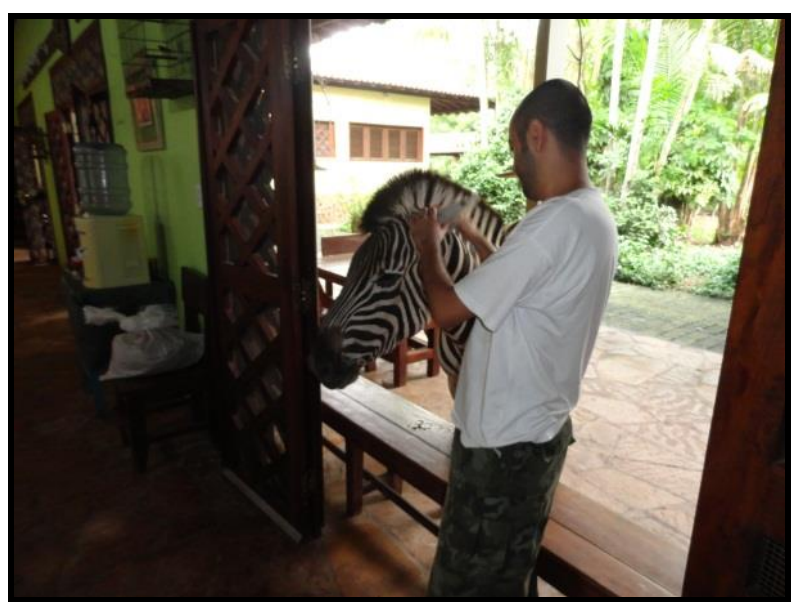

Fonte: (MARTINS, T. F., 2014)

Figura 9 - Animal e proprietários que apoiaram o projeto durante a expedição no nordeste do país

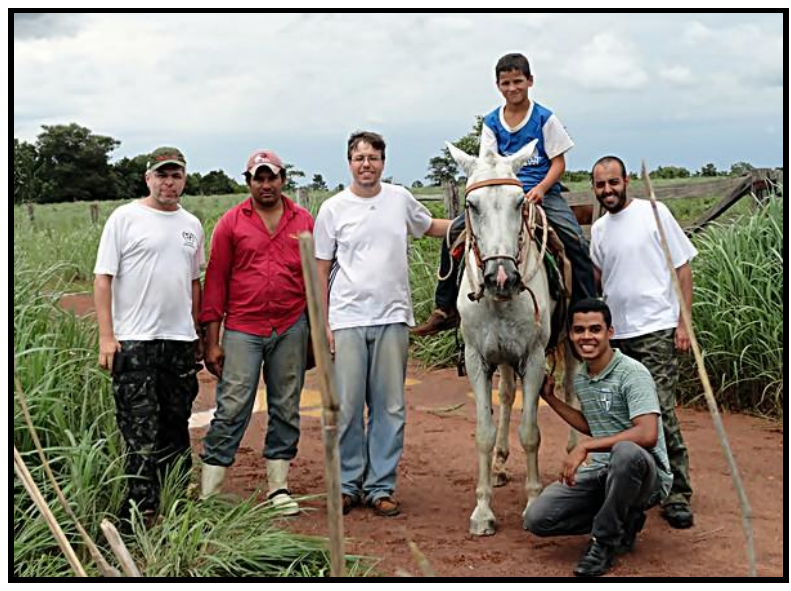

Fonte: (MARTINS, T. F., 2014) 
Figura 10 - Triagem de carrapatos do complexo Amblyomma cajennense no campo durante a expedição no nordeste do país

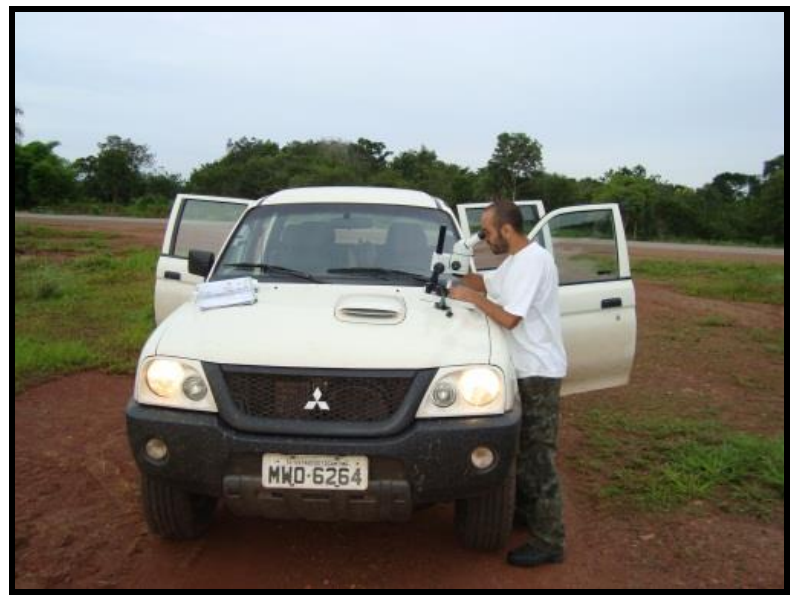

Fonte: (MARTINS, T. F., 2014)

Figura 11 - Abertura genital em forma de "V" com duas projeções largas nos bordos laterais da fêmea de Amblyomma cajennense sensu stricto

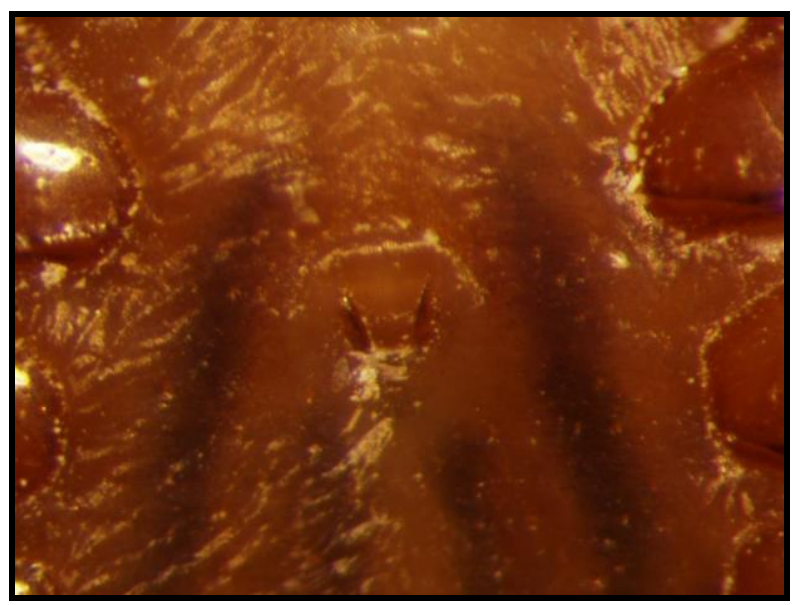

Fonte: (MARTINS, T. F., 2014)

Figura 12 - Abertura genital em forma de "U" com duas projeções estreitas nos bordos laterais da fêmea de Amblyomma sculptum

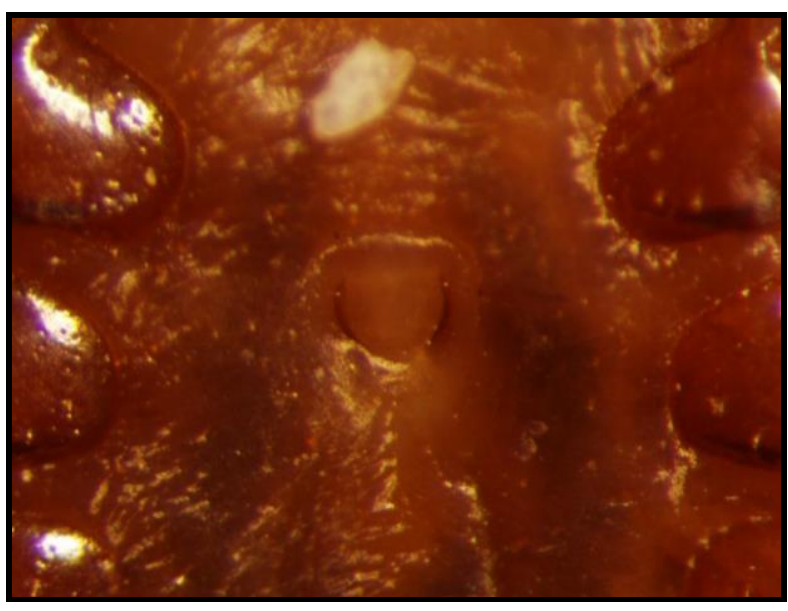

Fonte: (MARTINS, T. F., 2014) 


\subsection{PROCESSAMENTO DOS CARRAPATOS}

\subsubsection{Análises morfológicas}

Segundo Nava et al. $\left(2014^{6}\right)$, a distinção de A. cajennense s. s. e A. sculptum por morfologia externa só é possível com exatidão através do orifício genital das fêmeas, que se apresentam na forma de "V" com duas projeções largas nos bordos laterais em A. cajennense s. s. e em forma de "U" com duas projeções estreitas nos bordos laterais em A. sculptum (Figuras 11 e 12). Desta forma, somente os exemplares fêmeas, tanto das coleções examinadas, dos carrapatos adquiridos pelo LDP, assim como dos coletados a campo, é que foram utilizados para determinação da espécie por morfologia utilizando microscópio estereoscópico, com iluminação incidente. Nas localidades em que havia apenas exemplares machos, para os quais não puderam ser geradas sequências de DNA, a identificação taxonômica foi considerada como A. cajennense s. 1. .

\subsubsection{Análises moleculares}

De cada localidade, pelo menos um exemplar foi processado individualmente, embora foram processados no máximo quatro exemplares por localidade (Quadro 1 e Figuras 15 e 16). Nos locais das três expedições de coleta, quando só foram encontrados machos, todos foram processados para a identificação da espécie. Foram ainda priorizados os machos adquiridos pelo LDP para o processamento, pois com a permanência íntegra das fêmeas, essas foram depositadas nas coleções como referência para cada local de coleta. A extração de DNA foi realizada de acordo com a técnica de Isotiocianato de Guanidina (GT) descrita por Chomkzynski (1993) e posteriormente modificada por Sangioni et al. (2005). Uma vez

\footnotetext{
${ }^{6}$ NAVA, S.; BEATI, L.; LABRUNA, M. B.; CÁCERES, A. G.; MANGOLD, A. J.; GUGLIELMONE, A. A. Reassessment of the taxonomic status of Amblyomma cajennense (Fabricius, 1787) with the description of three new species, Amblyomma tonelliae n. sp., Amblyomma interandinum n. sp. and Amblyomma patinoi n. sp., and resurrection of Amblyomma mixtum Koch, 1844 and Amblyomma sculptum Berlese, 1888 (Ixodida: Ixodidae). Ticks and Tick-borne Diseases, No prelo, 2014
} 
extraído o DNA, cada carrapato foi submetido a um protocolo de reação em cadeia pela polimerase (PCR), buscando amplificar um fragmento de aproximadamente 1200-pb do segundo espaço transcrito interno (ITS2) do DNA ribossômico nuclear, presente em todas as espécies de carrapatos.

Para a PCR, foi utilizado um par de oligonucleotídeos iniciadores ("primers") 5'CCATCGATGTGAAYTGCAGGACA-3' (ZAHLER; GOTHE; RINDER, 1995) e 5'GTGAATTCTATGCTTAAATTCAGGGGGT-3' (McLAIN et al., 1995), os quais correspondem a seqüências da região $5.8 \mathrm{~S}$ e $28 \mathrm{~S}$, respectivamente, portanto, amplificam um fragmento de DNA contendo a seqüência completa do ITS2 do rDNA. O fragmento completo do ITS2 de carrapatos do gênero Amblyomma está em torno de 1100 nucleotídeos, com algumas pequenas variações intra e interespecíficas (MARRELLI et al., 2007). A reação de amplificação para o ITS2 foi realizada em microtubos de $200 \mu 1$ adicionando $2,5 \mu 1$ de DNA extraído acrescido de 22,5 $\mu \mathrm{l}$ de Mix Dream Taq Green PCR Master Mix (2x) (Thermo Scientific $\left.{ }^{\circledR}\right)$, sendo utilizado $12,5 \mu 1$ de Dream Taq, $1 \mu 1$ de primer senso, $1 \mu 1$ de primer antisenso e $8 \mu \mathrm{l}$ de $\mathrm{H}_{2} \mathrm{O}$. O protocolo térmico utilizado e realizado em termociclador Mastercycler Gadient (Eppendorf®) foi o seguinte: $95^{\circ} \mathrm{C}$ por 5 minutos, seguidos de 36 ciclos de $95^{\circ} \mathrm{C}$ por 45 segundos, $55^{\circ} \mathrm{C}$ por 1 minuto e $72^{\circ} \mathrm{C}$ por 1 minuto e 30 segundos seguido de $72^{\circ} \mathrm{C}$ por 10 minutos finalizando com a temperatura de $4^{\circ} \mathrm{C}$.

Todos os produtos da PCR foram submetidos à eletroforese horizontal em gel de agarose 1\% com tampão de corrida TBE $1 \mathrm{X}$ pH 8,0 (44,58 M Tris-base; 0,44 M ácido bórico; $12,49 \mathrm{mM}$ EDTA) à 110v/50mA. O gel era posteriormente corado com brometo de etídio $\left(0,5 \mu \mathrm{l} / \mathrm{ml}\right.$ - Invitrogen $\left.{ }^{\circledR}\right)$ e visualizado sob luz ultravioleta (UV) em câmara escura (Alphalmager®) (SAMBROOK; FRITSCH; MANIATIS, 1989) As amostras que revelavam bandas de DNA na altura do controle positivo (exemplar de A. sculptum peviamente confirmado por sequenciamento de DNA), eram consideradas positivas para a reação da PCR utilizada.

Os produtos da PCR foram purificados utilizando-se o produto comercial ExoSAP-IT (USB Corporation), que consiste em Exonuclease I (Exo I) para digerir excesso de primers e Shrimp Alkaline Phosphatase (SAP) para degradar excesso de nucleotídeos provenientes da PCR. Para tal, em microtubo identificado colocou-se $4 \mu$ l de ExoSAP e adicionou-se $10 \mu 1$ da amostra amplificada na PCR, em seguida as amostras foram colocadas no termociclador nas temperaturas de $37^{\circ} \mathrm{C}$ por 15 minutos e $80^{\circ} \mathrm{C}$ por mais 15 minutos.

Após a purificação os nucleotídeos estavam prontos para serem utilizados na reação de seqüenciamento com o kit comercial BigDye TM Terminator (Perkin Elmer) de acordo com 
especificações do fabricante: $5 \mu \mathrm{l}$ de DNA purificado - concentração máxima de 100 ng, $1 \mu \mathrm{l}$ de água MilliQ, $1 \mu 1$ de "Big Dye", $1 \mu 1$ de oligonucleotídeos iniciadores específicos senso e anti-senso ( 5 pmoles/ $\mu \mathrm{l})$, e $2 \mu \mathrm{l}$ de buffer. As amostras foram sequenciadas em sequenciador automático modelo ABI 377 (Applyed Biosystem, Foster, CA), disponível no Departamento de Medicina Veterinária Preventiva e Saúde Animal (VPS) da FMVZ-USP de acordo com as instruções do fabricante. 
Quadro 1 - Origem dos carrapatos do complexo Amblyomma cajennense que foram utilizados para as análises moleculares e filogenéticas no presente estudo

\begin{tabular}{|c|c|c|c|c|c|c|c|}
\hline \multirow{3}{*}{ Espécies } & \multicolumn{7}{|c|}{$\begin{array}{c}\text { Localidades adquiridas casualmente pelo Laboratório de Doenças Parasitárias e alguns locais das três expedições de coleta } \\
\text { no andamento do presente estudo }\end{array}$} \\
\hline & \multicolumn{2}{|c|}{ Origens } & \multicolumn{3}{|c|}{ Localidades } & \multicolumn{2}{|c|}{ Adultos utilizados } \\
\hline & Sexos & Hospedeiros & Regiões & Estados & Municípios & $\begin{array}{l}\text { Datas das } \\
\text { coletas }\end{array}$ & $\mathbf{n}$ \\
\hline Amblyomma cajennense sensu stricto & Macho & Equus caballus & Norte & PA & Cachoeira do Piriá & $01 / 2012$ & 1 \\
\hline A. cajennense s. s. & Machos & E. caballus & Norte & PA & São Domingos do Capim & $10 / 2011$ & 3 \\
\hline A. cajennense s. s. & Fêmeas & E. caballus & Norte & PA & São Geraldo do Araguaia & $01 / 2012$ & 4 \\
\hline Amblyomma sculptum & Fêmeas & E. caballus & Norte & RO & Pimenta Bueno & $01 / 2012$ & 4 \\
\hline A. cajennense s. s. & Machos & Syncerus caffer & Norte & RO & São Francisco do Guaporé & 09/2011 & 4 \\
\hline A. cajennense s. s. & Fêmeas & Vida livre & Norte & RO & Vilhena & $03 / 2002$ & 3 \\
\hline A. cajennense s. s. & Fêmeas* & Canis familiares & Norte & TO & Cristalândia & 08/2011 & 2 \\
\hline A. sculptum & Machos & Vida livre & Norte & TO & Tocantinópolis & $06 / 2011$ & 4 \\
\hline A. sculptum & Machos & E. caballus & Nordeste & BA & Campo Formoso & $08 / 2012$ & 4 \\
\hline A. sculptum & Machos & E. caballus & Nordeste & MA & Balsas & $07 / 2011$ & 3 \\
\hline A. cajennense s. s. & Machos & E. caballus & Nordeste & MA & Bequimão & $01 / 2012$ & 4 \\
\hline A. cajennense s. s. & Machos & E. caballus & Nordeste & MA & Chapadinha & $01 / 2012$ & 4 \\
\hline A. sculptum & Machos & E. caballus & Nordeste & MA & Imperatriz & $01 / 2012$ & 2 \\
\hline A. cajennense s. s. & Machos & E. caballus & Nordeste & MA & Pinheiro & $01 / 2012$ & 3 \\
\hline A. cajennense s. s. & Machos & E. caballus & Nordeste & MA & Santa Inês & $01 / 2012$ & 4 \\
\hline A. sculptum & Machos & Equus asinus & Nordeste & PI & José de Freitas & $01 / 2011$ & 4 \\
\hline A. sculptum & Machos & E. caballus & Centro-Oeste & GO & Cumari & $06 / 2011$ & 4 \\
\hline A. sculptum & Machos & E. caballus & Centro-Oeste & $\mathrm{GO}$ & Porangatu & $01 / 2012$ & 2 \\
\hline A. cajennense s. s. & Macho & Vida livre & Centro-Oeste & MT & Comodoro & $01 / 2012$ & 1 \\
\hline A. cajennense s. s. & Machos & E. caballus & Centro-Oeste & MT & Confresa & $04 / 2011$ & 2 \\
\hline A. sculptum & Machos & E. caballus & Centro-Oeste & MT & Poconé & $07 / 2011$ & 4 \\
\hline A. cajennense s. s. & Macho & E. caballus & Centro-Oeste & MT & Pontes e Lacerda & $01 / 2012$ & 1 \\
\hline A. cajennense s. s. & Machos & E. caballus & Centro-Oeste & MT & Sinop & $02 / 2013$ & 2 \\
\hline A. sculptum & Machos & Sus scrofa & Centro-Oeste & MS & Corumbá & $08 / 2010$ & 4 \\
\hline A. sculptum & Machos & E. caballus & Sudeste & $\mathrm{ES}$ & Pinheiros & $07 / 2011$ & 4 \\
\hline A. sculptum & Machos & E. caballus & Sudeste & MG & Itabira & $01 / 2011$ & 4 \\
\hline A. sculptum & Machos & E. caballus & Sudeste & RJ & Seropédica & 05/2011 & 4 \\
\hline A. sculptum & Machos & Vida livre & Sudeste & SP & Americana & $10 / 2011$ & 4 \\
\hline A. sculptum & Fêmeas & E. caballus & Sudeste & SP & Pirassununga & $12 / 2008$ & 3 \\
\hline A. sculptum & Machos & E. caballus & Sul & PR & Alvorada do Sul & $05 / 2012$ & 4 \\
\hline
\end{tabular}

* Todos os carrapatos foram coletados como ninfas no hospedeiro

n: Número de espécimes utilizados para as análises moleculares e filogenéticas no presente estudo 


\subsection{ANÁLISES FILOGENÉTICAS}

As seqüências obtidas foram alinhadas entre si utilizando-se o programa Clustal X (THOMPSON et al., 1997) alterando os parâmetros relativos à inserção de "indels" (peso de inserção=1, extensão=1) e manualmente ajustados no programa GeneDoc versão 2.6.01 (NICHOLAS et al., 1997). Em adição, a sequiência correspondente de Amblyomma americanum (AF291874) foi incluída como grupo externo (outgroup).

As árvores filogenéticas (Figuras 13 e 14) foram inferidas pelos métodos de máxima parcimônia (MP) e análise bayeseana (B). As árvores de MP foram construídas utilizando o programa PAUP * versão 4.0b10 (SWOFFORD, 1998) via busca heurística com 100 réplicas de adição aleatória dos terminais seguida de troca de ramos ("RAS-TBR Branch-breaking"). As análises de suporte por "bootstrap" foram feitas em 100 replicatas com os mesmos parâmetros empregados na busca. A matriz de divergência (Apêndice A) foi construída utilizando o programa Point Replacer v. 2.0.

As análises bayeseanas foram executadas no programa MrBayes versão 3.1.2 (RONQUIST; HUELSENBECK 2003). Foram empregadas 1000.000 gerações usando GTR como modelo de substituição e quatro categorias de gama mais proporção de sítios invariantes. Para a construção do dendrograma final foram utilizados apenas os diagramas obtidos nas últimas 75 réplicas. Para a verificação de suporte de ramos nas análises bayeseanas foram utilizados os valores de probabilidade a posteriori obtidos com o programa MrBayes.

\subsection{OBSERVAÇÃO DA DISTRIBUIÇÃO GEOGRÁFICA DO COMPLEXO Amblyomma cajennense NO BRASIL}

As localidades dos carrapatos A. cajennense s. 1. examinados nas coleções (CNC e IBSP), adquiridos pelo LDP e coletados a campo, após identificados no presente estudo por métodos morfológicos e/ou moleculares, foram utilizadas para construção de mapas de distribuição geográfica de A. cajennense s. s. e A. sculptum no Brasil, segundo as regiões geopolíticas (estados da federação), biomas, vegetação remanescente e climas (Figuras 17, 18, 
19 e 20). Os mapas foram obtidos através do site do IBGE (IBGE, 2013) e do Ministério do Meio Ambiente (MMA) (BRASIL, 2013) disponíveis na internet e construídos com o auxílio do programa ArcGIS versão 10,0 (ESRI), utilizando as coordenadas geográficas dos carrapatos identificados. 


\section{RESULTADOS}

A seguir estão os resultados morfológicos do material examinado, com os dados das regiões geopolíticas (grifado), estados da federação (em negrito), municípios com coordenadas geográficas, hospedeiros, quantidade, sexos, espécies de carrapatos encontradas, datas das coletas e número de tombo das coleções.

\subsection{LOCALIDADES DO MATERIAL DEPOSITADO NA COLEÇÃO CNC}

Norte - Pará: Altamira $\left(3^{\circ} 12^{\prime} \mathrm{S} 52^{\circ} 12^{\prime} \mathrm{W}\right)$ Hospedeiro Vida livre $10^{\lambda} 3 ㅇ ㅜ$ A.

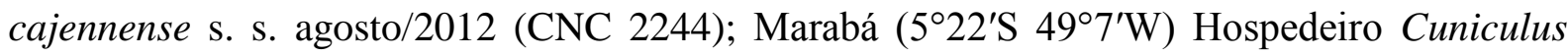
paca $1 \overbrace{}^{\lambda} 1$ 우 A. cajennense s. s. junho/2001 (CNC 499), Hospedeiro Hydrochoerus hydrochaeris $1 \hat{\jmath}$ A. cajennense s. 1. julho/2001 (CNC 503), Hospedeiro Tapirus terrestris

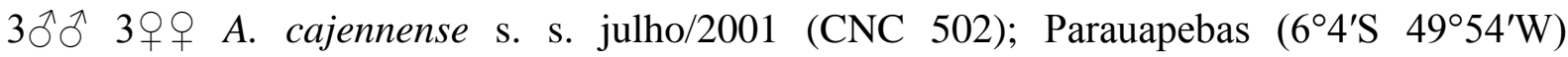
Hospedeiro T. terrestris $1 \delta^{\Uparrow} 5 q$ ㅇ A. cajennense s. s. novembro/2003 (CNC 827); Porto de

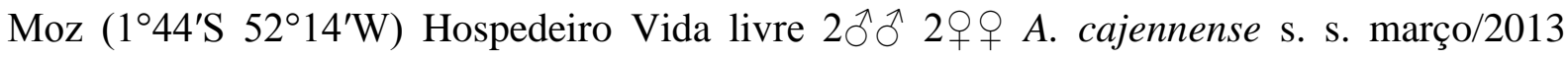
(CNC 2416). Rondônia: Campo Novo de Rondônia (10³5'S 6336'W) Hospedeiro Vida livre $5 \widehat{\jmath} 10$ 우 A. cajennense s. s. abril/2001 (CNC 446); Governador Jorge Teixeira

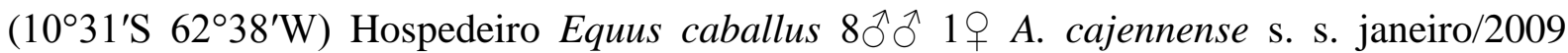
(CNC 1410), Hospedeiro Vida livre $14 \widehat{\jmath} \widehat{\jmath} 21 q$ A. cajennense s. s. dezembro/2008 (CNC 1808), Hospedeiro Pecari tajacu 1 + A. cajennense s. s. novembro/2000 (CNC 415), Hospedeiro T. terrestris $1 \bigcirc^{\lambda}$ A. cajennense s. 1. dezembro/2000 (CNC 413), Hospedeiro Vida

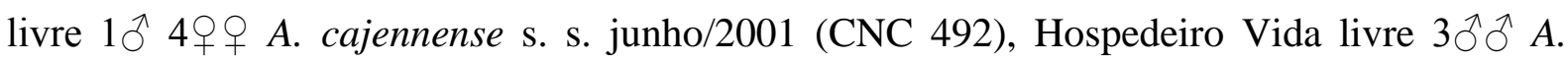

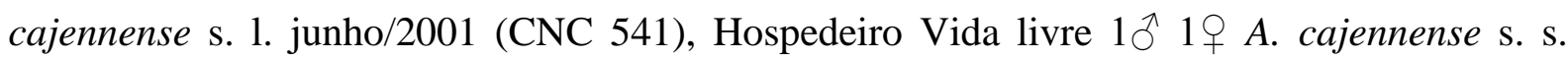

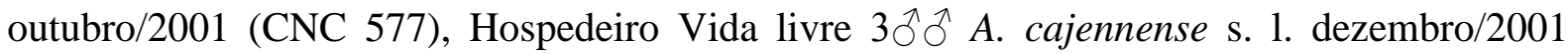
(CNC 579), Hospedeiro Vida livre $14 \hat{\jmath} \widehat{\widehat{o}} 6$ 우 (coletados como ninfas) A. cajennense s. s. outubro/2002 (CNC 599), Hospedeiro Vida livre 24ðð 26우 A. cajennense s. s. dezembro/2001 (CNC 627), Hospedeiro Vida livre 6ðð 4 우 A. cajennense s. s. abril/2002

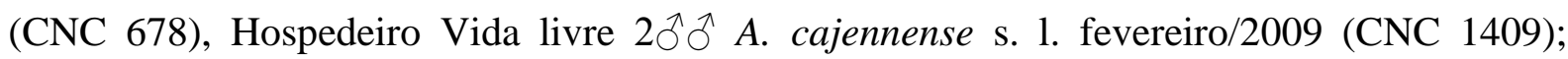
Vilhena $\left(12^{\circ} 44^{\prime} \mathrm{S} 60^{\circ} 8^{\prime} \mathrm{E}\right)$ Hospedeiro Vida livre $3 ㅇ ㅜ$ A. cajennense s. s. março/2002 (CNC 626). Tocantins: Aragominas $\left(7^{\circ} 9^{\prime} \mathrm{S} 48^{\circ} 31^{\prime} \mathrm{W}\right)$ Hospedeiro Tamandua tetradactyla 19 A. cajennense s. s. 1 q A. sculptum abril/2013 (CNC 2571); Araguaína ( $\left.7^{\circ} 11^{\prime} \mathrm{S} 48^{\circ} 12^{\prime} \mathrm{W}\right)$ 


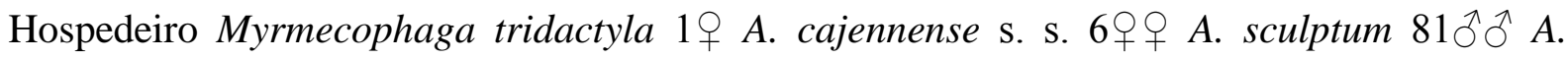
cajennense s. 1. abril/2013 (CNC 2574), Hospedeiro T. tetradactyla $1 \delta^{\Uparrow} 1 q$ A. sculptum abril/2013 (CNC 2507), Hospedeiro Vida livre 1ठิ A. cajennense s. 1. maio/2013 (CNC 2575);

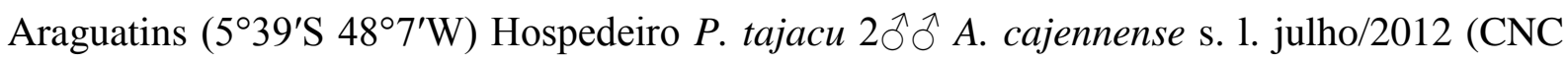
2263); Caseara ( $\left.9^{\circ} 16^{\prime} \mathrm{S} 49^{\circ} 57^{\prime} \mathrm{W}\right)$ Hospedeiro Bos taurus 5 우 A. cajennense s. s. maio/2009 (CNC 1707), Hospedeiro Canis familiaris 1ð̊ A. cajennense s. 1. maio/2009 (CNC 1710); Goiatins $\left(7^{\circ} 42^{\prime} \mathrm{S} 47^{\circ} 18^{\prime} \mathrm{W}\right)$ Hospedeiro B. taurus 1 q cajennense s. s. setembro/2007 (CNC 1062), Hospedeiro E. caballus $6 \overbrace{}^{\widehat{\partial}}$ A. cajennense s. 1. setembro/2007 (CNC 1059); Gurupi $\left(11^{\circ} 43^{\prime} \mathrm{S} 49^{\circ} 4^{\prime} \mathrm{W}\right)$ Hospedeiro M. tridactyla 4우 우 A. cajennense s. s. novembro/2012 (CNC 2328); Lagoa da Confusão $\left(10^{\circ} 47^{\prime} \mathrm{S} 49^{\circ} 37^{\prime} \mathrm{W}\right)$ Hospedeiro B. taurus $3 \partial^{\Uparrow}$ A. cajennense s. 1.

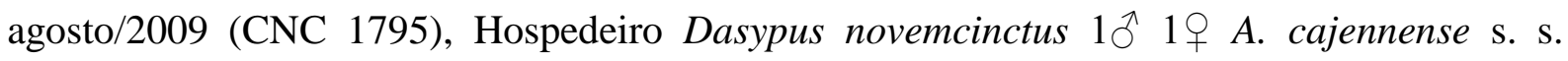
abril/2013 (CNC 2570), Hospedeiro M. tridactyla 199 우 A. cajennense s. s. $3 q 0+$ A. sculptum $36 \overbrace{}^{\Uparrow}$ A. cajennense s. 1. maio/2013 (CNC 2573); Palmas $\left(10^{\circ} 11^{\prime} \mathrm{S} 48^{\circ} 20^{\prime} \mathrm{W}\right)$ Hospedeiro $H$.

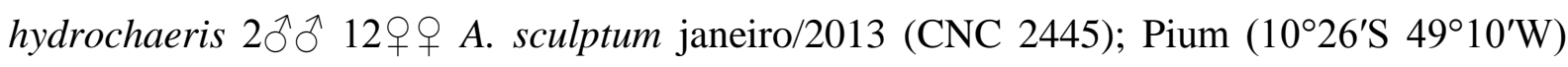
Hospedeiro B. taurus $2 \widehat{\jmath} 2$ ภำ A. cajennense s. s. agosto/2009 (CNC 1797), Hospedeiro C.

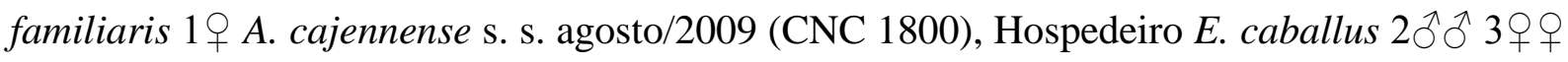
A. cajennense s. S. agosto/2009 (CNC 1794); Presidente Kennedy ( $\left.8^{\circ} 32^{\prime} \mathrm{S} 48^{\circ} 30^{\prime} \mathrm{W}\right)$ Hospedeiro T. tetradactyla 1ठ A. cajennense s. 1. dezembro/2012 (CNC 2330), Hospedeiro Vida livre $4 \widehat{\jmath} 1 q$ A. cajennense s. s. novembro/2012 (CNC 2340). Nordeste - Maranhão: Chapadinha $\left(3^{\circ} 44^{\prime} \mathrm{S} 43^{\circ} 21^{\prime} \mathrm{W}\right)$ Hospedeiro C. familiaris $1{ }^{\Uparrow} 2$ 우 A. sculptum fevereiro/2010

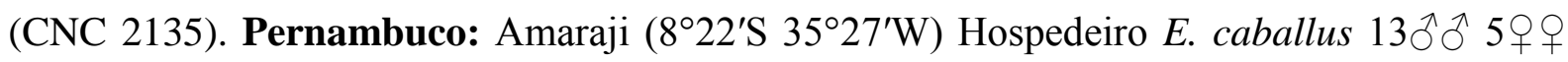
A. sculptum novembro/2007 (CNC 1314); Gravatá $\left(8^{\circ} 12^{\prime} \mathrm{S} 35^{\circ} 33^{\prime} \mathrm{W}\right)$ Hospedeiro E. caballus $1 \circlearrowleft$ A. cajennense s. 1. janeiro/2008 (CNC 1324), Hospedeiro E. caballus $1 \circlearrowleft$ A. cajennense s. 1. dezembro/2007 (CNC 1327); Sairé ( $\left.8^{\circ} 19^{\prime} \mathrm{S} 35^{\circ} 42^{\prime} \mathrm{W}\right)$ Hospedeiro E. caballus $1 \widehat{O}^{\widehat{O}} A$. cajennense s. 1. janeiro/2008 (CNC 1322). Piauí: Gilbués (949’S 45²0’W) Hospedeiro Homo sapiens $1 \hat{\jmath} 1$ ํ A. sculptum janeiro/2005 (CNC 889), Hospedeiro H. sapiens $1 \hat{\jmath} 3$ 우 A. sculptum novembro/2009 (CNC 1496). Centro-Oeste - Distrito Federal: Brasília (1547'S

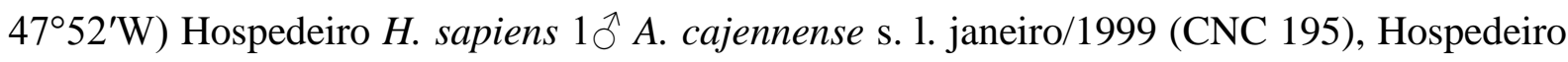
Panthera onca $2 \widehat{ึ}$ A. cajennense s. 1. janeiro/1999 (CNC 192). Goiás: Cumari (18¹5'S $\left.48^{\circ} 9^{\prime} \mathrm{W}\right)$ Hospedeiro C. familiaris 29 ㅇ A. sculptum abril/2013 (CNC 2438), Hospedeiro E.

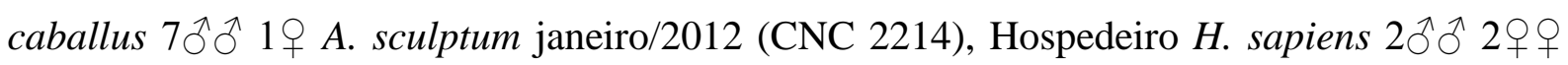
A. sculptum fevereiro/2012 (CNC 2213); Mineiros (17 $34^{\prime} \mathrm{S} 52^{\circ} 33^{\prime} \mathrm{W}$ ) Hospedeiro Chrysocyon brachyurus 19 A. sculptum outubro/1999 (CNC 312), Hospedeiro C. brachyurus $1 \hat{\jmath}$ A. cajennense s. 1. maio/2005 (CNC 1684), Hospedeiro C. brachyurus 19 A. sculptum 
(CNC 1696), Hospedeiro M. tridactyla 290 A. sculptum novembro/1999 (CNC 259), Hospedeiro P. onca 2 우 A. sculptum abril/2000 (CNC 313), Hospedeiro P. onca 4へぇ 5 우 A. sculptum julho/2002 (CNC 767), Hospedeiro P. onca $1 \overbrace{}^{\jmath}$ A. cajennense s. 1. agosto/2004 (CNC 1658), Hospedeiro P. onca $1 \delta^{\lambda} 7$ 우 A. sculptum janeiro/2007 (CNC 1691), Hospedeiro

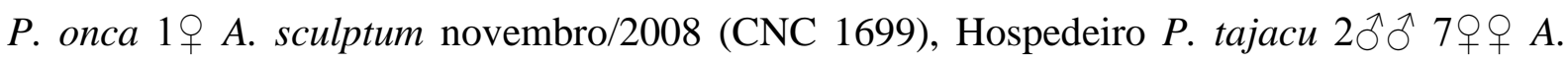

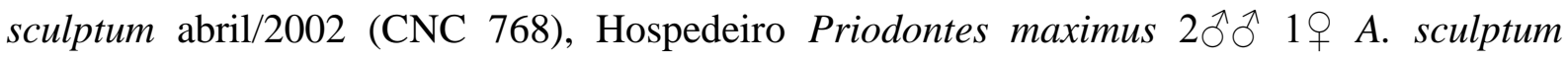
janeiro/2005 (CNC 1681), Hospedeiro Speothos venaticus $1 \sigma^{\widehat{A}}$. cajennense $\mathrm{s} .1$. novembro/2002 (CNC 819), Hospedeiro T. terrestris 6 우 A. sculptum abril/2000 (CNC 315), Hospedeiro T. terrestris 45ठ̂̉ 28 우 A. sculptum junho/2002 (CNC 776), Hospedeiro Tayassu pecari 46Љð 40 우 A. sculptum junho/2001 (CNC 769), Hospedeiro T. pecari

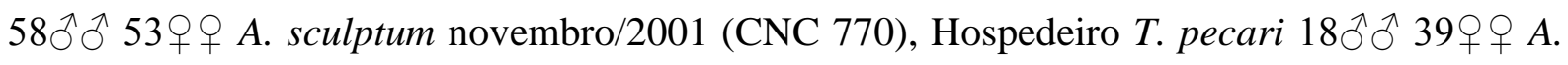
sculptum janeiro/2002 (CNC 772), Hospedeiro T. pecari 17ふోఓ 8 우 A. sculptum março/2003 (CNC 821), Hospedeiro T. pecari 19 A. sculptum julho/2004 (CNC 1655), Hospedeiro Vida livre $3 \hat{\jmath}$ đ 3 우 A. sculptum novembro/2000 (CNC 298). Mato Grosso: Alta Floresta (952'S

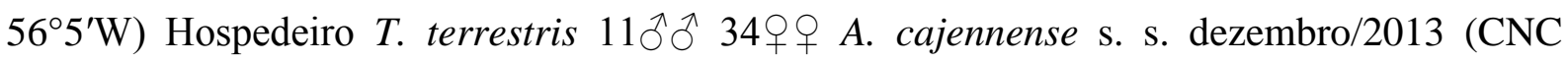

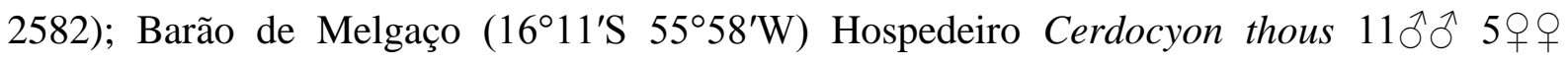

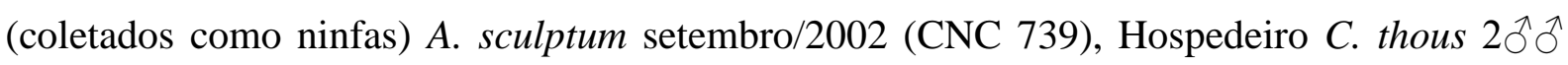

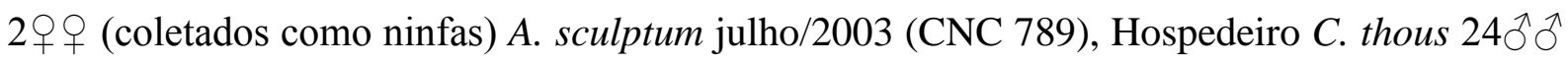
20 우 (coletados como larvas e ninfas) A. sculptum agosto/2003 (CNC 791), Hospedeiro C. thous $3 ㅇ$ (coletados como ninfas) A. sculptum outubro/2002 (CNC 793), Hospedeiro C.

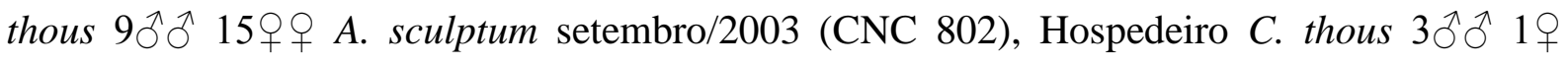
(coletados como ninfas) A. sculptum janeiro/2004 (CNC 828), Hospedeiro C. thous 4へえ 2 우 (coletados como larvas) A. sculptum março/2004 (CNC 841), Hospedeiro C. thous $14 \hat{\jmath}$ ○े 27우 (coletados como larvas e ninfas) A. sculptum julho/2004 (CNC 868), Hospedeiro C. thous 25 $ぇ 49 q \bigcirc$ (coletados como ninfas) A. sculptum setembro/2004 (CNC 870), Hospedeiro C. brachyurus $26 \hat{\jmath} \widehat{0} 49 q+$ (coletados como ninfas) A. sculptum agosto/2002 (CNC 731), Hospedeiro C. brachyurus 4ðð 9 우 (coletados como ninfas) $A$.

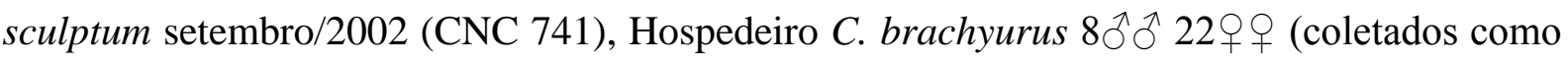
ninfas) A. sculptum outubro/2002 (CNC 794), Hospedeiro C. brachyurus 15ふึત 26우 (coletados como ninfas) A. sculptum dezembro/2003 (CNC 804), Hospedeiro C. brachyurus $7 \widehat{\jmath}$ ○ิ 12우 (coletados como ninfas) A. sculptum agosto/2006 (CNC 993), Hospedeiro Leopardus pardalis $2 \widehat{\jmath}$ (coletados como ninfas) A. cajennense s. 1. setembro/2001 (CNC 801), Hospedeiro L. pardalis $44 \hat{\jmath} \widehat{\jmath} 76$ 우 (coletados como larvas) A. sculptum julho/2004 (CNC 869), Hospedeiro Procyon cancrivorus $3 \hat{\jmath} \widehat{o} 10$ 우 (coletados como ninfas) A. 
sculptum julho/2002 (CNC 716), Hospedeiro P. cancrivorus $26 \lesssim \hat{\jmath} 11$ 우 (coletados como

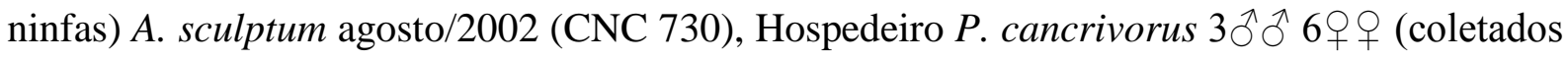
como ninfas) A. sculptum setembro/2002 (CNC 740), Hospedeiro P. cancrivorus $2 \widehat{\jmath} 4$ 우 (coletados como ninfas) A. sculptum outubro/2003 (CNC 803), Hospedeiro Puma concolor

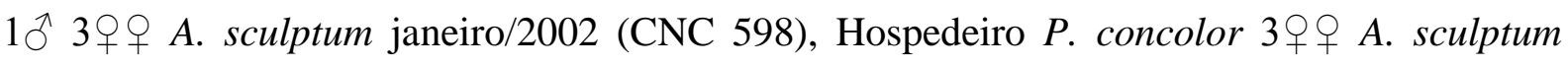
janeiro/2003 (CNC 760), Hospedeiro S. venaticus $1 ð 19$ (coletados como ninfas) A. sculptum julho/2004 (CNC 853), Hospedeiro S. venaticus $2 q q$ (coletados como ninfas) A. sculptum agosto/2006 (CNC 994); Chapada dos Guimarães $\left(15^{\circ} 27^{\prime} \mathrm{S} 55^{\circ} 45^{\prime} \mathrm{W}\right)$ Hospedeiro C. thous

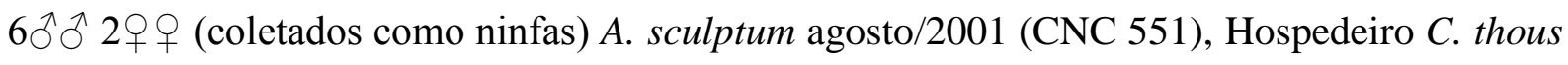
4 ㅊํ 2 우우 (coletados como ninfas) A. sculptum junho/2001 (CNC 552), Hospedeiro C. thous $8 \widehat{\jmath} \widehat{o} 9$ 우 (coletados como ninfas) A. sculptum junho/2001 (CNC 553), Hospedeiro C. thous $4 \widehat{\jmath} 7$ 우우 (coletados como ninfas) A. sculptum agosto/2001 (CNC 674), Hospedeiro T.

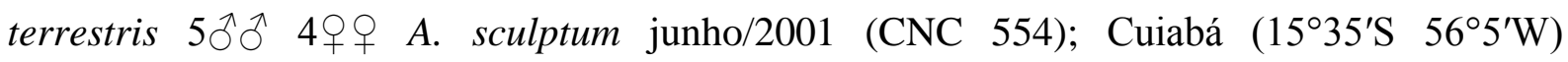
Hospedeiro Mazama gouazoubira 5 우 A. sculptum julho/2012 (CNC 2275); Jauru $\left(15^{\circ} 20^{\prime} \mathrm{S}\right.$ $\left.58^{\circ} 51^{\prime} \mathrm{W}\right)$ Hospedeiro H. sapiens $1 \overbrace{}^{\Uparrow} 1$ ㅇ A. sculptum março/2001 (CNC 433), Hospedeiro $H$. sapiens $1 \widehat{\jmath}$ (coletado como ninfa) A. cajennense s. 1. setembro/2002 (CNC 733), Hospedeiro T. terrestris $1 \widehat{\jmath} 1 q$ A. cajennense s. s. janeiro/2011 (CNC 2364); Lucas do Rio Verde

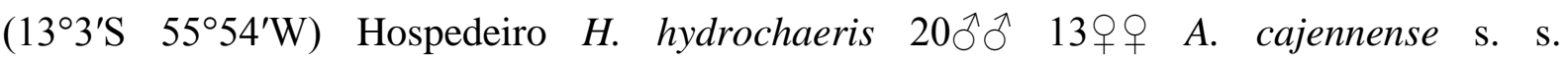
novembro/2013 (CNC 2544), Hospedeiro P. onca 2 우 A. cajennense s. s. $7 q 0$ 오 Aculptum

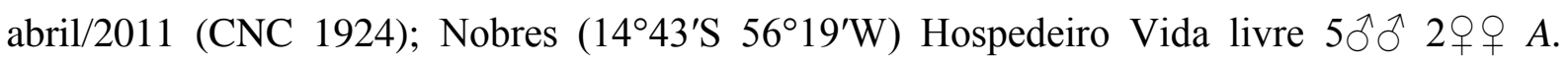

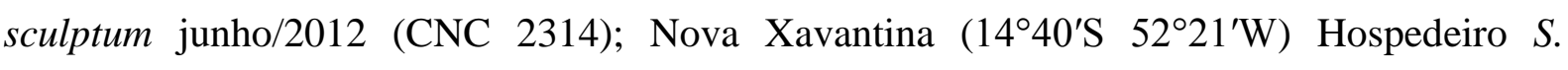

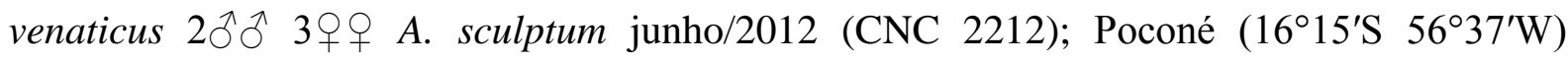
Hospedeiro B. taurus 2̧̄̋̂ A. cajennense s. 1. agosto/1997 (CNC 93), Hospedeiro C. familiaris 1 q A. sculptum abril/2002 (CNC 648), Hospedeiro E. caballus $2 \widehat{\jmath} \widehat{o} 12$ 우 A. sculptum abril/2002 (CNC 647), Hospedeiro E. caballus $1 \hat{\jmath} 6$ 우 A. sculptum outubro/2012

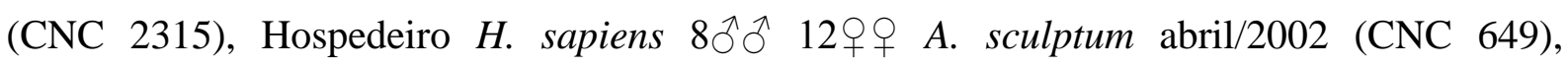
Hospedeiro P. onca 1 q A. sculptum agosto/1996 (CNC 144), Hospedeiro P. onca $1 \bigcirc 2$ đ sculptum novembro/2008 (CNC 1358), Hospedeiro P. onca 1 ㅇ A. sculptum junho/2011 (CNC

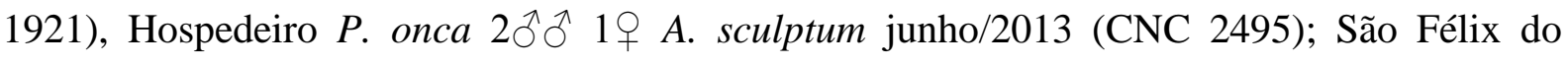
Araguaia $\left(11^{\circ} 37^{\prime} \mathrm{S} 50^{\circ} 40^{\prime} \mathrm{W}\right)$ Hospedeiro E. caballus 1 q cajennense s. s. maio/2008 (CNC

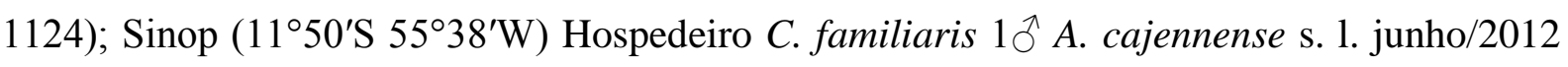

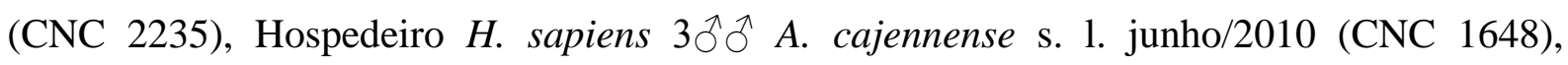
Hospedeiro H. hydrochaeris $1 \lesssim$ $4 \uparrow \bigcirc$ A. cajennense s. s. julho/2012 (CNC 2222), Hospedeiro P. tajacu $1 \lesssim 3$ ○ㅇ A. cajennense s. s. outubro/2012 (CNC 2271). Mato Grosso do Sul: Água 
Clara $\left(20^{\circ} 26^{\prime} \mathrm{S} 52^{\circ} 52^{\prime} \mathrm{W}\right)$ Hospedeiro C. thous 19 (coletado como ninfa) A. sculptum

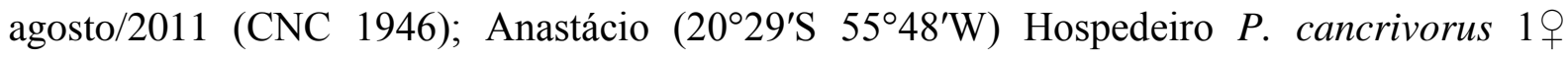
(coletado como ninfa) A. sculptum agosto/2011 (CNC 1945); Anaurilândia (22 $11^{\prime} \mathrm{S}$ $52^{\circ} 43^{\prime} \mathrm{W}$ ) Hospedeiro P. onca 1 ㅇ A. sculptum março/2001 (CNC 469), Hospedeiro P. onca $1 \widehat{\jmath} 3$ 우 A. sculptum fevereiro/2002 (CNC 833), Hospedeiro P. tajacu $3 \widehat{\jmath} 19$ A. sculptum

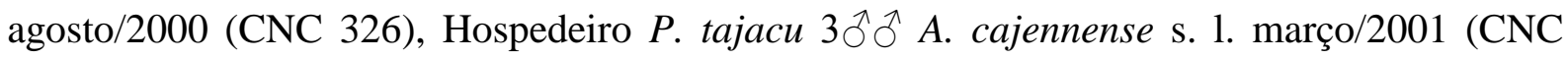
447), Hospedeiro P. concolor $2 \hat{\jmath} \widehat{\delta} 6$ 우 (coletados como larvas) A. sculptum junho/2001 (CNC 530), Hospedeiro P. concolor 2ふ̂̋ A. cajennense s. 1. novembro/2002 (CNC 834); Aquidauana $\left(20^{\circ} 28^{\prime} \mathrm{S} 55^{\circ} 47^{\prime} \mathrm{W}\right)$ Hospedeiro M. tridactyla $18 \widehat{\partial}^{\lambda} 13 ㅇ+$ (coletados como ninfas) A. sculptum novembro/2013 (CNC 2542), Hospedeiro T. terrestris $11 \widehat{ð} 28$ ○ㅇ A. sculptum setembro/2008 (CNC 1146), Hospedeiro T. terrestris $8 \lesssim \widehat{\jmath} 21$ 우 A. sculptum (CNC 1424), Hospedeiro T. terrestris 14ðð 56우 A. sculptum julho/2009 (CNC 1456),

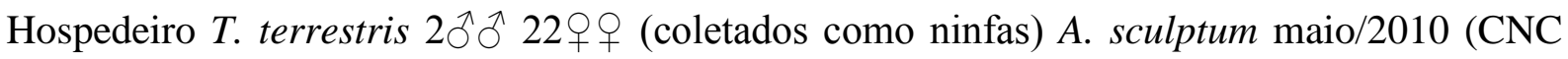
1588), Hospedeiro T. terrestris 17우 A. sculptum agosto/2010 (CNC 1651), Hospedeiro T.

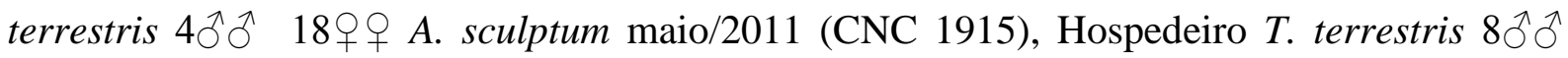
14웅 A. sculptum agosto/2011 (CNC 1937), Hospedeiro T. terrestris 30 $\widehat{\jmath} 53 q \propto$ (coletados

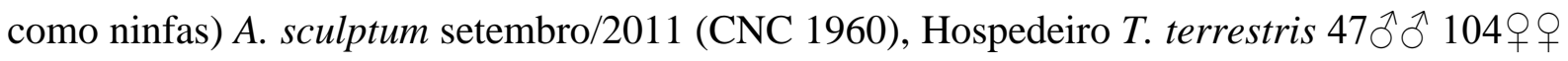
(coletados como ninfas) A. sculptum novembro/2011 (CNC 2080), Hospedeiro T. terrestris 6ろํ 24우 A. sculptum dezembro/2011 (CNC 2093), Hospedeiro T. terrestris 33우 A.

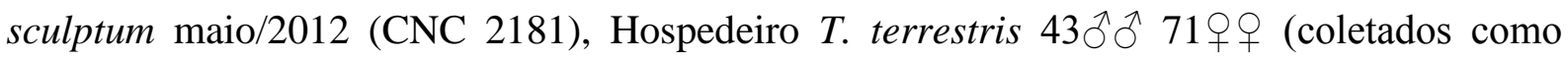
ninfas) A. sculptum julho/2012 (CNC 2237), Hospedeiro T. terrestris 32§ð $69 q+$ (coletados

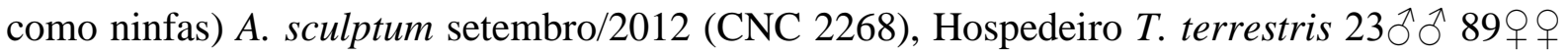
A. sculptum novembro/2012 (CNC 2304), Hospedeiro T. terrestris 36우 A. sculptum

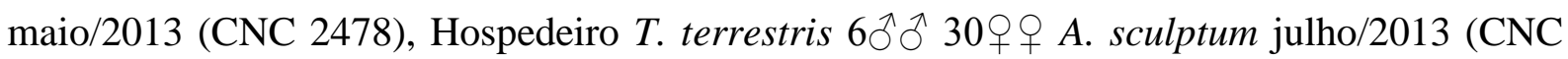

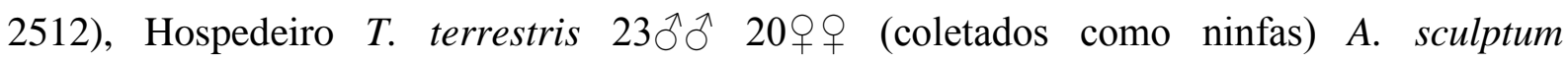
outubro/2013 (CNC 2538), Hospedeiro T. terrestris $13 q$ q A. sculptum dezembro/2013 (CNC 2583); Bataguassu $\left(21^{\circ} 42^{\prime} \mathrm{S} 52^{\circ} 25^{\prime} \mathrm{W}\right)$ Hospedeiro Blastocerus dichotomus $10^{\Uparrow} 1$ 和 sculptum fevereiro/2001 (CNC 420), Hospedeiro B. dichotomus 19 A. sculptum fevereiro/2001 (CNC 434), Hospedeiro B. dichotomus 1 ㅇ A. sculptum (CNC 435),

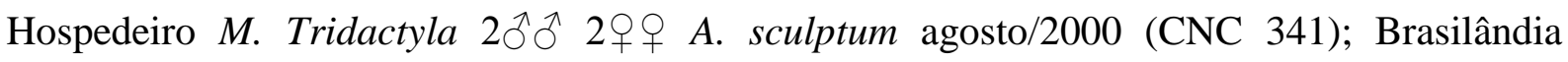

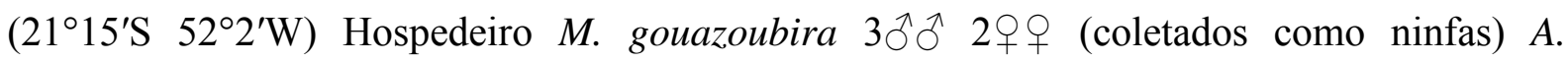
sculptum agosto/2000 (CNC 327), Hospedeiro M. tridactyla $1 \bigcirc^{\Uparrow}$ A. cajennense s. 1. abril/2000 (CNC 292), Hospedeiro M. tridactyla $1 \hat{\sigma} 2 q q$ (coletados como ninfas) A. sculptum julho/2000 (CNC 332), Hospedeiro M. tridactyla 7ðิð A. cajennense s. 1. julho/2000 (CNC 
333), Hospedeiro M. tridactyla $2 \widehat{\jmath} 3$ đ̊ A. sculptum agosto/2000 (CNC 339), Hospedeiro M. tridactyla $1 \lesssim$ A. cajennense s. 1. agosto/2000 (CNC 340), Hospedeiro T. tetradactyla $1 \lesssim$ (coletado como ninfa) A. cajennense s. 1. julho/2000 (CNC 334); Bonito $\left(21^{\circ} 7^{\prime} \mathrm{S} 56^{\circ} 28^{\prime} \mathrm{W}\right)$ Hospedeiro C. brachyurus 2 q 9 A. sculptum março/2002 (CNC 623), Hospedeiro H. sapiens $1 \bigcirc$ A. sculptum abril/2005 (CNC 897), Hospedeiro T. terrestris $1 \sigma^{\widehat{A}}$ A. cajennense s. 1. março/2002 (CNC 624), Hospedeiro T. terrestris 1 ^ 1 ㅇ A. sculptum março/2002 (CNC 625), Hospedeiro T. terrestris 8 우 A. sculptum março/2002 (CNC 658); Campo Grande (20²6'S $\left.54^{\circ} 38^{\prime} \mathrm{W}\right)$ Hospedeiro E. caballus $3 \widehat{\delta}^{\widehat{o}} 3$ 3우 A. sculptum dezembro/2012 (CNC 2322); Corumbá $\left(19^{\circ} 0^{\prime} \mathrm{S} 57^{\circ} 39^{\prime} \mathrm{W}\right)$ Hospedeiro E. caballus 3 우 A. sculptum janeiro/2009 (CNC 1364), Hospedeiro E. caballus $17 \hat{\jmath} 8$ 8 우 A. sculptum abril/2009 (CNC 1415), Hospedeiro

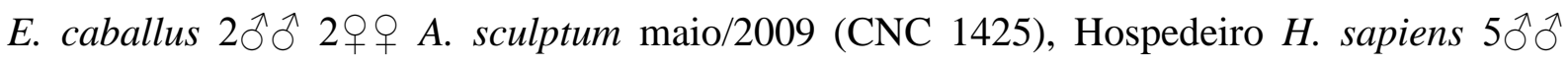

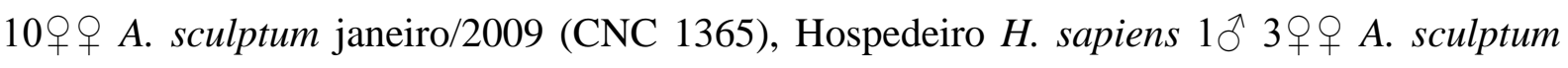
maio/2008 (CNC 1404), Hospedeiro H. sapiens 2 우 A. sculptum junho/2009 (CNC 1430), Hospedeiro H. hydrochaeris $2 \widehat{\jmath}$ A. cajennense s. 1. setembro/1997 (CNC 101), Hospedeiro H. hydrochaeris $1 \sigma^{\Uparrow}$ A. cajennense s. 1. setembro/1997 (CNC 102), Hospedeiro $H$. hydrochaeris 1 ㅇ A. sculptum setembro/1997 (CNC 103), Hospedeiro H. hydrochaeris $6 \hat{\jmath}$ 3 우 A. sculptum agosto/2008 (CNC 1360), Hospedeiro P. onca 11 ふふ઼ 38 우 A. sculptum

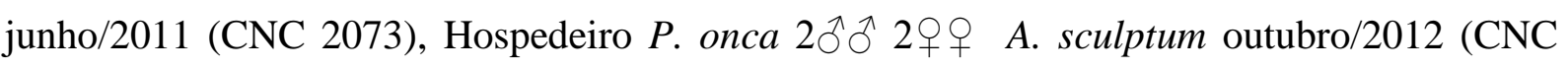

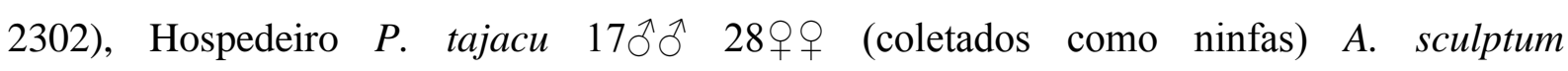
setembro/1997 (CNC 99), Hospedeiro P. tajacu $1 \delta^{\Uparrow} 19$ (coletados como ninfas) A. sculptum setembro/1997 (CNC 100), Hospedeiro Sus scrofa 8 ふึ 5 우 A. sculptum agosto/2010 (CNC

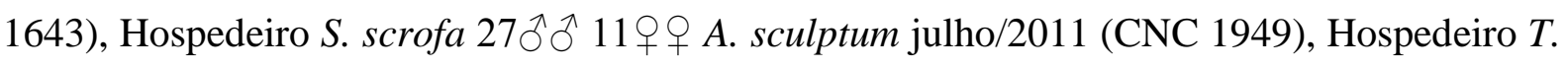

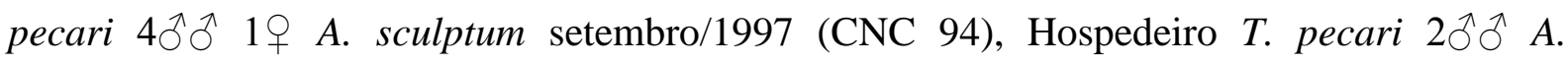
cajennense s. 1. setembro/1997 (CNC 95), Hospedeiro T. pecari $3 \widehat{\jmath} 3$ 3우 A. sculptum setembro/1997 (CNC 96), Hospedeiro T. pecari 1ð̊ 2우 A. sculptum setembro/1997 (CNC

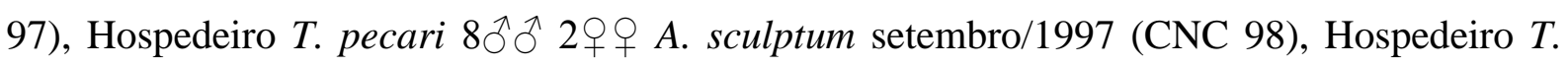
pecari $9 \widehat{\jmath} 7$ 웅 A. sculptum julho/2011 (CNC 1947), Hospedeiro Vida livre $3 \widehat{\jmath} A$.

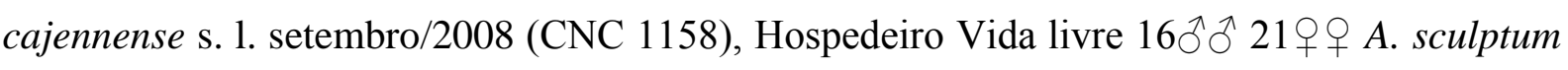
julho/2011 (CNC 1950); Miranda (20¹4'S 56 $\left.22^{\prime} \mathrm{W}\right)$ Hospedeiro Cabassous unicinctus 19 A. sculptum dezembro/2012 (CNC 2377), Hospedeiro C. familiaris $1 \hat{\sigma}$ A. cajennense s. 1. novembro/2008 (CNC 1709), Hospedeiro Euphractus sexcinctus 1 q A. sculptum julho/2012 (CNC 2378), Hospedeiro E. sexcinctus 290 A. sculptum junho/2013 (CNC 2498), Hospedeiro E. sexcinctus 1 A. sculptum dezembro/2013 (CNC 2602), Hospedeiro $H$. sapiens 1 q A. sculptum junho/2012 (CNC 2215), Hospedeiro M. tridactyla 12ðð 6 우우 


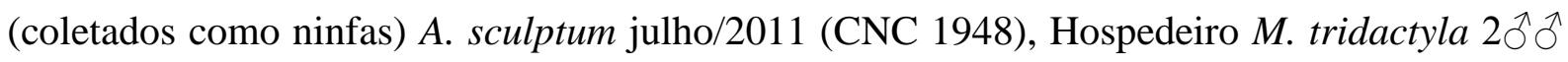
5 우 A. sculptum julho/2013 (CNC 2511), Hospedeiro M. tridactyla 11ððð 7 우 A. sculptum dezembro/2013 (CNC 2604), Hospedeiro P. onca $1 ð$ 4 9 ㅇ A. sculptum outubro/2003 (CNC 1675), Hospedeiro P. onca $1 \bigcirc^{\Uparrow} 2$ 우 A. sculptum dezembro/2004 (CNC 1678), Hospedeiro $P$.

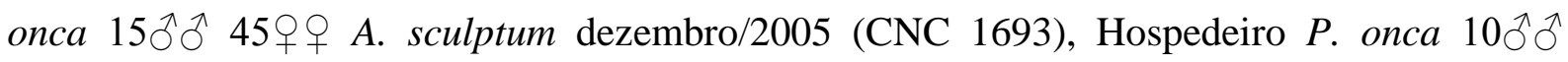
26 우 A. sculptum janeiro/2007 (CNC 1702), Hospedeiro P. onca $1 \delta^{\Uparrow} 1$ \& A. sculptum outubro/2011 (CNC 2173), Hospedeiro P. onca 4ภึ̄ 6우 A. sculptum abril/2012 (CNC 2216), Hospedeiro P. onca $16 \widehat{\jmath} 20$ ○ㅇ A. sculptum abril/2013 (CNC 2452), Hospedeiro $P$.

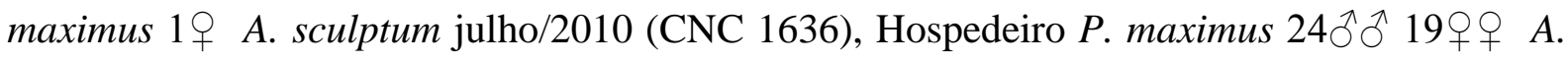
sculptum julho/2012 (CNC 2379), Hospedeiro P. maximus 36仓̋ 36 A. sculptum abril/2013 (CNC 2465), Hospedeiro P. maximus 42仓̋ð 32ๆ A. sculptum junho/2013 (CNC 2499),

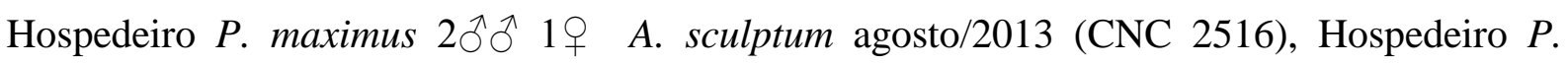

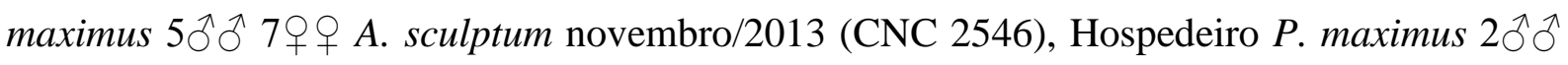
$6 ㅇ ㅜ$ A. sculptum dezembro/2013 (CNC 2603), Hospedeiro T. terrestris $6 \hat{\jmath} \widehat{\jmath} 290$ (coletados como ninfas) A. sculptum junho/2008 (CNC 1123), Hospedeiro T. terrestris 4તํำ 7 우 (coletados como ninfas) A. sculptum julho/2010 (CNC 1637), Hospedeiro Vida livre $1 \overbrace{}^{\Uparrow} 2 q$ ㅇ

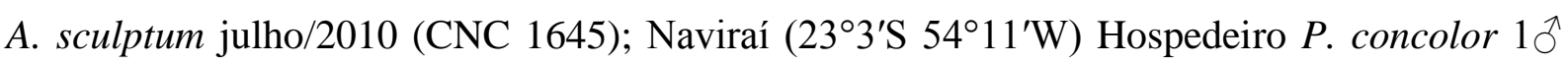

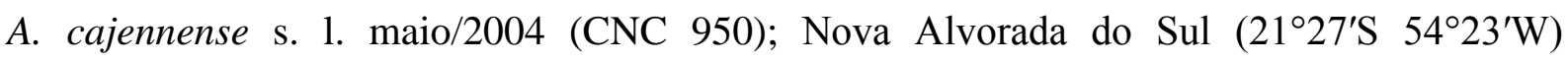
Hospedeiro M. tridactyla 9ð̋ 2 †ㅇ A. sculptum abril/2005 (CNC 895), Hospedeiro M.

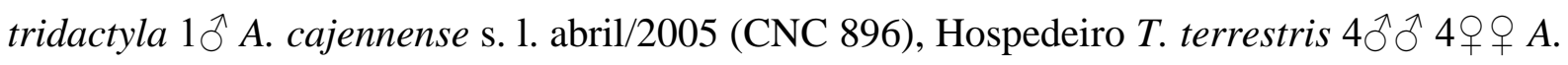
sculptum agosto/2013 (CNC 2513); Santa Rita do Pardo (21 $\left.{ }^{\circ} 18^{\prime} \mathrm{S} 52^{\circ} 49^{\prime} \mathrm{W}\right)$ Hospedeiro $M$.

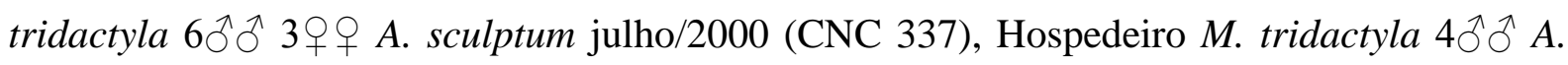
cajennense s. 1. agosto/2000 (CNC 343), Hospedeiro M. tridactyla 1ð A. cajennense s. 1. agosto/2000 (CNC 346), Hospedeiro M. tridactyla $3 \widehat{\jmath} \widehat{o} 1$ 1 A. sculptum agosto/2000 (CNC 347), Hospedeiro T. tetradactyla 19 A. sculptum agosto/2000 (CNC 352); Terenos $\left(20^{\circ} 26^{\prime} \mathrm{S}\right.$

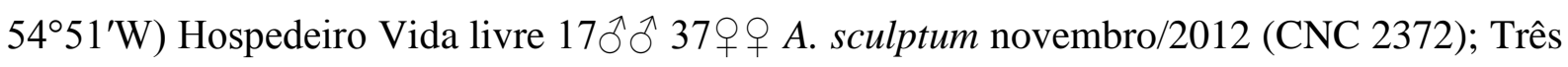
Lagoas $\left(20^{\circ} 45^{\prime} \mathrm{S} 51^{\circ} 40^{\prime} \mathrm{W}\right)$ Hospedeiro H. sapiens $1 \overbrace{}^{\Uparrow} 1$ ㅇ A. sculptum março/1999 (CNC 215). $\underline{\text { Sudeste }}$ - Espírito Santo: Colatina $\left(19^{\circ} 32^{\prime} \mathrm{S} 40^{\circ} 37^{\prime} \mathrm{W}\right)$ Hospedeiro H. sapiens 1 ㅇ

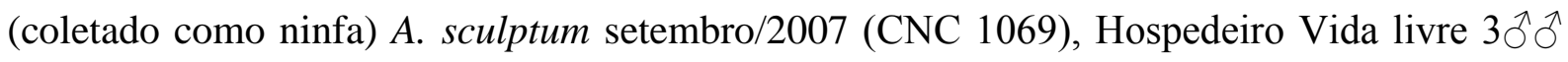

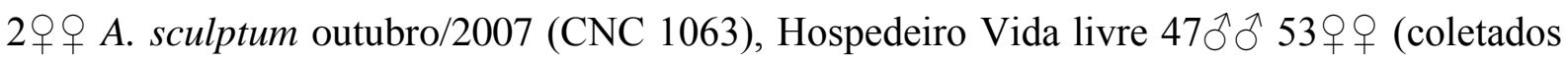
como ninfas) A. sculptum outubro/2007 (CNC 1082); Guarapari (20³9’S 40³0’W) Hospedeiro E. caballus $2 \widehat{\jmath} 7$ ๙ $ᄋ$ (coletados como ninfas) A. sculptum julho/2001 (CNC

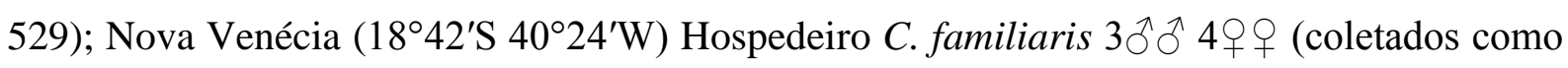

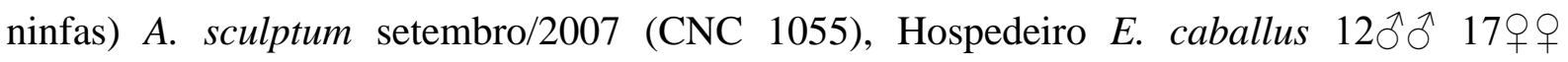


(coletados como ninfas) A. sculptum setembro/2007 (CNC 1056), Hospedeiro Vida livre 5ふえ 7 우우 A. sculptum maio/2007 (CNC 1045). Minas Gerais: Araguari $\left(18^{\circ} 38^{\prime} \mathrm{S} 48^{\circ} 11^{\prime} \mathrm{W}\right)$ Hospedeiro E. caballus 7 우 A. sculptum maio/2011 (CNC 1909); Chapada Gaúcha (15²18'S

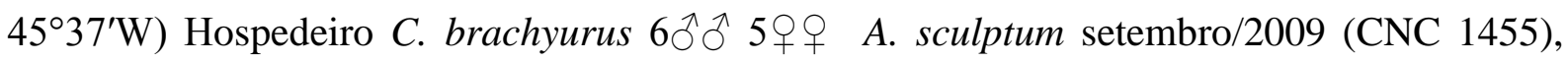
Hospedeiro $H$. sapiens $1 \widehat{\jmath} 3 q q$ A. sculptum dezembro/2007 (CNC 1414), Hospedeiro $H$.

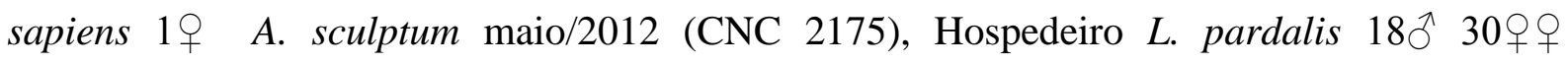
(coletados como larvas e ninfas) A. sculptum julho/2009 (CNC 1452), Hospedeiro P. onca

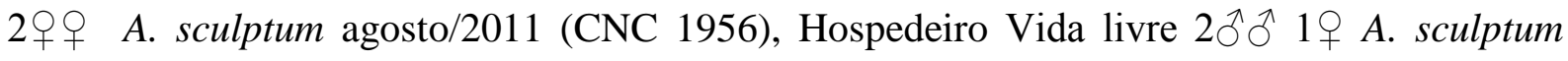
janeiro/2009 (CNC 1441), Hospedeiro Vida livre 1ð̋ $3+$ ㅇ A. sculptum maio/2012 (CNC

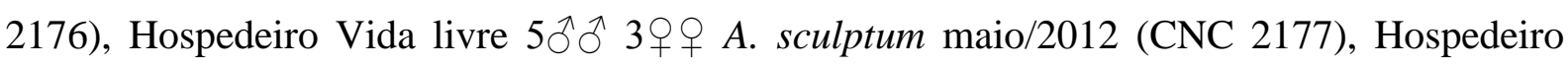
Vida livre $1 \widehat{\jmath}$ A. cajennense s. 1. maio/2012 (CNC 2178), Hospedeiro Vida livre $6 \widehat{\jmath} 21$ 웅 A. sculptum maio/2012 (CNC 2179); Doresópolis $\left(20^{\circ} 17^{\prime} \mathrm{S} 45^{\circ} 54^{\prime} \mathrm{W}\right)$ Hospedeiro Vida livre 1 ㅇ A. sculptum agosto/2008 (CNC 1341); Guarda-Mor (17 $\left.46^{\prime} \mathrm{S} 47^{\circ} 5^{\prime} \mathrm{W}\right)$ Hospedeiro $H$.

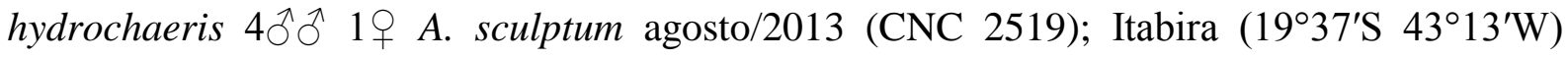
Hospedeiro C. familiaris 1 ㅇ A. sculptum dezembro/2010 (CNC 1780); Marliéria (1942'S $42^{\circ} 43^{\prime} \mathrm{W}$ ) Hospedeiro H. sapiens $1{ }^{\lambda}$ A. cajennense s. 1. outubro/2012 (CNC 2370), Hospedeiro H. sapiens $2 \widehat{\jmath} 4$ 우 A. sculptum setembro/2012 (CNC 2266), Hospedeiro Vida

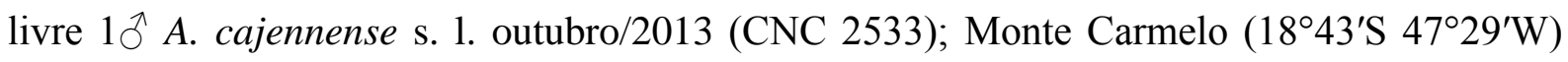
Hospedeiro M. tridactyla 1ठ 2 우 A. sculptum novembro/2013 (CNC 2543); Morada Nova de Minas $\left(18^{\circ} 36^{\prime} \mathrm{S} 45^{\circ} 21^{\prime} \mathrm{W}\right)$ Hospedeiro Dasyprocta azarae 19 A. sculptum maio/2009 (CNC 2083), Hospedeiro Vida livre 21ふðð 11 우 A. sculptum maio/2009 (CNC 1885); Pedra

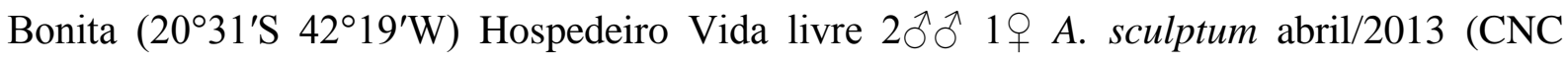

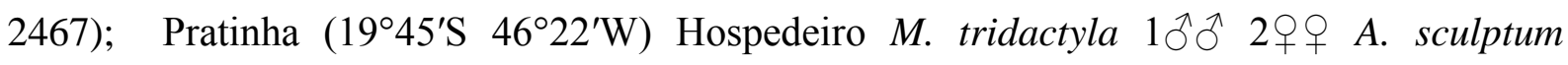
maio/2008 (CNC 1114); Santana do Riacho $\left(19^{\circ} 10^{\prime} \mathrm{S} 43^{\circ} 42^{\prime} \mathrm{W}\right)$ Hospedeiro C. familiaris

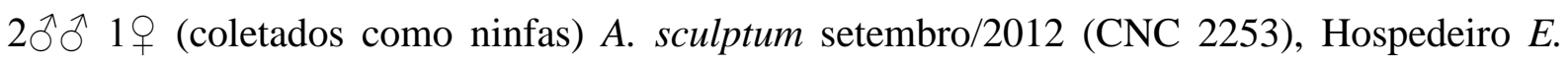
caballus $5 \hat{\jmath} \widehat{\partial} 11$ q $q$ (coletados como ninfas) A. sculptum setembro/2012 (CNC 2252), Hospedeiro H. hydrochaeris 147ठิð 110 우 A. sculptum setembro/2010 (CNC 1734); São

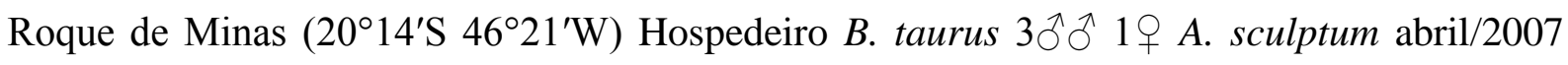
(CNC 1018), Hospedeiro C. brachyurus $4 q+$ (coletados como ninfas) A. sculptum janeiro/2005 (CNC 981), Hospedeiro C. brachyurus $1 \widehat{\delta} 1 q$ (coletados como ninfas) $A$. sculptum janeiro/2006 (CNC 1013), Hospedeiro C. brachyurus $6 \widehat{\jmath} \widehat{\jmath} 12$ 우 (coletados como ninfas) A. sculptum outubro/2006 (CNC 1022), Hospedeiro C. brachyurus $3 \widehat{\jmath} 3$ ๙ sculptum setembro/2007 (CNC 1362), Hospedeiro H. sapiens 1ठ઼ (coletado como ninfa) A. cajennense s. 1. abril/2007 (CNC 1024), Hospedeiro Lycalopex vetulus $3 \widehat{\jmath} \widehat{\jmath} 2$ 우 (coletados 
como ninfas) A. sculptum outubro/2005 (CNC 980), Hospedeiro S. scrofa 7ठ̋ð 16우 A.

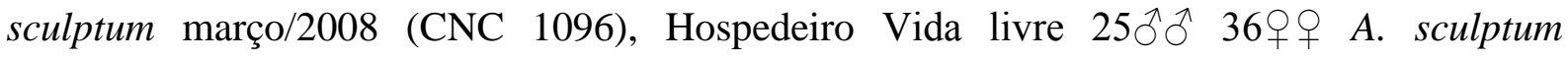
abril/2007 (CNC 1016), Hospedeiro Vida livre 3ð̋ 10 우 A. sculptum agosto/2007 (CNC 1046), Hospedeiro Vida livre $4 \hat{\jmath} \widehat{\jmath} 39$ ㅇ A. sculptum março/2008 (CNC 1099), Hospedeiro Vida livre $2 \widehat{\jmath} 1 q$ A. sculptum maio/2008 (CNC 1115), Hospedeiro Vida livre $8 \widehat{\jmath} 8$ 우 A. sculptum junho/2007 (CNC 1149), Hospedeiro Vida livre 14ふ̋ત 219 A. sculptum fevereiro/2009 (CNC 1417), Hospedeiro Vida Livre 1ð 4ㅇ A. sculptum maio/2009 (CNC 1495), Hospedeiro Vida Livre $1 ð 1$ 우 A. sculptum setembro/2011 (CNC 2048); Tiradentes

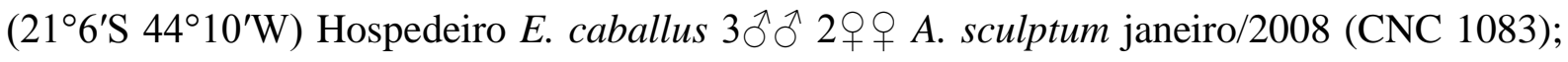
Três Marias $\left(18^{\circ} 12^{\prime} \mathrm{S} 45^{\circ} 14^{\prime} \mathrm{W}\right)$ Hospedeiro H. sapiens $6 \bigcirc^{\lambda} 5$ 우 우 A. sculptum setembro/2013

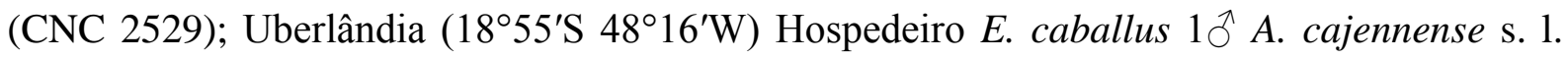

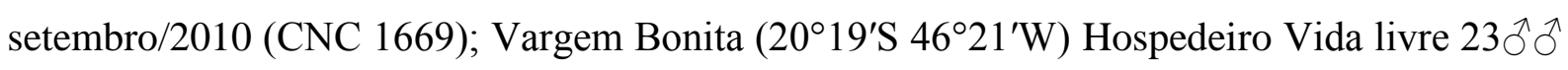

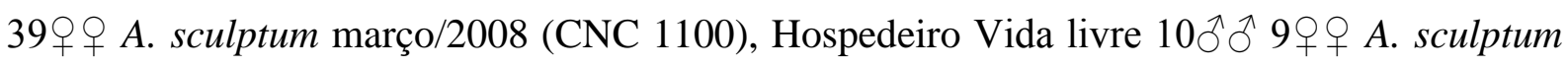

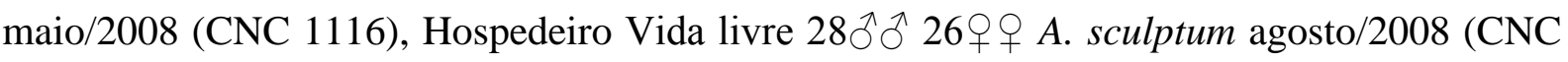
1150), Hospedeiro Vida livre $63 \hat{\jmath} \widehat{o} 123 q$ ○ A. sculptum fevereiro/2009 (CNC 1418). Rio de Janeiro: Teresópolis $\left(22^{\circ} 24^{\prime} \mathrm{S} 42^{\circ} 57^{\prime} \mathrm{W}\right)$ Hospedeiro T. tetradactyla $2 \hat{\jmath} 0^{\Uparrow}$ 우 A. sculptum

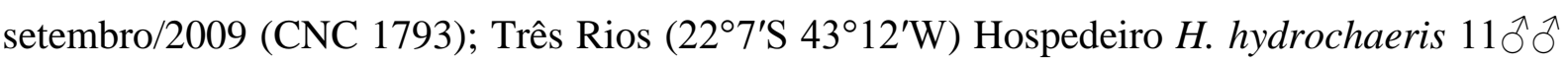
$44+9$ (coletados como ninfas) A. sculptum setembro/2008 (CNC 1159). São Paulo: Americana $\left(22^{\circ} 44^{\prime} \mathrm{S} 47^{\circ} 19^{\prime} \mathrm{W}\right)$ Hospedeiro $H$. sapiens $10^{\lambda}$ (coletado como ninfa) $A$. cajennense s. 1. setembro/2011 (CNC 2049), Hospedeiro Vida livre 14ð̋ð 22우 A. sculptum

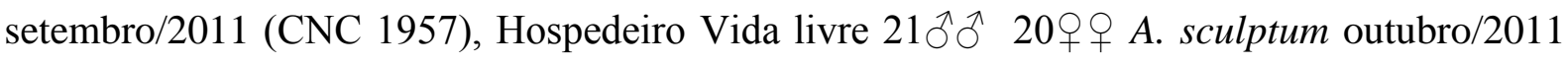

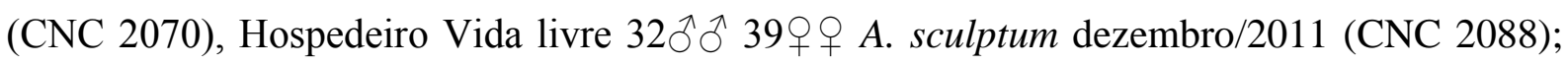

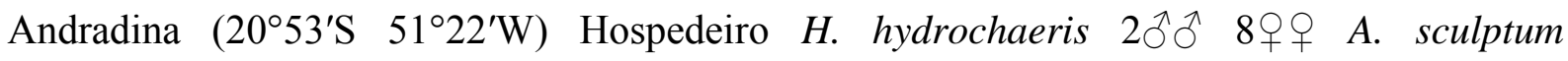

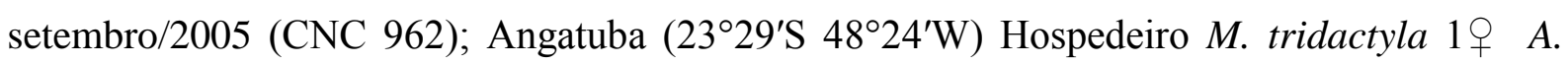
sculptum outubro/2010 (CNC 1739), Hospedeiro H. sapiens $1 \widehat{\jmath}$ A. cajennense s. 1. outubro/2010 (CNC 1742); Araçariguama (232 $6^{\prime} \mathrm{S} 47^{\circ} 3^{\prime} \mathrm{W}$ ) Hospedeiro C. familiaris 1 우 A. sculptum novembro/1997 (CNC 108), Hospedeiro C. familiaris $10^{\Uparrow} 1$ 早 A. sculptum janeiro/1998 (CNC 116), Hospedeiro C. familiaris $1+$ (coletado como ninfa) A. sculptum março/2009 (CNC 1405), Hospedeiro C. familiaris 1今̄ 2 우 (coletados como larvas) A. sculptum março/2009 (CNC 1434), Hospedeiro H. hydrochaeris 1 q A. sculptum julho/2013 (CNC 2514), Hospedeiro Vida livre $1 \hat{\jmath}$ A. cajennense s. 1. março/1998 (CNC 127), Hospedeiro Vida livre 1 + A. sculptum março/1998 (CNC 129); Araçoiaba da Serra $\left(23^{\circ} 30^{\prime} \mathrm{S}\right.$

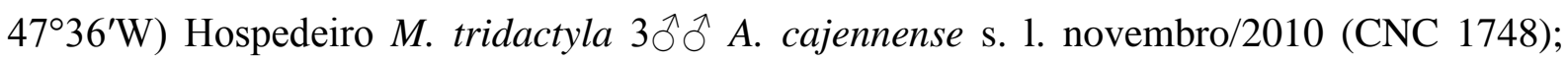
Atibaia $\left(23^{\circ} 7^{\prime} \mathrm{S} 46^{\circ} 33^{\prime} \mathrm{W}\right)$ Hospedeiro H. sapiens $1{ }^{\Uparrow}$ (coletado como ninfa) A. cajennense s. 1. 
setembro/2000 (CNC 371); Biritiba Mirim (2334'S 46²’W) Hospedeiro Sphiggurus villosus 1 ㅇ A. sculptum março/2005 (CNC 1119); Bragança Paulista (22 57'S 46³2'W) Hospedeiro

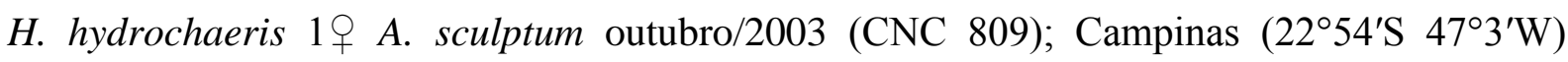
Hospedeiro H. sapiens $1 \widehat{\jmath}$ (coletado como ninfa) A. cajennense s. 1. setembro/2002 (CNC

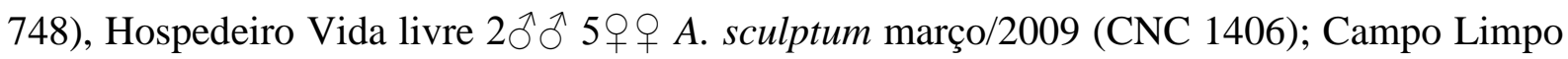
Paulista $\left(23^{\circ} 12^{\prime} \mathrm{S} 46^{\circ} 47^{\prime} \mathrm{W}\right)$ Hospedeiro C. familiaris $1+$ (coletado como ninfa) A. sculptum

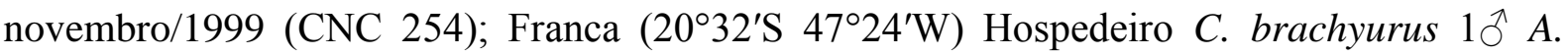
cajennense s. 1. outubro/2001 (CNC 518), Hospedeiro E. caballus 1 + A. sculptum março/2001 (CNC 520), Hospedeiro Theristicus caudatus $2 \widehat{\jmath} \widehat{\jmath} 2$ 우 (coletados como ninfas) A. sculptum julho/2002 (CNC 729); Guaraci $\left(20^{\circ} 29^{\prime} \mathrm{S} 48^{\circ} 56^{\prime} \mathrm{W}\right)$ Hospedeiro E. caballus $10^{\lambda}$ A. cajennense s. 1. janeiro/2005 (CNC 911); Guarulhos (2327'S 46 $\left.31^{\prime} \mathrm{W}\right)$ Hospedeiro $H$. hydrochaeris $1 \delta^{\Uparrow} 3 q$ ㅇ A. sculptum março/2005 (CNC 961), Hospedeiro Tyto alba (coletado como ninfa) $1 \overbrace{}^{\lambda} A$. cajennense s. 1. agosto/2003 (CNC 797); Indaiatuba $\left(23^{\circ} 5^{\prime} \mathrm{S} 47^{\circ} 13^{\prime} \mathrm{W}\right)$ Hospedeiro C. familiaris $1 \hat{\jmath}$ (coletado como ninfa) A. cajennense s. 1. agosto/2000 (CNC

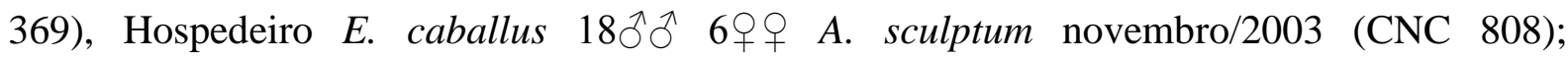
Itapetininga $\left(23^{\circ} 35^{\prime} \mathrm{S} 48^{\circ} 3^{\prime} \mathrm{W}\right)$ Hospedeiro M. tridactyla 1 \% A. sculptum janeiro/2008 (CNC 1086); Itu $\left(23^{\circ} 15^{\prime} \mathrm{S} 47^{\circ} 17^{\prime} \mathrm{W}\right)$ Hospedeiro H. sapiens $1 q$ (coletado como ninfa) A. sculptum

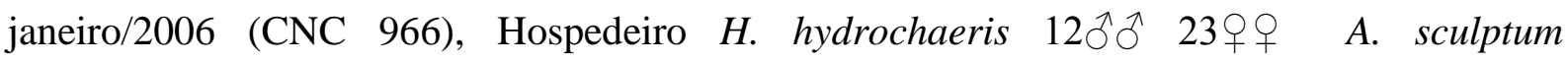
setembro/2008 (CNC 1537), Hospedeiro H. hydrochaeris 1 \% A. sculptum novembro/2010 (CNC 1749), Hospedeiro M. tridactyla 3ふðત 6우 A. sculptum julho/2008 (CNC 1132), Hospedeiro M. tridactyla $1 \widehat{\bigcirc} 5$ 우 (coletados como ninfas) A. sculptum abril/2009 (CNC 1416), Hospedeiro M. tridactyla 1ठ 16우 A. sculptum novembro/2009 (CNC 1503), Hospedeiro T. terrestris 19 (coletado como ninfa) A. sculptum maio/2001 (CNC 493),

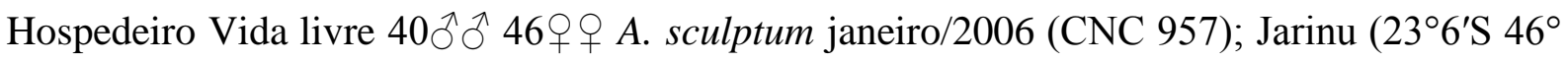
$43^{\prime} \mathrm{W}$ ) Hospedeiro C. familiaris $2 \widehat{\jmath} \partial^{\Uparrow} 1 q$ (coletados como ninfas) A. sculptum outubro/2009 (CNC 1454), Hospedeiro Hospedeiro H. sapiens $1 q$ A. sculptum fevereiro/2009 (CNC 1368); Jundiaí $\left(23^{\circ} 11^{\prime} \mathrm{S} 46^{\circ} 53^{\prime} \mathrm{W}\right)$ Hospedeiro Cariama cristata 1 ㅇ A. sculptum novembro/2001 (CNC 687), Hospedeiro “Gavião" 19 (coletado como ninfa) A. sculptum outubro/1998 (CNC 172), Hospedeiro H. hydrochaeris 1 ㅇ A. sculptum abril/2000 (CNC 692), Hospedeiro M.

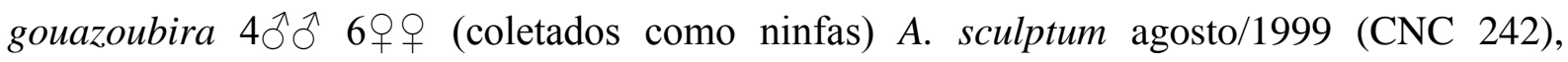
Hospedeiro M. gouazoubira $29 q$ (coletados como ninfas) A. sculptum agosto/1999 (CNC

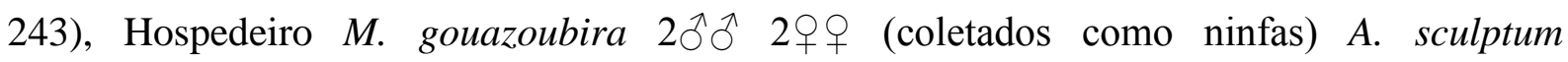
novembro/1999 (CNC 276), Hospedeiro P. cancrivorus $1 \delta^{\Uparrow}$ (coletado como ninfa) A. cajennense s. 1. outubro/1998 (CNC 169), Hospedeiro Sylvilagus brasiliensis 1 ㅇ (coletado 


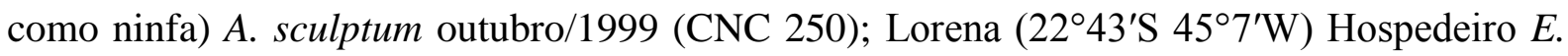

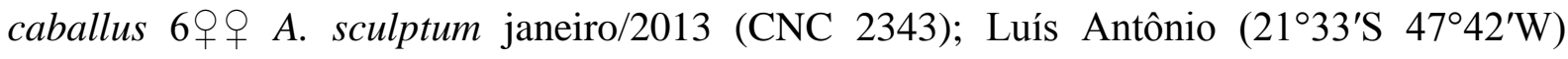
Hospedeiro P. tajacu $1 \delta^{\Uparrow} 2 q+$ (coletados como ninfas) A. sculptum agosto/2001 (CNC 565), Hospedeiro P. tajacu 1 + A. sculptum julho/2002 (CNC 738); Mogi das Cruzes $\left(23^{\circ} 31^{\prime} \mathrm{S}\right.$ $\left.46^{\circ} 11^{\prime} \mathrm{W}\right)$ Hospedeiro Vida livre 270 $\overbrace{}^{\lambda} 237$ 우 A. sculptum outubro/2005 (CNC 964);

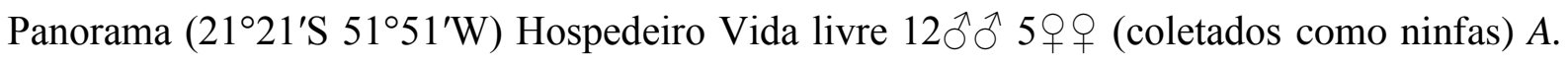

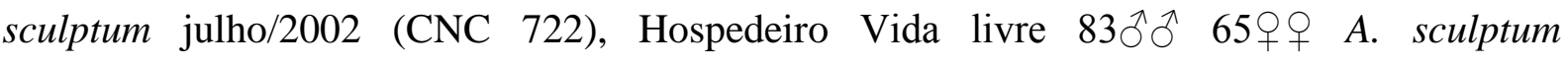
novembro/2002 (CNC 747); Pauliceia $\left(21^{\circ} 19^{\prime} \mathrm{S} 51^{\circ} 49^{\prime} \mathrm{W}\right)$ Hospedeiro B. dichotomus 1 ㅇ A. sculptum abril/2001 (CNC 505), Hospedeiro E. caballus $1 \overbrace{}^{\lambda} 8$ 우 A. sculptum abril/2001 (CNC 454), Hospedeiro E. caballus 1ð̊ 19 A. sculptum abril/2001 (CNC 513), Hospedeiro E.

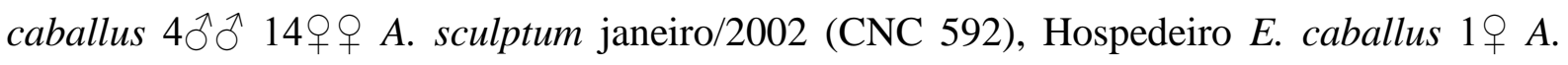
sculptum abril/2002 (CNC 641), Hospedeiro E. caballus 3 우 (coletados como ninfas) A. sculptum julho/2002 (CNC 720), Hospedeiro H. sapiens $1 \overbrace{}^{\Uparrow}$ A. cajennense s. 1. abril/2001 (CNC 452), Hospedeiro Vida livre 19ð̋

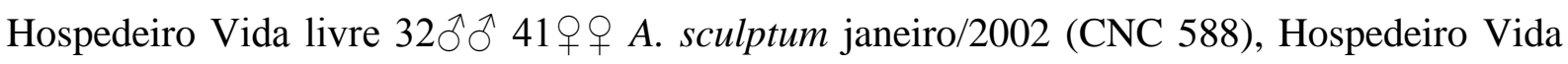
livre 19 A. sculptum janeiro/2002 (CNC 589), Hospedeiro Vida livre $12 \widehat{\jmath} 6$ 우 A. sculptum janeiro/2002 (CNC 590), Hospedeiro Vida livre 14ðð 37우 A. sculptum janeiro/2002 (CNC 591), Hospedeiro Vida livre $16 \hat{\jmath} 8$ 8 ㅇ A. sculptum abril/2002 (CNC 636), Hospedeiro Vida

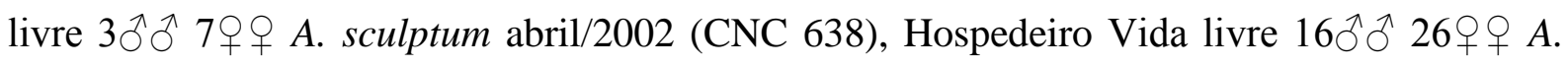
sculptum abril/2002 (CNC 639), Hospedeiro Vida livre $6 \widehat{\jmath} 9$ 9 우 A. sculptum abril/2002

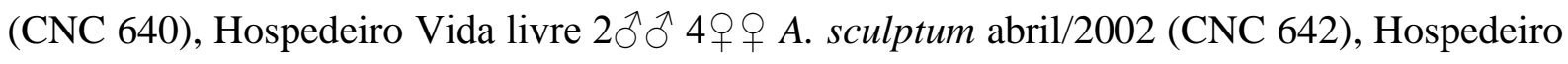
Vida livre $1 \delta^{\lambda} 3 ㅇ$ ㅇ (coletados como ninfas) A. sculptum abril/2002 (CNC 668), Hospedeiro Vida livre $2 \widehat{\jmath} 5$ 우 (coletados como ninfas) A. sculptum abril/2002 (CNC 683), Hospedeiro

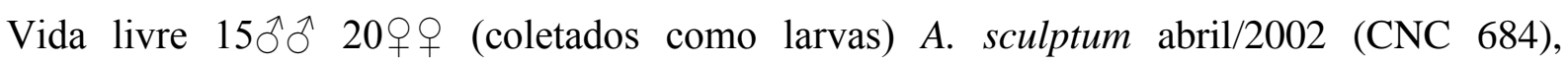

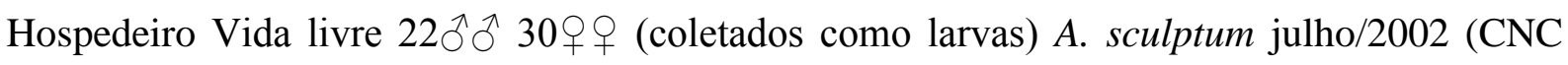
736); Pedreira ( $\left.22^{\circ} 44^{\prime} \mathrm{S} 46^{\circ} 54^{\prime} \mathrm{W}\right)$ Hospedeiro H. sapiens 5 ふぇ 2 우우 (coletados como ninfas) A. sculptum dezembro/2000 (CNC 425), Hospedeiro Leopardus tigrinus $1 \hat{\jmath}$ A. cajennense s.

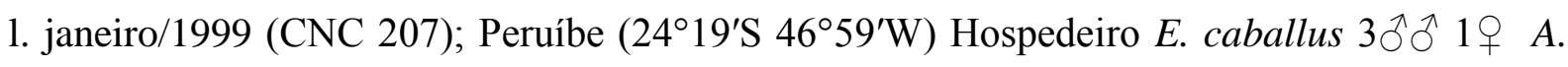
sculptum fevereiro/2011 (CNC 1813), Hospedeiro Vida livre $1 q$ A. sculptum novembro/2010 (CNC 1855); Piracicaba $\left(22^{\circ} 43^{\prime} \mathrm{S} 47^{\circ} 38^{\prime} \mathrm{W}\right)$ Hospedeiro H. hydrochaeris $5 \hat{\jmath} \widehat{o} 6$ 우 A. sculptum março/2001 (CNC 436), Hospedeiro H. hydrochaeris $27 ふ \widehat{\jmath} 18$ 早 A. sculptum outubro/2001 (CNC 566); Pirassununga (21 $\left.{ }^{\circ} 59^{\prime} \mathrm{S} 47^{\circ} 25^{\prime} \mathrm{W}\right)$ Hospedeiro Didelphis albiventris $1{ }^{\lambda} 3$ 우 (coletados como ninfas) A. sculptum outubro/2000 (CNC 364), Hospedeiro E.

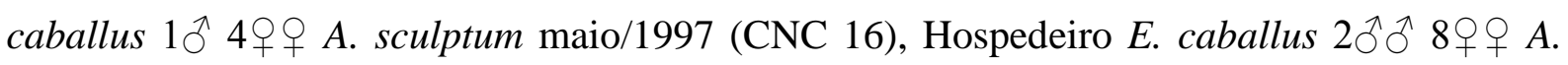


sculptum dezembro/2008 (CNC 1809), Hospedeiro Vida livre 19 A. sculptum outubro/2000

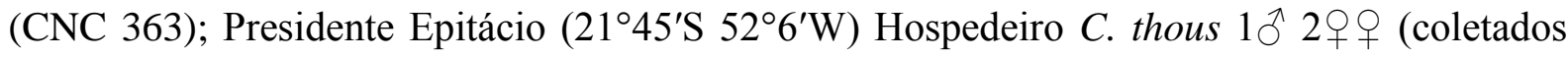

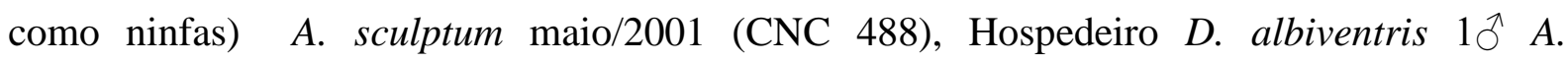

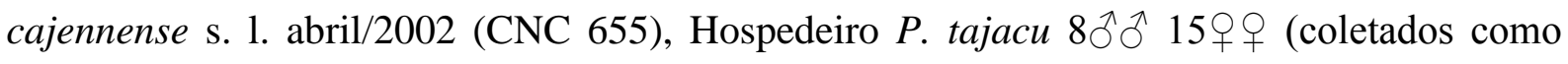
ninfas) A. sculptum maio/2001 (CNC 489); Presidente Prudente (22 $\left.7^{\prime} \mathrm{S} 51^{\circ} 23^{\prime} \mathrm{W}\right)$

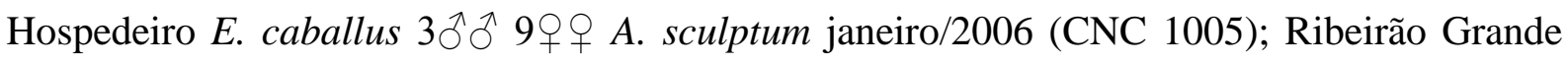

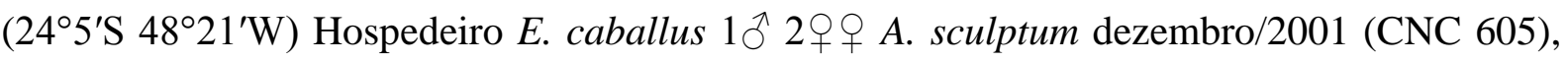
Hospedeiro M. gouazoubira $3 \widehat{\jmath} \widehat{\jmath} 12$ 우 (coletados como ninfas) A. sculptum dezembro/2001 (CNC 606), Hospedeiro Vida livre 1ð̊ A. cajennense s. 1. julho/2005 (CNC 959), Hospedeiro

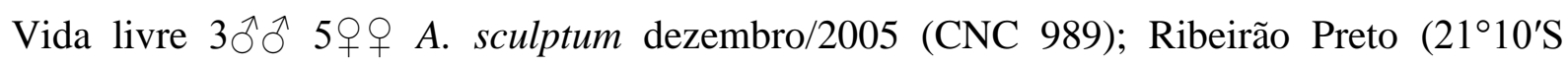

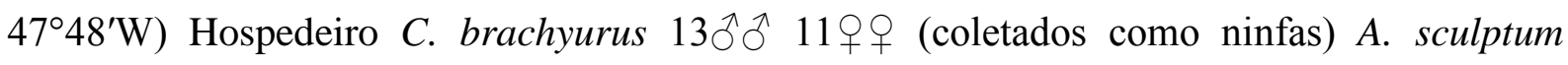
agosto/1999 (CNC 297), Hospedeiro C. brachyurus 19 (coletado como ninfa) A. sculptum setembro/2002 (CNC 799), Hospedeiro H. hydrochaeris 30 $\widehat{\jmath} 9$ 9우 A. sculptum março/2005 (CNC 960); Santa Cruz do Rio Pardo $\left(22^{\circ} 53^{\prime} \mathrm{S} 49^{\circ} 37^{\prime} \mathrm{W}\right)$ Hospedeiro Vida livre $1 \widehat{O}^{\hat{A}} A$. cajennense s. 1. abril/2007 (CNC 1019); Santa Rita do Passa Quatro (21 $\left.42^{\prime} \mathrm{S} 47^{\circ} 28^{\prime} \mathrm{W}\right)$

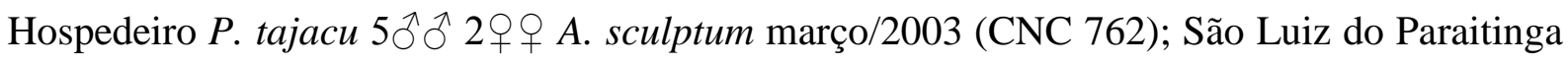

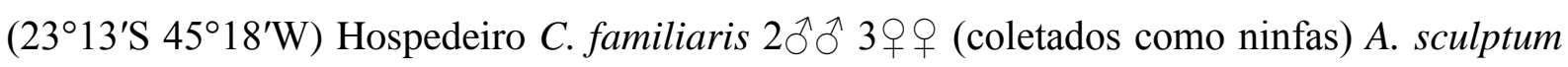

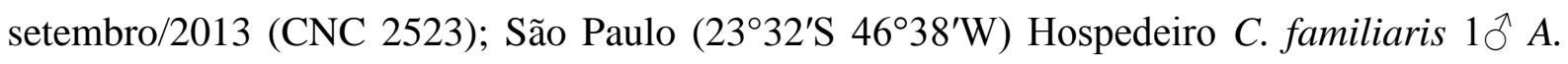
cajennense s. 1. novembro/2000 (CNC 367), Hospedeiro Capra hircus $2 \hat{\jmath}$ (coletados como ninfas) A. cajennense s. 1. junho/2002 (CNC 715), Hospedeiro D. novemcinctus $19 A$. sculptum janeiro/2013 (CNC 2424), Hospedeiro H. sapiens $1 \overbrace{}^{\hat{\jmath}}$ (coletado como ninfa) A. cajennense s. 1. julho/2000 (CNC 372), Hospedeiro H. hydrochaeris $4 \widehat{\jmath} 1$ ㅇ (coletados

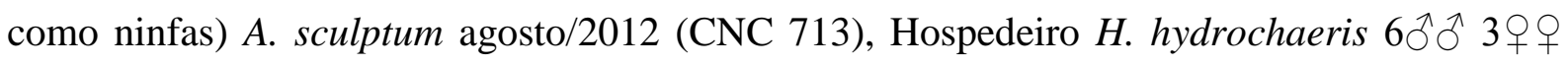
(coletados como ninfas) A. sculptum junho/2006 (CNC 983), Hospedeiro H. hydrochaeris

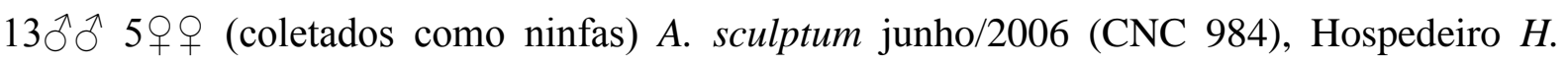

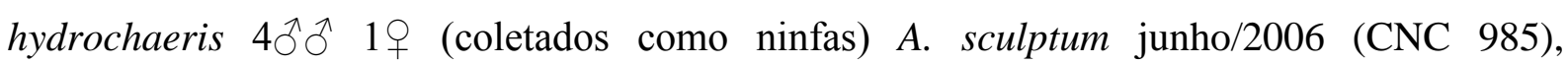

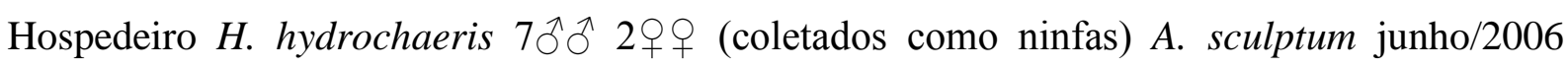
(CNC 986), Hospedeiro H. hydrochaeris 1 ㅇ A. sculptum julho/2005 (CNC 2435), Hospedeiro H. hydrochaeris 1 ð 3 q $ᄋ$ A. sculptum junho/2013 (CNC 2487), Hospedeiro Nasua nasua 1 ㅇ A. sculptum junho/2013 (CNC 2484), Hospedeiro T. terrestris 1 ㅇ A. sculptum fevereiro/2010

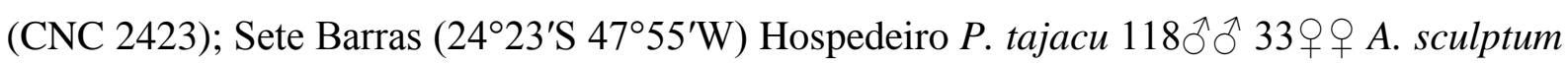
fevereiro/2013 (CNC 2427); Sorocaba $\left(23^{\circ} 30^{\prime} \mathrm{S} 47^{\circ} 27^{\prime} \mathrm{W}\right)$ Hospedeiro C. cristata 2 우 (coletados como ninfas) A. sculptum setembro/2007 (CNC 1053), Hospedeiro C. brachyurus

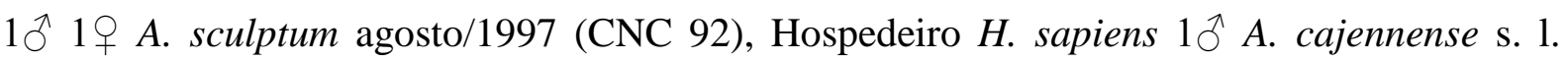


abril/2013 (CNC 2454), Hospedeiro H. hydrochaeris 19 A. sculptum junho/2007 (CNC

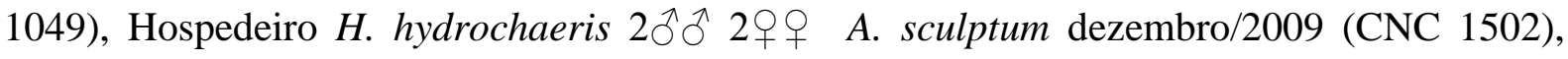

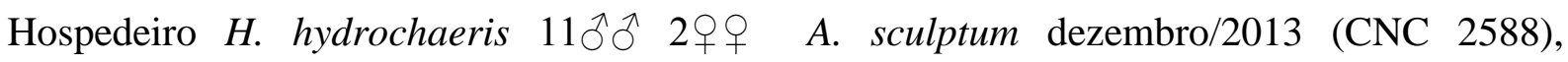

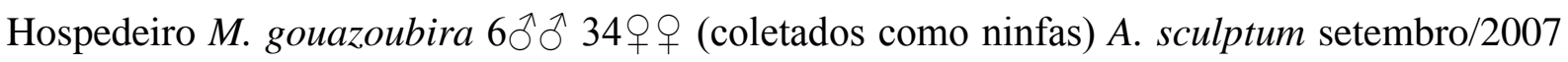

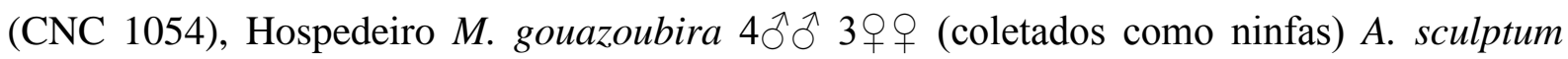
setembro/2007 (CNC 1077), Hospedeiro M. tridactyla 1 ㅇ A. sculptum dezembro/2012 (CNC 2300), Hospedeiro S. villosus 1ठ A. cajennense s. 1. outubro/2007 (CNC 1078); Teodoro

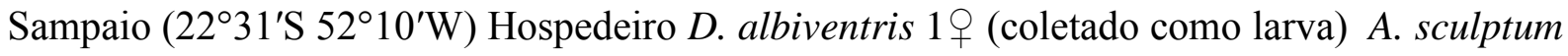
junho/2008 (CNC 1134), Hospedeiro D. azarae 1ठ 2 우 (coletados como ninfas) A. sculptum maio/2002 (CNC 701), Hospedeiro D. azarae $1 q$ (coletado como ninfa) A. sculptum janeiro/2009 (CNC 1366), Hospedeiro D. azarae 1ð (coletado como ninfa) A. cajennense s. 1. agosto/2009 (CNC 1443), Hospedeiro H. sapiens $1 \sigma^{\widehat{A}}$ (coletado como ninfa) A. cajennense s. 1. dezembro/2000 (CNC 611), Hospedeiro L. Pardalis 1ㅇ A. sculptum novembro/1999 (CNC 1439), Hospedeiro P. onca 8 우 A. sculptum julho/2003 (CNC 790), Hospedeiro P. tajacu $1 \widehat{O}^{\lambda}$

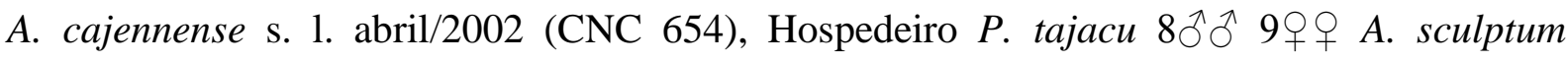
julho/2002 (CNC 753), Hospedeiro P. tajacu $1 ð 1$ 1 9 A. sculptum junho/2002 (CNC 757),

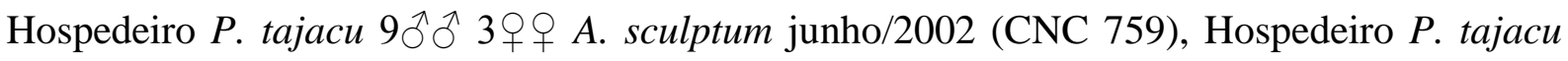

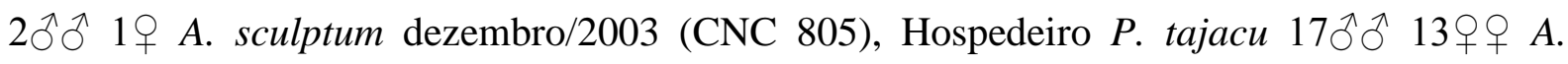
sculptum janeiro/2004 (CNC 856), Hospedeiro P. tajacu 1ð A. cajennense s. 1. julho/2001

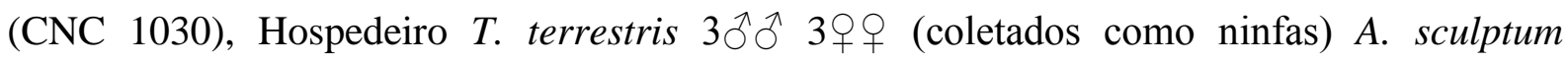

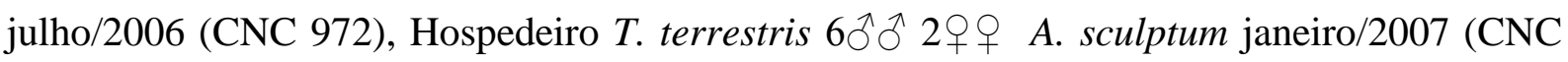

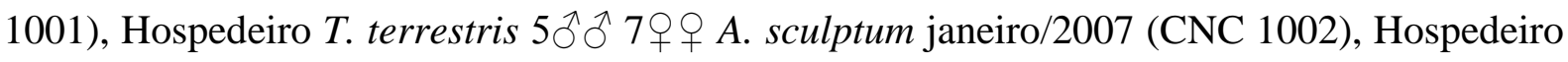

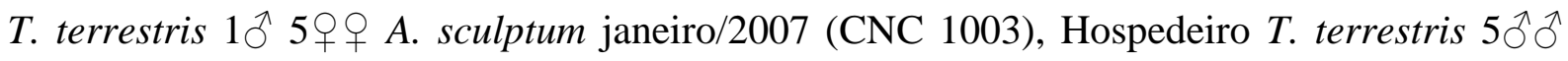

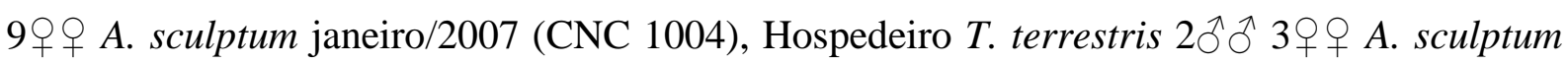

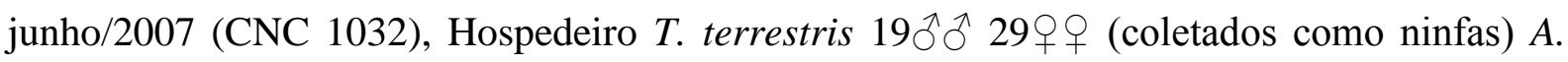

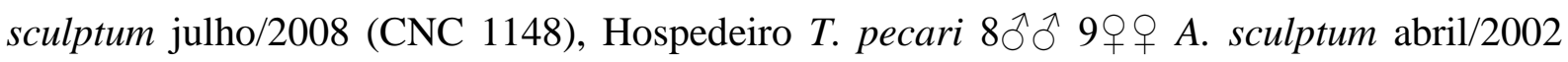
(CNC 653), Hospedeiro T. pecari 1ठ A. cajennense s. 1. maio/2002 (CNC 682), Hospedeiro

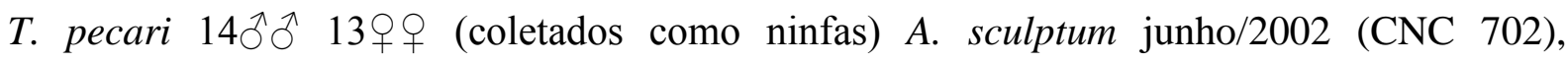
Hospedeiro T. pecari 1 $\delta^{\lambda} 5$ 우 A. sculptum março/2004 (CNC 839), Hospedeiro T. pecari 2 우 (coletados como ninfas) A. sculptum maio/2004 (CNC 850), Hospedeiro T. pecari

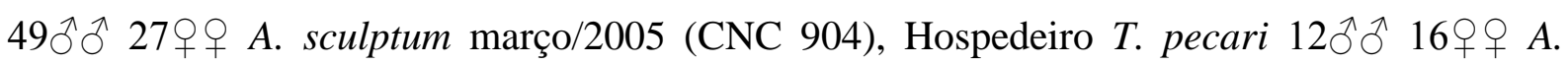

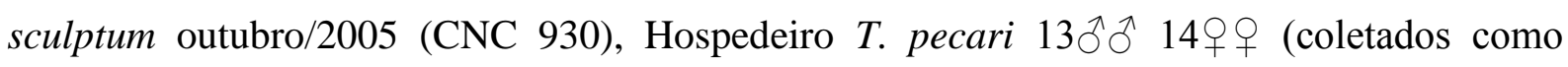

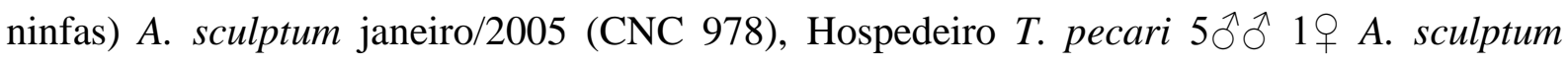
julho/2001 (CNC 1029), Hospedeiro T. pecari $1 \widehat{\jmath} 3 q$ q A. sculptum janeiro/2001 (CNC 
1031), Hospedeiro Vida livre 19 A. sculptum setembro/2000 (CNC 360), Hospedeiro Vida

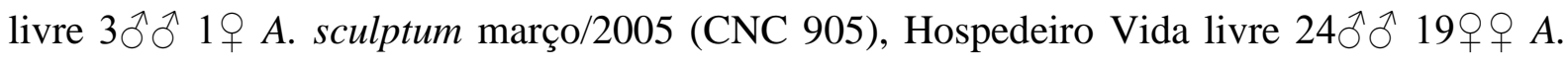

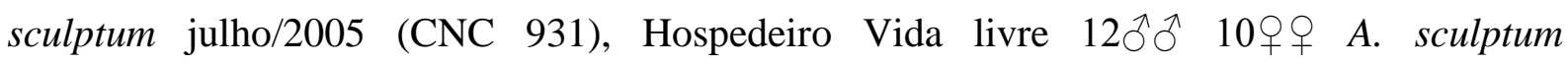

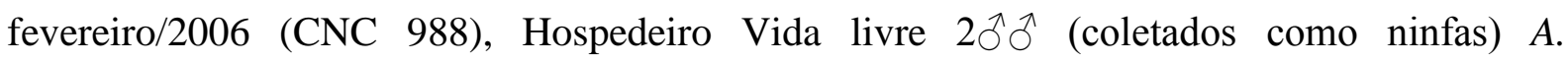
cajennense s. 1. julho/2006 (CNC 1201), Hospedeiro Vida livre $1 \AA 3 q q$ (coletados como

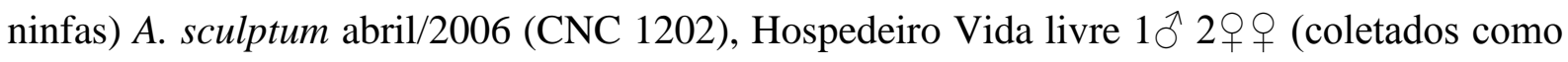
ninfas) A. sculptum novembro/2006 (CNC 1203), Hospedeiro Vida livre 32ふðત 21우 (coletados como ninfas) A. sculptum outubro/2005 (CNC 1206), Hospedeiro Vida livre $23 \hat{\jmath} \widehat{\jmath}$ $29 ㅇ ㅜ$ (coletados como ninfas) A. sculptum agosto/2005 (CNC 1207), Hospedeiro Vida livre

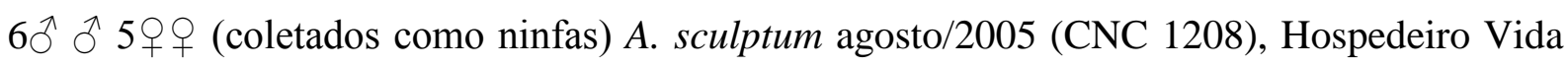

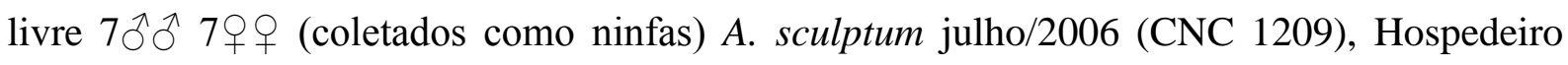
Vida livre 15ふð 21 ○ (coletados como ninfas) A. sculptum outubro/2005 (CNC 1210),

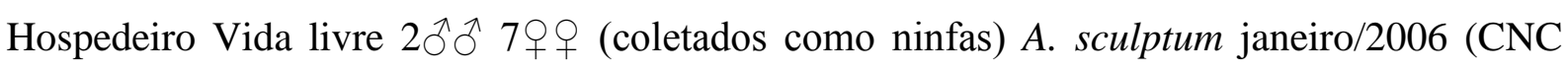
1211), Hospedeiro Vida livre $15 \hat{\jmath} \widehat{\delta} 7 q$ 우 (coletados como ninfas) A. sculptum maio/2005 (CNC 1212), Hospedeiro Vida livre $22 \widehat{\jmath} 8$ ภํ A. sculptum novembro/2006 (CNC 1213), Hospedeiro Vida livre $16 \hat{\jmath} \widehat{\partial} 20 q$ ㅇ (coletados como ninfas) A. sculptum novembro/2006 (CNC 1214), Hospedeiro Vida livre 67우 (coletados como ninfas) A. sculptum agosto/2005

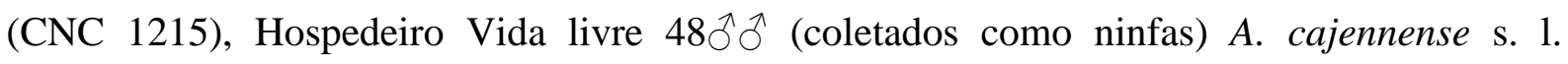
agosto/2005 (CNC 1216), Hospedeiro Vida livre 200ðð (coletados como ninfas) $A$. cajennense s. 1. agosto/2005 (CNC 1218), Hospedeiro Vida livre $222 \widehat{\jmath}$ (coletados como ninfas) A. cajennense s. 1. agosto/2005 (CNC 1219), Hospedeiro Vida livre $200 \circ q$ (coletados como ninfas) A. sculptum agosto/2005 (CNC 1220), Hospedeiro Vida livre $213 q q$ (coletados como ninfas) A. sculptum agosto/2005 (CNC 1221), Hospedeiro Vida livre $66 \hat{\jmath} 8$ 우

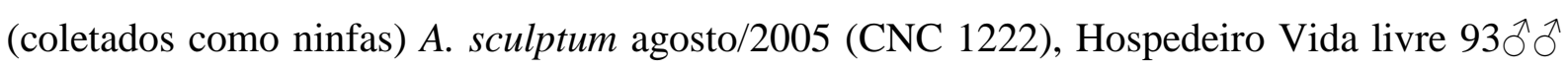
(coletados como ninfas) A. cajennense s. 1. outubro/2005 (CNC 1223), Hospedeiro Vida livre 100 우 (coletados como ninfas) A. sculptum outubro/2005 (CNC 1224), Hospedeiro Vida livre $124 \hat{\jmath}$ (coletados como ninfas) A. cajennense s. 1. outubro/2005 (CNC 1225), Hospedeiro Vida livre 130 + $q$ (coletados como ninfas) A. sculptum outubro/2005 (CNC 1226), Hospedeiro Vida livre $83 \hat{\jmath} \widehat{\partial}$ (coletados como ninfas) A. cajennense s. 1. outubro/2005 (CNC 1227), Hospedeiro Vida livre 899 q (coletados como ninfas) A. sculptum outubro/2005 (CNC 1228), Hospedeiro Vida livre 100 q $q$ (coletados como ninfas) A. sculptum julho/2005 (CNC 1230), Hospedeiro Vida livre 100 우 (coletados como ninfas) A. sculptum julho/2005 (CNC 1231), Hospedeiro Vida livre 120 q $q$ (coletados como ninfas) A. sculptum julho/2005 (CNC 1232), Hospedeiro Vida livre $150 \widehat{\jmath}$ (coletados como ninfas) A. cajennense s. 1. 


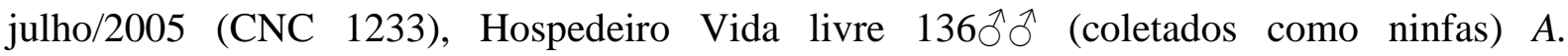
cajennense s. 1. julho/2005 (CNC 1234), Hospedeiro Vida livre 62 $\widehat{\jmath} 47 q$ 우 (coletados como ninfas) A. sculptum setembro/2005 (CNC 1235), Hospedeiro Vida livre 5ふえへ 4ㅇ A. sculptum outubro/2005 (CNC 1236), Hospedeiro Vida livre $6 \hat{\jmath} \widehat{\jmath} 3 q$ (coletados como ninfas) A. sculptum outubro/2005 (CNC 1237), Hospedeiro Vida livre $15 \hat{\jmath} \widehat{\sigma} 34$ 우 (coletados como ninfas) A. sculptum julho/2006 (CNC 1238), Hospedeiro Vida livre $2 \widehat{\jmath} 1$ 1 q A. sculptum abril/2006 (CNC 1239), Hospedeiro Vida livre 1ð̊ (coletados como ninfas) A. cajennense s. 1. junho/2005 (CNC 1240), Hospedeiro Vida livre $5 \hat{\jmath} \widehat{\jmath}$ (coletados como ninfas) A. cajennense s. 1. janeiro/2006 (CNC 1241), Hospedeiro Vida livre $1 \lesssim 38 q \uparrow$ (coletados como ninfas) A. sculptum agosto/2005 (CNC 1242), Hospedeiro Vida livre 15ðð 7 우 (coletados como ninfas) A. sculptum outubro/2005 (CNC 1244), Hospedeiro Vida livre $1 \widehat{\nearrow} A$. cajennense s. 1. julho/2005 (CNC 1246), Hospedeiro Vida livre 41つ̋ ninfas) A. sculptum julho/2005 (CNC 1247), Hospedeiro Vida livre $7 \lesssim ð 12 \uparrow q$ (coletados como ninfas) A. sculptum julho/2006 (CNC 1248), Hospedeiro Vida livre 33ð̋ð 26우 A.

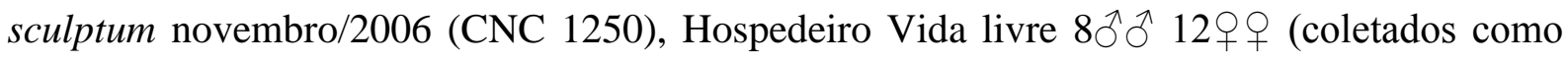
ninfas) A. sculptum novembro/2006 (CNC 1251); Ubatuba $\left(23^{\circ} 26^{\prime} \mathrm{S} 45^{\circ} 4^{\prime} \mathrm{W}\right)$ Hospedeiro Vida livre 1 ô $1 q$ A. sculptum janeiro/2005 (CNC 880). Sul - Paraná: Adrianópolis (24³9'S $48^{\circ} 59^{\prime} \mathrm{W}$ ) Hospedeiro C. familiaris 1 ( (coletado como ninfa) A. sculptum agosto/2012 (CNC

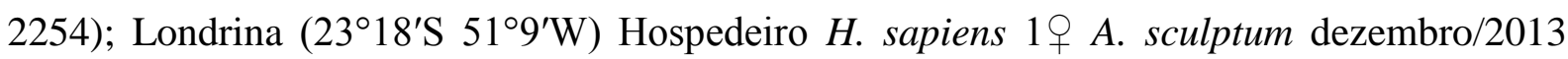

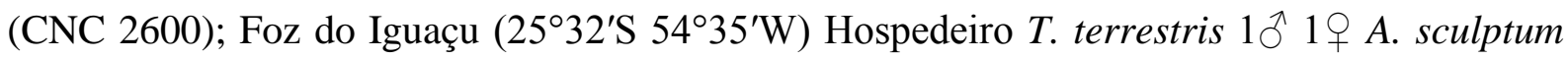

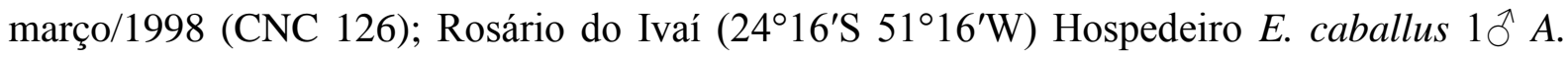
cajennense s. 1. fevereiro/2001 (CNC 441).

\subsection{LOCALIDADES DO MATERIAL DEPOSITADO NA COLEÇÃO IBSP}

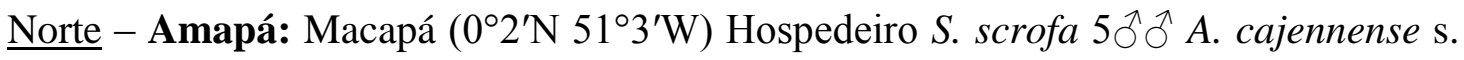

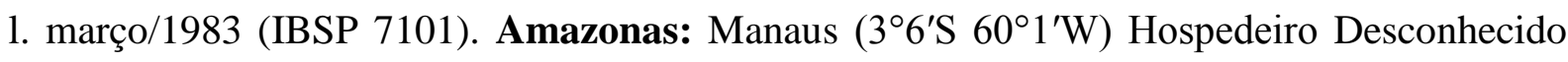
$1 \delta^{\Uparrow}$ A. cajennense s. 1. maio/1955 (IBSP 5732). Pará: Altamira $\left(3^{\circ} 12^{\prime} \mathrm{S} 52^{\circ} 12^{\prime} \mathrm{W}\right)$ Hospedeiro T. terrestris 1 ㅇ A. cajennense s. s. março/1939 (IBSP 1661), Hospedeiro T. terrestris $3 \widehat{\nwarrow}$ 4 우 A. cajennense s. s. março/1939 (IBSP 1665); Belém (1²7'S 48³0’W) Hospedeiro E. caballus $1 \overbrace{}^{\Uparrow} 1 q$ A. sculptum setembro/1998 (IBSP 6860); Canaã dos Carajás (6²9'S $49^{\circ} 52^{\prime} \mathrm{W}$ ) Hospedeiro Vida livre $1 \delta^{\Uparrow}$ A. cajennense s. 1. dezembro/1970 (IBSP 6861); Monte 
Alegre $\left(2^{\circ} 0^{\prime} \mathrm{S} 54^{\circ} 4^{\prime} \mathrm{W}\right)$ Hospedeiro E. caballus $1 \delta^{\Uparrow} 2 q 0$ A. cajennense s. s. agosto/1957 (IBSP 5196), Hospedeiro H. sapiens 1ðึ A. cajennense s. 1. outubro/2007 (IBSP 9895), Hospedeiro H. sapiens $29 \widehat{\jmath} 16$ 우 A. cajennense s. s. agosto/1957 (IBSP 5179), Hospedeiro H. sapiens $4 \hat{\jmath} 8$ 웅 A. cajennense s. s. agosto/1957 (IBSP 5193), Hospedeiro T. terrestris

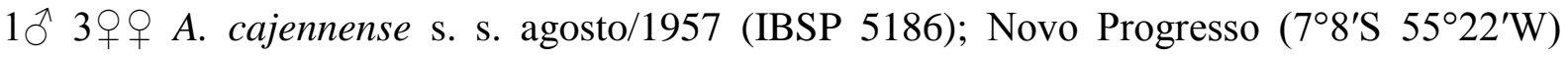
Hospedeiro T. terrestris $2 \widehat{\jmath} 30$ ㅇ A. cajennense s. s. março/1958 (IBSP 5641); Parauapebas $\left(6^{\circ} 4^{\prime} \mathrm{S} 49^{\circ} 54^{\prime} \mathrm{W}\right)$ Hospedeiro Desconhecido $1+$ A. cajennense s. s. setembro/2012 (IBSP 11590), Hospedeiro Desconhecido 1 ㅇ A. cajennense s. s. setembro/2012 (IBSP 11597), Hospedeiro Desconhecido 1ð A. cajennense s. 1. setembro/2012 (IBSP 11600); São Félix do Xingu $\left(6^{\circ} 38^{\prime} \mathrm{S} 51^{\circ} 59^{\prime} \mathrm{W}\right)$ Hospedeiro Chelonoidis denticulata 290 A. cajennense s. s.

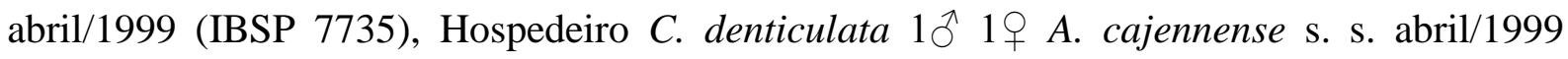
(IBSP 7749), Hospedeiro Vida livre $2 \widehat{\jmath} 19$ A. cajennense s. s. abril/1999 (IBSP 7751);

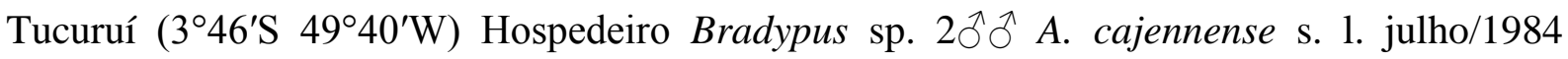
(IBSP 6775), Hospedeiro Desconhecido 1ð^ A. cajennense s. 1. julho/1984 (IBSP 6773), Hospedeiro H. sapiens $1 ð$ A. cajennense s. 1. julho/1984 (IBSP 6755), Hospedeiro H. sapiens

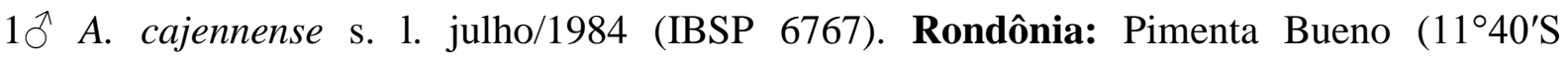
$\left.61^{\circ} 11^{\prime} \mathrm{W}\right)$ Hospedeiro Vida livre 1 ㅇ A. cajennense s. s. julho/2000 (IBSP 7794). Tocantins:

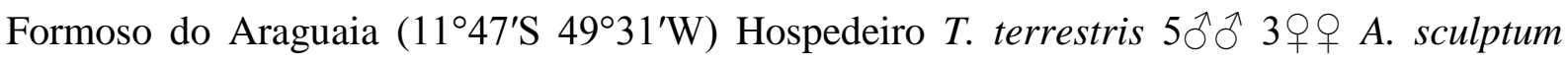
dezembro/1953 (IBSP 4946); Ipueiras $\left(11^{\circ} 14^{\prime} \mathrm{S} 48^{\circ} 27^{\prime} \mathrm{W}\right)$ Hospedeiro Desconhecido $1 \delta^{\lambda} A$.

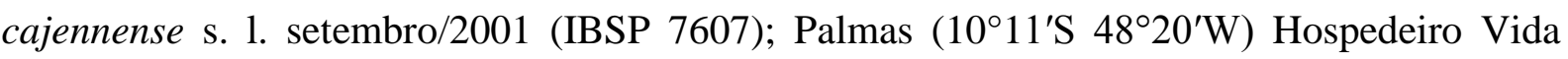
livre $1 \overbrace{}^{\Uparrow} 3$ 우 A. sculptum junho/2001 (IBSP 7349). Nordeste - Bahia: Ilhéus (1447'S $\left.39^{\circ} 2^{\prime} \mathrm{W}\right)$ Hospedeiro Vida livre $1 \delta^{\lambda}$ A. cajennense s. 1. janeiro/1999 (IBSP 7612), Hospedeiro Vida livre 19 A. sculptum janeiro/1999 (IBSP 7614), Hospedeiro Vida livre $1 ð$ A. cajennense

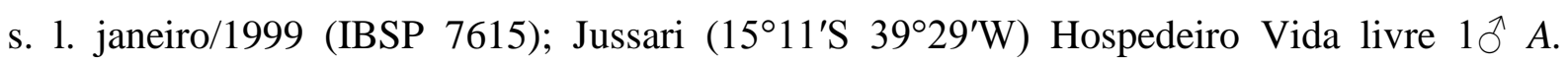

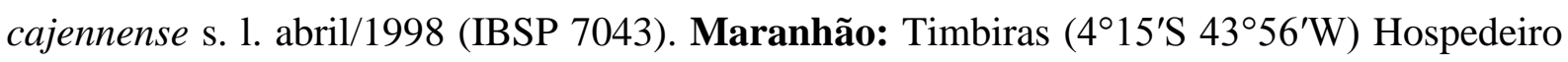
Felis catus $5 \hat{\jmath} 7$ đㅇ A. sculptum fevereiro/1952 (IBSP 4541). Centro-Oeste - Distrito Federal: Brasília $\left(15^{\circ} 47^{\prime} \mathrm{S} 47^{\circ} 52^{\prime} \mathrm{W}\right)$ Hospedeiro H. sapiens 1 ㅇ A. sculptum maio/1998 (IBSP 6895). Goiás: Ceres $\left(15^{\circ} 18^{\prime} \mathrm{S} 49^{\circ} 35^{\prime} \mathrm{W}\right)$ Hospedeiro H. sapiens 1 ㅇ A. sculptum

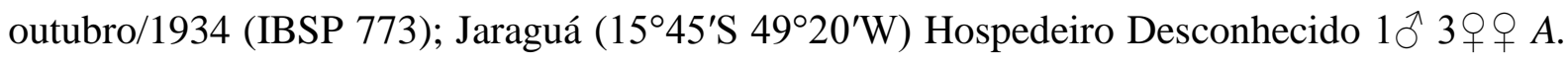

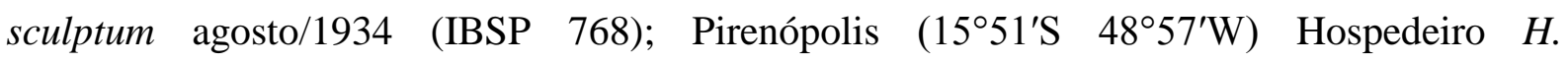
hydrochaeris 4えึึ 9우 A. sculptum maio/1934 (IBSP 769). Mato Grosso: Canarana $\left(13^{\circ} 33^{\prime} \mathrm{S} 52^{\circ} 16^{\prime} \mathrm{W}\right)$ Hospedeiro Vida livre $3 ㅇ$ A. cajennense s. s. dezembro/2000 (IBSP 7627); Cuiabá $\left(15^{\circ} 35^{\prime} \mathrm{S} 56^{\circ} 5^{\prime} \mathrm{W}\right)$ Hospedeiro C. thous $10^{\Uparrow} 1$ q A. sculptum setembro/1952 (IBSP 4598), Hospedeiro Iguana iguana 1 ㅇ A. sculptum abril/1997 (IBSP 7702), Hospedeiro 
M. tridactyla $3 ठ \widehat{ð} 5$ 우 A. sculptum setembro/2006 (IBSP 7703), Hospedeiro T. terrestris

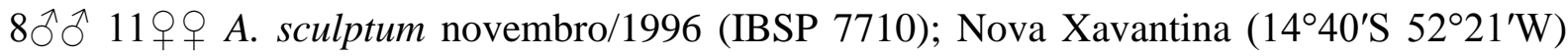
Hospedeiro C. familiaris $8 \hat{\jmath} \widehat{\partial} 14+q$ 우 (coletados como ninfas) A. cajennense s. $\mathrm{s}$. setembro/1969 (IBSP 5950), Hospedeiro T. terrestris 5ðð $3 q+q$ A. cajennense s. s. fevereiro/1952 (IBSP 3867); Reserva do Cabaçal $\left(15^{\circ} 4^{\prime} \mathrm{S} 58^{\circ} 27^{\prime} \mathrm{W}\right)$ Hospedeiro H. sapiens

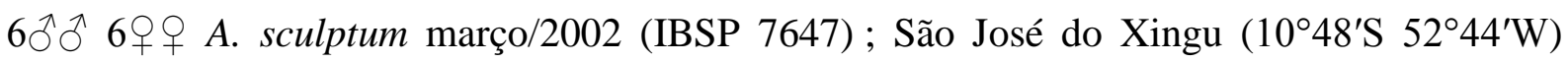
Hospedeiro C. familiaris 1 ㅇ (coletado como ninfa) A. cajennense s. s. outubro/1969 (IBSP

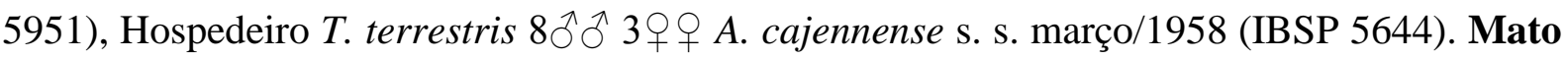

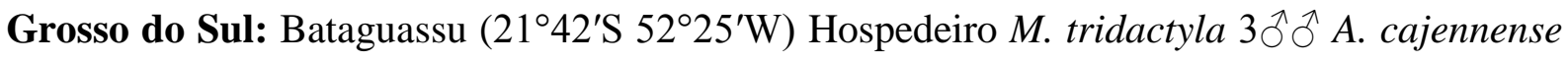

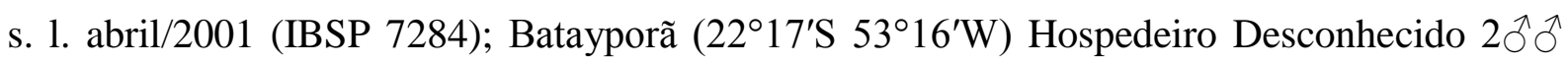
1 우 A. sculptum fevereiro/2001 (IBSP 7308); Bonito $\left(21^{\circ} 7^{\prime} \mathrm{S} 56^{\circ} 28^{\prime} \mathrm{W}\right)$ Hospedeiro Vida livre

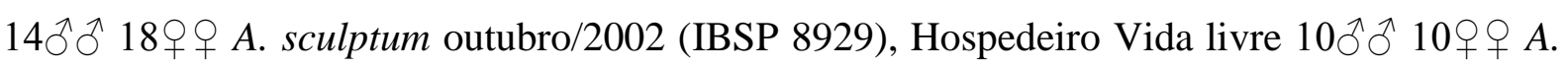
sculptum outubro/2002 (IBSP 8930), Hospedeiro Vida livre $1 \hat{\sigma} 10$ \% outubro/2002 (IBSP 8931), Hospedeiro Vida livre 14ðึ̋ 12 우 A. sculptum outubro/2002

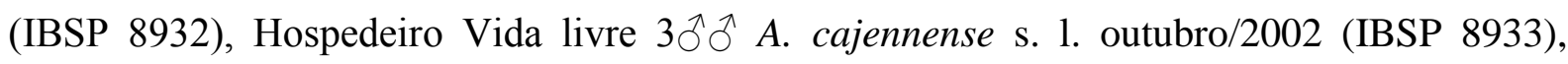
Hospedeiro Vida livre $5 \widehat{\jmath} 3$ ภํ A. sculptum outubro/2002 (IBSP 8934); Campo Grande $\left(20^{\circ} 26^{\prime} \mathrm{S} 54^{\circ} 38^{\prime} \mathrm{W}\right)$ Hospedeiro Desconhecido $1 \overbrace{}^{\Uparrow}$ A. cajennense s. 1. julho/1995 (IBSP 7585), Hospedeiro D. albiventris 19 A. sculptum julho/1997 (IBSP 6888); Corumbá $\left(19^{\circ} 0^{\prime} \mathrm{S}\right.$ $\left.57^{\circ} 39^{\prime} \mathrm{W}\right)$ Hospedeiro Desconhecido 1ðึ A. cajennense s. 1. maio/1999 (IBSP 7419), Hospedeiro E. caballus $1 \overbrace{}^{\Uparrow} 4$ 우 A. sculptum janeiro/1998 (IBSP 7030), Hospedeiro $H$.

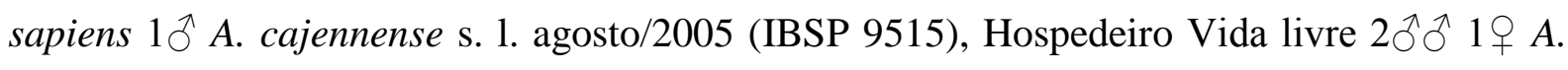
sculptum junho/1998 (IBSP 6919), Hospedeiro Vida livre 1 ㅇ A. sculptum novembro/1998 (IBSP 7416), Hospedeiro Vida livre 1ð A. cajennense s. 1. janeiro/2000 (IBSP 7631), Hospedeiro Vida livre $1 \widehat{\circlearrowleft}$ A. cajennense s. 1. janeiro/2000 (IBSP 7632), Hospedeiro Vida livre $1 \lesssim$ A. cajennense s. 1. janeiro/2000 (IBSP 7633), Hospedeiro Vida livre 19 A. sculptum janeiro/2000 (IBSP 7634), Hospedeiro Vida livre 1ð A. cajennense s. 1. janeiro/2000 (IBSP 7635), Hospedeiro Vida livre 1ð A. cajennense s. 1. agosto/2005 (IBSP 9513); Coxim $\left(18^{\circ} 30^{\prime} \mathrm{S} 54^{\circ} 45^{\prime} \mathrm{W}\right)$ Hospedeiro Desconhecido 1 ㅇ A. sculptum junho/1952 (IBSP 4532); Ivinhema $\left(22^{\circ} 18^{\prime} \mathrm{S} 53^{\circ} 48^{\prime} \mathrm{W}\right)$ Hospedeiro Vida livre $1{ }^{\Uparrow}$ A. cajennense s. 1. janeiro/2004 (IBSP

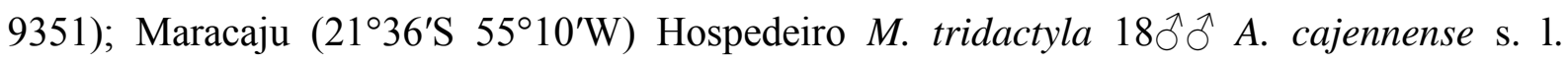

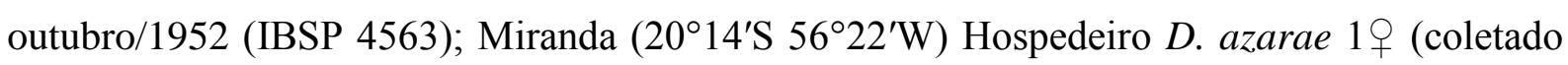
como ninfa) A. sculptum agosto/1952 (IBSP 4542), Hospedeiro T. tetradactyla 9 ふぇ 18 우 A. sculptum setembro/1952 (IBSP 4557), Hospedeiro T. tetradactyla $1 \hat{\jmath}$ A. cajennense s. 1. setembro/1952 (IBSP 4570), Hospedeiro T. tetradactyla 1 q (coletado como ninfa) $A$. 
sculptum setembro/1952 (IBSP 4581); Ponta Porã $\left(22^{\circ} 32^{\prime} \mathrm{S} 55^{\circ} 43^{\prime} \mathrm{W}\right)$ Hospedeiro $T$. tetradactyla 1 우 A. sculptum setembro/1952 (IBSP 4549); Porto Murtinho (21 ${ }^{\circ} 41^{\prime} \mathrm{S} 57^{\circ} 52^{\prime} \mathrm{W}$ ) Hospedeiro T. terrestris $21 ð ð 21 ㅇ$ ㅇ A. sculptum outubro/1952 (IBSP 4962); Ribas do Rio Pardo $\left(20^{\circ} 26^{\prime} \mathrm{S} 53^{\circ} 45^{\prime} \mathrm{W}\right)$ Hospedeiro M. tridactyla $14 \overbrace{}^{\lambda}{ }^{\wedge} 1$ 우 A. sculptum outubro/1952 (IBSP 4544), Hospedeiro M. tridactyla 14ðึ A. cajennense s. 1. outubro/1952 (IBSP 4546),

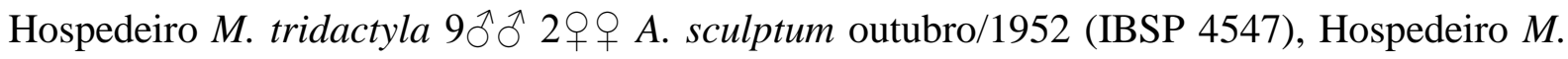
tridactyla $4 \hat{\jmath} \widehat{o} 1$ ㅇ A. sculptum setembro/1952 (IBSP 4554), Hospedeiro M. tridactyla $5 \hat{\jmath} \widehat{\sigma}$

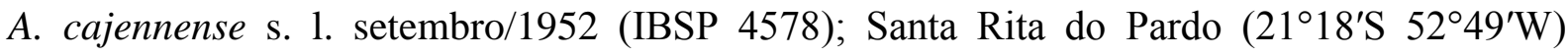
Hospedeiro Vida livre $1 \overbrace{}^{\Uparrow}$ A. cajennense s. 1. abril/2001 (IBSP 7479); Três Lagoas $\left(20^{\circ} 45^{\prime} \mathrm{S}\right.$ $51^{\circ} 40^{\prime} \mathrm{W}$ ) Hospedeiro T. terrestris $2 \widehat{\jmath}$ A. cajennense s. 1. janeiro/1952 (IBSP 4509). Sudeste

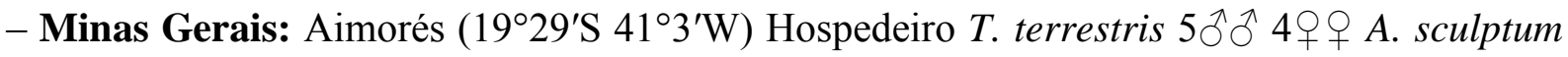
agosto/1950 (IBSP 4436); Além Paraíba (2153'S 4242’W) Hospedeiro Didelphis aurita $9 \widehat{\jmath} \widehat{0} 7$ 우우 (coletados como ninfas) A. sculptum outubro/1955 (IBSP 3843); Araguari

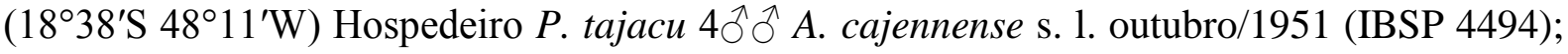

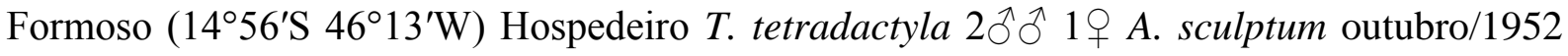
(IBSP 4582); Itabirito $\left(20^{\circ} 15^{\prime} \mathrm{S} 43^{\circ} 48^{\prime} \mathrm{W}\right)$ Hospedeiro Vida livre $1 q$ A. sculptum abril/2007 (IBSP 9873); Juatuba $\left(19^{\circ} 57^{\prime} \mathrm{S} 44^{\circ} 20^{\prime} \mathrm{W}\right)$ Hospedeiro $H$. sapiens $1 \widehat{O}^{\lambda}$ A. cajennense s. 1.

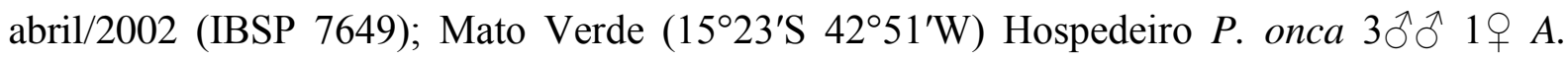

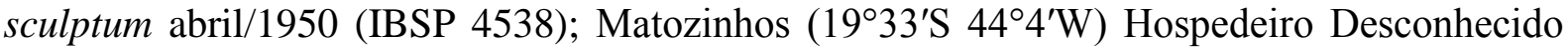
$1 \delta^{\wedge}$ A. cajennense s. 1. março/2013 (IBSP 11602); Morada Nova de Minas (18 $36^{\prime} \mathrm{S} 45^{\circ} 21^{\prime} \mathrm{W}$ ) Hospedeiro Desconhecido $1 \overbrace{}^{\Uparrow} 1 q$ A. sculptum janeiro/2009 (IBSP 10848); Ouro Preto $\left(20^{\circ} 23^{\prime} \mathrm{S} 43^{\circ} 30^{\prime} \mathrm{W}\right)$ Hospedeiro Desconhecido 1 ㅇ A. sculptum janeiro/2000 (IBSP 7640); Santa Helena de Minas (16 $\left.58^{\prime} \mathrm{S} 40^{\circ} 41^{\prime} \mathrm{W}\right)$ Hospedeiro Coendou prehensilis 19 A. sculptum

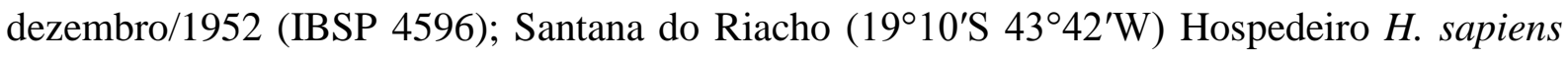
$1{ }^{\top}$ A. cajennense s. 1. setembro/2006 (IBSP 9848); São João del-Rei $\left(21^{\circ} 8^{\prime} \mathrm{S} 44^{\circ} 15^{\prime} \mathrm{W}\right)$ Hospedeiro Crax blumenbachii 1ㅇ A. sculptum dezembro/1937 (IBSP 1212), Hospedeiro Desconhecido 1 A. sculptum janeiro/1940 (IBSP 1862), Hospedeiro F. catus 1 $A$. sculptum dezembro/1937 (IBSP 1213), Hospedeiro H. hydrochaeris $1 \delta^{\Uparrow} 1$ A A. sculptum novembro/1937 (IBSP 1206), Hospedeiro H. hydrochaeris 4§ึ A. cajennense s. 1. maio/1938 (IBSP 1656), Hospedeiro H. hydrochaeris $7 \widehat{\jmath} \hat{\jmath} 1 q$ A. sculptum março/1939 (IBSP 1660), Hospedeiro T. terrestris $3 \widehat{\jmath} 6$ 우 A. sculptum novembro/1937 (IBSP 1209), Hospedeiro T. terrestris 5ㅇ A. sculptum março/1939 (IBSP 1659), Hospedeiro T. terrestris $29 q$ A. sculptum março/1939 (IBSP 1668); São Romão (16²2'S 454’W) Hospedeiro T. terrestris $2 \widehat{\jmath}$ A. cajennense s. 1. abril/1939 (IBSP 1893); Taiobeiras $\left(15^{\circ} 48^{\prime} \mathrm{S} 42^{\circ} 13^{\prime} \mathrm{W}\right)$ Hospedeiro 
Vida livre 19 A. sculptum abril/2002 (IBSP 9932). Rio de Janeiro: Campos dos Goytacazes $\left(21^{\circ} 45^{\prime} \mathrm{S} 41^{\circ} 19^{\prime} \mathrm{W}\right)$ Hospedeiro Bradypus torquatus 1 ㅇ A. sculptum fevereiro/1991 (IBSP 7309); Parati $\left(23^{\circ} 13^{\prime} \mathrm{S} 44^{\circ} 42^{\prime} \mathrm{W}\right)$ Hospedeiro Desconhecido $1 \delta^{\lambda}$ A. cajennense s. 1. agosto/2006 (IBSP 9755); Resende $\left(22^{\circ} 28^{\prime} \mathrm{S} 44^{\circ} 26^{\prime} \mathrm{W}\right)$ Hospedeiro H. sapiens $3 \widehat{\sigma}^{\Uparrow} 1$ ㅇ A. sculptum setembro/1950 (IBSP 4439), Hospedeiro Vida livre 19 A. sculptum abril/1995 (IBSP 7587); Rio de Janeiro $\left(22^{\circ} 54^{\prime} \mathrm{S} 43^{\circ} 12^{\prime} \mathrm{W}\right)$ Hospedeiro Desconhecido $1 \bigcirc^{\Uparrow} 1 q A$. sculptum novembro/1938 (IBSP 1534), Hospedeiro E. caballus $1 \delta^{\lambda}$ A. cajennense s. 1. janeiro/1930 (IBSP 842); Seropédica $\left(22^{\circ} 44^{\prime} \mathrm{S} 43^{\circ} 42^{\prime} \mathrm{W}\right)$ Hospedeiro E. caballus $1 \delta^{\Uparrow} A$. cajennense s. 1. junho/2003 (IBSP 8748), Hospedeiro E. caballus 1ð A. cajennense s. 1. junho/2003 (IBSP 8751), Hospedeiro E. caballus 2 q 9 A. sculptum outubro/2000 (IBSP 7107). São Paulo: Águas da Prata (21 $\left.{ }^{\circ} 56^{\prime} \mathrm{S} 46^{\circ} 43^{\prime} \mathrm{W}\right)$ Hospedeiro H. sapiens 1 ㅇ A. sculptum julho/2004 (IBSP 9062), Hospedeiro Vida livre 1 q A. sculptum agosto/2000 (IBSP 7065), Hospedeiro Vida livre 1 q A. sculptum março/2003 (IBSP 8757); Águas de São Pedro

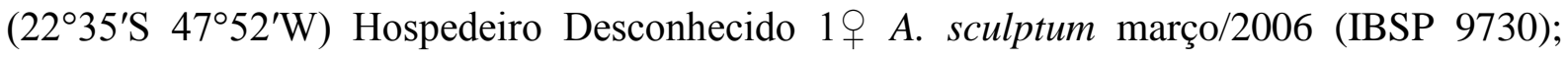
Álvares Machado $\left(22^{\circ} 4^{\prime} \mathrm{S} 51^{\circ} 28^{\prime} \mathrm{W}\right)$ Hospedeiro C. familiaris $3 \hat{\partial} \widehat{\partial}$ A. cajennense s. 1.

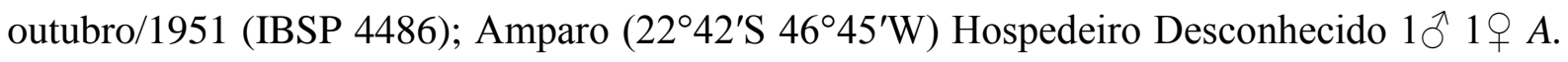
sculptum março/2004 (IBSP 8941); Araçariguama $\left(23^{\circ} 26^{\prime} \mathrm{S} 47^{\circ} 3^{\prime} \mathrm{W}\right)$ Hospedeiro E. caballus

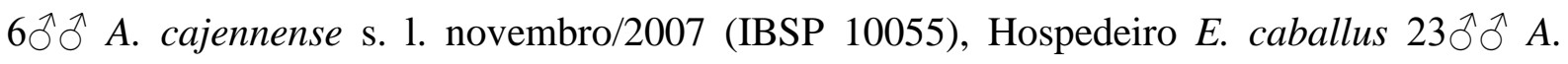
cajennense s. 1. novembro/2007 (IBSP 10056); Araraquara $\left(21^{\circ} 47^{\prime} \mathrm{S} 48^{\circ} 10^{\prime} \mathrm{W}\right)$ Hospedeiro Desconhecido $1 \delta^{\Uparrow}$ A. cajennense s. 1. janeiro/2010 (IBSP 10379); Atibaia (23ำ'S 46 $33^{\prime} \mathrm{W}$ ) Hospedeiro Desconhecido 4우 A. sculptum novembro/1953 (IBSP 4944), Hospedeiro E.

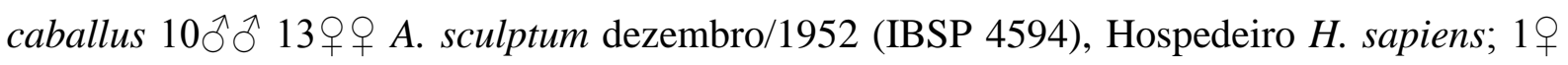
A. sculptum outubro/2001 (IBSP 7451), Hospedeiro Ovis aries; $5 \hat{\jmath}$ 5 q $ᄋ$ A. sculptum dezembro/1952 (IBSP 4595); Avaré (235'S 4855'W) Hospedeiro Rhynchotus rufescens

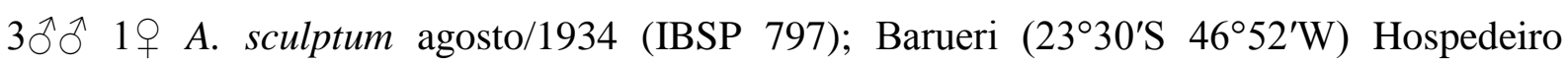
Desconhecido 1 q A. sculptum junho/2006 (IBSP 9753), Hospedeiro Desconhecido 1 우․ sculptum setembro/2007 (IBSP 10444), Hospedeiro Desconhecido $1 \circlearrowleft^{\Uparrow} 19$ A. sculptum

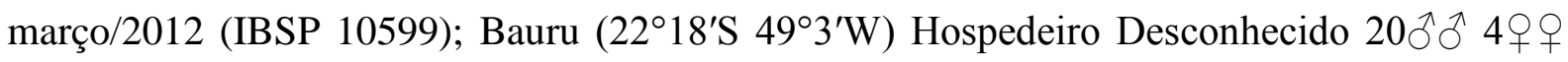
A. sculptum fevereiro/1942 (IBSP 4283); Bebedouro (2056'S 48 $28^{\prime} \mathrm{W}$ ) Hospedeiro $P$. concolor 2 우 A. sculptum maio/1952 (IBSP 4521), Hospedeiro Sapajus nigritus $1 \hat{\sigma}$ A. cajennense s. 1. outubro/1950 (IBSP 4451); Botucatu $\left(22^{\circ} 53^{\prime} \mathrm{S} 48^{\circ} 26^{\prime} \mathrm{W}\right.$ ) Hospedeiro Desconhecido $3 ㅇ$ A. sculptum fevereiro/1942 (IBSP 4418), Hospedeiro H. hydrochaeris;

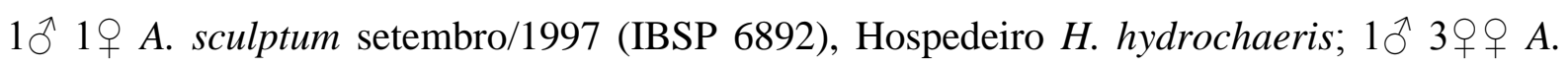
sculptum setembro/1997 (IBSP 6896), Hospedeiro H. hydrochaeris; $1 \overbrace{}^{\Uparrow}$ A. cajennense s. 1. 


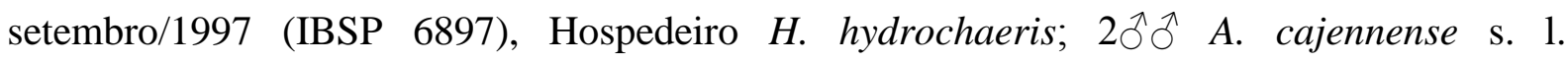
setembro/1997 (IBSP 6898), Hospedeiro H. hydrochaeris; $1 \overbrace{}^{\lambda} 3 q+A^{\prime}$. sculptum setembro/1997 (IBSP 6899), Hospedeiro H. hydrochaeris; $1 \sigma^{\lambda}$ A. cajennense s. 1. setembro/1997 (IBSP 6900), Hospedeiro H. hydrochaeris; $3 \hat{\jmath} \hat{~ A . ~ c a j e n n e n s e ~ s . ~} 1$. setembro/1997 (IBSP 6901); Bragança Paulista (2257'S 46³2’W) Hospedeiro Desconhecido $1 \lesssim$ A. cajennense s. 1. novembro/2006 (IBSP 9791), Hospedeiro H. sapiens $1 \circlearrowleft$ A. cajennense

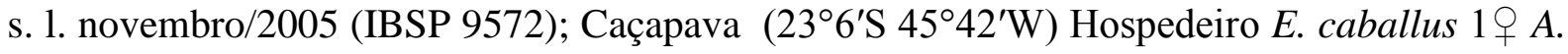

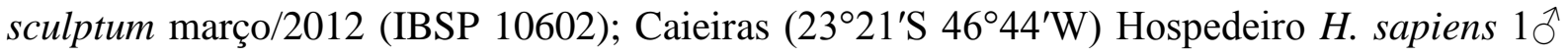
A. cajennense s. 1. novembro/2005 (IBSP 9588), Hospedeiro H. sapiens 1 \% A. sculptum novembro/2005 (IBSP 9589); Caraguatatuba (233 $\left.37^{\prime} \mathrm{S} 45^{\circ} 24^{\prime} \mathrm{W}\right)$ Hospedeiro H. sapiens 1 q A. sculptum dezembro/2005 (IBSP 9595), Hospedeiro H. sapiens 3ðえ 10 우 A. sculptum

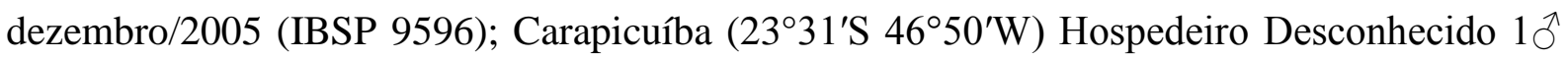
A. cajennense s. 1. maio/2013 (IBSP 11245), Hospedeiro H. sapiens 1 ㅇ A. sculptum novembro/2005 (IBSP 9551); Casa Branca $\left(21^{\circ} 46^{\prime} \mathrm{S}\right.$ 47 $\left.5^{\circ} \mathrm{W}\right)$ Hospedeiro Desconhecido

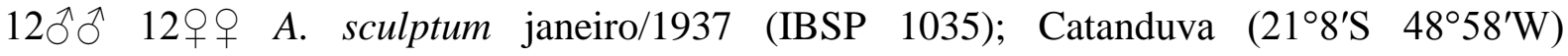
Hospedeiro H. sapiens 1 A. sculptum dezembro/2005 (IBSP 9611); Charqueada $\left(22^{\circ} 30^{\prime} \mathrm{S}\right.$ $\left.47^{\circ} 46^{\prime} \mathrm{W}\right)$ Hospedeiro Vida livre 19 A. sculptum maio/1995 (IBSP 6941); Colina (2042'S

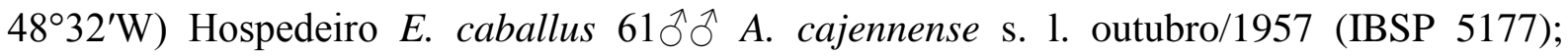
Conchas $\left(23^{\circ} 0^{\prime} \mathrm{S} 48^{\circ} 0^{\prime} \mathrm{W}\right)$ Hospedeiro M. tridactyla $1 \bigcirc^{\top}$ A. cajennense s. 1 . outubro/1952

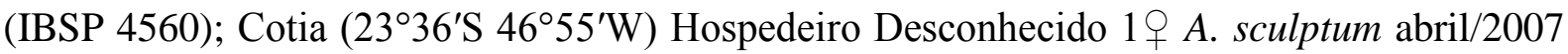
(IBSP 9811), Hospedeiro E. sexcinctus 1 q A. sculptum janeiro/1973 (IBSP 9253), Hospedeiro

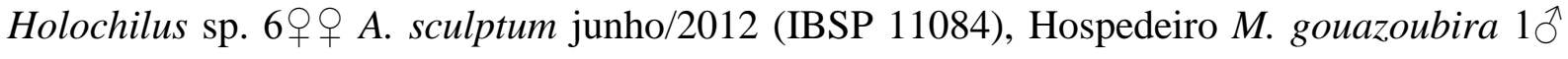
2 우 A. sculptum outubro/1934 (IBSP 839); Embu-Guaçu (2349'S 4648’W) Hospedeiro Desconhecido $1 \hat{\sigma}$ A. cajennense s. 1. dezembro/2012 (IBSP 11122), Hospedeiro H. sapiens 1 A. sculptum janeiro/2010 (IBSP 10374); Francisco Morato $\left(23^{\circ} 16^{\prime} \mathrm{S} 46^{\circ} 44^{\prime} \mathrm{W}\right)$ Hospedeiro H. sapiens 1 ㅇ A. sculptum novembro/2005 (IBSP 9548), Hospedeiro H. sapiens 1 우 A. sculptum novembro/2005 (IBSP 9549), Hospedeiro $H$. sapiens 1 우 A. sculptum

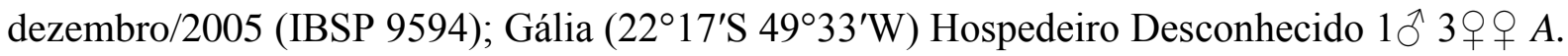

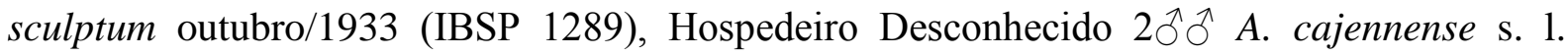

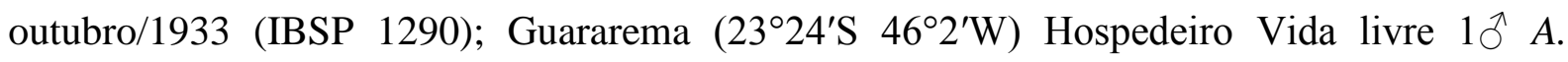
cajennense s. 1. fevereiro/2002 (IBSP 7482); Guarulhos $\left(23^{\circ} 27^{\prime} \mathrm{S} 46^{\circ} 31^{\prime} \mathrm{W}\right)$ Hospedeiro

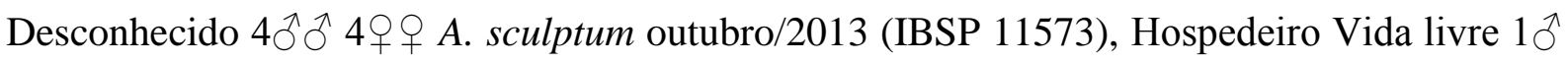
A. cajennense s. 1. setembro/2001 (IBSP 7427); Herculândia $\left(22^{\circ} 0^{\prime} \mathrm{S} 50^{\circ} 23^{\prime} \mathrm{W}\right)$ Hospedeiro $B$.

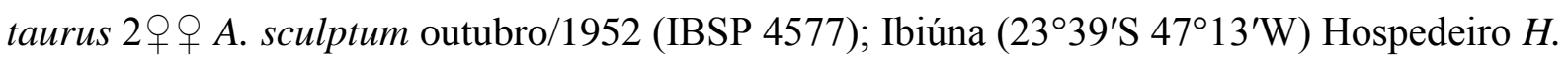


sapiens 49 ㅇ A. sculptum dezembro/2005 (IBSP 9606); Igaratá (2312'S 469’W) Hospedeiro Desconhecido $1 \overbrace{}^{\lambda} A$. cajennense s. 1. novembro/2007 (IBSP 9788); Iporanga $\left(24^{\circ} 35^{\prime} \mathrm{S}\right.$ $48^{\circ} 35^{\prime} \mathrm{W}$ ) Hospedeiro Desconhecido 1 + A. sculptum março/2006 (IBSP 9734); Itapetininga (233'ㄴ $\left.48^{\circ} 3^{\prime} \mathrm{W}\right)$ Hospedeiro H. sapiens 19 A. sculptum fevereiro/2006 (IBSP 9625); Itapevi

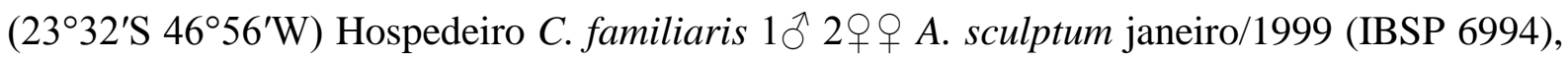
Hospedeiro Desconhecido 1q A. sculptum novembro/1999 (IBSP 7176), Hospedeiro D. aurita 19 A. sculptum novembro/1999 (IBSP 7235), Hospedeiro E. caballus $1 \hat{\jmath} A$. cajennense s. 1. outubro/2000 (IBSP 7216), Hospedeiro Vida livre $1+$ A. sculptum janeiro/2000 (IBSP 7073), Hospedeiro Vida livre 1ðત A. cajennense s. 1. dezembro/1999 (IBSP 7178); Itapura $\left(20^{\circ} 38^{\prime} \mathrm{S} 51^{\circ} 30^{\prime} \mathrm{W}\right)$ Hospedeiro Mazama americana $9 \widehat{\jmath} \widehat{\widehat{O}} 13$ 우 A.

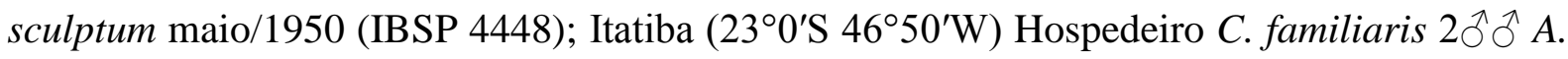
cajennense s. 1. julho/2011 (IBSP 10557), Hospedeiro Desconhecido $1 \widehat{\jmath}$ A. cajennense s. 1. abril/2007 (IBSP 9824); Itirapina $\left(22^{\circ} 15^{\prime} \mathrm{S} 47^{\circ} 49^{\prime} \mathrm{W}\right)$ Hospedeiro Desconhecido $1 \delta^{\lambda} A$. cajennense s. 1. dezembro/2000 (IBSP 9056); Itú $\left(23^{\circ} 15^{\prime} \mathrm{S} 47^{\circ} 17^{\prime} \mathrm{W}\right)$ Hospedeiro Desconhecido $1 \delta^{\lambda} A$. cajennense s. 1. maio/2005 (IBSP 10035); Itupeva $\left(23^{\circ} 9^{\prime} \mathrm{S} 47^{\circ} 3^{\prime} \mathrm{W}\right.$ ) Hospedeiro Desconhecido 1 ㅇ A. sculptum janeiro/2009 (IBSP 10470); Jundiaí (231'S

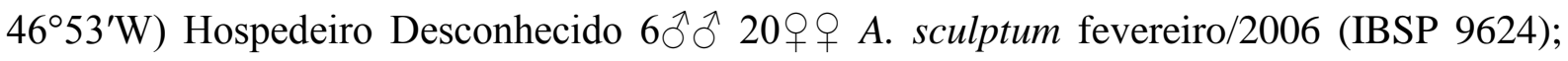

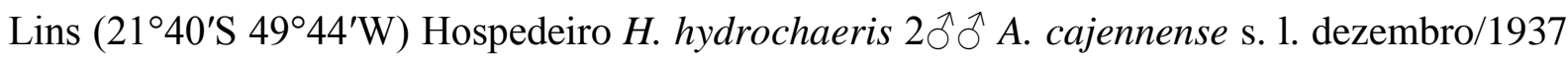

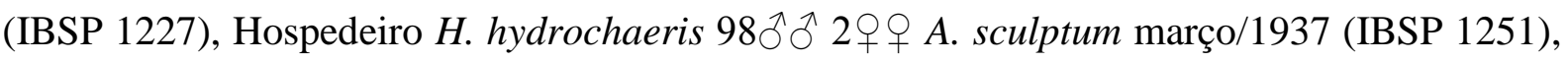

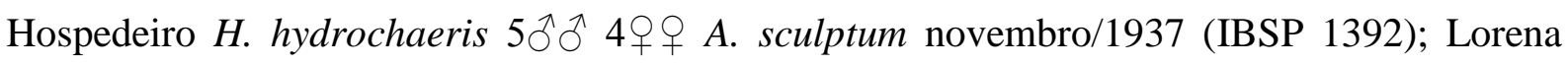
$\left(22^{\circ} 43^{\prime} \mathrm{S} 45^{\circ} 7^{\prime} \mathrm{W}\right)$ Hospedeiro Desconhecido $3 \widehat{\jmath}$ ふૈ 1 ㅇ A. sculptum abril/1937 (IBSP 1087);

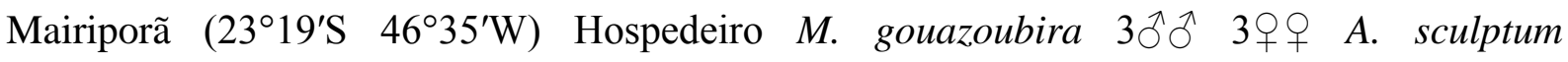

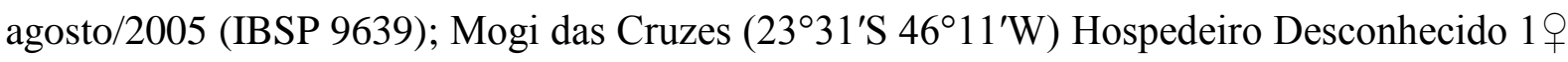
A. sculptum janeiro/2010 (IBSP 10382), Hospedeiro Vida livre 19 A. sculptum janeiro/1940 (IBSP 1871); Mogi Guaçu $\left(22^{\circ} 22^{\prime} \mathrm{S} 46^{\circ} 56^{\prime} \mathrm{W}\right)$ Hospedeiro E. caballus $1 \delta^{\Uparrow}$ A. cajennense s. 1.

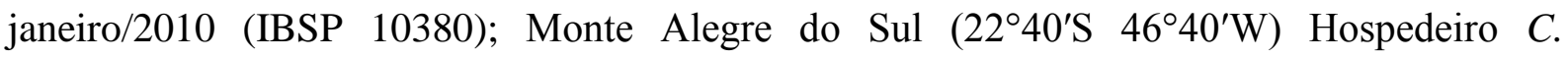
familiaris 1 ㅇ A. sculptum junho/2002 (IBSP 8915); Osasco (2331'S 46 $47^{\circ} \mathrm{W}$ ) Hospedeiro Desconhecido $1 \hat{O}$ A. cajennense s. 1. abril/2006 (IBSP 9739), Hospedeiro H. sapiens 1 ㅇ A.

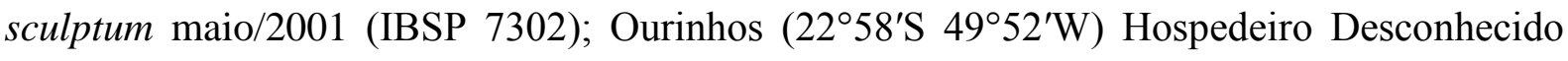
$1{ }^{\Uparrow}$ A. cajennense s. 1. outubro/1999 (IBSP 7153); Penápolis $\left(21^{\circ} 25^{\prime} \mathrm{S} 50^{\circ} 4^{\prime} \mathrm{W}\right)$ Hospedeiro $T$.

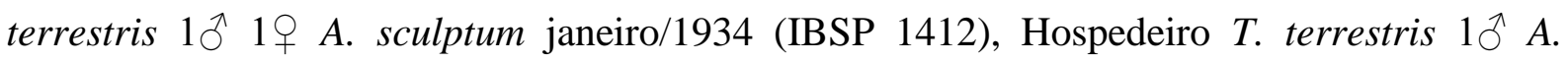
cajennense s. 1. janeiro/1934 (IBSP 1724), Hospedeiro T. terrestris 10우 A. sculptum

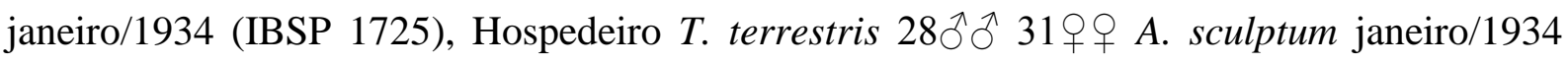
(IBSP 1726); Pindamonhangaba $\left(22^{\circ} 55^{\prime} \mathrm{S} 45^{\circ} 27^{\prime} \mathrm{W}\right)$ Hospedeiro C. familiaris $1 \circ$ A A sculptum 
dezembro/1934 (IBSP 840), Hospedeiro Vida livre 19 A. sculptum maio/1998 (IBSP 6940), Hospedeiro Vida livre 1 $\bigcirc^{\Uparrow}$ A. cajennense s. 1. setembro/1995 (IBSP 6952); Piracicaba (2243'S $47^{\circ} 38^{\prime} \mathrm{W}$ ) Hospedeiro H. hydrochaeris $29 \bigcirc^{\nwarrow}$ A. cajennense s. 1. dezembro/2005 (IBSP 9881),

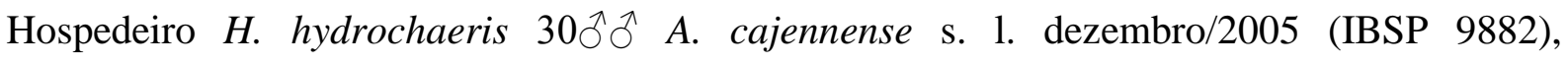

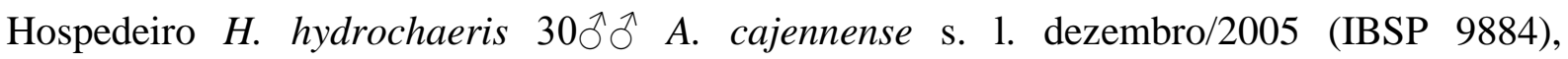
Hospedeiro H. hydrochaeris 21 q 9 A. sculptum dezembro/2005 (IBSP 9885), Hospedeiro $H$. hydrochaeris $25 \hat{\jmath}$ A. cajennense s. 1. dezembro/2005 (IBSP 9886), Hospedeiro $H$. hydrochaeris 60ภิ A cajennense s. 1. dezembro/2005 (IBSP 9888), Hospedeiro $H$. hydrochaeris 30 우 A. sculptum dezembro/2005 (IBSP 9889); Presidente Epitácio (214ㄴ'S $\left.52^{\circ} 6^{\prime} \mathrm{W}\right)$ Hospedeiro Desconhecido $1 q$ A. sculptum janeiro/1999 (IBSP 7002); Ribeirão Pires $\left(23^{\circ} 42^{\prime} \mathrm{S} 46^{\circ} 24^{\prime} \mathrm{W}\right)$ Hospedeiro S. scrofa $1 \delta^{\Uparrow} 1$ ㅇ A. sculptum novembro/1939 (IBSP 1801);

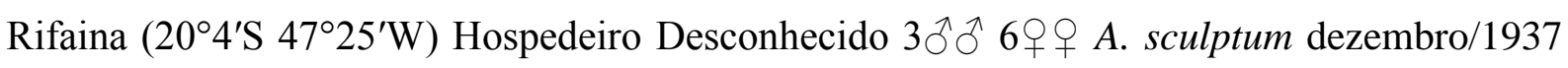

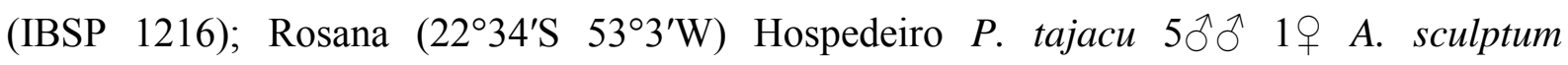

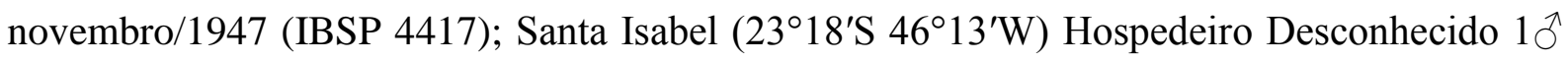
A. cajennense s. 1. março/2008 (IBSP 10418), Hospedeiro Desconhecido $1 q$ A. sculptum agosto/2007 (IBSP 10425), Hospedeiro Vida livre 1ð A. cajennense s. 1. outubro/1996 (IBSP 6951), Hospedeiro Vida livre $1 ð$ A. cajennense s. 1. outubro/1996 (IBSP 6954), Hospedeiro Vida livre $1 \delta^{\Uparrow} A$. cajennense s. 1. outubro/1996 (IBSP 6955); Santana de Parnaíba $\left(23^{\circ} 26^{\prime} \mathrm{S}\right.$ $\left.46^{\circ} 55^{\prime} \mathrm{W}\right)$ Hospedeiro Desconhecido $10^{\Uparrow} 1$ ㅅ A. sculptum novembro/2012 (IBSP 11212); Santa Rita do Passa Quatro $\left(21^{\circ} 42^{\prime} \mathrm{S} 47^{\circ} 28^{\prime} \mathrm{W}\right)$ Hospedeiro Vida livre $3 q 0$ A. sculptum

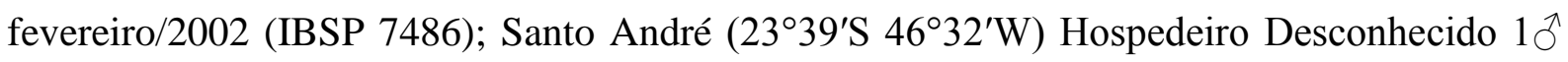
A. cajennense s. 1. novembro/2006 (IBSP 9790); São Bernardo do Campo (234ㄴ ${ }^{\prime} \mathrm{S} 46^{\circ} 33^{\prime} \mathrm{W}$ ) Hospedeiro M. tridactyla 1ð^A. cajennense s. 1. dezembro/1999 (IBSP 7164); São José do Barreiro $\left(22^{\circ} 38^{\prime} \mathrm{S} 44^{\circ} 34^{\prime} \mathrm{W}\right)$ Hospedeiro B. taurus $2 \widehat{\jmath} \widehat{0} 5$ 우 A. sculptum dezembro/2005 (IBSP 9506), Hospedeiro B. taurus 1 q A. sculptum dezembro/2005 (IBSP 9509), Hospedeiro E. caballus 6 우 A. sculptum dezembro/2005 (IBSP 9508), Hospedeiro E. caballus 2 우 A. sculptum dezembro/2005 (IBSP 9510), Hospedeiro E. caballus 4ふぇં 5우 A. sculptum

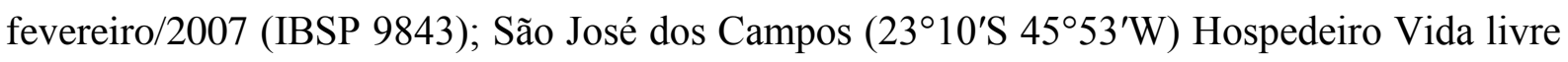
$10^{\Uparrow}$ A. cajennense s. 1. dezembro/2007 (IBSP 9967); São Lourenço da Serra $\left(23^{\circ} 51^{\prime} \mathrm{S}\right.$ 46 $56^{\prime} \mathrm{W}$ ) Hospedeiro Desconhecido 19 A. sculptum março/2009 (IBSP 10023), Hospedeiro

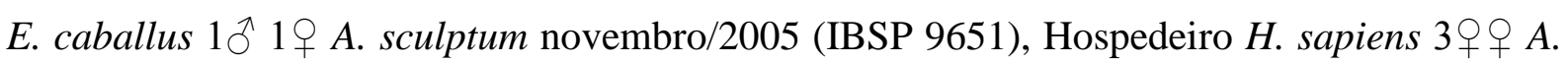
sculptum novembro/2005 (IBSP 9577), Hospedeiro H. sapiens $1 \widehat{\circlearrowleft} 29+$ A. sculptum novembro/2005 (IBSP 9578), Hospedeiro H. sapiens $1 \sigma^{\widehat{A}} 1$ q A. sculptum novembro/2005 (IBSP 9579), Hospedeiro H. sapiens $1 \sigma^{\widehat{A}}$ A. cajennense s. 1. novembro/2005 (IBSP 9586), 
Hospedeiro $H$. sapiens $1 \sigma^{\Uparrow}$ A. cajennense s. 1. novembro/2005 (IBSP 9593); São Luiz do Paraitinga $\left(23^{\circ} 13^{\prime} \mathrm{S} 45^{\circ} 18^{\prime} \mathrm{W}\right)$ Hospedeiro Desconhecido $1 \overbrace{}^{\wedge}$ A. cajennense s. 1. março/2007 (IBSP 9805), Hospedeiro Desconhecido $1{ }^{\Uparrow}$ A. cajennense s. 1. março/2006 (IBSP 9732); São Paulo $\left(23^{\circ} 32^{\prime} \mathrm{S} 46^{\circ} 38^{\prime} \mathrm{W}\right)$ Hospedeiro Alouatta guariba $1 q$ A. sculptum dezembro/2006 (IBSP 9796), Hospedeiro B. taurus 1 + A. sculptum março/1932 (IBSP 687), Hospedeiro B. taurus

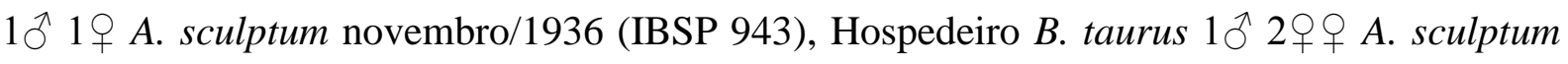
novembro/1936 (IBSP 945), Hospedeiro B. taurus 2ðð A. cajennense s. 1. novembro/1936 (IBSP 958), Hospedeiro Bradypus variegatus 1q A. sculptum agosto/1935 (IBSP 800), Hospedeiro Heterospizias meridionalis 1 ㅇ A. sculptum dezembro/2006 (IBSP 9792), Hospedeiro C. familiaris $2 \widehat{\jmath} 2$ 2우 A. sculptum outubro/1934 (IBSP 841), Hospedeiro C. thous $1 \lesssim$ A. cajennense s. 1. novembro/1934 (IBSP 838), Hospedeiro C. thous 1 ㅇ A. sculptum dezembro/1997 (IBSP 6937), Hospedeiro C. thous $1 \widehat{\jmath}$ A. cajennense s. 1. dezembro/1999 (IBSP 7157), Hospedeiro “Coruja" $1 \delta^{\widehat{O}} 13$ 우 A. sculptum abril/2002 (IBSP 8399), Hospedeiro Desconhecido 1 ㅇ A. sculptum maio/1936 (IBSP 770), Hospedeiro Desconhecido 19 A. sculptum fevereiro/1942 (IBSP 4277), Hospedeiro Desconhecido 19 A. sculptum março/2006 (IBSP 9736), Hospedeiro Desconhecido 1 q A. sculptum abril/2006 (IBSP 9740), Hospedeiro Desconhecido 19 A. sculptum abril/2006 (IBSP 9741), Hospedeiro Desconhecido 1今̂ A. cajennense s. 1. abril/2006 (IBSP 9743), Hospedeiro Desconhecido 290 A. sculptum outubro/2006 (IBSP 9782), Hospedeiro Desconhecido 19 A. sculptum julho/2006 (IBSP

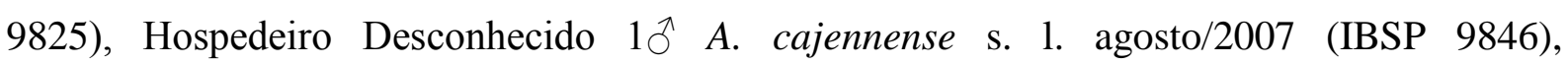
Hospedeiro Desconhecido 1 ㅇ A. sculptum dezembro/1937 (IBSP 1218), Hospedeiro Desconhecido $1 \hat{\bigcirc} 3$ 우 A. sculptum janeiro/2010 (IBSP 10377), Hospedeiro Desconhecido 1 A. sculptum agosto/2007 (IBSP 10467), Hospedeiro Desconhecido $1 ð$ A. cajennense s. 1. junho/2013 (IBSP 11286), Hospedeiro D. albiventris 19 A. sculptum outubro/2006 (IBSP

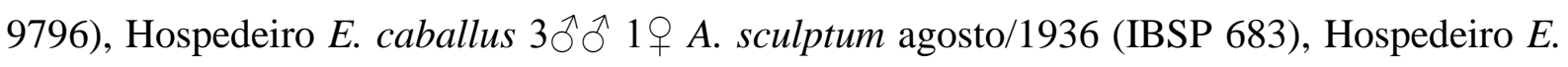

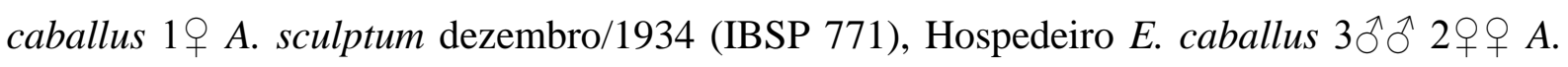
sculptum outubro/1934 (IBSP 844), Hospedeiro E. caballus $1 \sigma^{\Uparrow} 19$ A. sculptum dezembro/1930 (IBSP 1277), Hospedeiro E. caballus 1ð A. cajennense s. 1. junho/2003 (IBSP 8748), Hospedeiro E. caballus 1ð̃ A. cajennense s. 1. junho/2003 (IBSP 8751),

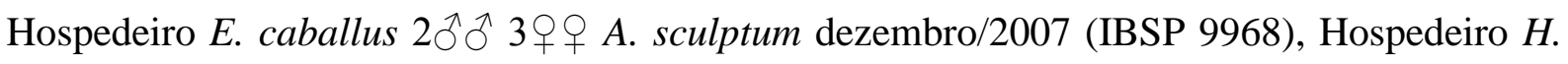
sapiens $2 \hat{\jmath}$ A. cajennense s. 1. março/1932 (IBSP 685), Hospedeiro H. sapiens $1 \hat{\sigma} A$. cajennense s. 1. março/1937 (IBSP 1082), Hospedeiro H. sapiens 1 ㅇ A. sculptum janeiro/1940 (IBSP 1825), Hospedeiro H. sapiens 1ठ A. cajennense s. 1. agosto/1940 (IBSP 1992), Hospedeiro H. sapiens 1 A. sculptum novembro/2005 (IBSP 9555), Hospedeiro H. sapiens 
$1 ð$ A. cajennense s. 1. novembro/2005 (IBSP 9566), Hospedeiro H. sapiens 1 ㅇ A. sculptum novembro/2005 (IBSP 9571), Hospedeiro H. sapiens 1ðึ A. cajennense s. 1. novembro/2005 (IBSP 9580), Hospedeiro H. sapiens $1 \overbrace{}^{\lambda}$ A. cajennense s. 1. dezembro/2005 (IBSP 9599), Hospedeiro $H$. sapiens $1 \overbrace{}^{\uparrow} A$. cajennense s. 1. dezembro/2005 (IBSP 9608), Hospedeiro $H$. sapiens 19 A. sculptum janeiro/2006 (IBSP 9616), Hospedeiro H. sapiens 19 A. sculptum janeiro/2006 (IBSP 9617), Hospedeiro H. sapiens 1 A. sculptum janeiro/2006 (IBSP 9618), Hospedeiro H. sapiens 19 A. sculptum janeiro/2006 (IBSP 9619), Hospedeiro H. sapiens $1 \widehat{ }$ A. cajennense s. 1. fevereiro/2006 (IBSP 9623), Hospedeiro H. sapiens $1 \overbrace{}^{\lambda}$ A. cajennense s. 1. fevereiro/2006 (IBSP 9626), Hospedeiro H. hydrochaeris 1 ㅇ A. sculptum março/2004 (IBSP 8940), Hospedeiro H. hydrochaeris 1 q A. sculptum dezembro/2003 (IBSP 8912), Hospedeiro H. hydrochaeris $1 \lesssim 1$ ○. sculptum outubro/2002 (IBSP 7989), Hospedeiro H. hydrochaeris $6 \widehat{\jmath}$ A. cajennense s. 1. março/1939 (IBSP 1776), Hospedeiro H. hydrochaeris $1 \hat{\jmath} A$. cajennense s. 1. junho/1937 (IBSP 1101), Hospedeiro H. hydrochaeris 5 ㅊㅀ 7 우 우 A. sculptum junho/2002 (IBSP 7760), Hospedeiro H. hydrochaeris 2 q 9 A. sculptum fevereiro/2002 (IBSP 7562), Hospedeiro H. hydrochaeris 1 ㅇ A. sculptum fevereiro/2002 (IBSP 7484), Hospedeiro H. hydrochaeris $1 \widehat{\jmath} 3$ 우 A. sculptum janeiro/2002 (IBSP 7459), Hospedeiro H. hydrochaeris

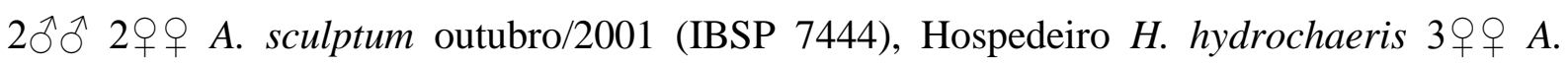
sculptum outubro/2001 (IBSP 7440), Hospedeiro H. hydrochaeris 4우 A. sculptum setembro/2000 (IBSP 7049), Hospedeiro H. hydrochaeris 9ðぇ A. cajennense s. 1.

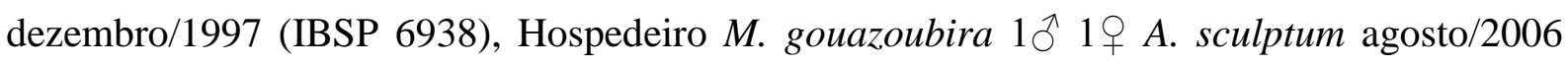
(IBSP 9775), Hospedeiro M. tridactyla 1 ㅇ A. sculptum janeiro/1940 (IBSP 1861), Hospedeiro M. tridactyla $1 \overbrace{}^{\Uparrow}$ A. cajennense s. 1. outubro/1652 (IBSP 4572), Hospedeiro Rupornis magnirostris $1 \hat{\jmath}$ A. cajennense s. 1. outubro/2004 (IBSP 9650), Hospedeiro S. villosus 1 ㅅ A. sculptum setembro/2002 (IBSP 7967), Hospedeiro S. scrofa 1 ^઼ 1 q A. sculptum maio/1939 (IBSP 1717), Hospedeiro Vida livre 19 A. sculptum abril/1938 (IBSP 1307), Hospedeiro

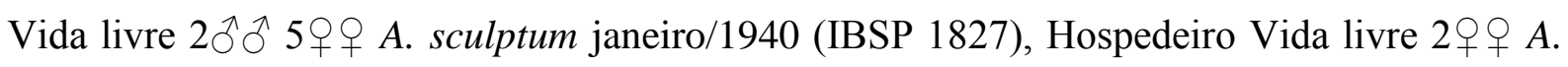
sculptum fevereiro/1940 (IBSP 1874), Hospedeiro Vida livre $3 \hat{\jmath} 1$ 1 A. sculptum dezembro/2000 (IBSP 7060), Hospedeiro Vida livre $1 q$ A. sculptum outubro/2000 (IBSP

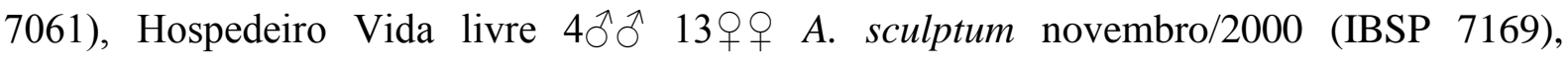
Hospedeiro Vida livre $1 \lesssim 1 q$ A. sculptum abril/2001 (IBSP 7286), Hospedeiro Vida livre $1 q$ A. sculptum maio/2001 (IBSP 7305), Hospedeiro Vida livre 1 + A. sculptum novembro/2000 (IBSP 7429); São Roque $\left(23^{\circ} 31^{\prime} \mathrm{S} 47^{\circ} 8^{\prime} \mathrm{W}\right)$ Hospedeiro Desconhecido 290 A. sculptum março/2000 (IBSP 7209), Hospedeiro Desconhecido $1 q$ A. sculptum abril/2000 (IBSP 7211), Hospedeiro Desconhecido $1 \delta^{\Uparrow} 2$ 우 A. sculptum abril/2000 (IBSP 7217$)$; Sorocaba $\left(23^{\circ} 30^{\prime} \mathrm{S}\right.$ 
$47^{\circ} 27^{\prime} \mathrm{W}$ ) Hospedeiro B. variegatus 19 A. sculptum setembro/1934 (CNC 843); Taubaté $\left(23^{\circ} 1^{\prime} \mathrm{S} 45^{\circ} 33^{\prime} \mathrm{W}\right)$ Hospedeiro H. sapiens 1 A. sculptum novembro/2007 (IBSP 9783); Teodoro Sampaio $\left(22^{\circ} 31^{\prime} \mathrm{S} 52^{\circ} 10^{\prime} \mathrm{W}\right)$ Hospedeiro H. sapiens $1{ }^{\Uparrow} 19$ A. sculptum abril/1951

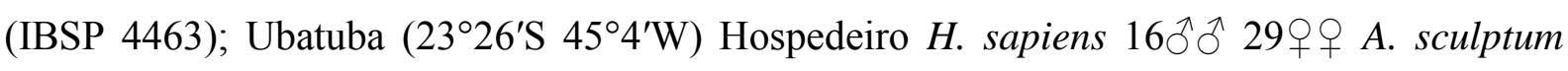
novembro/2005 (IBSP 9564), Hospedeiro H. sapiens $1 q$ A. sculptum novembro/2005 (IBSP 9565), Hospedeiro H. sapiens 1 ㅇ A. sculptum novembro/2005 (IBSP 9584), Hospedeiro $H$.

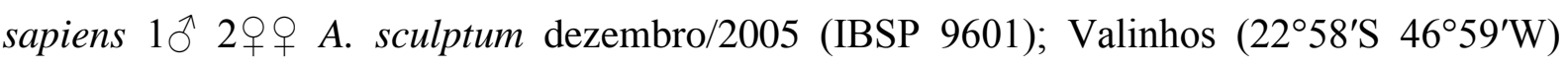
Hospedeiro C. familiaris $1 \uparrow$ A. sculptum outubro/2002 (IBSP 7990); Vargem Grande Paulista

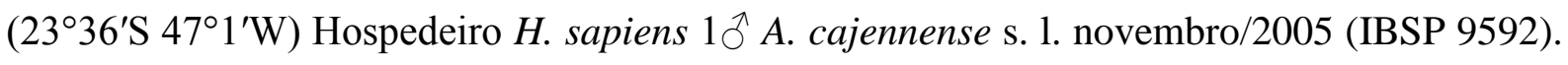
Sul - Paraná: Japurá $\left(23^{\circ} 28^{\prime} \mathrm{S} 52^{\circ} 33^{\prime} \mathrm{W}\right)$ Hospedeiro C. thous $10^{\Uparrow}$ A. cajennense s. 1.

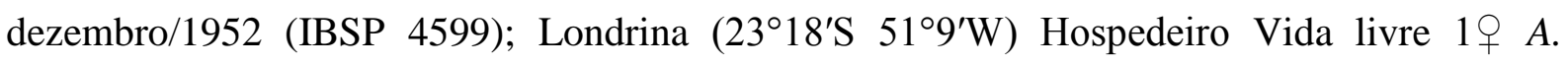
sculptum março/2005 (IBSP 10483); São José dos Pinhais (2532'S 49¹2’W) Hospedeiro Desconhecido $2 \widehat{\diamond}$ A. cajennense s. 1. abril/1937 (IBSP 1089). Santa Catarina: Presidente Getúlio $\left(27^{\circ} 3^{\prime} \mathrm{S} 49^{\circ} 37^{\prime} \mathrm{W}\right)$ Hospedeiro C. familiaris $1{ }^{\Uparrow}$ A. cajennense s. 1. agosto/1936 (IBSP 499).

\subsection{LOCALIDADES ADQUIRIDAS CASUALMENTE PELO LDP NO ANDAMENTO DO PRESENTE ESTUDO}

Norte - Pará: Belém $\left(1^{\circ} 27^{\prime} \mathrm{S} 48^{\circ} 30^{\prime} \mathrm{W}\right)$ Hospedeiro M. tridactyla $3 \partial^{\Uparrow} 2 q q A$.

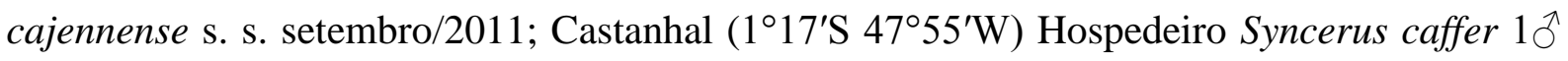
A. cajennense s. 1. junho/2009; Santa Isabel do Pará (1 $\left.{ }^{\circ} 17^{\prime} \mathrm{S} 48^{\circ} 9^{\prime} \mathrm{W}\right)$ Hospedeiro S. caffer

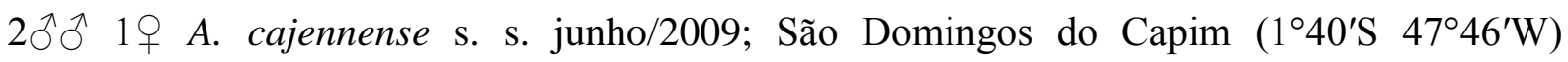
Hospedeiro E. caballus $3 \widehat{\jmath}$ A. cajennense s. s. outubro/2011. Rondônia: São Francisco do

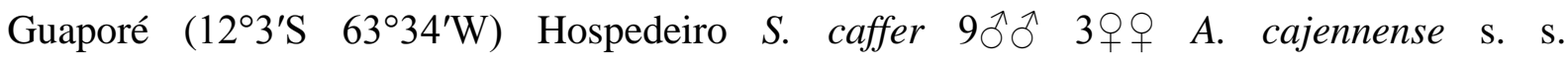
setembro/2011. Tocantins: Cristalândia $\left(10^{\circ} 36^{\prime} \mathrm{S} 49^{\circ} 11^{\prime} \mathrm{W}\right)$ Hospedeiro C. familiaris 14 우 (coletados como ninfas) A. cajennense s. s. $99+$ A. sculptum (coletados como ninfas) $10 \hat{\jmath}$

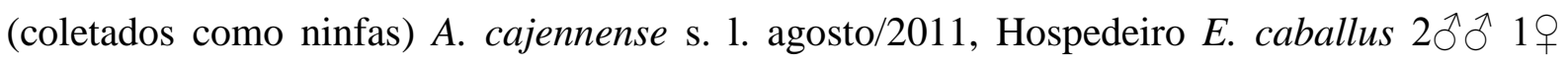
(coletados como ninfas) A. cajennense s. s. agosto/2011; Lagoa da Confusão $\left(10^{\circ} 47^{\prime} \mathrm{S}\right.$ $49^{\circ} 37^{\prime} \mathrm{W}$ ) Hospedeiro B. taurus 1 ㅇ (coletado como ninfa) A. cajennense s. s. setembro/2011, Hospedeiro C. familiaris 290 (coletados como ninfas) A. cajennense s. s. setembro/2011; Pium $\left(10^{\circ} 26^{\prime} \mathrm{S} 49^{\circ} 10^{\prime} \mathrm{W}\right)$ Hospedeiro B. taurus $29+$ (coletados como ninfas) A. cajennense s. 
s. agosto/2011, Hospedeiro Equus asinus $2 q q$ (coletados como ninfas) A. cajennense s. s. $1 q$ A. sculptum agosto/2011, Hospedeiro Vida livre $1 \hat{\jmath} 1 \uparrow$ A. cajennense s. s. agosto/2009; Tocantinópolis $\left(6^{\circ} 19^{\prime} \mathrm{S} 47^{\circ} 24^{\prime} \mathrm{W}\right)$ Hospedeiro Vida livre $5 ડ^{\Uparrow} 7$ 우 A. sculptum junho/2011.

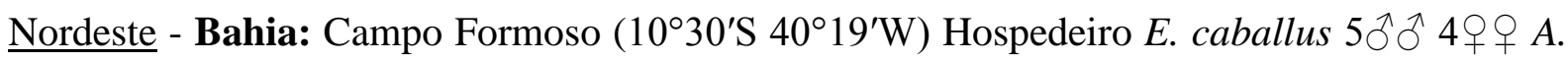

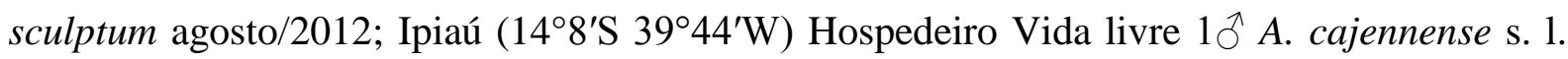

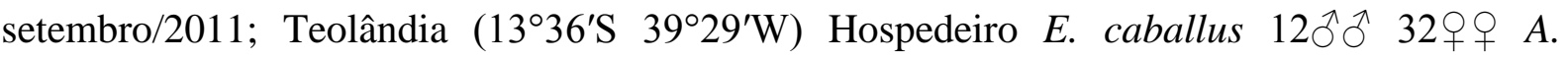

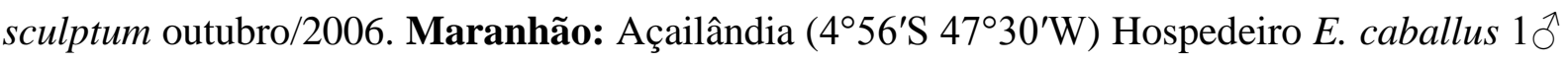

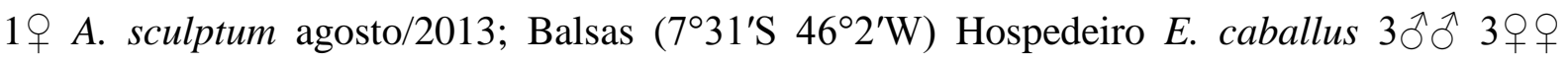
(coletados como ninfas) A. sculptum julho/2011; Barreirinhas $\left(2^{\circ} 44^{\prime} \mathrm{S} 42^{\circ} 49^{\prime} \mathrm{W}\right)$ Hospedeiro C. familiaris $1{ }^{\Uparrow} 1 q$ (coletados como ninfas) A. cajennense s. s. agosto/2011, Hospedeiro $C$. familiaris 1 ㅇ A. sculptum agosto/2013; Campestre do Maranhão $\left(6^{\circ} 10^{\prime} \mathrm{S} \quad 47^{\circ} 21^{\prime} \mathrm{W}\right)$

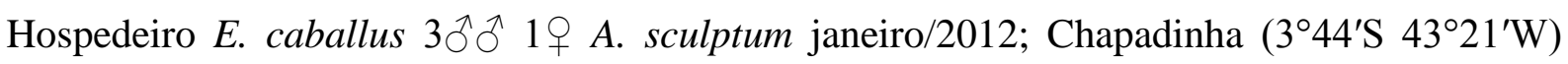
Hospedeiro C. familiaris $5 \hat{\jmath} \widehat{\partial} 6$ 우 (coletados como ninfas) A. cajennense s. s. março/2010, Hospedeiro C. familiaris $1 \widehat{\jmath} 1 q$ A. sculptum março/2010, Hospedeiro D. novemcinctus 1 q A.

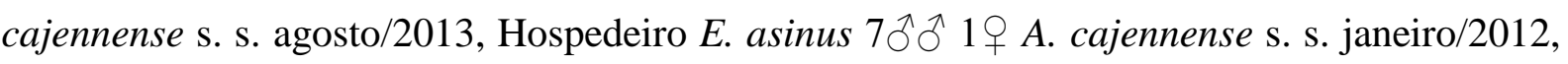
Hospedeiro E. caballus 14へ̋ 17 우 A. cajennense s. s. janeiro/2012; Milagres do Maranhão

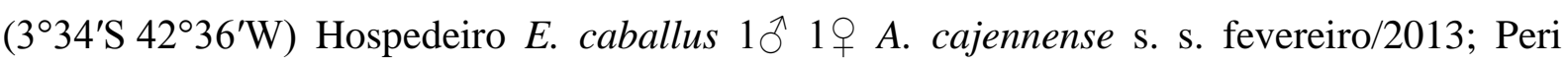
Mirim ( $\left.2^{\circ} 34^{\prime} \mathrm{S} 44^{\circ} 51^{\prime} \mathrm{W}\right)$ Hospedeiro E. caballus $1{ }^{\Uparrow} 1 q$ A. cajennense s. s. agosto/2013; São Bento $\left(2^{\circ} 41^{\prime} \mathrm{S} 44^{\circ} 49^{\prime} \mathrm{W}\right)$ Hospedeiro E. caballus 1 \% A. cajennense s. s. agosto/2011; São Bernardo $\left(3^{\circ} 21^{\prime} \mathrm{S} 42^{\circ} 25^{\prime} \mathrm{W}\right)$ Hospedeiro E. caballus 1 ㅇ A. cajennense s. s. fevereiro/2013; Urbano Santos $\left(3^{\circ} 12^{\prime} \mathrm{S} 43^{\circ} 24^{\prime} \mathrm{W}\right)$ Hospedeiro H. sapiens $1 q$ A. cajennense s. s. agosto/2011; Viana $\left(3^{\circ} 13^{\prime} \mathrm{S} 45^{\circ} 0^{\prime} \mathrm{W}\right)$ Hospedeiro S. scofra 27 ภิ A. cajennense s. 1. fevereiro/2013,

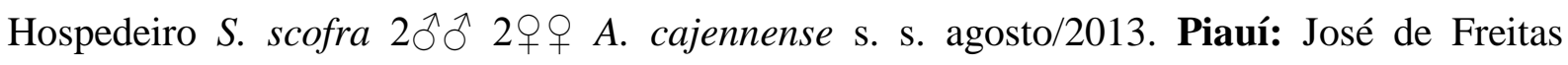
$\left(4^{\circ} 45^{\prime} \mathrm{S} 42^{\circ} 34^{\prime} \mathrm{W}\right)$ Hospedeiro E. asinus $5 \partial^{\Uparrow} 5$ 우 A. sculptum janeiro/2011. Centro-Oeste Goiás: Cumari $\left(18^{\circ} 15^{\prime} \mathrm{S} 48^{\circ} 9^{\prime} \mathrm{W}\right)$ Hospedeiro E. caballus $6 \overbrace{}^{\Uparrow} 8$ 8 9 A. sculptum junho/2011. Mato Grosso: Confresa $\left(10^{\circ} 38^{\prime} \mathrm{S} 51^{\circ} 34^{\prime} \mathrm{W}\right)$ Hospedeiro E. caballus $2{ }_{\curvearrowright} 2$ 우 A. cajennense s. s. abril/2011; Nobres $\left(14^{\circ} 43^{\prime} \mathrm{S} 56^{\circ} 19^{\prime} \mathrm{W}\right)$ Hospedeiro H. sapiens $1 \mathrm{O}^{\wedge} 1$ ㅇ A. sculptum

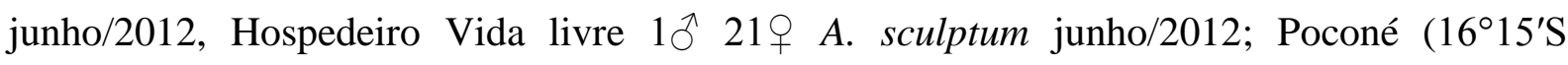
$\left.56^{\circ} 37^{\prime} \mathrm{W}\right)$ Hospedeiro E. caballus $13 \hat{\partial} \widehat{\partial} 22$ 2 + A. sculptum julho/2011. Mato Grosso do

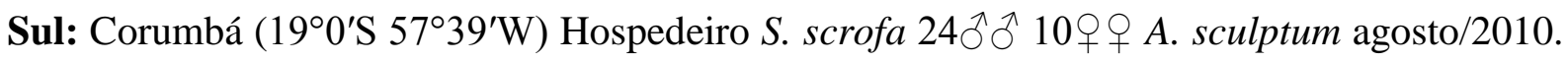

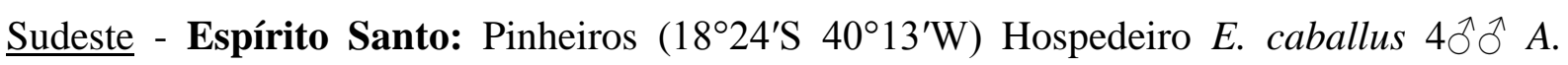
sculptum julho/2011. Minas Gerais: Araguari $\left(18^{\circ} 38^{\prime} \mathrm{S} 48^{\circ} 11^{\prime} \mathrm{W}\right)$ Hospedeiro E. caballus

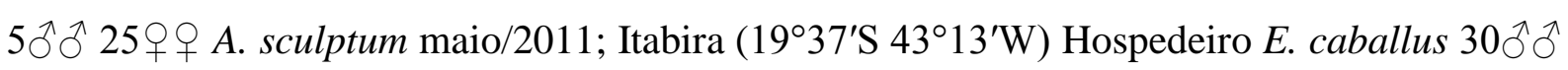

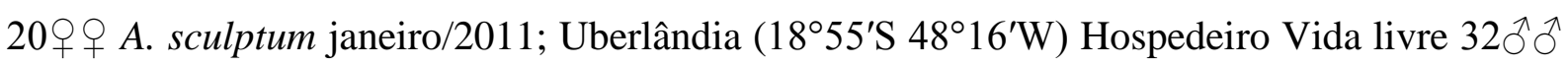


$26 ㅇ$ A. sculptum dezembro/2011. Rio de Janeiro: Seropédica $\left(22^{\circ} 44^{\prime} \mathrm{S} \quad 43^{\circ} 42^{\prime} \mathrm{W}\right)$ Hospedeiro E. caballus $6 \hat{\jmath}$ đ웅 A. sculptum maio/2011. São Paulo: Americana $\left(22^{\circ} 44^{\prime}\right.$ S $\left.47^{\circ} 19^{\prime} \mathrm{W}\right)$ Hospedeiro Vida livre $29{ }^{\Uparrow} 0^{\Uparrow} 64$ 우 A. sculptum maio/2005; Pedreira $\left(22^{\circ} 44^{\prime} \mathrm{S}\right.$ 46 $\left.54^{\prime} \mathrm{W}\right)$ Hospedeiro Vida livre 5ภํ 5우 A. sculptum fevereiro/2011. Sul - Paraná: Alvorada do Sul $\left(22^{\circ} 46^{\prime} \mathrm{S} 51^{\circ} 13^{\prime} \mathrm{W}\right)$ Hospedeiro E. caballus 4 우 우 A. sculptum maio/2012; Londrina $\left(23^{\circ} 18^{\prime} \mathrm{S} 51^{\circ} 9^{\prime} \mathrm{W}\right)$ Hospedeiro E. caballus $21 q$ ㅇ A. sculptum junho/2004; Rosário do Ivaí ( $\left.24^{\circ} 16^{\prime} \mathrm{S} 51^{\circ} 16^{\prime} \mathrm{W}\right)$ Hospedeiro E. caballus $1{ }^{\jmath} 1 q$ A. sculptum janeiro/2012.

\subsection{LOCALIDADES DA EXPEDIÇÃO BEQUIMÃO/MA À ESTRELA DO NORTE/GO}

Norte - Pará: Cachoeira do Piriá ( $\left.1^{\circ} 50.888^{\prime} S 45^{\circ} 23.452^{\prime} W\right)$ Hospedeiro E. caballus

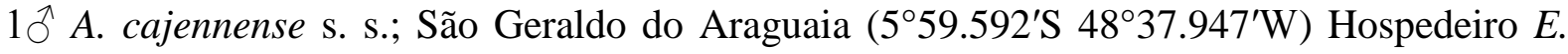

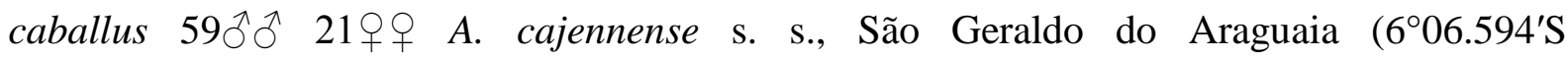
$\left.48^{\circ} 35.672^{\prime} \mathrm{W}\right)$ Hospedeiro E. caballus 19 A. cajennense s. s. $1+$ A. sculptum $1 \hat{\jmath}$ A. cajennense s. 1.. Tocantins: Alvorada $\left(12^{\circ} 23.111^{\prime} \mathrm{S} 49^{\circ} 07.061^{\prime} \mathrm{W}\right)$ Hospedeiro E. caballus $2 ㅇ ㅜ$ A. cajennense s. s. 8 우 A. sculptum $7 \widehat{\delta}^{\widehat{o}}$ A. cajennense s. 1.; Araguaína $\left(7^{\circ} 19.570^{\prime} \mathrm{S}\right.$

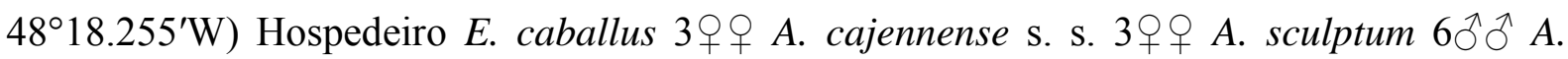

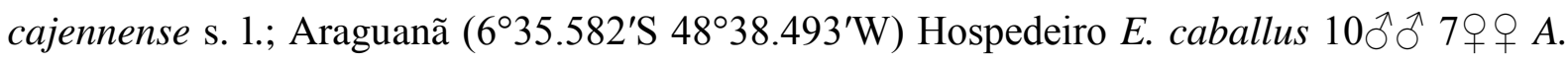
cajennense s. s., Araguanã $\left(6^{\circ} 51.336^{\prime} \mathrm{S} 48^{\circ} 30.986^{\prime} \mathrm{W}\right)$ Hospedeiro E. caballus 3 우 A.

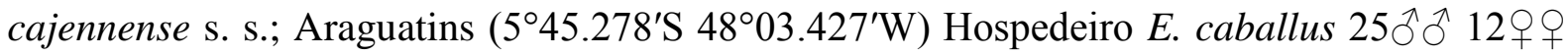

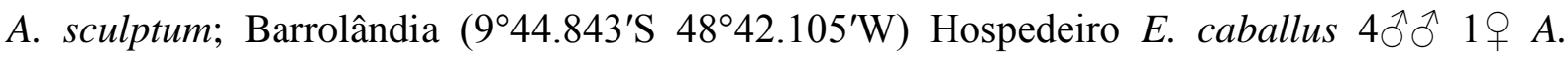
sculptum, Barrolândia ( $\left.9^{\circ} 51.657^{\prime} \mathrm{S} 48^{\circ} 43.446^{\prime} \mathrm{W}\right)$ Hospedeiro E. caballus 1 q A. cajennense s.

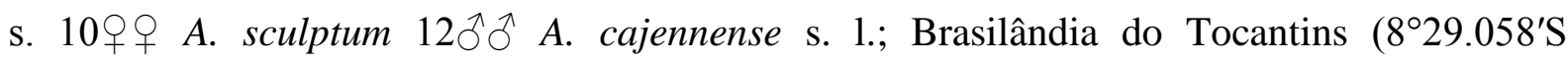

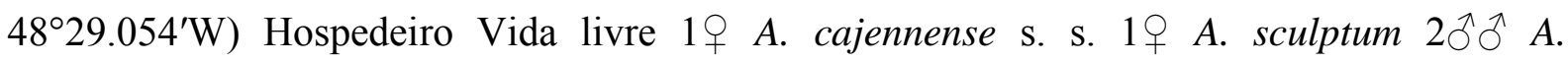
cajennense s. 1.; Brejinho de Nazaré $\left(11^{\circ} 02.660^{\prime} \mathrm{S} 48^{\circ} 45.039^{\prime} \mathrm{W}\right)$ Hospedeiro E. caballus 1 q A. cajennense s. s. $2 \nmid+$ A. sculptum $3 \widehat{\partial} A$. cajennense s. 1., Brejinho de Nazaré $\left(10^{\circ} 59.359^{\prime} \mathrm{S} 48^{\circ} 33.451^{\prime} \mathrm{W}\right)$ Hospedeiro E. caballus 19ðึત 1ㅇ A. sculptum; Cariri do Tocantins $\left(11^{\circ} 53.841^{\prime} \mathrm{S} 49^{\circ} 10.020^{\prime} \mathrm{W}\right)$ Hospedeiro E. caballus 5 우 A. cajennense s. s. 18 우 A. sculptum $44 \overbrace{}^{\Uparrow} A$. cajennense s. 1.; Crixás do Tocantins $\left(11^{\circ} 12.863^{\prime} \mathrm{S} 48^{\circ} 55.806^{\prime} \mathrm{W}\right)$

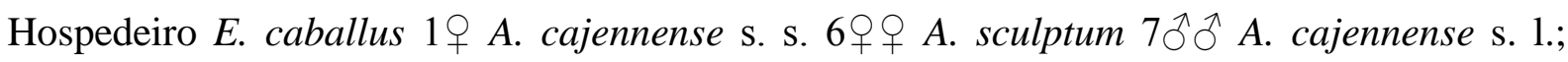
Figueirópolis $\left(12^{\circ} 13.940^{\prime} \mathrm{S} 49^{\circ} 09.919^{\prime} \mathrm{W}\right)$ Hospedeiro E. caballus $4+9$ ㅇ A. cajennense s. s. $74+9$ A. sculptum 141ठ̋ð A. cajennense s. 1.; Fortaleza do Tabocão $\left(9^{\circ} 07.003^{\prime} \mathrm{S}\right.$ 


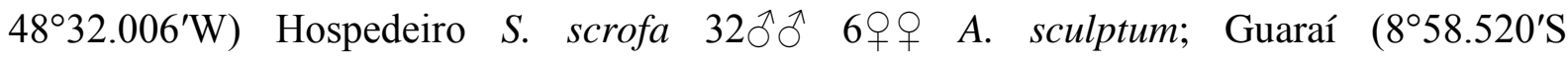

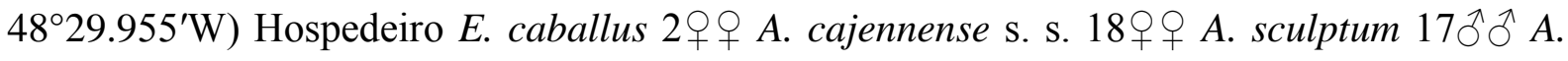
cajennense s. 1.; Gurupi $\left(11^{\circ} 33.700^{\prime} \mathrm{S} 49^{\circ} 01.503^{\prime} \mathrm{W}\right)$ Hospedeiro E. caballus $11^{\widehat{\partial}} 9$ 우 A. sculptum, Gurupi $\left(11^{\circ} 49.618^{\prime} \mathrm{S} 49^{\circ} 07.801^{\prime} \mathrm{W}\right)$ Hospedeiro E. caballus 5 우 A. cajennense s. s. 9 우 A. sculptum 19ðð A. cajennense s. 1.; Luzinópolis $\left(6^{\circ} 10.583^{\prime} \mathrm{S} 47^{\circ} 51.664^{\prime} \mathrm{W}\right)$

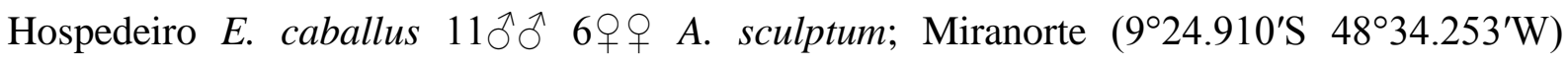
Hospedeiro M. tridactyla $89+$ A. cajennense s. s. $5 q$ 우 A. sculptum $27 \widehat{\jmath}$ A. cajennense s. 1.;

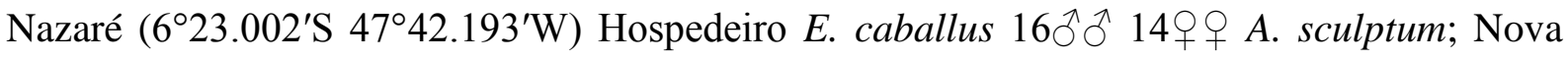

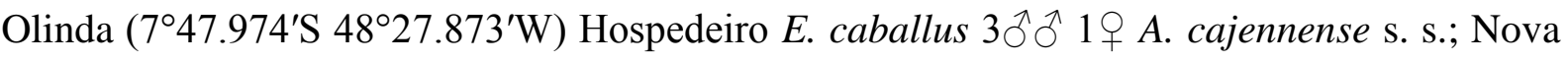
Rosalândia $\left(10^{\circ} 34.032^{\prime} \mathrm{S} 48^{\circ} 55.116^{\prime} \mathrm{W}\right)$ Hospedeiro E. caballus 1 q A. cajennense s. s. 4 우 A. sculptum $1 \bigcirc^{\Uparrow} A$. cajennense s. 1.; Paraíso do Tocantins $\left(10^{\circ} 07.183^{\prime} \mathrm{S} 48^{\circ} 52.998^{\prime} \mathrm{W}\right)$ Hospedeiro E. caballus $1 \bigcirc^{\Uparrow} 3$ 우 A. sculptum; Porto Nacional $\left(10^{\circ} 29.502^{\prime} \mathrm{S} 48^{\circ} 20.153^{\prime} \mathrm{W}\right)$

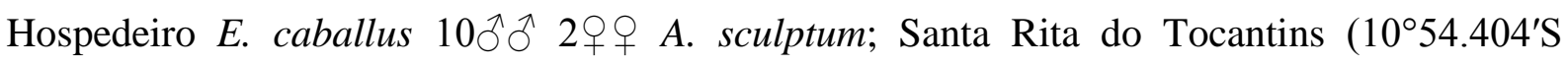
$\left.48^{\circ} 54.798^{\prime} \mathrm{W}\right)$ Hospedeiro E. caballus 7 우 A. cajennense s. s. $49+$ A. sculptum $45 \hat{\jmath} \widehat{\jmath}$ A. cajennense s. 1.; São Bento do Tocantins $\left(5^{\circ} 58.436^{\prime} \mathrm{S} 47^{\circ} 52.737^{\prime} \mathrm{W}\right)$ Hospedeiro E. caballus 1 A. cajennense s. s. $2 \nmid+q$ A. sculptum $1{ }^{\lambda}$ A. cajennense s. 1.; Talismã $\left(12^{\circ} 47.346^{\prime} \mathrm{S}\right.$ $\left.49^{\circ} 05.470^{\prime} \mathrm{W}\right)$ Hospedeiro E. caballus 19 A. cajennense s. s. 19 A. sculptum $24 \hat{\jmath} \widehat{\partial}$. cajennense s. 1.; Tocantinópolis $\left(6^{\circ} 15.035^{\prime} \mathrm{S} 47^{\circ} 27.741^{\prime} \mathrm{W}\right)$ Hospedeiro E. caballus 2 우 A.

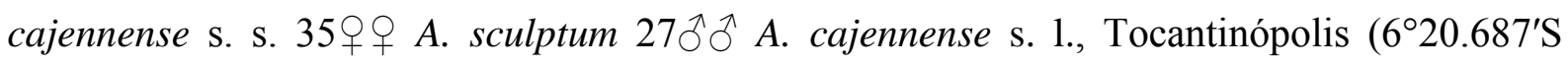
$\left.47^{\circ} 33.018^{\prime} \mathrm{W}\right)$ Hospedeiro E. caballus 19 A. cajennense s. s. $39+9$ A. sculptum $6 \hat{\jmath} \widehat{A}$. cajennense s. 1.; Xambioá $\left(6^{\circ} 24.783^{\prime} \mathrm{S} 48^{\circ} 32.321^{\prime} \mathrm{W}\right)$ Hospedeiro E. caballus 1 ㅇ A. cajennense s. s.. Nordeste - Maranhão: Bequimão ( $\left.2^{\circ} 27.784^{\prime} \mathrm{S} 44^{\circ} 47.416^{\prime} \mathrm{W}\right)$ Hospedeiro E. caballus $10 \widehat{o ̄}^{\lambda} A$. cajennense s. s.; Bom Jesus das Selvas $\left(4^{\circ} 31.142^{\prime} \mathrm{S} 46^{\circ} 46.691^{\prime} \mathrm{W}\right)$ Hospedeiro S. scrofa $18 \hat{\jmath} \widehat{\jmath} 7$ 우 A. cajennense s. s.; Imperatriz $\left(5^{\circ} 33.209^{\prime} \mathrm{S} 47^{\circ} 27.766^{\prime} \mathrm{W}\right)$

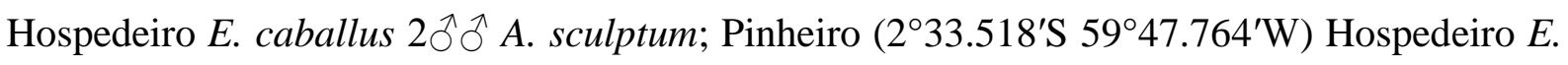

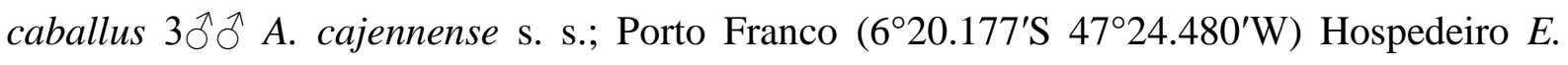
caballus $2{ }^{\Uparrow} \widehat{\jmath} 2$ 우 A. cajennense s. s.; Santa Helena $\left(2^{\circ} 15.681^{\prime} \mathrm{S} 45^{\circ} 16.235^{\prime} \mathrm{W}\right)$ Hospedeiro

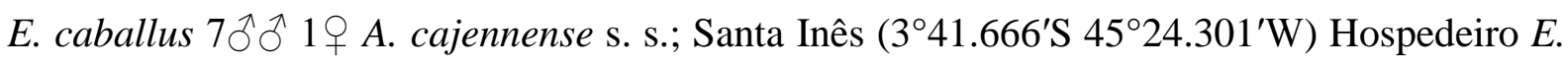

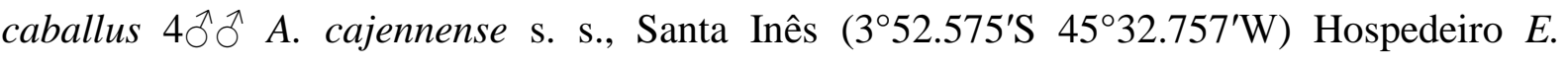
caballus 7 ふ઼ 9 우 A. cajennense s. s.; Santa Luzia do Tide $\left(4^{\circ} 04.668^{\prime} \mathrm{S} 45^{\circ} 57.052^{\prime} \mathrm{W}\right)$ Hospedeiro E. caballus $5 \hat{\partial} \widehat{\partial} 7+q$ A Aajennense s. s.. Centro-Oeste - Goiás: Estrela do

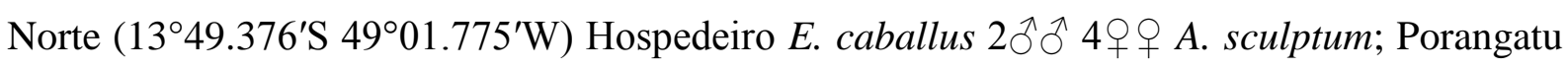

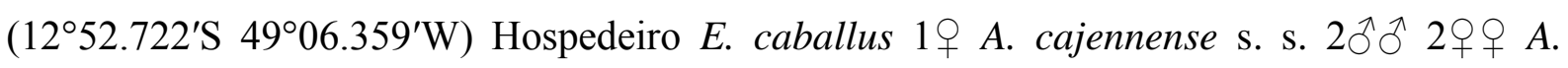
sculptum, Porangatu $\left(12^{\circ} 53.209^{\prime} \mathrm{S} 49^{\circ} 06.390^{\prime} \mathrm{W}\right)$ Hospedeiro E. caballus 5 ふぇ 5 우 A. 
sculptum, Porangatu $\left(13^{\circ} 24.868^{\prime} \mathrm{S} 4^{\circ} 08.118^{\prime} \mathrm{W}\right)$ Hospedeiro E. caballus $21 \delta^{\Uparrow} 6^{\circ}$ 우 A. sculptum, Porangatu $\left(13^{\circ} 15.364^{\prime} \mathrm{S} 4^{\circ} 08.122^{\prime} \mathrm{W}\right)$ Hospedeiro E. caballus 4ふえへ 1 A.

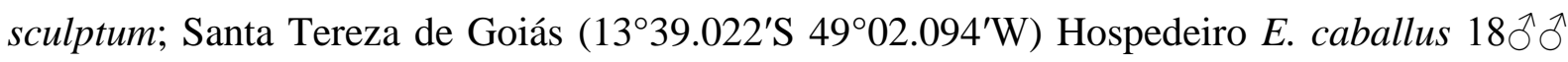
7 우 A. sculptum.

\subsection{LOCALIDADES DA EXPEDIÇÃO PRESIDENTE MÉDICI/RO À VILA BELA DA SANTÍSSIMA TRINDADE/MT}

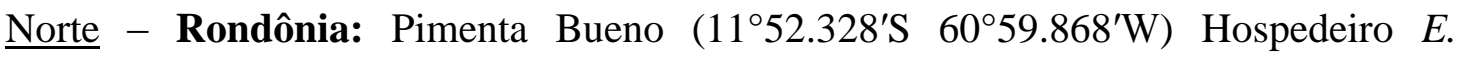
caballus $5 ㅇ$ A. cajennense s. s. $12 q$ 우 A. sculptum $7 \lesssim \widehat{ठ}$ A. cajennense s. 1.; Presidente Médici $\left(11^{\circ} 09.754^{\prime} \mathrm{S} 61^{\circ} 54.095^{\prime} \mathrm{W}\right)$ Hospedeiro E. caballus; $1 \delta^{\Uparrow} 2$ 2 ㅇ A. cajennense s. s.; Vilhena $\left(12^{\circ} 43.412^{\prime} \mathrm{S} 60^{\circ} 15.417^{\prime} \mathrm{W}\right)$ Hospedeiro Vida livre 2 우 A. cajennense s. s., Vilhena $\left(12^{\circ} 29.545^{\prime} \mathrm{S} 60^{\circ} 28.309^{\prime} \mathrm{W}\right)$ Hospedeiro Vida livre $4{ }^{\Uparrow}{ }^{\Uparrow} 1 q$ A. cajennense s. s.. Centro-Oeste

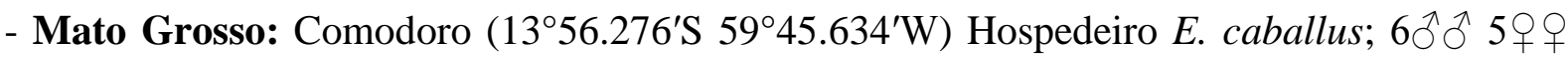

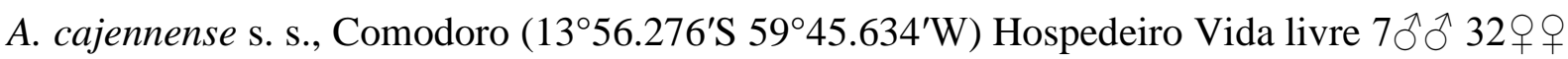
A. cajennense s. s., Comodoro $\left(13^{\circ} 19.058^{\prime} \mathrm{S} 59^{\circ} 52.654^{\prime} \mathrm{W}\right)$ Hospedeiro Vida livre 2 우 A. cajennense s. s., Comodoro $\left(13^{\circ} 05.216^{\prime} \mathrm{S} 59^{\circ} 53.509^{\prime} \mathrm{W}\right)$ Hospedeiro Vida livre $1 \widehat{O}^{\wedge} A$. cajennense s. s., Comodoro $\left(13^{\circ} 00.277^{\prime} \mathrm{S} 59^{\circ} 57.472^{\prime} \mathrm{W}\right)$ Hospedeiro Vida livre $3 \overbrace{}^{\Uparrow} \sigma^{\circ} 4$ 우 $A$. cajennense s. s.; Conquista d'Oeste $\left(14^{\circ} 46.905^{\prime} \mathrm{S} 59^{\circ} 20.774^{\prime} \mathrm{W}\right)$ Hospedeiro E. caballus $1 q$ A. cajennense s. s. 49 우 A. sculptum $26 \widehat{\partial}^{\widehat{\partial}}$ A. cajennense s. 1.; Nova Lacerda $\left(14^{\circ} 10.232^{\prime} \mathrm{S}\right.$

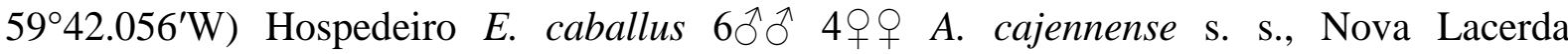
$\left(14^{\circ} 07.560^{\prime} \mathrm{S} 59^{\circ} 42.607^{\prime} \mathrm{W}\right)$ Hospedeiro Vida livre $1 \delta^{\nearrow} 1$ ㅇ A. cajennense s. s.; Pontes e Lacerda $\left(15^{\circ} 09.292^{\prime} \mathrm{S} 59^{\circ} 28.354^{\prime} \mathrm{W}\right)$ Hospedeiro E. caballus $1{ }^{\wedge}$ A. cajennense s. s., Pontes e Lacerda $\left(15^{\circ} 20.685^{\prime} \mathrm{S} 59^{\circ} 23.777^{\prime} \mathrm{W}\right)$ Hospedeiro E. caballus $3 \widehat{\jmath}$ ð 4 우 A. sculptum, Pontes e Lacerda $\left(14^{\circ} 53.271^{\prime} \mathrm{S} 59^{\circ} 16.735^{\prime} \mathrm{W}\right)$ Hospedeiro E. caballus 3 우 A. sculptum; Vila Bela da Santíssima Trindade $\left(15^{\circ} 07.393^{\prime} \mathrm{S} 5^{\circ} 34.550^{\prime} \mathrm{W}\right)$ Hospedeiro E. caballus $3 \widehat{\partial} \widehat{\partial} 3 q 0+A$. sculptum, Vila Bela da Santíssima Trindade $\left(1^{\circ} 00.374^{\prime} \mathrm{S} 59^{\circ} 57.109^{\prime} \mathrm{W}\right)$ Hospedeiro E.

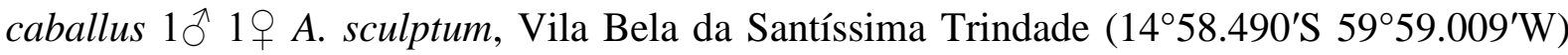
Hospedeiro E. caballus $11 \widehat{\partial} \widehat{\widehat{O}} 5 q 0$ A. sculptum, Vila Bela da Santíssima Trindade $\left(14^{\circ} 55.576^{\prime} \mathrm{S} 60^{\circ} 01.216^{\prime} \mathrm{W}\right)$ Hospedeiro Vida livre 19 A. cajennense s. s. 31 우 A. sculptum $31 \lesssim \widehat{\jmath}$ A. cajennense s. 1., Vila Bela da Santíssima Trindade $\left(15^{\circ} 05.634^{\prime} \mathrm{S} 59^{\circ} 51.829^{\prime} \mathrm{W}\right)$ Hospedeiro Vida livre $11 \widehat{\jmath} \widehat{\jmath} 11$ 우 A. sculptum. 


\subsection{LOCALIDADES DA EXPEDIÇÃO SINOP/MT À CUIABÁ/MT}

Centro-Oeste - Mato Grosso: Diamantino (14³3.153'S 56 $\left.{ }^{\circ} 13.418^{\prime} \mathrm{W}\right)$ Hospedeiro E.

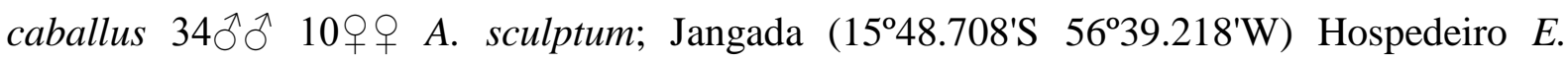

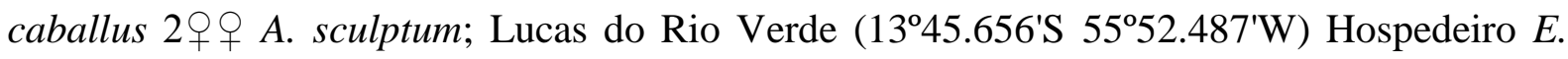
caballus $3 q 0$ 우 cajennense s. s. 19 A. sculptum $7 \hat{\jmath} \widehat{\partial}$ A. cajennense s. 1.; Nobres

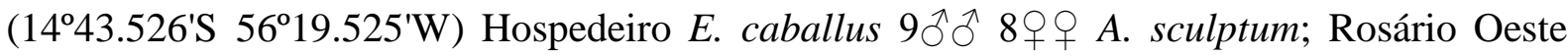

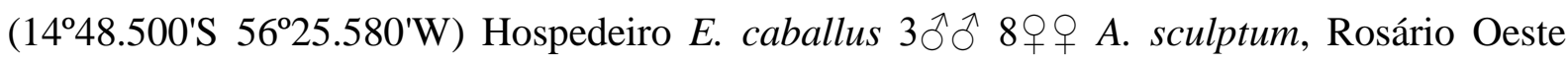

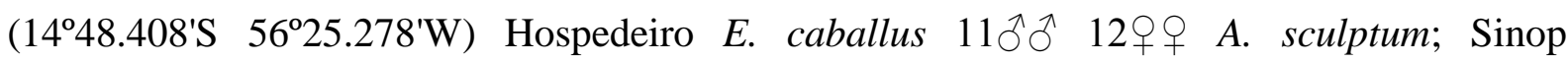

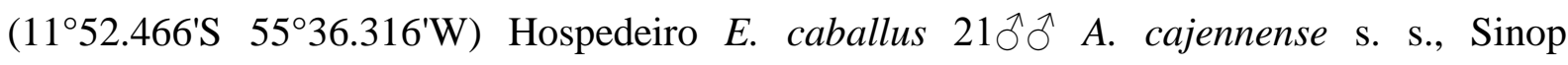

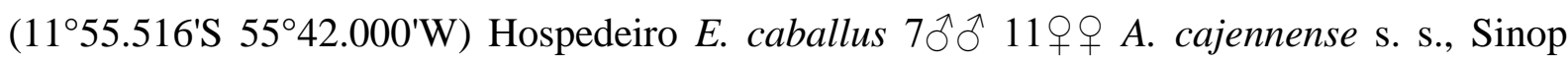

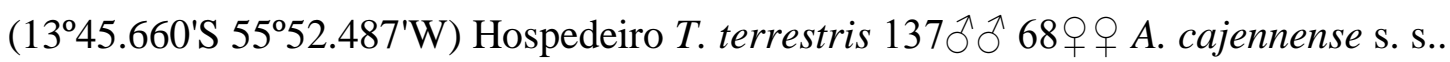

\section{7 ÁRVORES FILOGENÉTICAS}

As análises dos carrapatos das localidades apresentadas nas figuras abaixo (Figuras 15 e 16) geraram duas árvores. A primeira (Figura 13), baseada num alinhamento de 1034 nucleotídeos, demonstrou que os carrapatos do complexo A. cajennense do Brasil se separaram em dois grandes clados, com grande valor de bootstrap (100\%). O primeiro clado foi composto por haplótipos de amostras provenientes das regiões Norte (Pará, Rondônia e Tocantins), Nordeste (Maranhão) e Centro-Oeste (Mato Grosso). Como todas as fêmeas deste clado foram previamente identificadas como A. cajennense s. s., considera-se que os machos deste clado foram identificados como A. cajennense s. s. pelas análises genéticas. O segundo clado foi composto por haplótipos de amostras provenientes das regiões Norte (Rondônia e Tocantins), Nordeste (Bahia, Maranhão e Piauí), Centro-Oeste (Goiás, Mato Grosso e Mato Grosso do Sul), Sudeste (Espírito Santo, Minas Gerais, Rio de Janeiro e São Paulo) e Sul (Paraná). Como todas as fêmeas deste clado foram previamente identificadas como $A$. sculptum, considera-se que os machos deste clado correspondem a A. sculptum.

$\mathrm{Na}$ segunda árvore (Figura 14), foram incluídas sequências representativas das seis espécies que compõem o complexo A. cajennense, derivadas do GenBank e geradas nos 
trabalhos de Beati et al. (2013) e Nava et al. $\left(2014^{7}\right)$. Estas sequências foram alinhadas com as geradas no presente estudo, resultando em um alinhamento final de 871 nucleotídeos. Neste caso, pode-se confirmar que as sequências geradas de carrapatos coletados em diferentes localidades do Brasil no presente estudo correspondem a apenas duas espécies do complexo A. cajennense (A. cajennense s. s. e A. sculptum). Isso indica que não foi gerada qualquer evidência da presença de alguma outra espécie conhecida (A. mixtum, A. interandinum, A. patinoi e A. tonelliae) ou desconhecida do complexo A. cajennense no Brasil.

\footnotetext{
${ }^{7}$ NAVA, S.; BEATI, L.; LABRUNA, M. B.; CÁCERES, A. G.; MANGOLD, A. J.; GUGLIELMONE, A. A. Reassessment of the taxonomic status of Amblyomma cajennense (Fabricius, 1787) with the description of three new species, Amblyomma tonelliae n. sp., Amblyomma interandinum n. sp. and Amblyomma patinoi n. sp., and resurrection of Amblyomma mixtum Koch, 1844 and Amblyomma sculptum Berlese, 1888 (Ixodida: Ixodidae). Ticks and Tick-borne Diseases, No prelo, 2014
} 
Figura 13 - Árvore filogenética construída por máxima parcimônia, baseada em seqüências de ITS2 rDNA mitocondrial (1034 caracteres, 114 sítios informativos) de carrapatos de 30 diferentes localidades. Amblyomma americanum foi utilizado como grupo externo. Legenda: Os números nos ramos correspondem aos valores de suporte de bootstrap em 100 replicatas. As sequências geradas no presente estudo estão em negrito, representadas pelo nome do município, seguido pelo estado brasileiro entre parênteses. Números entre colchetes representam números de acesso do Genbank.

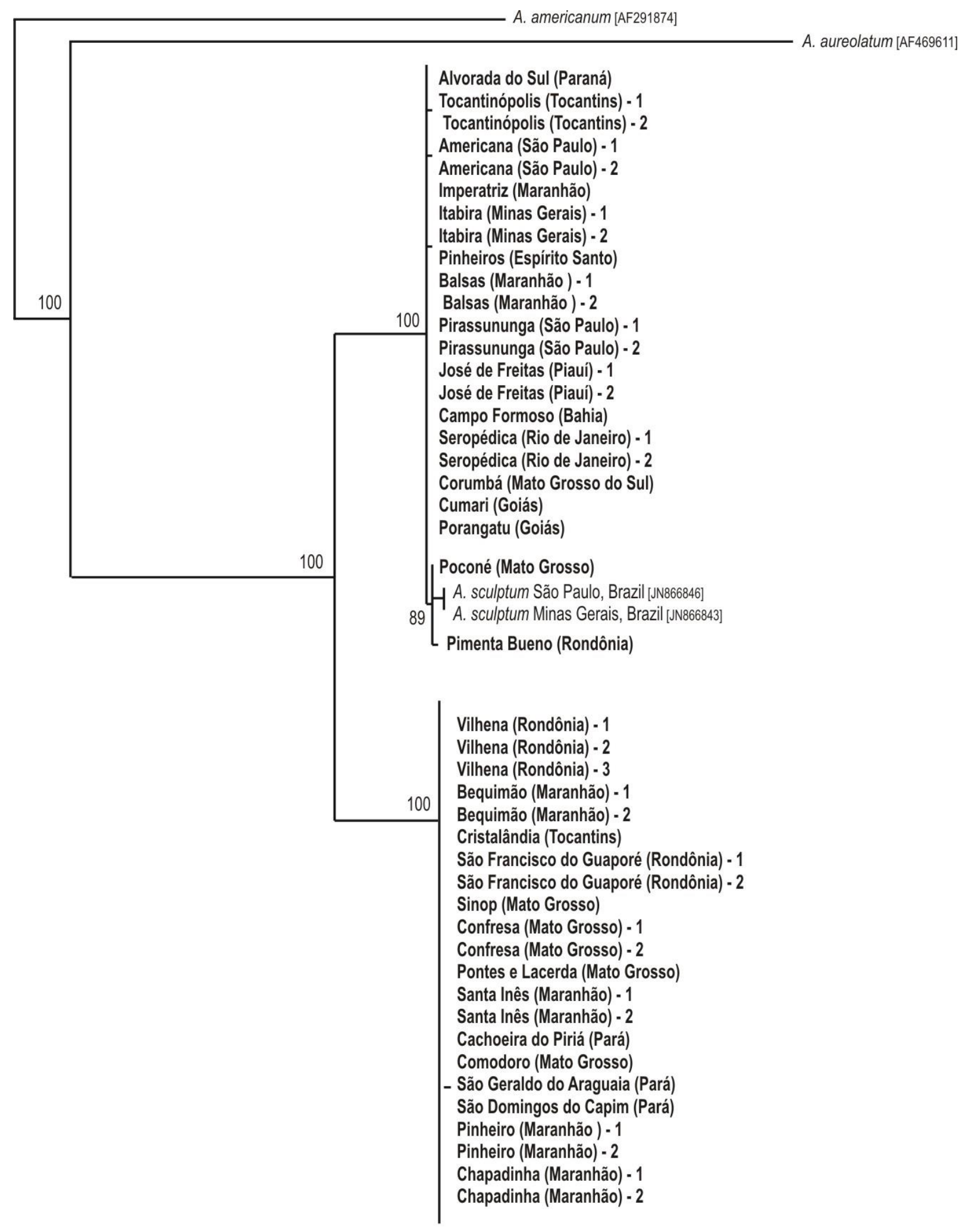


Figura 14 - Árvore filogenética construída por máxima parcimônia, baseada em seqüências de ITS2 rDNA mitocondrial (871 caracteres, 71 sítios informativos) de carrapatos de 30 diferentes localidades. Amblyomma americanum foi utilizado como grupo externo, além de sequências de Amblyomma mixtum, Amblyomma interandinum, Amblyomma patinoi e Amblyomma tonelliae obtidas no

GenBanK. Legenda: Os números correspondem aos valores de suporte de bootstrap em 100 replicatas. As sequências geradas no presente estudo estão em negrito, representadas pelo nome do município, seguido pelo estado brasileiro entre parênteses. Números entre colchetes representam números de acesso do Genbank.

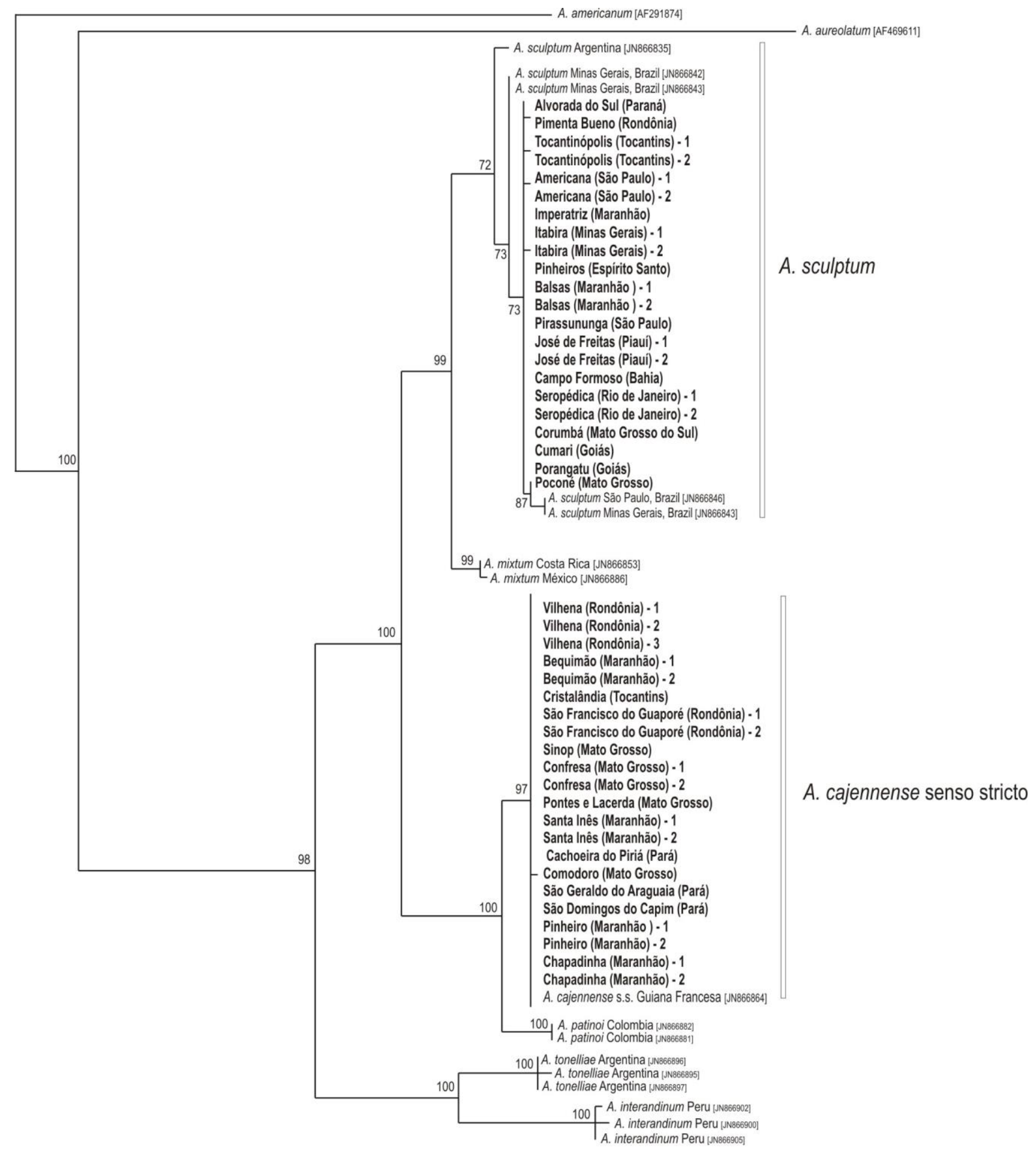

Fonte: (MARTINS, T. F., 2014) 
Figura 15 - Localidades (regiões geopolíticas) onde amostras de carrapatos identificados morfologicamente como sendo do complexo Amblyomma cajennense foram coletados no Brasil para as análises moleculares e filogenéticas no presente estudo. Legenda: Os pontos $(\bullet \bullet)$ correspondem às localidades descritas na Tabela 1

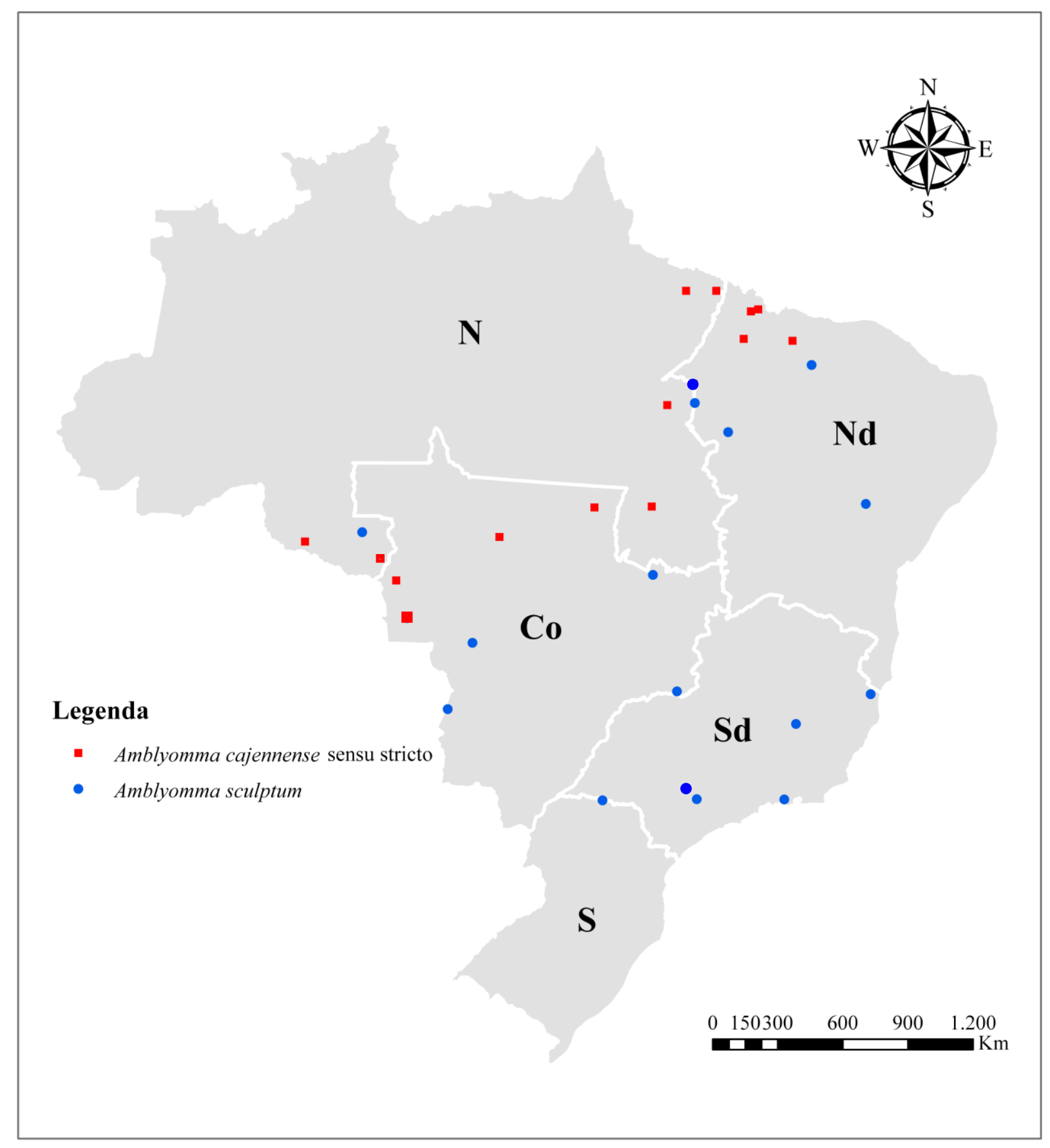


Figura 16 - Localidades (estados da federação) onde amostras de carrapatos identificados morfologicamente como sendo do complexo Amblyomma cajennense foram coletados no Brasil para as análises moleculares e filogenéticas no presente estudo. Legenda: Os pontos $(\bullet \bullet)$ correspondem às localidades descritas na Tabela 1

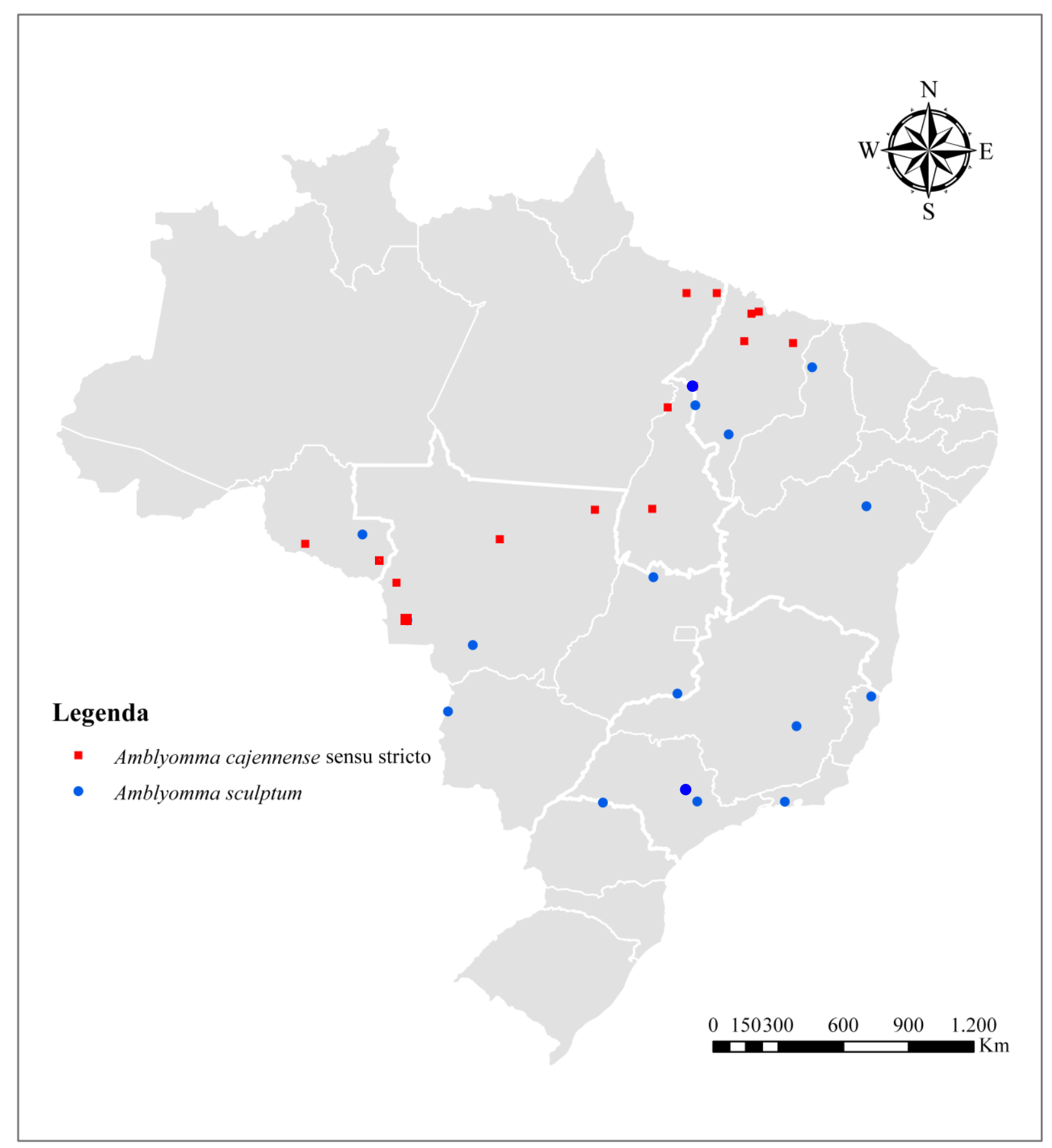




\subsection{MAPAS DE DISTRIBUIÇÃO GEOGRÁFICA DE CARRAPATOS DO COMPLEXO Amblyomma cajennense NO BRASIL}

Nas figuras abaixo (Figuras 17, 18, 19 e 20), são apresentadas as distribuições

geográficas das espécies A. cajennense s. s. e A. sculptum no Brasil, conforme as regiões geopolíticas (estados da federação), biomas, vegetação remanescente e climas. 
Figura 17 - Mapa do Brasil com os estados da federação, demonstrando a distribuição geográfica do complexo Amblyomma cajennense no país

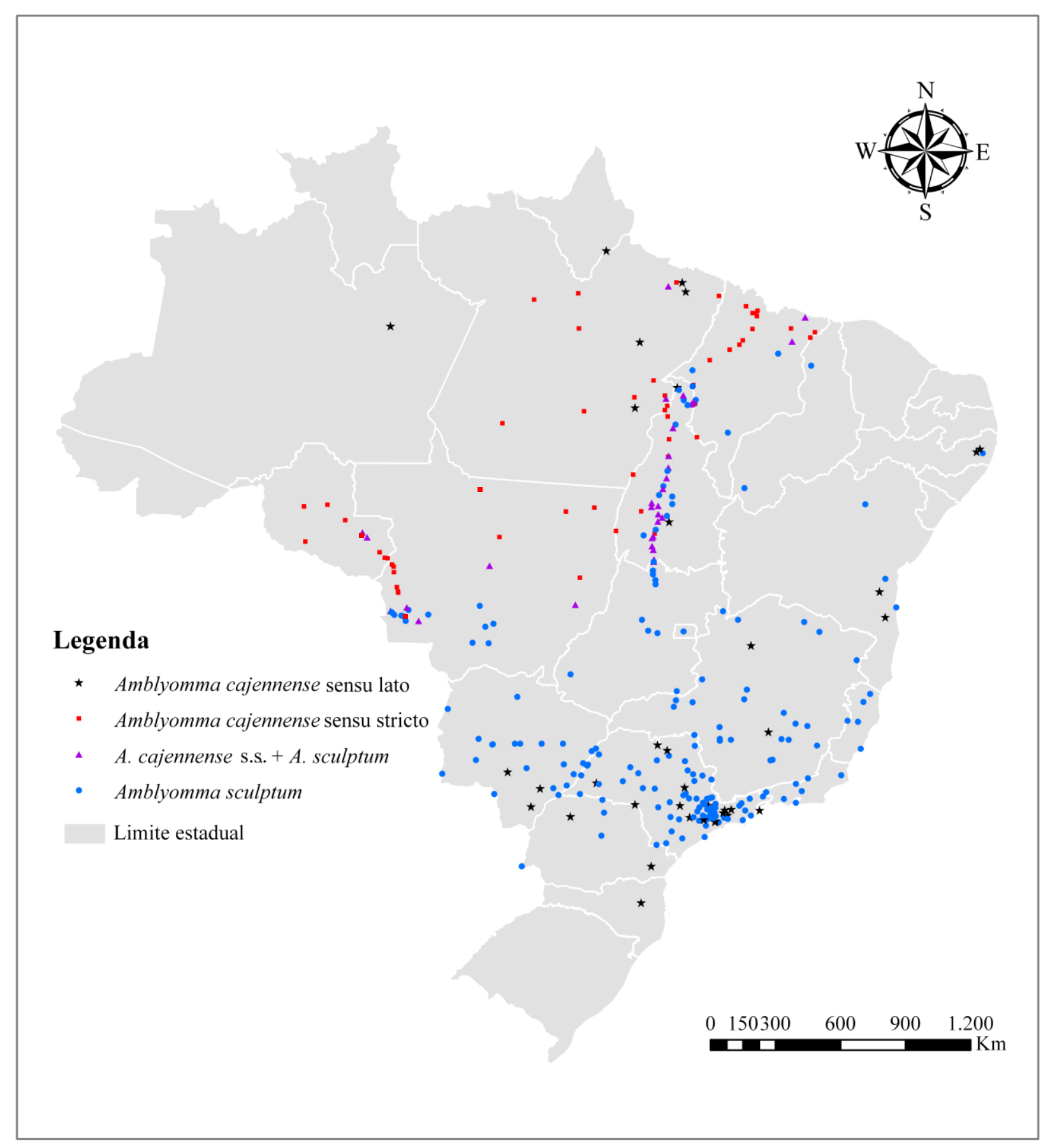


Figura 18 - Mapa do Brasil com os biomas, demonstrando a distribuição geográfica do complexo Amblyomma cajennense no país

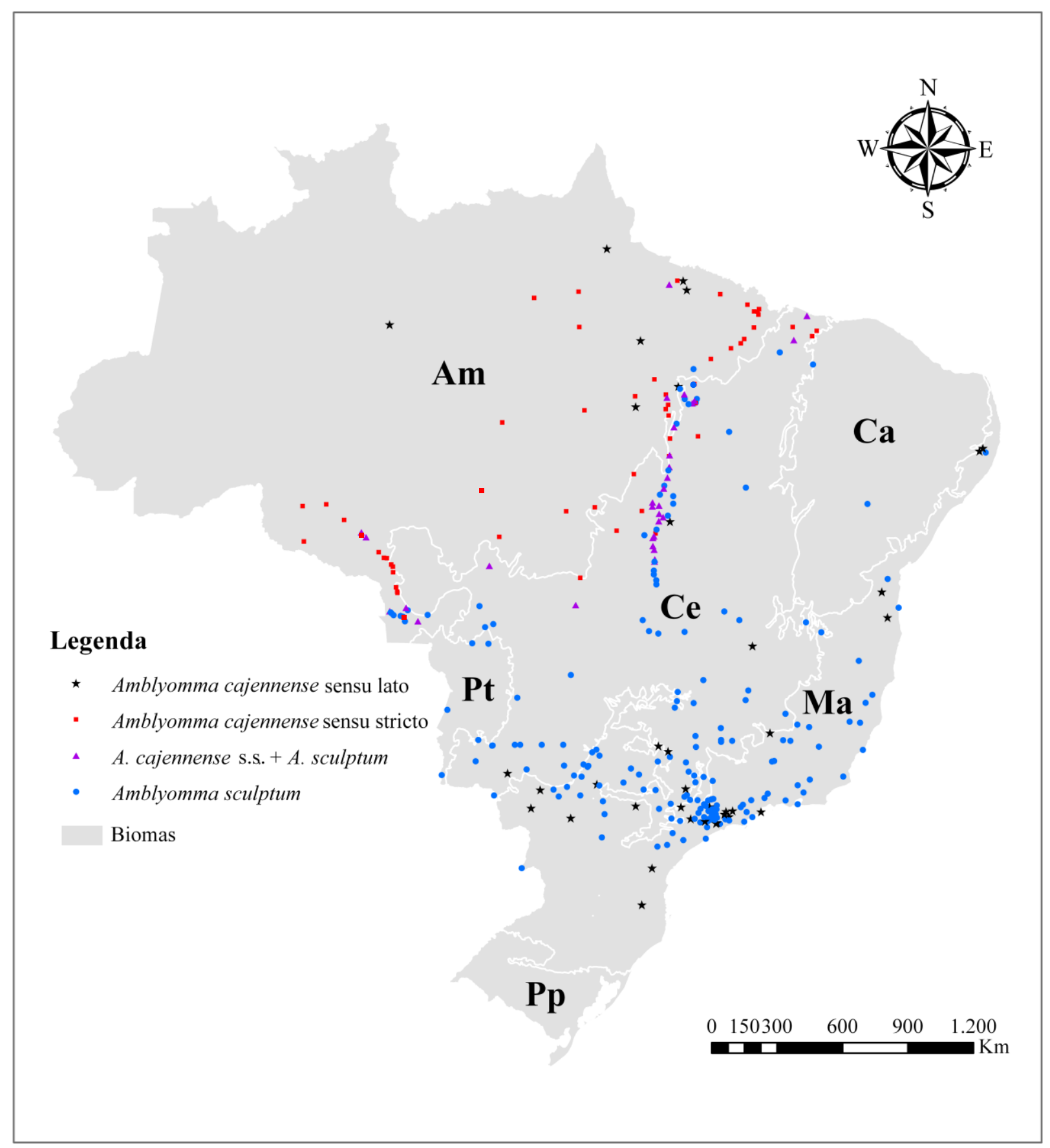

Fonte: (MARTINS, T. F., 2014) 
Figura 19 - Mapa do Brasil com a vegetação remanescente, demonstrando a distribuição geográfica do complexo Amblyomma cajennense no país

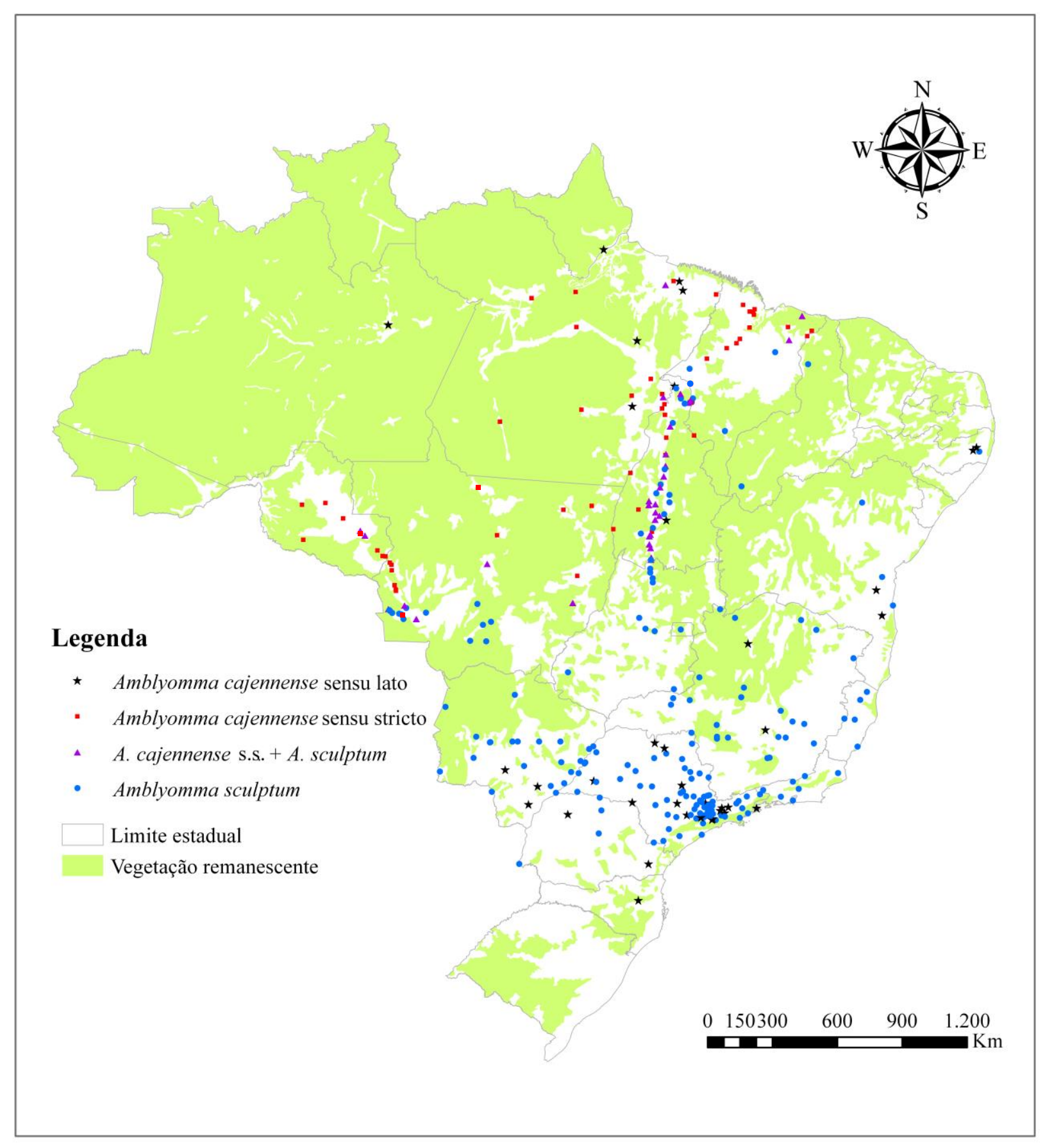

Fonte: (MARTINS, T. F., 2014) 
Figura 20 - Mapa do Brasil com os climas, demonstrando a distribuição geográfica do complexo Amblyomma cajennense no país

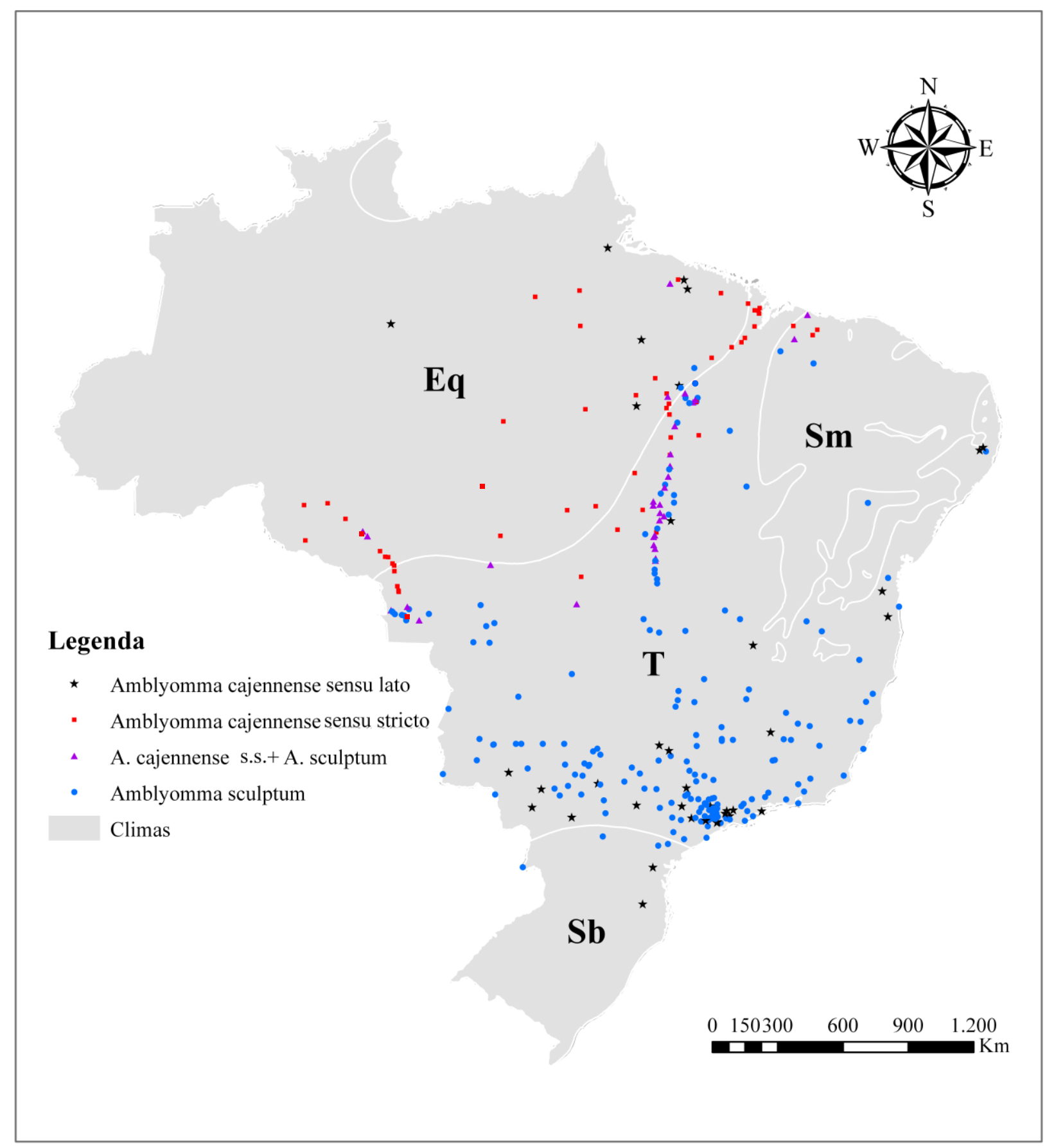

Fonte: (MARTINS, T. F., 2014) 


\section{DISCUSSÃO}

A tarefa básica da sistemática é compreender os modos de especiação. Atualmente os trabalhos sobre especiação de carrapatos são realizados através da análise de diferentes linhas de evidência como caracteres morfológicos discretos e contínuos, cruzamentos e acasalamentos e sequências de DNA. Neste contexto o presente estudo está de acordo com os trabalhos biológicos prévios realizados por Labruna et al. (2011a) e Mastropaolo et al. (2011). O presente estudo corrobora também com os trabalhos recentes de Beati et al. (2013) e Nava et al. $\left(2014^{8}\right)$, tanto nas análises moleculares quanto nas análises morfológicas, que demonstraram que o carrapato A. cajennense é um complexo de seis espécies.

As árvores filogenéticas dos carrapatos do complexo A. cajennense do Brasil construídas no presente estudo demonstraram clados distintos, que tiveram suporte das análises morfológicas dos exemplares fêmeas usados para análises moleculares. O processamento de espécimes machos para análises moleculares foram extremamente necessárias para a identificação exata das espécies em questão, uma vez que segundo Nava et al. $\left(2014^{9}\right)$ os machos do complexo A. cajennense não são facilmente distinguíveis. A separação das fêmeas de A. cajennense s. s. de A. sculptum puderam ser facilmente realizadas pela morfologia da abertura genital, estando de acordo com Nava et al. (2014 ${ }^{10}$ ). Análises integradas (moleculares e morfológicas) foram necessárias para a determinação correta das espécies, principalmente nas áreas de transição entre os biomas Amazônia e Cerrado, corroborando também com Nava et al. $\left(2014^{11}\right)$.

Segundo Nava et al. $\left(2014^{12}\right)$, em termos de distribuição geográfica no território brasileiro A. cajennense s. s. é encontrada na região Amazônica nos estados do Pará, Rondônia, Roraima e Tocantins, enquanto que A. sculptum ocorre em áreas fora da Amazônia nos estados de Pernambuco, Piauí, Goiás, Mato Grosso, Mato Grosso do Sul, Espírito Santo, Minas Gerais, Rio de Janeiro, São Paulo, e Paraná. O presente estudo amplia a distribuição geográfica de A. cajennense s. s. para os estados do Maranhão e Mato Grosso, assim como A. sculptum para os estados do Pará, Rondônia, Tocantins, Bahia, Maranhão e Distrito Federal.

\footnotetext{
8, 9, 10, 11, 12 NAVA, S.; BEATI, L.; LABRUNA, M. B.; CÁCERES, A. G.; MANGOLD, A. J.; GUGLIELMONE, A. A. Reassessment of the taxonomic status of Amblyomma cajennense (Fabricius, 1787) with the description of three new species, Amblyomma tonelliae n. sp., Amblyomma interandinum n. sp. and Amblyomma patinoi n. sp., and resurrection of Amblyomma mixtum Koch, 1844 and Amblyomma sculptum Berlese, 1888 (Ixodida:

Ixodidae). Ticks and Tick-borne Diseases, No prelo, 2014
} 
Apesar de Nava et al. $\left(2014^{13}\right)$ ter relatado A. cajennense s. s. de um hospedeiro desconhecido da Estação Ecológica de Maracá no estado de Roraima, nenhum carrapato foi encontrado para este estado nas duas grandes coleções (CNC e IBSP) analisadas no presente estudo. Por outro lado, foram encontrados machos de A. cajennense s. 1. coletados em um suíno doméstico no município de Macapá, localizado no extremo Norte do país, estado do Amapá, assim como um macho de A. cajennense s. 1. coletado também de um hospedeiro desconhecido no município de Manaus, estado do Amazonas, ambos depositados na coleção IBSP.

Não foi realizada a extração de DNA dos machos de A. cajennense s. 1. depositados nas coleções, devido ao pequeno número de exemplares, assim como a dificuldade de amplificar o DNA extraído no decorrer do presente estudo, embora foram feitas inúmeras tentativas para o estado de Pernambuco por exemplo. Desta forma, optou-se pela permanência íntegra dos machos depositados nas coleções como referência para cada local de coleta.

No presente estudo não foram encontrados carrapatos $A$. cajennense s. 1. em dois estados da região Norte (Acre e Roraima), cinco estados do Nordeste (Alagoas, Ceará, Paraíba, Rio Grande do Norte e Sergipe) e um estado do Sul (Rio Grande do Sul). No entanto, trabalhos anteriores relataram a ocorrência de carrapatos do complexo A. cajennense nos estados de Roraima, Ceará, Paraíba, Rio Grande do Norte, Sergipe e Rio Grande do Sul (ARAGÃO, 1936; ONOFRIO 2007; NAVA et al., 2014 ${ }^{14}$ ). Os estados brasileiros do Acre e Alagoas permanecem sem registros de carrapatos deste complexo, sendo que mais trabalhos devem ser conduzidos no território nacional para conhecer melhor a distribuição geográfica deste complexo no país.

Foram encontrados no presente estudo espécimens de A. sculptum parasitando equinos nos municípios de Belém (Pará) e Pimenta Bueno (Rondônia), dentro da região Amazônica. Esses achados não eram esperados, pois estavam mais adentro do bioma Amazônico, circundados apenas por registros de A. cajennense s. s. (Figura 17). Este padrão diferencia das áreas de transição entre as duas espécies no norte do estado de Mato Grosso, no Tocantins e no oeste do Maranhão, onde A. cajennense s. s. e A. sculptum foram coletados de forma simpátrica em pontos contíguos. Estes dois achados de Belém e Pimenta Bueno podem estar

\footnotetext{
${ }^{13,14}$ NAVA, S.; BEATI, L.; LABRUNA, M. B.; CÁCERES, A. G.; MANGOLD, A. J.; GUGLIELMONE, A. A. Reassessment of the taxonomic status of Amblyomma cajennense (Fabricius, 1787) with the description of three new species, Amblyomma tonelliae n. sp., Amblyomma interandinum n. sp. and Amblyomma patinoi n. sp., and resurrection of Amblyomma mixtum Koch, 1844 and Amblyomma sculptum Berlese, 1888 (Ixodida: Ixodidae).
}

Ticks and Tick-borne Diseases, No prelo, 2014 
associados ao trânsito tanto de animais domésticos (ação antrópica) quanto silvestres, assim como a degradação ambiental e o desmatamento florestal acelerado do bioma Amazônia nestes dois estados (SOUZA et al., 2013). No presente estudo também foram encontrados nos municípios de Pontes e Lacerda e Vila Bela da Santíssima Trindade no Vale do Guaporé, estado do Mato Grosso, a espécie A. sculptum dentro do bioma Amazônico em cavalos e vida livre. Entretanto mais trabalhos de biologia em condições naturais e experimentais (efeitos de diferentes condições de umidade relativa, temperatura e fotoperíodo no desenvolvimento e sobrevivência de cada estágio de vida de carrapatos deste complexo) devem ser realizados para comprovar estas hipóteses e o estabelecimento de A. sculptum dentro da Amazônia brasileira.

Segundo Labruna et al. (2005) o carrapato A. cajennense s. 1. (publicado como A. cajennense) é muito abundante nas regiões Sudeste e Centro-Oeste do Brasil, especialmente no bioma Cerrado e em áreas originais do bioma Mata Atlântica onde a floresta tropical tenha sido degradada ou substituída por pastagens para o gado, contrastando com raros encontros desta espécie de carrapato no bioma Amazônia, região que apesar de ampla no seu território, ainda é mais preservada, com menos interferência humana.

Um trabalho realizado por Szabó et al. (2006) no Parque Estadual de Intervales localizado no estado de São Paulo, demosntraram a ausência de A. sculptum (publicado como A. cajennense) em hospedeiros veado-mateiro-pequeno (Mazama bororo) que vivem dentro da Mata Atlântica da floresta do Parque, sendo encontrado A. sculptum (coletados como ninfas) apenas em uma carcaça de veado-catingueiro (Mazama gouazoubira) fora do Parque, área esta que tinha apenas pequenas manchas de floresta e várias pastagens com animais domésticos (equinos e bovinos). Este resultado indica que este carrapato não habita as florestas tropicais úmidas, mesmo quando os hospedeiros primários estão presentes, demonstrando que o desmatamento ou degradação ambiental pode realmente propiciar a sua propagação, estando de acordo com o presente estudo, uma vez que foram encontrados carrapatos desta espécie em áreas desmatadas da floresta Amazônica.

Ainda no Parque Estadual de Intervales, Szabó et al. (2009) não encontraram A. sculptum (publicado como A. cajennense) em vida livre nas trilhas dentro do Parque, embora os autores tenham relatado a presença de potenciais hospedeiros para o estágio adulto. Este trabalho também indica que este carrapato não habita ambientes não favoráveis (elevada umidade, relativa escuridão e/ou temperaturas relativamente baixas), que poderiam estar impedindo o estabelecimento de A. sculptum dentro da floresta densa, uma vez que um grande número desta espécie de carrapato foi encontrado nas áreas abertas do Parque. Parece 
provável que a distribuição desta espécie de carrapato tenha aumentado como resultado da destruição da Mata Atlântica ao longo dos últimos séculos, ao passo que a distribuição de outras espécies típicas de floresta densa e úmida (ex. Amblyomma incisum Neumann, 1906) possa ter se tornado mais restrita após alterações ambientais.

Este fato é reforçado por Klompen et al. (1996) quando analisaram as associações entre carrapato-hospedeiro, habitat e padrões biogeográficos, demostrando que o meio ambiente é mais importante que os hospedeiros para o estabelecimento de uma determinada espécie de carrapato em uma determinada região, uma vez que o carrapato passa a maior parte do seu tempo no ambiente (especificidade ecológica) e não no hospedeiro.

Nesta mesma linha de pesquisa Nava e Guglielmone (2013) concluíram que a estrita especificidade ao hospedeiro não é comum entre os carrapatos ixodídeos Neotropicais, sugerindo que a influência da ecologia do carrapato e evolução da especificidade ao habitat, tempo de geração do carrapato, fenologia, o tempo gasto fora do hospedeiro e do tipo de ciclo de vida, poderiam ser mais importantes do que as espécies de hospedeiros.

Com todos os fatos expostos acima, é provável que no futuro, áreas hoje ocupadas apenas por A. cajennense s. s., venham a ser ocupadas por A. sculptum no território Amazônico.

A associação negativa entre florestas tropicais (floresta Amazônica) e A. cajennense s. s. (publicado como A. cajennense) foi também relatada anteriormente por Labruna et al. (2005), assim como a associação positiva entre o bioma Cerrado e a espécie A. sculptum (publicado como A. cajennense) foi também relatada previamente (SZABÓ; OLEGÁRIO; SANTOS, 2007).

De uma forma geral, a distribuição da espécie A. cajennense s. s. está confirmada no território brasileiro em dois biomas (Amazônia e em áreas de transição com o Cerrado) corroborando com Labruna et al. (2005) e Nava et al. $\left(2014^{15}\right)$. Já a espécie A. sculptum ocorre tipicamente em três biomas (Cerrado, Pantanal e Mata Atlântica) estando de acordo com Bechara et al. (2000); Szabó et al. (2006) e Veronez et al. (2010). Salientam-se raros achados no bioma Amazônico e um achado na Caatinga de A. sculptum no presente estudo (Figura 18).

\footnotetext{
15 NAVA, S.; BEATI, L.; LABRUNA, M. B.; CÁCERES, A. G.; MANGOLD, A. J.; GUGLIELMONE, A. A. Reassessment of the taxonomic status of Amblyomma cajennense (Fabricius, 1787) with the description of three new species, Amblyomma tonelliae n. sp., Amblyomma interandinum n. sp. and Amblyomma patinoi n. sp., and resurrection of Amblyomma mixtum Koch, 1844 and Amblyomma sculptum Berlese, 1888 (Ixodida: Ixodidae).
}

Ticks and Tick-borne Diseases, No prelo, 2014 
Em quase todas as localidades tanto do material depositado nas duas coleções, quanto as localidades adquiridas pelo LDP, assim como as localidades das três expedições de coleta de A. cajennense s. s., foram realizadas em áreas fragmentadas, fora da vegetação remanescente (Figura 19). O presente estudo corrobora com o trabalho de Labruna et al. (2005), uma vez que os mesmos coletaram carrapatos em corredores mais secos e não nas áreas mais profundas e úmidas da floresta tropical da região Amazônica. O presente estudo também está de acordo o trabalho de Estrada-Peña, Guglielmone e Mangold (2004), que relataram carrapatos na floresta Amazônica em locais dispersos onde a vegetação original tinha sido substituída pela agricultura e pastagens.

Dos 84 registros de A. cajennense s. s., 32 (38\%) estão dentro da área de clima Equatorial e 47 (56\%) dentro da área de clima Tropical. Como a maior parte desses registros ficaram perto da borda geográfica que separa oficialmente estes dois tipos climáticos (Figura 20), esses resultados corroboram os trabalhos anteriores de Estrada-Peña, Guglielmone e Mangold (2004) e Labruna et al. (2005), que relataram que A. cajennense s. 1. não está associado a áreas mais adentro da floresta Amazônica, onde a vegetação encontra-se naturalmente preservada. Os resultados também estão de acordo com Nava et al. $\left(2014^{16}\right)$, que relataram que A. cajennense s. s. ocorre tipicamente nas bordas do bioma Amazônia. Por outro lado, a grande maioria dos registros de A. sculptum do presente estudo está dentro da área de clima Tropical, indicando que este carrapato está fortemente associado a este tipo climático no Brasil, onde estão incluídos os biomas Cerrado, Pantanal e Mata Atlântica corroborando desta forma com Pereira et al. (2000); Szabó et al. (2007) e Szabó et al. (2009).

Foram encontrados ainda no presente estudo carrapatos dentro da região de clima Semiárido, correspondendo às espécies A. cajennense s. s. e A. sculptum em seis municípios do estado do Maranhão, e A. sculptum no município de José de Freitas no estado do Piauí. Horta et al. (2011) trabalhando numa área de clima Semiárido no estado de Pernambuco não encontraram carrapatos desta espécie no bioma Caatinga. Estes achados sugerem uma associção negativa entre estas duas espécies de carrapatos e o clima Semiárido. Entretanto mais trabalhos devem ser conduzidos nos estados da região Nordeste do território nacional

\footnotetext{
16 NAVA, S.; BEATI, L.; LABRUNA, M. B.; CÁCERES, A. G.; MANGOLD, A. J.; GUGLIELMONE, A. A. Reassessment of the taxonomic status of Amblyomma cajennense (Fabricius, 1787) with the description of three new species, Amblyomma tonelliae n. sp., Amblyomma interandinum n. sp. and Amblyomma patinoi n. sp., and resurrection of Amblyomma mixtum Koch, 1844 and Amblyomma sculptum Berlese, 1888 (Ixodida: Ixodidae).
}

Ticks and Tick-borne Diseases, No prelo, 2014 
para estudar o estabelecimento real de carrapatos deste complexo em temperaturas relativamente altas e umidade extremamente baixa.

Foi encontrada a espécie A. sculptum no bioma Caatinga apenas na região de clima Tropical em um único município localizado no estado da Bahia (Campo Formoso). O presente encontro desta espécie na Caatinga está de acordo com Estrada-Peña, Guglielmone e Mangold (2004) e Guglielmone et al. (2004). Aragão (1936) também relatou a ocorrência de carrapatos deste complexo neste bioma em alguns municípios dos estados do Nordeste (Bahia, Ceará, Paraíba e Piauí). Desta forma, a presença de A. sculptum no bioma Caatinga parece ser bem restrita, estando mais associada a regiões de clima Tropical, e praticamente ausente nas áreas de clima Semiárido.

No presente estudo não foram encontrados carrapatos do complexo A. cajennense no bioma Pampa de clima Subtropical. A ausência de carrapatos deste complexo no Pampa corrobora também com Estrada-Peña, Guglielmone e Mangold (2004) que demonstraram carrapatos identificados erroneamente como sendo deste complexo no Sul do Brasil e Uruguai. Entretanto Aragão (1936) relatou a ocorrência de carrapatos deste complexo no bioma Pampa no estado do Rio Grande do Sul nos municípios de Porto Alegre e Pedras Altas na divisa com o Uruguai. Segundo Evans, Martins e Guglielmone (2000), os relatos de $A$. cajennense s. 1. para o Rio Grande do Sul são inválidos, o que exclui este estado da área de distribuição geográfica deste complexo de carrapatos.

$\mathrm{O}$ achado mais meridional de carrapatos do complexo A. cajennense s. 1. do presente estudo correspondeu a um macho de A. cajennense s. 1. coletado em um cão doméstico no município de Presidente Getúlio, no Vale do Itajaí, estado de Santa Catarina, depositado na coleção IBSP. Este encontro está de acordo com Evans, Martins e Guglielmone (2000) e Estrada-Peña, Guglielmone e Mangold (2004), uma vez que as temperaturas extremamente baixas nos estados do Sul limitam o estabelecimento de carrapatos deste complexo nesta região do país.

O presente estudo demonstra que as espécies de carrapatos $A$. cajennense s. s. e $A$. sculptum possuem distribuição geográfica ampla, ocorrem em ecorregiões e climas particulares com zonas de hibridização estreitas. Em um trabalho realizado no continente Africano, mais precisamente na Tanzânia, Lynen et al. (2008) seguindo gradientes climáticos, demonstraram que a zona de sobreposição nos intervalos de distribuição de Rhipicephalus (Boophilus) microplus e Rhipicephalus (Boophilus) decoloratus é caracterizada por uma diminuição da taxa de infestação, bem como a exclusão mútua em bovinos infestados, uma vez que em laboratório foi demonstrado que as cruzas entre essas duas espécies de carrapatos 
geram descendentes inférteis. Muito embora Labruna et al. (2011a) demonstraram que as cruzas entre A. cajennense s. s. e A. sculptum também geram descendentes inférteis, sendo que mais trabalhos devem ser realizados em áreas de sobreposição destas duas espécies do complexo A. cajennense no Brasil para chegar a uma conclusão sobre o índice de infestação em animais parasitados.

A origem geográfica pode ajudar na identificação destas duas espécies nas áreas de distribuição parapátricas, como por exemplo, nos estados do Sudeste do Brasil, onde apenas A. sculptum está estabelecido. Entretanto, nas áreas de transição entre os biomas Amazônia e Cerrado, onde frequentemente foi obervada a ocorrência simpátrica de $A$. cajennense s. s. e A. sculptum, esta identificação taxonômica deve ser realizada com cautela, baseando-se em análises morfológicas das fêmeas ou análises moleculares. Além disso, vale também salientar que o presente estudo foi realizado apenas analisando carrapatos adultos deste complexo, assim como o trabalho de Nava et al. $\left(2014^{17}\right)$, portanto será necessário recolher informações adicionais da morfologia dos estágios imaturos destas duas espécies para uma atualização completa do complexo no país.

O presente estuda indica que o papel de cada uma destas espécies na transmissão de patógenos para hospedeiros deve ser reavaliado de acordo com seu novo status taxonômico, uma vez que pouco se conhecia sobre este complexo no território brasileiro, no que diz respeito à sua distribuição geográfica e taxonomia, assim como diferenças genéticas, biológicas e ecológicas, que podem apontar para diferentes associações com hospedeiros, patógenos e ambiente.

\footnotetext{
${ }^{17}$ NAVA, S.; BEATI, L.; LABRUNA, M. B.; CÁCERES, A. G.; MANGOLD, A. J.; GUGLIELMONE, A. A. Reassessment of the taxonomic status of Amblyomma cajennense (Fabricius, 1787) with the description of three new species, Amblyomma tonelliae n. sp., Amblyomma interandinum n. sp. and Amblyomma patinoi n. sp., and resurrection of Amblyomma mixtum Koch, 1844 and Amblyomma sculptum Berlese, 1888 (Ixodida: Ixodidae).

Ticks and Tick-borne Diseases, No prelo, 2014
} 


\section{CONCLUSÃO}

Os resultados morfológicos e moleculares obtidos no presente estudo demonstraram a ocorrência no Brasil de apenas duas espécies do complexo A. cajennense (A. cajennense s. s. e A. sculptum).

De modo geral, a distribuição da espécie $A$. cajennense s. s. está confirmada no país em três estados do Norte (Pará, Rondônia e Tocantins), em um estado do Nordeste (Maranhão) e no Centro-Oeste (Mato Grosso). Salienta-se um único encontro de uma fêmea de A. cajennense s. s. em uma propriedade rural no município de Porangatu, no extremo Norte do estado de Goiás, na divisa com o estado de Tocantins.

A ocorrência de A. sculptum está confirmada nos seguintes estados brasileiros do Norte: Pará, Rondônia e Tocantins; Nordeste: Bahia, Maranhão, Pernambuco e Piauí; CentroOeste: Distrito Federal, Goiás, Mato Grosso e Mato Grosso do Sul; Sudeste: Espírito Santo, Minas Gerais, Rio de Janeiro e São Paulo; e Sul: Paraná. 


\section{REFERÊNCIAS}

ARAGÃO, H. B. Ixodidas brasileiros e de alguns paizes limitrophes. Memórias do Instituto Oswaldo Cruz, Rio de Janeiro, v. 31, p. 759-844, 1936.

ARAGÃO, H. B.; FONSECA, F. Notas de Ixodologia. V. A propósito da validade de algumas espécies do continente Americano (Acari: Ixodídae). Memórias do Instituto Oswaldo Cruz, Rio de Janeiro, v. 51, p. 485-492, 1953.

ARAGÃO, H. B.; FONSECA, F. Notas de Ixodologia. VIII. Lista e chave para os representantes da fauna ixodológica brasileira. Memórias do Instituto Oswaldo Cruz, Rio de Janeiro, v. 59, p. 115-155, 1961.

ARZUA, M.; BRESCOVIT, A. D. Métodos de coleta e preservação para identificação. In: BARROS-BATTESTI, D. M.; ARZUA, M.; BECHARA, G. H. (Ed.). Carrapatos de importância médico-veterinária da região neotropical: um guia ilustrado para identificação de espécies. São Paulo: Vox/ICTTD-3/Butantan, 2006. p. 183-189.

BARRÉ, N.; UILENBERG, G.; MOREL, P. C.; CAMUS, E. Danger of introducing heartwater onto the American mainland: potential role of indigenous and exotic Amblyomma ticks. Onderstepoort Journal of Veterinary Research, v. 54, p. 405-417, 1987.

BEATI, L.; NAVA, S.; BURKMAN, E. J.; BARROS-BATTESTI, D.; LABRUNA, M. B.; GUGLIELMONE, A. A.; CÁCERES, A. G.; GUZMÁN-CORNEJO, C.; LÉON, R.; DURDEN, A. L.; FACCINI, J. L. H. Amblyomma cajennense (Fabricius, 1787) (Acari: Ixodidae), the Cayenne tick: phylogeography and evidence for allopatric speciation. BMC Evolutionary Biology, v. 13, n.1, p.267, 2013.

BECHARA, G.H.; SZABÓ, M. J. P.; DUARTE, J. M. B.; MATUSHIMA, E. R.; PEREIRA, M. C.; RECHAV, Y.; KEIRANS, J. E. FIELDEN, L. Ticks associated with wild animals in the Nhecolândia Pantanal, Brazil. Annals of the New York Academy of Sciences, v. 916, p. 289-297, 2000.

BELLE, E. A.; KING, S. D.; GRIFFITHS, B. B.; GRANT, L. S. Epidemiological investigation for arboviruses in Jamaica. American Journal of Tropical Medicine and Hygiene, v. 29, p. 667-675, 1980. 
BITTENCOURT, V. R. E.; MASSARD, C. L.; GRISI, L. Atividade in vitro de alguns piretróides sintéticos no carrapato Amblyomma cajennense (Fabricius, 1787). Pesquisa Agropecuária Brasileira, v. 24, p. 1193-1199, 1989.

BRASIL. MINISTÉRIO DO MEIO AMBIENTE. Geoprocessamento. Disponível em: (www.mma.gov.br). Acessado em: 26 nov. 2013.

CABRERA, R. R.; LABRUNA, M. B. Influence of photoperiod and temperature on the larval behavioral diapause of Amblyomma cajennense (Acari: Ixodidae). Journal of Medical Entomology, v. 46, p. 1303-1309, 2009.

CASALS, J. Antigenic properties of tickborne viruses: present state and knowledge. Miscellaneous Publications of the Entomological Society of America, v. 7, p. 327-329, 1970.

CAVALCANTI, I. F. A.; FERREIRA, N. J.; JUSTI, M. G. A.; DIAS, M. A. F. Tempo e Clima no Brasil. Editora Oficina de Textos, 2009. 464 p.

CHOMKZYNSKI, P. A. A reagent for the single-step simultaneous isolation of RNA, DNA and proteins from cell and tissue samples. Biotechniques, v. 15, p. 532-537, 1993.

DE QUEIROZ, K. Ernst Mayr and the modern concept of species. Proceedings of the National Academy of Sciences of the United States of America, v. 102, p. 6600-6607, 2005. Supplement. 1.

ESTRADA-PEÑA, A.; GUGLIELMONE, A. A.; MANGOLD, A. J.; CASTELLÁ, J. Patterns of cuticular hydrocarbon variation and genetic similarity between natural populations of Amblyomma cajennense (Acari: Ixodoidea). Acta Tropica, v. 55, p. 61-78, 1993.

ESTRADA-PEÑA, A.; GUGLIELMONE, A. A.; MANGOLD, A. J. The distribution and ecological "preferences" of the tick Amblyomma cajennense (Acari: Ixodidae), an ectoparasite of humans and other mammals in the Americas. Annals of Tropical Medicine and Parasitology, v. 98, p. 283-292, 2004.

EVANS, D. E.; MARTINS, J. R.; GUGLIELMONE, A. A. A Review of the Ticks (Acari, Ixodida) of Brazil, Their Hosts and Geographic Distribution - 1. The State of Rio Grande do Sul, Southern Brazil. Memórias do Instituto Oswaldo Cruz, Rio de Janeiro, v. 95, p. 453470, 2000. 
FACCINI, J. L. H.; BARROS-BATTESTI, D. M. Aspectos gerais da biologia e identificação de carrapatos. In: BARROS-BATTESTI, D. M.; ARZUA, M.; BECHARA, G. H. (Ed.). Carrapatos de importância médico-veterinária da região neotropical: um guia ilustrado para identificação de espécies. São Paulo: Vox/ICTTD-3/Butantan, 2006. p. 5-12.

FIGUEIREDO, L. T. M.; BADRA, S. J.; PEREIRA, L. E.; SZABÓ, M. P. J. Report of ticks collected in the southeast and mid-west regions of Brazil: analyzing the potential transmission of tick-borne pathogens to man. Revista da Sociedade Brasileira de Medicina Tropical, v. 32, p. 613-619, 1999.

FONSECA, A. H.; SALLES, R. S.; SALLES, S. A. N.; MADUREIRA, R. C.; YOSHINARI, N. H. Borreliose de Lyme simile: uma doença emergente e relevante para a dermatologia no Brasil. Anais Brasileiros de Dermatologia, v. 80, p. 171-178, 2005.

FONSECA, F. Notas de Acareologia. XXI. Gymnandromorphismo em Amblyomma cajennense (Fabr., 1787). Memórias do Instituto Butantan, São Paulo, v. 10, p. 39-41, 1935.

FONSECA, G. A. B.; HERRMAN, G.; LEITE, Y. L. R.; MITTERMEIER, R. A.; RYLANDS, A. B.; PATTON, J. L. Lista anotada dos mamíferos do Brasil. Occasional Papers in Conservation Biology, v. 4, p. 1-38, 1996.

GUGLIELMONE, A. A.; BECHARA, G. H.; SZABÓ, M. P. J.; BARROS-BATTESTI, D. M.; FACCINI, J. L. H.; LABRUNA, M. B.; DE LA VEGA, R.; ARZUA, M.; CAMPOS PEREIRA, M.; FURLONG, J.; MANGOLD, A. J.; MARTINS, J. R.; RODRÍGUES, M.; SERRA-FREIRE, N. M.; VENZAL, J. M. Ticks of importance for domestic animals in Latin America and Caribbean countries. Netherlands: International Consortium on Ticks and Tick-Borne Diseases-2 of the European Comission INCO-DEV programme, 2004. 1CD.

GUGLIELMONE, A. A.; BEATI, L.; BARROS-BATTESTI, D. M.; LABRUNA, M. B.; NAVA, S.; VENZAL, J. M.; MANGOLD, A. J.; SZABÓ, M. P. J.; MARTINS, J. R.; GONZALEZ-ACUÑA, D.; ESTRADA-PEÑA, A. Ticks (Ixodidae) on humans in South America. Experimental and Applied Acarology, v. 40, p. 83-100, 2006 a.

GUGLIELMONE, A. A.; ESTRADA-PEÑA, A.; KEIRANS, J. E.; ROBBINS, R. G. Ticks (Acari: Ixodida) of the neotropical zoogeographic region. Atalanta Houten: International Consortium on Ticks and Tick-borne Diseases, 2003. 173 p.

GUGliELMONE, A. A.; MANGOLD, A. J.; AGUIRRE, D. H.; GAIDO, A. B. Ecological aspects of four species of ticks found on cattle in Salta, northwest Argentina. Veterinary Parasitology, v. 35, p. 93-101, 1990. 
GUGLIELMONE, A. A.; MANGOLD, A. J.; OYOLA, B. C. Ciclo de vida del Amblyomma cajennense (Fabricius, 1787) (Acari: Ixodidae) en condiciones de laboratorio. Revista de Medicina Veterinária, Buenos Aires, v. 73, p. 184-187, 1992.

GUGLIELMONE, A. A.; ROBBINS, R. G.; APANASKEVICH, D. A.; PETNEY, T. N.; ESTRADA-PEÑA, A.; HORAK, I. G. The Hard Ticks of the World (Acari: Ixodida: Ixodidae). Netherlands, Springer Science + Business Media, 2014. 738 p.

GUGLIELMONE, A. A.; SZABÓ, M. P. J.; MARTINS, J. R.; ESTRADA-PEÑA, A. Diversidade e importância de carrapatos na sanidade animal. p. 115-138. In BARROSBATTESTI, D. M.; ARZUA, M.; BECHARA, G. H. (eds.), Carrapatos de importância médico-veterinária da região neotropical: um guia ilustrado para identificação de espécies. São Paulo: Vox/ICTTD-3/Butantan, 2006b. 223p.

GUIMARÃES, J. H.; TUCCI, E. C.; BARROS-BATTESTI, D. M. Ectoparasitas de Importância Veterinária. São Paulo: Editora Plêiade/FAPESP, 2001. p. 52-104.

HILBURN, L. R.; GUNN, S. J.; CASTILLO, C. A comparison of the isozyme phenotypes of the morphologically similar ticks Amblyomma cajennense and A. imitator (Acari: Ixodidae) from South Texas. Journal of Medical Entomology, v. 26, p. 23-29, 1989.

HORTA, M. C.; NASCIMENTO, G. F.; MARTINS, T. F.; LABRUNA, M. B.; MACHADO, L. C. P.; NICOLA, P. A. Ticks (Acari: Ixodida) parasitizing free-living wild animals in the Caatinga biome in the State of Pernambuco, northeastern Brazil. Systematic and Applied Acarology, v. 16, p. 207-2011, 2011.

HUNT, L. M. Differentiation between three species of Amblyomma ticks (Acari: Ixodidae) by analysis of cuticular hydrocarbons. Annals of Tropical Medicine and Parasitology, v. 35, p. 245-249, 1986.

IBGE. INSTITUTO BRASILEIRO DE GEOGRAFIA E ESTATÍSTICA. Mapas. Disponível em: (www.ibge.gov.br). Acessado em: 26 nov. 2013.

KERBER, C. E.; LABRUNA, M. B.; FERREIRA, F.; DE WAAL, D. T.; KNOWLES, D. P.; GENNARI, S. M. Prevalence of equine Piroplasmosis and its association with tick infestation in the State of São Paulo, Brazil. Revista Brasileira de Parasitologia Veterinária, v. 18, p. $1-8,2009$.

KLOMPEN, J. S. H.; BLACK, W. C. IV.; KEIRANS, J. E.; OLIVER JR., J. H. Evolution of ticks. Annual Review of Entomology, v. 41, p. 141-161, 1996. 
KOCH, C. L. Systematische Übersicht über die Ordnung der Zecken. Archiv für Naturgeschicthe, v. 10, p. 217-239, 1844.

KOHLS, G. M. Amblyomma imitator, a new species of tick from Texas and Mexico, and remarks on the synonymy of $A$. cajennense (Fabricius) (Acarina-Ixodidae). Journal of Parasitology, v. 44, p. 430-433, 1958.

LABRUNA, M. B. Brazilian Spotted Fever: The Role of Capybaras. p. 371-383. In FERRAZ, K. M. P. M. B.; HERRERA, E. A.; MACDONALD, D. W. (eds.), Capybara: biology, use and conservation of an exceptional neotropical species. New York, Springer Science + Business Media, 2013. 419p.

LABRUNA, M. B. Ecology of Rickettsia in South America. Annals of the New York Academy of Sciences, v. 1166, p. 156-166, 2009.

LABRUNA, M. B.; AMAKU, M.; METZNER, J. A.; PINTER, A.; FERREIRA, F. Larval behavioral diapause regulates life cycle of Amblyomma cajennense (Acari: Ixodidae) in southeast Brazil. Journal of Medical Entomology, v. 40, p. 170-178, 2003.

LABRUNA, M. B.; CAMARGO, L. M. A.; TERRASSINI, F. A.; FERREIRA, F.; SCHUMAKER, T. S.; CAMARGO, E. P. Ticks (Acari: Ixodidae) from the state of Rondônia, western Amazon, Brazil. Systematic and Applied Acarology, v. 10, p. 17-32, 2005.

LABRUNA, M. B.; KASAI, N.; FERREIRA, F.; FACCINI, J. L. H.; GENNARI, S. M. Seasonal dynamics of ticks (Acari: Ixodidae) on horses in the state of São Paulo, Brazil. Veterinary Parasitology, v. 105, p. 65-77, 2002a.

LABRUNA, M. B.; KERBER, C. E.; FERREIRA, F.; FACCINI, J. L. H.; DE WAAL, D. T.; GENNARI, S. M. Risk factors to tick infestations and their occurrence on horses in the state of São Paulo, Brazil. Veterinary Parasitology, v. 97, p. 1-14, 2001.

LABRUNA, M. B.; LEITE, R. C.; GOBESSO, A. A. O.; GENNARI, S. M.; KASAI, N. Controle estratégico do carrapato Amblyomma cajennense em eqüinos. Ciência Rural, v. 34, p. 195-200, 2004a.

LABRUNA, M. B.; MACHADO, R. Z. Agentes transmitidos por carrapatos na região Neotropical. In: BARROS-BATTESTI, D. M.; ARZUA, M.; BECHARA, G. H. (Ed.). Carrapatos de importância médico-veterinária da região neotropical: um guia ilustrado para identificação de espécies. São Paulo: Vox/ICTTD-3/Butantan, 2006. p. 155-164. 
LABRUNA, M. B.; MCBRIDE, J. W.; BOUYER, D. H.; CAMARGO, L. M. A.; CAMARGO, E. P.; WALKER, D. H. Rickettsia bellii and Rickettsia amblyommii in Amblyomma ticks from the state of Rondônia, Western Amazon, Brazil. Journal of Medical Entomology, v. 41, p. 1073-1081, 2004b.

LABRUNA, M. B.; RIBEIRO, A. F.; CRUZ, M. V.; CAMARGO, L. M. A.; CAMARGO, E. P. Gynandromorphism in Amblyomma cajennense and Rhipicephalus sanguineus (Acari: Ixodidae). Journal of Parasitology, v. 88, p. 810-811, 2002b.

LABRUNA, M. B.; SOARES, J. F.; MARTINS, T. F.; SOARES, H. S.; CABRERA, R. R. Cross-mating experiments with geographically different populations of Amblyomma cajennense (Acari: Ixodidae). Experimental and Applied Acarology, v. 54, p. 41-49, 2011 a.

LABRUNA, M. B.; TERRASSINI, F. A.; CAMARGO, L. M. A. Notes on population dynamics of Amblyomma ticks (Acari: Ixodidae) in Brazil. Journal of Parasitology, v. 95, p. 1016-1018, 2009.

LABRUNA, M. B.; VELILLA S. M.; NAVA, S.; BERMUDEZ, S.; VENZAL, J. M.; DOLZ, G.; ABARCA, K.; ROMERO, L.; DE SOUSA, R.; OTEO, J.; ZAVALA-CASTRO, J. Rickettsiosis in Latin America, Caribbean, Spain and Portugal. Revista MVZ Córdoba, v. 16, p. 2435-2457, 2011b.

LINTHICUM, K. J.; LOGAN, T. M.; BAILEY, C. L.; GORDON, S. W.; PETERS, C. J.; MONATH, T. P.; OSORIO, J.; FRANCY, D. B.; MCLEAN, R. G.; LEDUC, J. W.; GRAHAM, R. R.; JAHRLING, P. B.; MOULTON, J. R.; DOHM, D. J. Venezuelan equine encephalomyelitis virus infection and transmission by the tick Amblyomma cajennense (Arachnida: Ixodidae). Journal of Medical Entomology, v. 28, p. 405-409, 1991.

LYNEN, G.; ZEMAN, P.; BAKUNAME, C.; DI GIULIO, G.; MTUI, P.; SANKA, P.; JONGEJAN, F. Shifts in the distributional ranges of Boophilus ticks in Tanzania: evidence that a parapatric boundary between Boophilus microplus and B. decoloratus follows climate gradients. Experimental and Applied Acarology, v. 44, p. 147-164, 2008.

MANTOVANI, E.; COSTA, I. P.; GAUDITANO, G.; BONOLDI, V. L. N.; HIGUCHI, M. L.; YOSHINARI, N. H. Description of Lyme disease-like syndrome in Brazil. Is it a new tick borne disease or Lyme disease variation? Brazilian Journal of Medical and Biological Research, v. 40, p. 443-456, 2007. 
MARRELLI, M. T.; SOUZA, L. F.; MARQUES, R. C.; LABRUNA, M. B.; MATIOLI, S. R.; TONON, A. P.; RIBOLLA, P. E.; MARINOTTI, O.; SCHUMAKER, T. T. Taxonomic and phylogenetic relationships between neotropical species of ticks from genus Amblyomma (Acari: Ixodidae) inferred from second internal transcribed spacer sequences of rDNA. Journal of Medical Entomology, v. 44, p. 222-228, 2007.

MARTINS, J. R.; FURLONG, J.; LEITE, R. C. Controle de carrapatos. In: BARROSBATTESTI, D. M.; ARZUA, M.; BECHARA, G. H. (Ed.). Carrapatos de importância médico-veterinária da região neotropical: um guia ilustrado para identificação de espécies. São Paulo: Vox/ICTTD-3/Butantan, 2006. p. 145-153.

MASTROPAOLO, M.; NAVA, S.; GUGLIELMONE, A. A.; MANGOLD, A. J. Biological differences between two allopatric populations of Amblyomma cajennense (Acari: Ixodidae) in Argentina. Experimental and Applied Acarology, v. 53, p. 371-375, 2011.

MCLAIN, D. K.; WESSON, D. M.; OLIVER JR, J. H.; COLLINS, F. H. Variation in ribosomal DNA internal transcribed spaces 1 among eastern populations of Ixodes scapularis (Acari: Ixodidae). Journal of Medical Entomology, v. 32, p. 353-360, 1995.

MENDONÇA, F.; DANNI-OLIVEIRA, I. M. Climatologia-noções básicas e climas do Brasil. São Paulo: Editora Oficina de Textos, 2007. 206 p.

NAVA, S.; BEATI, L.; LABRUNA, M. B.; CÁCERES, A. G.; MANGOLD, A. J.; GUGLIELMONE, A. A. Reassessment of the taxonomic status of Amblyomma cajennense (Fabricius, 1787) with the description of three new species, Amblyomma tonelliae n. sp., Amblyomma interandinum n. sp. and Amblyomma patinoi n. sp., and resurrection of Amblyomma mixtum Koch, 1844 and Amblyomma sculptum Berlese, 1888 (Ixodida: Ixodidae). Ticks and Tick-borne Diseases, 2014 (no prelo).

NAVA, S.; GUGLIELMONE, A. A. A meta-analysis of host specificity in Neotropical hard ticks (Acari: Ixodidae). Bulletin of Entomological Research, v. 103, p. 216-224, 2013.

NEUMANN, L. G. Révision de la famille des Ixodidés (3ème mémoire). Mémoires de la Sociéte Zoologique de France, v. 12, p. 107-294, 1899.

NICHOLAS, K. B.; NICHOLAS JR., H. B. GeneDoc: a tool for editing and annotating multiple sequence alignments. Pittsburgh: Pittsburgh Supercomputing Center, 1997. 1 CDROM.

OLIVEIRA, P. R.; BORGES, L. M.; LEITE, R. C.; FREITAS, C. M. Seasonal dynamics of the cayenne tick, Amblyomma cajennense on horses in Brazil. Medical and Veterinary Entomology, v. 17, p. 412-416, 2003. 
OLIVEIRA, P. R.; BORGES, L. M. F.; LOPES, C. M. L.; LEITE, R. C. Population dynamics of the free-living stages of Amblyomma cajennense (Fabricius, 1787) (Acari: Ixodidae) on pastures of Pedro Leopoldo, Minas Gerais State, Brazil. Veterinary Parasitology, v. 92, p. 395-301, 2000.

ONOFRIO, V. C. Revisão do gênero Amblyomma Koch, 1844 (Acari: Ixodidae) no Brasil. 2007. 174 f. Tese (Doutorado em Ciências Veterinárias) - Universidade Federal Rural do Rio de Janeiro, Seropédica, 2007.

ONOFRIO, V. C.; LABRUNA, M. B.; PINTER, A.; GIACOMIN, F. G.; BARROSBATTESTI, D. M. Comentários e chaves para as espécies do gênero Amblyomma. In: BARROS-BATTESTI, D. M.; ARZUA, M.; BECHARA, G. H. (Ed.). Carrapatos de importância médico-veterinária da região neotropical: um guia ilustrado para identificação de espécies. São Paulo: Vox/ICTTD-3/Butantan, 2006. p. 53-113.

PAGLIA, A. P.; FONSECA, G. A. B.; RYLANDS, A. B.; HERRMAN, G.; AGUIAR, L. M. S.; CHIARELLO, A. G.; LEITE, Y. L. R.; COSTA, L. P.; SICILIANO, S.; KIERULFF, M. C. M.; MENDES, S. L.; TAVARES, V. C.; MITTERMEIER, R. A.; PATTON, J. L. Lista anotada dos mamíferos do Brasil. Occasional Papers in Conservation Biology, v. 6, p. 1-76, 2012.

PECKLE, M.; PIRES, M. S.; DOS SANTOS, T. M.; ROIER, E. C.; DA SILVA, C. B.; VILELA, J. A.; SANTOS, H. A.; MASSARD, C. L. Molecular epidemiology of Theileria equi in horses and their association with possible tick vectors in the state of Rio de Janeiro, Brazil. Parasitology Research, v. 112, p. 2017-2025, 2013.

PEREIRA, M. C.; SZABÓ, M. J. P.; BECHARA, G. H.; MATUSHIMA, E. R.; DUARTE, J. M. B.; RECHAV, Y.; FIELDEN, L.; KEIRANS, J. E. Ticks (Acari: Ixodidae) Associated with Wild Animals in the Pantanal Region of Brazil. Journal of Medical Entomology, v. 37, p. 979-983, 2000.

POUCHER, K. L.; HUTCHESON, H. J.; KEIRANS, J. E.; DURDEN, L. A.; BLACK, W. C. Molecular genetic key for the identification of 17 Ixodes species of the United States (Acari: Ixodidae): a methods model. Journal of Parasitology, v. 85, p. 623-629, 1999.

REIS, N.; PERACCHI, A. L.; PEDRO, W. A.; LIMA, I. P. Mamíferos do Brasil. 2. ed. Londrina, PR, UEL, 2011. 439p. 
RIBEIRO, M. F.; DA SILVEIRA, J. A.; BASTOS, C. V. Failure of the Amblyomma cajennense nymph to become infected by Theileria equi after feeding on acute or chronically infected horses. Experimental Parasitology, v. 128, p. 324-327, 2011.

RIBEIRO, M. F. B.; GUIMARÃES, A. M. Encephalitozoon-like Microsporidia in ticks Amblyomma cajennense and Anocentor nitens (Acari: Ixodidae). Journal of Medical Entomology, v. 35, p. 1029-1033, 1998.

ROBINSON, L. E. Ticks. A monograph of the Ixodoidea Part IV. The genus Amblyomma. London: Cambridge University Press, 1926. 302 p.

RONQUIST, F.; HUELSENBECK, J. P. Mrbayes 3: Bayesian phylogenetic inference under mixed models. Bioinformatics, v. 19, p. 1572-1574, 2003.

SAMBROOK, J.; FRITSCH, E. F.; MANIATIS, T. Molecular cloning: a laboratory manual. 2. ed. Michigan: Cold Spring Harbour Laboratory Press, 1989. 2344 p.

SANGIONI, L. A.; HORTA, M. C.; VIANNA, M. C. B.; GENNARI, S. M.; SOARES, R. M.; GALVÃO, M. A. M.; SCHUMAKER, T. T. S.; FERREIRA, F.; VIDOTTO, O.; LABRUNA, M. B. Rickettsial infection in animals and Brazilian Spotted Fever endemicity. Emerging Infectious Diseases, v. 11, p. 265-270, 2005.

SBH. SOCIEDADE BRASILEIRA DE HERPETOLOGIA Lista de espécies de répteis do Brasil. Disponível em: (http://www.sbherpetologia.org.br/checklist/repteis.htm). Acessado em: 26 maio 2012.

SCHWARTZ, D. A.; SOBOTTKA, I.; LEITCH, G. J.; VISVESVARA, G. S. Pathology of microsporidiosis. Emerging parasitic infections in patients with immunodeficiency syndrome. Archives of Pathology and Laboratory Medicine, v. 120, p. 173-188, 1996.

SERRA-FREIRE, N. M. Tick paralysis in Brasil. Tropical Animal Health and Production, V. 15 , p. 124-126, 1983.

SHINJO, S. K.; GAUDITANO, G.; MARCHIORI, P. E.; BONOLDI, V. L. N.; COSTA, I. P.; MANTOVANI, E.; YOSHINARI, N. H. Manifestação neurológica na síndrome de BaggioYoshinari (Síndrome brasileira semelhante à doença de Lyme). Revista Brasileira de Reumatologia, v. 49, p. 492-505, 2009.

SICK, H. Ornitologia brasileira. Rio de Janeiro: Nova Fronteira, 1997. 912 p. 
SCOLES, G. A.; HUTCHESON, H. J.; SCHLATER, J. L.; HENNAGER, S. G.; PELZEL, A. M.; KNOWLES, D. P. Equine piroplasmosis associated with Amblyomma cajennense Ticks, Texas, USA. Emerging Infectious Disease, v. 17, p. 1903-1905, 2011.

SOARES, J. F.; SOARES, H. S.; BARBIERI, A. M.; LABRUNA, M. B. Experimental infection of the tick Amblyomma cajennense, Cayenne tick, with Rickettsia rickettsii, the agent of Rocky Mountain spotted fever. Medical and Veterinary Entomology, v. 26, p. 139$151,2011$.

SOUZA, A. P.; SERRA-FREIRE, N. M. Variação sazonal da fase não parasitária de Amblyomma cajennense e Anocentor nitens, no município de Itaguaí, RJ: avaliação epidemiológica e metodológica. Revista da Universidade Rural - Série Ciências da Vida, v. 16, p. 67-74, 1994.

SOUZA JR, C.; SIQUEIRA, J.; RIBEIRO, J.; SALES, M. Desmatamento e degradação florestal do Bioma Amazônia (2000-2010). Belém: Imazon, 2013. p. 2.

STOCKMAN, A. K.; BOND, J. E. Delimiting cohesion species: extreme population structuring and the role of ecological interchangeability. Molecular Ecology, v. 16, p. 33743392, 2007.

SWOFFORD, D. L. PAUP*: Phylogenetic Analysis Using Parsimony (and other methods). Versão 4.0 beta. Sunderland MA: Sinauer Associates. University State Florida, 1998. 1 CD-ROM.

SZABÓ, M. P. J.; LABRUNA, M. B.; GARCIA, M.; PINTER, A.; CASTAGNOLLI, K.; CASTRO, M. B.; VERONEZ, V.; MAGALHAES, G.; VOGLIOTTI, A.; DUARTE, J. M. B. Ecological aspects of the free-living ticks (Acari: Ixodidae) on animal trails within Atlantic rainforest in south-eastern Brazil. Annals of Tropical Medicine and Parasitology, v. 103, p. 57-72, 2009.

SZABÓ, M. P. J.; LABRUNA, M. B.; VOGLIOTTI, A; DUARTE, J. M. B. Ticks (Acari: Ixodidae) on Small Red Brocket Deer (Mazama bororo Duarte) along Deer Trails in the Atlantic Rain Forest of Southeastern Brazil. Systematic and Applied Acarology, v. 11, p. 41-45, 2006.

SZABÓ, M. P. J.; OLEGÁRIO, M. M.; SANTOS, A. L. Q. Tick fauna from two locations in the Brazilian savannah. Experimental and Applied Acarology, v. 43, p. 73-84, 2007. 
TERRASSINI, F. A.; BARBIERI, F. S.; ALBUQUERQUE, S.; SZABÓ, M. P. J.;

CAMARGO, L. M. A.; LABRUNA, M. B.; CAMARGO, L. M. A. Comparison of two methods for collecting free-living ticks in the Amazonian forest. Ticks and Tick-borne Diseases, v. 1, p. 194-196, 2010.

THOMPSON, J. D.; GIBSON, T. J.; PLEWNIAK, F.; JEANMOUGIN, F.; HIGGINS, D. G. The Clustal_X windows interface: flexible strategies for multiple sequence alignment aided by quality analysis tools. Nucleic Acids Research, v. 27, p. 4876-4882, 1997.

TONELLI-RONDELLI, M. Ixodoidea. Parte II. Contributo alla conoscenza della fauna ixodologica sud-americana. Spedizione del Prof. Beccari nella Gujana inglese ed a Trinidad. Rivista di Parassitologia, v. 3, p. 39-55, 1939.

UILENBERG, G. Heartwater (Cowdria ruminantium infection): current status. Advances in Veterinary Science and Comparative Medicine, v. 27, p. 427-480, 1983.

VEITIA, R. A.; VAIMAN, D. Exploring the mechanistic bases of heterosis from the perspective of macromolecular complexes. Faseb Journal, v. 25, p. 476-482, 2011.

VERONEZ, V. A.; FREITAS, B. Z.; OLEGÁRIO, M. M.; CARVALHO, W. M.; PASCOLI, G. V.; THORGA, K.; GARCIA, M. V.; SZABÓ, M. P. J. Ticks (Acari: Ixodidae) within various phytophysiognomies of a Cerrado reserve in Uberlândia, Minas Gerais, Brazil. Experimental and Applied Acarology, v. 50, p. 169-179, 2010.

VIEIRA, A. M. L.; SOUZA, C. E.; LABRUNA, M. B.; MAYO, R. C.; SOUZA, S. S. L.; CAMARGO-NEVES, V. L. F. Manual de Vigilância Acarológica do Estado de São Paulo. São Paulo: SUCEN, 2004. 62 p.

YOSHINARI, N. H.; BARROS, P. J. L.; BONOLDI, V. L. N.; ISHIKAWA, M.; BARROSBATTESTI, D. M.; PIRANA, S.; FONSECA, A. H.; SCHUMAKER, T. T. Outline of Lyme borreliosis in Brazil. Revista do Hospital das Clínicas da Faculdade de Medicina da Universidade de São Paulo, v. 52, p. 111-117, 1997.

WHEELER, Q.; MEIER, R. Species concepts and phylogenetic theory. New York: Columbia Univ. Press, 2000. v. 1, 230 p.

ZAHLER, M.; GOTHE, R.; RINDER, H. Genetic evidence against a morphologically suggestive conspecificity of Dermacentor reticulatus and D. marginatus (Acari: Ixodidae). International Journal for Parasitology, v. 25, p. 1413-1419, 1995. 
Apêndice A - Matriz de divergência (\%) das sequências obtidas no presente estudo e comparadas às sequências obtidas no Genbank

\begin{tabular}{|c|c|c|c|c|c|c|c|c|c|c|}
\hline & & 1 & 2 & 3 & 4 & 5 & 6 & 7 & 8 & 9 \\
\hline A. americanum [AF291874] & 1 & & & & & & & & & \\
\hline A. aureolatum [AF469611] & 2 & 19.06 & & & & & & & & \\
\hline A. sculptum Argentina [JN866835] & 3 & 13.19 & 16.98 & & & & & & & \\
\hline A. tonelliae Argentina [JN866896] & 4 & 14.13 & 18.28 & 6.66 & & & & & & \\
\hline A. interandinum Peru [JN866902] & 5 & 14.20 & 18.33 & 7.62 & 3.82 & & & & & \\
\hline A. sculptum Minas Gerais, Brazil [JN866843] & 6 & 12.83 & 16.96 & 0.49 & 6.65 & 7.61 & & & & \\
\hline A. cajennense s. s. Guiana Francesa [JN866864] & 7 & 13.07 & 17.79 & 3.94 & 7.51 & 8.47 & 3.94 & & & \\
\hline A. tonelliae Argentina [JN866895] & 8 & 14.37 & 18.51 & 6.91 & 0.25 & 4.06 & 6.90 & 7.76 & & \\
\hline A. patinoi Colômbia [JN866882] & 9 & 12.59 & 17.43 & 4.31 & 7.64 & 8.47 & 4.31 & 1.36 & 7.88 & \\
\hline A. patinoi Colômbia [JN866881] & 10 & 12.59 & 17.43 & 4.31 & 7.64 & 8.47 & 4.31 & 1.36 & 7.88 & 0.00 \\
\hline A. interandinum Peru [JN866902] & 11 & 14.29 & 18.41 & 7.72 & 3.93 & 0.37 & 7.71 & 8.57 & 4.18 & 8.57 \\
\hline A. mixtum Costa Rica [JN866853] & 12 & 12.83 & 16.51 & 1.48 & 6.54 & 7.25 & 1.48 & 3.57 & 6.78 & 3.94 \\
\hline A. tonelliae Argentina [JN866897] & 13 & 14.13 & 18.28 & 6.66 & 0.00 & 3.82 & 6.65 & 7.51 & 0.25 & 7.64 \\
\hline A. sculptum Minas Gerais, Brazil [JN866843] & 14 & 12.83 & 16.96 & 0.49 & 6.65 & 7.61 & 0.00 & 3.94 & 6.90 & 4.31 \\
\hline A. mixtum México [JN866886] & 15 & 12.95 & 16.63 & 1.61 & 6.41 & 7.37 & 1.60 & 3.69 & 6.66 & 4.06 \\
\hline A. interandinum Peru [JN866900] & 16 & 14.08 & 18.21 & 7.49 & 3.69 & 0.12 & 7.48 & 8.34 & 3.94 & 8.34 \\
\hline A. sculptum São Paulo, Brazil [JN866846] & 17 & 12.95 & 17.08 & 0.37 & 6.77 & 7.73 & 0.12 & 4.06 & 7.02 & 4.43 \\
\hline Santa Inês (Maranhão) - 1 & 18 & 13.07 & 17.79 & 3.94 & 7.51 & 8.47 & 3.94 & 0.00 & 7.76 & 1.36 \\
\hline A. sculptum Minas Gerais, Brazil [JN866842] & 19 & 13.07 & 16.96 & 0.99 & 7.37 & 8.32 & 0.74 & 4.42 & 7.62 & 4.79 \\
\hline Alvorada do Sul (Paraná) & 20 & 12.61 & 16.75 & 0.74 & 6.89 & 7.84 & 0.25 & 3.94 & 7.13 & 4.31 \\
\hline Americana (São Paulo) - 1 & 21 & 12.61 & 16.75 & 0.74 & 6.89 & 7.84 & 0.25 & 3.94 & 7.13 & 4.31 \\
\hline Tocantinópolis (Tocantins) - 1 & 22 & 12.73 & 16.75 & 0.86 & 7.01 & 7.97 & 0.37 & 4.06 & 7.26 & 4.43 \\
\hline Tocantinópolis (Tocantins) - 2 & 23 & 12.61 & 16.75 & 0.74 & 6.89 & 7.84 & 0.25 & 3.94 & 7.13 & 4.31 \\
\hline Imperatriz (Maranhão) & 24 & 12.73 & 16.86 & 0.86 & 7.01 & 7.72 & 0.37 & 4.06 & 7.26 & 4.43 \\
\hline Itabira (Minas Gerais) - 1 & 25 & 12.61 & 16.75 & 0.74 & 6.89 & 7.84 & 0.25 & 3.94 & 7.13 & 4.31 \\
\hline Poconé (Mato Grosso) & 26 & 12.73 & 16.86 & 0.62 & 7.01 & 7.97 & 0.37 & 4.06 & 7.26 & 4.43 \\
\hline Pinheiros (Espírito Santo) & 27 & 12.61 & 16.75 & 0.74 & 6.89 & 7.84 & 0.25 & 3.94 & 7.13 & 4.31 \\
\hline Balsas (Maranhão) - 1 & 28 & 12.61 & 16.75 & 0.74 & 6.89 & 7.84 & 0.25 & 3.94 & 7.13 & 4.31 \\
\hline Balsas (Maranhão) - 2 & 29 & 12.73 & 16.86 & 0.86 & 7.01 & 7.97 & 0.37 & 4.06 & 7.26 & 4.43 \\
\hline Americana (São Paulo) - 2 & 30 & 12.61 & 16.75 & 0.74 & 6.89 & 7.84 & 0.25 & 3.94 & 7.13 & 4.31 \\
\hline Pirassununga (São Paulo) - 1 & 31 & 12.61 & 16.75 & 0.74 & 6.89 & 7.84 & 0.25 & 3.94 & 7.13 & 4.31 \\
\hline Pirassununga (São Paulo) - 2 & 32 & 12.61 & 16.75 & 0.74 & 6.89 & 7.84 & 0.25 & 3.94 & 7.13 & 4.31 \\
\hline Pirassununga (São Paulo) - 3 & 33 & 12.61 & 16.75 & 0.74 & 6.89 & 7.84 & 0.25 & 3.94 & 7.13 & 4.31 \\
\hline José de Freitas (Piauí) - 1 & 34 & 12.61 & 16.75 & 0.74 & 6.89 & 7.84 & 0.25 & 3.94 & 7.13 & 4.31 \\
\hline Campo Formoso (Bahia) & 35 & 12.61 & 16.75 & 0.74 & 6.89 & 7.84 & 0.25 & 3.94 & 7.13 & 4.31 \\
\hline Itabira (Minas Gerais) - 2 & 36 & 12.61 & 16.75 & 0.74 & 6.89 & 7.84 & 0.25 & 3.94 & 7.13 & 4.31 \\
\hline Corumbá (Mato Grosso do Sul) & 37 & 12.73 & 16.63 & 0.86 & 7.01 & 7.97 & 0.37 & 4.06 & 7.26 & 4.43 \\
\hline José de Freitas (Piauí) - 2 & 38 & 12.61 & 16.75 & 0.74 & 6.89 & 7.84 & 0.25 & 3.94 & 7.13 & 4.31 \\
\hline Seropédica (Rio de Janeiro) - 1 & 39 & 12.61 & 16.75 & 0.74 & 6.89 & 7.84 & 0.25 & 3.94 & 7.13 & 4.31 \\
\hline Seropédica (Rio de Janeiro) - 2 & 40 & 12.73 & 16.63 & 0.86 & 7.01 & 7.97 & 0.37 & 4.06 & 7.26 & 4.43 \\
\hline Porangatu (Goiás) & 41 & 12.61 & 16.75 & 0.74 & 6.89 & 7.84 & 0.25 & 3.94 & 7.13 & 4.31 \\
\hline Cumari (Goiás) & 42 & 12.61 & 16.75 & 0.74 & 6.89 & 7.84 & 0.25 & 3.94 & 7.13 & 4.31 \\
\hline Chapadinha (Maranhão) - 1 & 43 & 13.19 & 17.67 & 4.06 & 7.64 & 8.59 & 4.06 & 0.12 & 7.88 & 1.48 \\
\hline Chapadinha (Maranhão) - 2 & 44 & 13.19 & 17.67 & 4.06 & 7.64 & 8.59 & 4.06 & 0.12 & 7.88 & 1.48 \\
\hline São Francisco do Guaporé (Rondônia) - 1 & 45 & 13.07 & 17.79 & 3.94 & 7.51 & 8.47 & 3.94 & 0.00 & 7.76 & 1.36 \\
\hline Pontes e Lacerda (Mato Grosso) & 46 & 13.07 & 17.79 & 3.94 & 7.51 & 8.47 & 3.94 & 0.00 & 7.76 & 1.36 \\
\hline Cristalândia (Tocantins) - 1 & 47 & 13.07 & 17.79 & 3.94 & 7.51 & 8.47 & 3.94 & 0.00 & 7.76 & 1.36 \\
\hline Pimenta Bueno (Rondônia) & 48 & 13.19 & 17.67 & 4.06 & 7.64 & 8.59 & 4.06 & 0.12 & 7.88 & 1.48 \\
\hline Vilhena (Rondônia) - 1 & 49 & 13.07 & 17.79 & 3.94 & 7.51 & 8.47 & 3.94 & 0.00 & 7.76 & 1.36 \\
\hline Vilhena (Rondônia) - 2 & 50 & 13.07 & 17.79 & 3.94 & 7.51 & 8.47 & 3.94 & 0.00 & 7.76 & 1.36 \\
\hline Vilhena (Rondônia) - 3 & 51 & 13.07 & 17.79 & 3.94 & 7.51 & 8.47 & 3.94 & 0.00 & 7.76 & 1.36 \\
\hline São Francisco do Guaporé (Rondônia) - 2 & 52 & 13.07 & 17.79 & 3.94 & 7.51 & 8.47 & 3.94 & 0.00 & 7.76 & 1.36 \\
\hline Cristalândia (Tocantins) - 2 & 53 & 13.07 & 17.79 & 3.94 & 7.51 & 8.47 & 3.94 & 0.00 & 7.76 & 1.36 \\
\hline Cristalândia (Tocantins) - 3 & 54 & 13.07 & 17.79 & 3.94 & 7.51 & 8.47 & 3.94 & 0.00 & 7.76 & 1.36 \\
\hline Sinop (Mato Grosso) & 55 & 13.07 & 17.79 & 3.94 & 7.51 & 8.47 & 3.94 & 0.00 & 7.76 & 1.36 \\
\hline Confresa (Mato Grosso) - 1 & 56 & 13.07 & 17.79 & 3.94 & 7.51 & 8.47 & 3.94 & 0.00 & 7.76 & 1.36 \\
\hline Confresa (Mato Grosso) - 2 & 57 & 13.07 & 17.79 & 3.94 & 7.51 & 8.47 & 3.94 & 0.00 & 7.76 & 1.36 \\
\hline Bequemão (Maranhão) - 1 & 58 & 13.07 & 17.79 & 3.94 & 7.51 & 8.47 & 3.94 & 0.00 & 7.76 & 1.36 \\
\hline Pinheiro (Maranhão) - 1 & 59 & 13.17 & 17.88 & 3.82 & 7.63 & 8.58 & 3.81 & 0.12 & 7.87 & 1.48 \\
\hline Pinheiro (Maranhão) - 2 & 60 & 13.07 & 17.79 & 3.94 & 7.51 & 8.47 & 3.94 & 0.00 & 7.76 & 1.36 \\
\hline Cachoeira do Piriá (Pará) & 61 & 13.19 & 17.67 & 4.06 & 7.64 & 8.59 & 4.06 & 0.12 & 7.88 & 1.48 \\
\hline Santa Inês (Maranhão) - 2 & 62 & 13.07 & 17.79 & 3.94 & 7.51 & 8.47 & 3.94 & 0.00 & 7.76 & 1.36 \\
\hline Bequemão (Maranhão) - 2 & 63 & 13.07 & 17.79 & 3.94 & 7.51 & 8.47 & 3.94 & 0.00 & 7.76 & 1.36 \\
\hline Comodoro (Mato Grosso) & 64 & 13.07 & 17.79 & 3.94 & 7.51 & 8.47 & 3.94 & 0.00 & 7.76 & 1.36 \\
\hline São Domingos do Capim (Pará) & 65 & 13.07 & 17.79 & 3.94 & 7.51 & 8.47 & 3.94 & 0.00 & 7.76 & 1.36 \\
\hline São Geraldo do Araguaia (Pará) & 66 & 13.17 & 17.67 & 3.82 & 7.39 & 8.34 & 3.81 & 0.12 & 7.64 & 1.48 \\
\hline
\end{tabular}




\begin{tabular}{|c|c|c|c|c|c|c|c|c|c|c|c|c|c|c|c|c|c|}
\hline & 10 & 11 & 12 & 13 & 14 & 15 & 16 & 17 & 18 & 19 & 20 & 21 & 22 & 23 & 24 & 25 & 26 \\
\hline 1 & & & & & & & & & & & & & & & & & \\
\hline 2 & & & & & & & & & & & & & & & & & \\
\hline 3 & & & & & & & & & & & & & & & & & \\
\hline 4 & & & & & & & & & & & & & & & & & \\
\hline 5 & & & & & & & & & & & & & & & & & \\
\hline 6 & & & & & & & & & & & & & & & & & \\
\hline 7 & & & & & & & & & & & & & & & & & \\
\hline 8 & & & & & & & & & & & & & & & & & \\
\hline 9 & & & & & & & & & & & & & & & & & \\
\hline 10 & & & & & & & & & & & & & & & & & \\
\hline 11 & 8.57 & & & & & & & & & & & & & & & & \\
\hline 12 & 3.94 & 7.35 & & & & & & & & & & & & & & & \\
\hline 13 & 7.64 & 3.93 & 6.54 & & & & & & & & & & & & & & \\
\hline 14 & 4.31 & 7.71 & 1.48 & 6.65 & & & & & & & & & & & & & \\
\hline 15 & 4.06 & 7.48 & 0.12 & 6.41 & 1.60 & & & & & & & & & & & & \\
\hline 16 & 8.34 & 0.25 & 7.13 & 3.69 & 7.48 & 7.25 & & & & & & & & & & & \\
\hline 17 & 4.43 & 7.83 & 1.60 & 6.77 & 0.12 & 1.73 & 7.61 & & & & & & & & & & \\
\hline 18 & 1.36 & 8.57 & 3.57 & 7.51 & 3.94 & 3.69 & 8.34 & 4.06 & & & & & & & & & \\
\hline 19 & 4.79 & 8.42 & 2.22 & 7.37 & 0.74 & 2.34 & 8.20 & 0.62 & 4.42 & & & & & & & & \\
\hline 20 & 4.31 & 7.95 & 1.73 & 6.89 & 0.25 & 1.85 & 7.72 & 0.37 & 3.94 & 0.49 & & & & & & & \\
\hline 21 & 4.31 & 7.95 & 1.73 & 6.89 & 0.25 & 1.85 & 7.72 & 0.37 & 3.94 & 0.49 & 0.00 & & & & & & \\
\hline 22 & 4.43 & 8.07 & 1.85 & 7.01 & 0.37 & 1.97 & 7.84 & 0.49 & 4.06 & 0.62 & 0.12 & 0.12 & & & & & \\
\hline 23 & 4.31 & 7.95 & 1.73 & 6.89 & 0.25 & 1.85 & 7.72 & 0.37 & 3.94 & 0.49 & 0.00 & 0.00 & 0.12 & & & & \\
\hline 24 & 4.43 & 7.82 & 1.85 & 7.01 & 0.37 & 1.97 & 7.60 & 0.49 & 4.06 & 0.62 & 0.12 & 0.12 & 0.25 & 0.12 & & & \\
\hline 25 & 4.31 & 7.95 & 1.73 & 6.89 & 0.25 & 1.85 & 7.72 & 0.37 & 3.94 & 0.49 & 0.00 & 0.00 & 0.12 & 0.00 & 0.12 & & \\
\hline 26 & 4.43 & 8.07 & 1.85 & 7.01 & 0.37 & 1.97 & 7.84 & 0.25 & 4.06 & 0.37 & 0.12 & 0.12 & 0.25 & 0.12 & 0.25 & 0.12 & \\
\hline 27 & 4.31 & 7.95 & 1.73 & 6.89 & 0.25 & 1.85 & 7.72 & 0.37 & 3.94 & 0.49 & 0.00 & 0.00 & 0.12 & 0.00 & 0.12 & 0.00 & 0.12 \\
\hline 28 & 4.31 & 7.95 & 1.73 & 6.89 & 0.25 & 1.85 & 7.72 & 0.37 & 3.94 & 0.49 & 0.00 & 0.00 & 0.12 & 0.00 & 0.12 & 0.00 & 0.12 \\
\hline 29 & 4.43 & 8.07 & 1.85 & 7.01 & 0.37 & 1.97 & 7.84 & 0.49 & 4.06 & 0.62 & 0.12 & 0.12 & 0.25 & 0.12 & 0.25 & 0.12 & 0.25 \\
\hline 30 & 4.31 & 7.95 & 1.73 & 6.89 & 0.25 & 1.85 & 7.72 & 0.37 & 3.94 & 0.49 & 0.00 & 0.00 & 0.12 & 0.00 & 0.12 & 0.00 & 0.12 \\
\hline 31 & 4.31 & 7.95 & 1.73 & 6.89 & 0.25 & 1.85 & 7.72 & 0.37 & 3.94 & 0.49 & 0.00 & 0.00 & 0.12 & 0.00 & 0.12 & 0.00 & 0.12 \\
\hline 32 & 4.31 & 7.95 & 1.73 & 6.89 & 0.25 & 1.85 & 7.72 & 0.37 & 3.94 & 0.49 & 0.00 & 0.00 & 0.12 & 0.00 & 0.12 & 0.00 & 0.12 \\
\hline 33 & 4.31 & 7.95 & 1.73 & 6.89 & 0.25 & 1.85 & 7.72 & 0.37 & 3.94 & 0.49 & 0.00 & 0.00 & 0.12 & 0.00 & 0.12 & 0.00 & 0.12 \\
\hline 34 & 4.31 & 7.95 & 1.73 & 6.89 & 0.25 & 1.85 & 7.72 & 0.37 & 3.94 & 0.49 & 0.00 & 0.00 & 0.12 & 0.00 & 0.12 & 0.00 & 0.12 \\
\hline 35 & 4.31 & 7.95 & 1.73 & 6.89 & 0.25 & 1.85 & 7.72 & 0.37 & 3.94 & 0.49 & 0.00 & 0.00 & 0.12 & 0.00 & 0.12 & 0.00 & 0.12 \\
\hline 36 & 4.31 & 7.95 & 1.73 & 6.89 & 0.25 & 1.85 & 7.72 & 0.37 & 3.94 & 0.49 & 0.00 & 0.00 & 0.12 & 0.00 & 0.12 & 0.00 & 0.12 \\
\hline 37 & 4.43 & 8.07 & 1.85 & 7.01 & 0.37 & 1.97 & 7.84 & 0.49 & 4.06 & 0.37 & 0.12 & 0.12 & 0.25 & 0.12 & 0.25 & 0.12 & 0.25 \\
\hline 38 & 4.31 & 7.95 & 1.73 & 6.89 & 0.25 & 1.85 & 7.72 & 0.37 & 3.94 & 0.49 & 0.00 & 0.00 & 0.12 & 0.00 & 0.12 & 0.00 & 0.12 \\
\hline 39 & 4.31 & 7.95 & 1.73 & 6.89 & 0.25 & 1.85 & 7.72 & 0.37 & 3.94 & 0.49 & 0.00 & 0.00 & 0.12 & 0.00 & 0.12 & 0.00 & 0.12 \\
\hline 40 & 4.43 & 8.07 & 1.85 & 7.01 & 0.37 & 1.97 & 7.84 & 0.49 & 4.06 & 0.37 & 0.12 & 0.12 & 0.25 & 0.12 & 0.25 & 0.12 & 0.25 \\
\hline 41 & 4.31 & 7.95 & 1.73 & 6.89 & 0.25 & 1.85 & 7.72 & 0.37 & 3.94 & 0.49 & 0.00 & 0.00 & 0.12 & 0.00 & 0.12 & 0.00 & 0.12 \\
\hline 42 & 4.31 & 7.95 & 1.73 & 6.89 & 0.25 & 1.85 & 7.72 & 0.37 & 3.94 & 0.49 & 0.00 & 0.00 & 0.12 & 0.00 & 0.12 & 0.00 & 0.12 \\
\hline 43 & 1.48 & 8.69 & 3.69 & 7.64 & 4.06 & 3.82 & 8.47 & 4.18 & 0.12 & 4.30 & 4.06 & 4.06 & 4.18 & 4.06 & 4.18 & 4.06 & 4.18 \\
\hline 44 & 1.48 & 8.69 & 3.69 & 7.64 & 4.06 & 3.82 & 8.47 & 4.18 & 0.12 & 4.30 & 4.06 & 4.06 & 4.18 & 4.06 & 4.18 & 4.06 & 4.18 \\
\hline 45 & 1.36 & 8.57 & 3.57 & 7.51 & 3.94 & 3.69 & 8.34 & 4.06 & 0.00 & 4.42 & 3.94 & 3.94 & 4.06 & 3.94 & 4.06 & 3.94 & 4.06 \\
\hline 46 & 1.36 & 8.57 & 3.57 & 7.51 & 3.94 & 3.69 & 8.34 & 4.06 & 0.00 & 4.42 & 3.94 & 3.94 & 4.06 & 3.94 & 4.06 & 3.94 & 4.06 \\
\hline 47 & 1.36 & 8.57 & 3.57 & 7.51 & 3.94 & 3.69 & 8.34 & 4.06 & 0.00 & 4.42 & 3.94 & 3.94 & 4.06 & 3.94 & 4.06 & 3.94 & 4.06 \\
\hline 48 & 1.48 & 8.69 & 3.69 & 7.64 & 4.06 & 3.82 & 8.47 & 4.18 & 0.12 & 4.30 & 4.06 & 4.06 & 4.18 & 4.06 & 4.18 & 4.06 & 4.18 \\
\hline 49 & 1.36 & 8.57 & 3.57 & 7.51 & 3.94 & 3.69 & 8.34 & 4.06 & 0.00 & 4.42 & 3.94 & 3.94 & 4.06 & 3.94 & 4.06 & 3.94 & 4.06 \\
\hline 50 & 1.36 & 8.57 & 3.57 & 7.51 & 3.94 & 3.69 & 8.34 & 4.06 & 0.00 & 4.42 & 3.94 & 3.94 & 4.06 & 3.94 & 4.06 & 3.94 & 4.06 \\
\hline 51 & 1.36 & 8.57 & 3.57 & 7.51 & 3.94 & 3.69 & 8.34 & 4.06 & 0.00 & 4.42 & 3.94 & 3.94 & 4.06 & 3.94 & 4.06 & 3.94 & 4.06 \\
\hline 52 & 1.36 & 8.57 & 3.57 & 7.51 & 3.94 & 3.69 & 8.34 & 4.06 & 0.00 & 4.42 & 3.94 & 3.94 & 4.06 & 3.94 & 4.06 & 3.94 & 4.06 \\
\hline 53 & 1.36 & 8.57 & 3.57 & 7.51 & 3.94 & 3.69 & 8.34 & 4.06 & 0.00 & 4.42 & 3.94 & 3.94 & 4.06 & 3.94 & 4.06 & 3.94 & 4.06 \\
\hline 54 & 1.36 & 8.57 & 3.57 & 7.51 & 3.94 & 3.69 & 8.34 & 4.06 & 0.00 & 4.42 & 3.94 & 3.94 & 4.06 & 3.94 & 4.06 & 3.94 & 4.06 \\
\hline 55 & 1.36 & 8.57 & 3.57 & 7.51 & 3.94 & 3.69 & 8.34 & 4.06 & 0.00 & 4.42 & 3.94 & 3.94 & 4.06 & 3.94 & 4.06 & 3.94 & 4.06 \\
\hline 56 & 1.36 & 8.57 & 3.57 & 7.51 & 3.94 & 3.69 & 8.34 & 4.06 & 0.00 & 4.42 & 3.94 & 3.94 & 4.06 & 3.94 & 4.06 & 3.94 & 4.06 \\
\hline 57 & 1.36 & 8.57 & 3.57 & 7.51 & 3.94 & 3.69 & 8.34 & 4.06 & 0.00 & 4.42 & 3.94 & 3.94 & 4.06 & 3.94 & 4.06 & 3.94 & 4.06 \\
\hline 58 & 1.36 & 8.57 & 3.57 & 7.51 & 3.94 & 3.69 & 8.34 & 4.06 & 0.00 & 4.42 & 3.94 & 3.94 & 4.06 & 3.94 & 4.06 & 3.94 & 4.06 \\
\hline 59 & 1.48 & 8.68 & 3.45 & 7.63 & 3.81 & 3.57 & 8.46 & 3.94 & 0.12 & 4.30 & 3.81 & 3.81 & 3.94 & 3.81 & 3.94 & 3.81 & 3.94 \\
\hline 60 & 1.36 & 8.57 & 3.57 & 7.51 & 3.94 & 3.69 & 8.34 & 4.06 & 0.00 & 4.42 & 3.94 & 3.94 & 4.06 & 3.94 & 4.06 & 3.94 & 4.06 \\
\hline 61 & 1.48 & 8.69 & 3.69 & 7.64 & 4.06 & 3.82 & 8.47 & 4.18 & 0.12 & 4.30 & 4.06 & 4.06 & 4.18 & 4.06 & 4.18 & 4.06 & 4.18 \\
\hline 62 & 1.36 & 8.57 & 3.57 & 7.51 & 3.94 & 3.69 & 8.34 & 4.06 & 0.00 & 4.42 & 3.94 & 3.94 & 4.06 & 3.94 & 4.06 & 3.94 & 4.06 \\
\hline 63 & 1.36 & 8.57 & 3.57 & 7.51 & 3.94 & 3.69 & 8.34 & 4.06 & 0.00 & 4.42 & 3.94 & 3.94 & 4.06 & 3.94 & 4.06 & 3.94 & 4.06 \\
\hline 64 & 1.36 & 8.57 & 3.57 & 7.51 & 3.94 & 3.69 & 8.34 & 4.06 & 0.00 & 4.42 & 3.94 & 3.94 & 4.06 & 3.94 & 4.06 & 3.94 & 4.06 \\
\hline 65 & 1.36 & 8.57 & 3.57 & 7.51 & 3.94 & 3.69 & 8.34 & 4.06 & 0.00 & 4.42 & 3.94 & 3.94 & 4.06 & 3.94 & 4.06 & 3.94 & 4.06 \\
\hline 66 & 1.48 & 8.45 & 3.45 & 7.39 & 3.81 & 3.57 & 8.22 & 3.94 & 0.12 & 4.30 & 3.81 & 3.81 & 3.94 & 3.81 & 3.94 & 3.81 & 3.94 \\
\hline
\end{tabular}




\begin{tabular}{|c|c|c|c|c|c|c|c|c|c|c|c|c|c|c|c|c|c|}
\hline & 27 & 28 & 29 & 30 & 31 & 32 & 33 & 34 & 35 & 36 & 37 & 38 & 39 & 40 & 41 & 42 & 43 \\
\hline 1 & & & & & & & & & & & & & & & & & \\
\hline 2 & & & & & & & & & & & & & & & & & \\
\hline 3 & & & & & & & & & & & & & & & & & \\
\hline 4 & & & & & & & & & & & & & & & & & \\
\hline 5 & & & & & & & & & & & & & & & & & \\
\hline 6 & & & & & & & & & & & & & & & & & \\
\hline 7 & & & & & & & & & & & & & & & & & \\
\hline 8 & & & & & & & & & & & & & & & & & \\
\hline 9 & & & & & & & & & & & & & & & & & \\
\hline 10 & & & & & & & & & & & & & & & & & \\
\hline 11 & & & & & & & & & & & & & & & & & \\
\hline 12 & & & & & & & & & & & & & & & & & \\
\hline 13 & & & & & & & & & & & & & & & & & \\
\hline 14 & & & & & & & & & & & & & & & & & \\
\hline 15 & & & & & & & & & & & & & & & & & \\
\hline 16 & & & & & & & & & & & & & & & & & \\
\hline 17 & & & & & & & & & & & & & & & & & \\
\hline 18 & & & & & & & & & & & & & & & & & \\
\hline 19 & & & & & & & & & & & & & & & & & \\
\hline 20 & & & & & & & & & & & & & & & & & \\
\hline 21 & & & & & & & & & & & & & & & & & \\
\hline 22 & & & & & & & & & & & & & & & & & \\
\hline 23 & & & & & & & & & & & & & & & & & \\
\hline 24 & & & & & & & & & & & & & & & & & \\
\hline 25 & & & & & & & & & & & & & & & & & \\
\hline 26 & & & & & & & & & & & & & & & & & \\
\hline 27 & & & & & & & & & & & & & & & & & \\
\hline 28 & 0.00 & & & & & & & & & & & & & & & & \\
\hline 29 & 0.12 & 0.12 & & & & & & & & & & & & & & & \\
\hline 30 & 0.00 & 0.00 & 0.12 & & & & & & & & & & & & & & \\
\hline 31 & 0.00 & 0.00 & 0.12 & 0.00 & & & & & & & & & & & & & \\
\hline 32 & 0.00 & 0.00 & 0.12 & 0.00 & 0.00 & & & & & & & & & & & & \\
\hline 33 & 0.00 & 0.00 & 0.12 & 0.00 & 0.00 & 0.00 & & & & & & & & & & & \\
\hline 34 & 0.00 & 0.00 & 0.12 & 0.00 & 0.00 & 0.00 & 0.00 & & & & & & & & & & \\
\hline 35 & 0.00 & 0.00 & 0.12 & 0.00 & 0.00 & 0.00 & 0.00 & 0.00 & & & & & & & & & \\
\hline 36 & 0.00 & 0.00 & 0.12 & 0.00 & 0.00 & 0.00 & 0.00 & 0.00 & 0.00 & & & & & & & & \\
\hline 37 & 0.12 & 0.12 & 0.25 & 0.12 & 0.12 & 0.12 & 0.12 & 0.12 & 0.12 & 0.12 & & & & & & & \\
\hline 38 & 0.00 & 0.00 & 0.12 & 0.00 & 0.00 & 0.00 & 0.00 & 0.00 & 0.00 & 0.00 & 0.12 & & & & & & \\
\hline 39 & 0.00 & 0.00 & 0.12 & 0.00 & 0.00 & 0.00 & 0.00 & 0.00 & 0.00 & 0.00 & 0.12 & 0.00 & & & & & \\
\hline 40 & 0.12 & 0.12 & 0.25 & 0.12 & 0.12 & 0.12 & 0.12 & 0.12 & 0.12 & 0.12 & 0.00 & 0.12 & 0.12 & & & & \\
\hline 41 & 0.00 & 0.00 & 0.12 & 0.00 & 0.00 & 0.00 & 0.00 & 0.00 & 0.00 & 0.00 & 0.12 & 0.00 & 0.00 & 0.12 & & & \\
\hline 42 & 0.00 & 0.00 & 0.12 & 0.00 & 0.00 & 0.00 & 0.00 & 0.00 & 0.00 & 0.00 & 0.12 & 0.00 & 0.00 & 0.12 & 0.00 & & \\
\hline 43 & 4.06 & 4.06 & 4.18 & 4.06 & 4.06 & 4.06 & 4.06 & 4.06 & 4.06 & 4.06 & 3.94 & 4.06 & 4.06 & 3.94 & 4.06 & 4.06 & \\
\hline 44 & 4.06 & 4.06 & 4.18 & 4.06 & 4.06 & 4.06 & 4.06 & 4.06 & 4.06 & 4.06 & 3.94 & 4.06 & 4.06 & 3.94 & 4.06 & 4.06 & 0.00 \\
\hline 45 & 3.94 & 3.94 & 4.06 & 3.94 & 3.94 & 3.94 & 3.94 & 3.94 & 3.94 & 3.94 & 4.06 & 3.94 & 3.94 & 4.06 & 3.94 & 3.94 & 0.12 \\
\hline 46 & 3.94 & 3.94 & 4.06 & 3.94 & 3.94 & 3.94 & 3.94 & 3.94 & 3.94 & 3.94 & 4.06 & 3.94 & 3.94 & 4.06 & 3.94 & 3.94 & 0.12 \\
\hline 47 & 3.94 & 3.94 & 4.06 & 3.94 & 3.94 & 3.94 & 3.94 & 3.94 & 3.94 & 3.94 & 4.06 & 3.94 & 3.94 & 4.06 & 3.94 & 3.94 & 0.12 \\
\hline 48 & 4.06 & 4.06 & 4.18 & 4.06 & 4.06 & 4.06 & 4.06 & 4.06 & 4.06 & 4.06 & 3.94 & 4.06 & 4.06 & 3.94 & 4.06 & 4.06 & 0.00 \\
\hline 49 & 3.94 & 3.94 & 4.06 & 3.94 & 3.94 & 3.94 & 3.94 & 3.94 & 3.94 & 3.94 & 4.06 & 3.94 & 3.94 & 4.06 & 3.94 & 3.94 & 0.12 \\
\hline 50 & 3.94 & 3.94 & 4.06 & 3.94 & 3.94 & 3.94 & 3.94 & 3.94 & 3.94 & $\begin{array}{l}3.94 \\
\end{array}$ & 4.06 & 3.94 & 3.94 & 4.06 & 3.94 & 3.94 & 0.12 \\
\hline 51 & 3.94 & 3.94 & 4.06 & 3.94 & 3.94 & 3.94 & 3.94 & 3.94 & 3.94 & 3.94 & 4.06 & 3.94 & 3.94 & 4.06 & 3.94 & 3.94 & 0.12 \\
\hline 52 & 3.94 & 3.94 & 4.06 & 3.94 & 3.94 & 3.94 & 3.94 & 3.94 & 3.94 & 3.94 & 4.06 & 3.94 & 3.94 & 4.06 & 3.94 & 3.94 & 0.12 \\
\hline 53 & 3.94 & 3.94 & 4.06 & 3.94 & 3.94 & 3.94 & 3.94 & 3.94 & 3.94 & 3.94 & 4.06 & 3.94 & 3.94 & 4.06 & 3.94 & 3.94 & 0.12 \\
\hline 54 & 3.94 & 3.94 & 4.06 & 3.94 & 3.94 & 3.94 & 3.94 & 3.94 & 3.94 & 3.94 & 4.06 & 3.94 & 3.94 & 4.06 & 3.94 & 3.94 & 0.12 \\
\hline 55 & 3.94 & 3.94 & 4.06 & 3.94 & 3.94 & 3.94 & 3.94 & 3.94 & 3.94 & 3.94 & 4.06 & 3.94 & 3.94 & 4.06 & 3.94 & 3.94 & 0.12 \\
\hline 56 & 3.94 & 3.94 & 4.06 & 3.94 & 3.94 & 3.94 & 3.94 & 3.94 & 3.94 & 3.94 & 4.06 & 3.94 & 3.94 & 4.06 & 3.94 & 3.94 & 0.12 \\
\hline 57 & 3.94 & 3.94 & 4.06 & 3.94 & 3.94 & 3.94 & 3.94 & 3.94 & 3.94 & 3.94 & 4.06 & 3.94 & 3.94 & 4.06 & 3.94 & 3.94 & 0.12 \\
\hline 58 & 3.94 & 3.94 & 4.06 & 3.94 & 3.94 & 3.94 & 3.94 & 3.94 & 3.94 & 3.94 & 4.06 & 3.94 & 3.94 & 4.06 & 3.94 & 3.94 & 0.12 \\
\hline 59 & 3.81 & 3.81 & 3.94 & 3.81 & 3.81 & 3.81 & 3.81 & 3.81 & 3.81 & 3.81 & 3.94 & 3.81 & 3.81 & 3.94 & 3.81 & 3.81 & 0.25 \\
\hline 60 & 3.94 & 3.94 & 4.06 & 3.94 & 3.94 & 3.94 & 3.94 & 3.94 & 3.94 & 3.94 & 4.06 & 3.94 & 3.94 & 4.06 & 3.94 & 3.94 & 0.12 \\
\hline 61 & 4.06 & 4.06 & 4.18 & 4.06 & 4.06 & 4.06 & 4.06 & 4.06 & 4.06 & 4.06 & 3.94 & 4.06 & 4.06 & 3.94 & 4.06 & 4.06 & 0.00 \\
\hline 62 & 3.94 & 3.94 & 4.06 & 3.94 & 3.94 & 3.94 & 3.94 & 3.94 & 3.94 & 3.94 & 4.06 & 3.94 & 3.94 & 4.06 & 3.94 & 3.94 & 0.12 \\
\hline 63 & 3.94 & 3.94 & 4.06 & 3.94 & 3.94 & 3.94 & 3.94 & 3.94 & 3.94 & 3.94 & 4.06 & 3.94 & 3.94 & 4.06 & 3.94 & 3.94 & 0.12 \\
\hline 64 & 3.94 & 3.94 & 4.06 & 3.94 & 3.94 & 3.94 & 3.94 & 3.94 & 3.94 & 3.94 & 4.06 & 3.94 & 3.94 & 4.06 & 3.94 & 3.94 & 0.12 \\
\hline 65 & 3.94 & 3.94 & 4.06 & 3.94 & 3.94 & 3.94 & 3.94 & 3.94 & 3.94 & 3.94 & 4.06 & 3.94 & 3.94 & 4.06 & 3.94 & 3.94 & 0.12 \\
\hline 66 & 3.81 & 3.81 & 3.94 & 3.81 & 3.81 & 3.81 & 3.81 & 3.81 & 3.81 & 3.81 & 3.94 & 3.81 & 3.81 & 3.94 & 3.81 & 3.81 & 0.25 \\
\hline
\end{tabular}




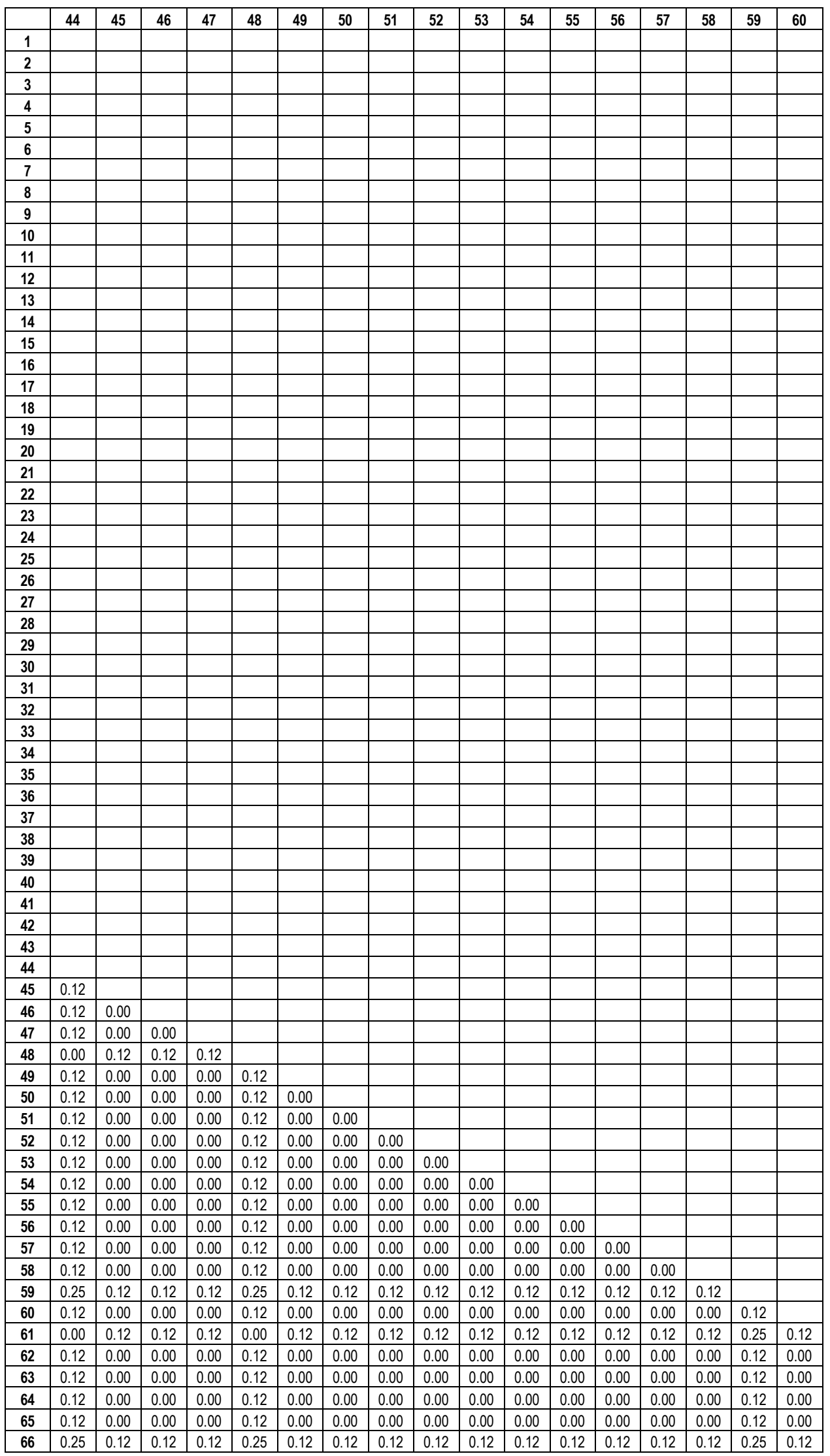




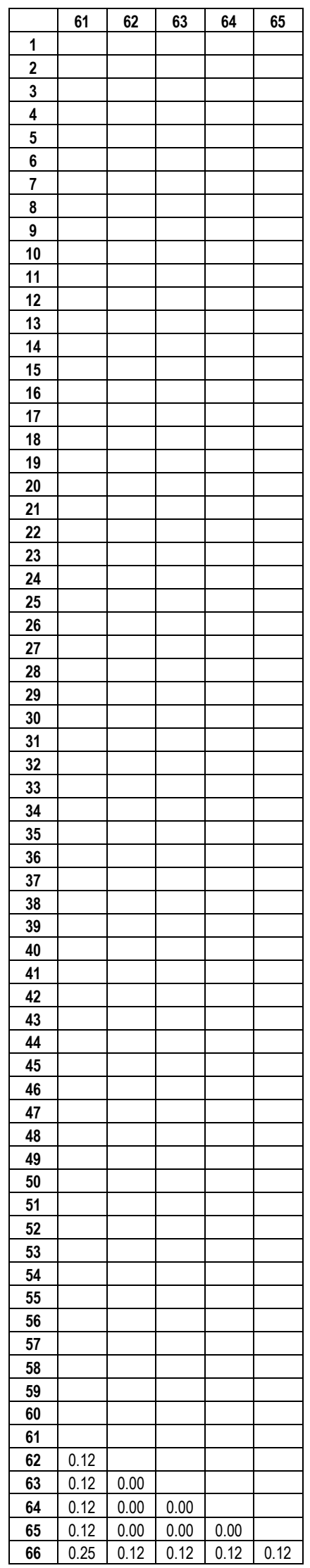

Fonte: (MARTINS, T. F., 2014) 